\title{
Identification of risk factors associated with highway fatalities occurring to law enforcement professionals
}

\author{
Melissa W. Abbott \\ West Virginia University
}

Follow this and additional works at: https://researchrepository.wvu.edu/etd

\section{Recommended Citation}

Abbott, Melissa W., "Identification of risk factors associated with highway fatalities occurring to law enforcement professionals" (2008). Graduate Theses, Dissertations, and Problem Reports. 2738.

https://researchrepository.wvu.edu/etd/2738

This Dissertation is protected by copyright and/or related rights. It has been brought to you by the The Research Repository @ WVU with permission from the rights-holder(s). You are free to use this Dissertation in any way that is permitted by the copyright and related rights legislation that applies to your use. For other uses you must obtain permission from the rights-holder(s) directly, unless additional rights are indicated by a Creative Commons license in the record and/ or on the work itself. This Dissertation has been accepted for inclusion in WVU Graduate Theses, Dissertations, and Problem Reports collection by an authorized administrator of The Research Repository @ WVU.

For more information, please contact researchrepository@mail.wvu.edu. 


\title{
Identification of risk factors associated with highway fatalities occurring to law enforcement professionals.
}

\author{
Melissa W. Abbott \\ Dissertation submitted to the \\ at West Virginia University \\ Doctor of Philosophy \\ in \\ Occupational Safety \\ Gary Winn, Ph.D. Chair \\ Ian Rockett, Ph.D. \\ Wafik Iskander, Ph.D. \\ Warren Myers, Ph.D. \\ Elyce Biddle, Ph.D.
} College of Engineering and Mineral Resources in partial fulfillment of the requirements for the degree of

Department of Industrial Management Systems Engineering

\author{
Morgantown, West Virginia \\ 2008
}

Keywords: Law Enforcement Fatalities, Highway Fatalities, Highway Risk Factors Copyright 2008 Melissa W. Abbott 


\title{
ABSTRACT \\ Identification of risk factors associated with highway fatalities occurring to law enforcement professionals.
}

\author{
Melissa W. Abbott
}

This study was designed to identify the risk factors most commonly associated with law enforcement highway fatalities. Three approaches were used to assist in the identification of the most relevant risk factors. These approaches included as descriptive study, utilization of a focus group and a simple and multiple logistic regression analysis.

The descriptive study was performed on data extracted from the National Highway Transportation Safety Administration's (NHTSA) Fatality Analysis Risk System (FARS). The data was divided into three categories; Fatalities while driving, Fatalities while not driving-inside the vehicle and Fatalities while not driving outside the vehicle. The focus group consisted of 5 experts in various professional capacities related to law enforcement highway safety. These volunteer experts were asked to rank order the top five risk factors believed to be associated with law enforcement highway fatalities. A Spearman Rank Order Correlation was used determine if there was a correlation between the descriptive study and the results of the focus group. The third element involved a logistic regression analysis on the data segregated into the categories identified above. The results of the simple logistic regression analysis identified two elements with an association to incidents resulting in dead on arrival. These elements included lighting conditions where it was dark but artificially lighted and roadways other then straight. The dependent variable selected for the study was dead on arrival versus incidents in which the victim received medical treatment. The dependant variable serves as a limitation of the study. A multiple regression analysis was also performed on the risk factors identified by the focus group. However, there was not enough evidence to support any associations.

The results of the study have identified 4 basic factors that may potentially have an impact on law enforcement highway fatalities. These four elements include traveling speed, driver related factors, environmental elements and driver training. Protective measures should be taken by agencies to assist in the reduction of law enforcement highway fatalities. Future research should also be administered to allow for better data collection and analysis. 


\section{Acknowledgements}

Without the love and support of my family, this dissertation would have never come to fruition. They were there to listen and encourage me in times of joy and success as well as the times of setbacks and frustrations. I want to thank my loving husband, JL Abbott and my two children, Baylee and Jake Abbott for having the patience with me during this enduring process. JL has been very supportive and encouraging during those times I didn't want to work. He kept me focused and on task. He also listened during those times when I needed him most. Baylee and Jake have truly grown through this process and I am very proud of them. While I spent many hours working on this dissertation, they had to assume many responsibilities around the house. I am very proud and thankful to have all of them in my life.

Thanks to my many friends and family who helped me by getting my kids to practices, parties, school functions, etc. so that I could work and complete my coursework. I would like to extend a special thanks to my very dear friend, mentor and colleague Kim Murphy for all of her help and support. Without her continued encouragement, I don't know if my Ph.D. would have ever become a realization. She could always turn my frustrations into laughter.

My committee deserves a special thank you for their support during this process. Much appreciation goes to Dr. Gary Winn who served as my Chair and supportive voice during this enduring process. I want to extend a special thanks to Dr. Ian Rockett for serving as my mentor who helped me to design the study to ensure that quality research was being performed. I greatly appreciate the friendship and all of the conversations I had with Dr. Elyce Biddle in her teachings related to the field of research and how to successfully conduct research. Dr. Myers and Dr. Iskander both served as a great strength in encouragement to ensure that my research offered a sound study for future endeavors. I wish to thank them all for their guidance, support, wisdom and encouragement. 


\section{Identification of risk factors associated with highway fatalities occurring to law enforcement professionals.}

\section{Table of Contents}

CHAPTER 1 - INTRODUCTION

Page Number

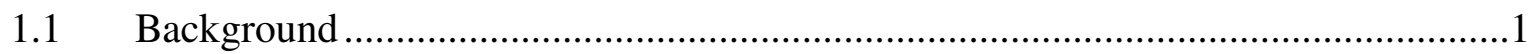

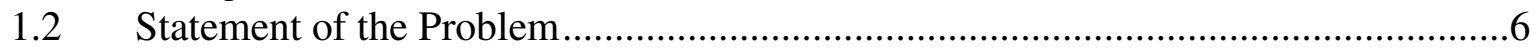

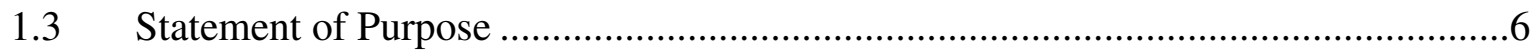

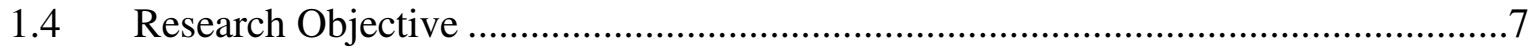

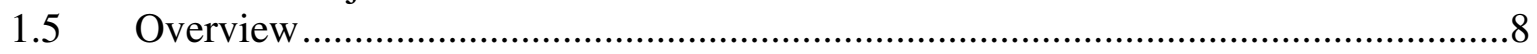

\section{CHAPTER 2 - REVIEW OF LITERATURE}

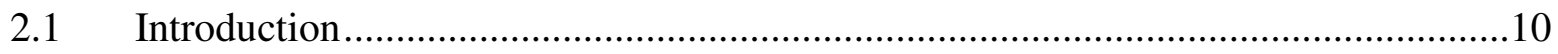

$2.2 \quad$ Automobile Incidents .................................................................................11

2.2.1 Driver Related Factors in Enforcement and Occupational Injuries ..............12

2.2.2 Vehicle Related Factors in Enforcement and Occupational Injuries .............14

2.2.3 Environmental Conditions in Enforcement and Occupational Injuries .........17

2.3 Motorcycle Incidents ..............................................................................20

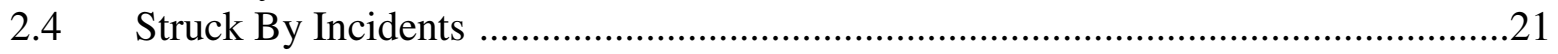

2.5 Fatality Reduction Efforts for Law Enforcement Officers ….............................22

2.6 Data Sets Available for External Analysis...................................................28

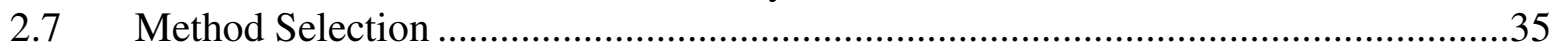

\section{CHAPTER 3 - METHODOLOGY}

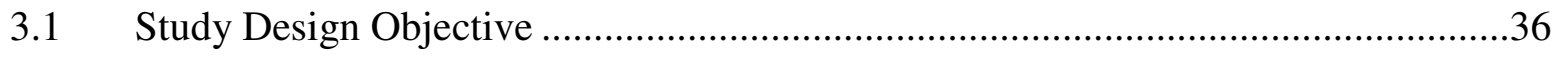

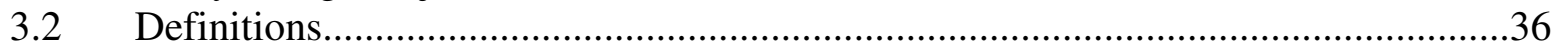

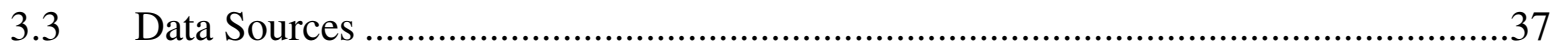

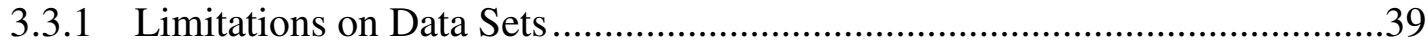

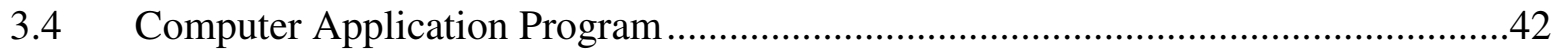

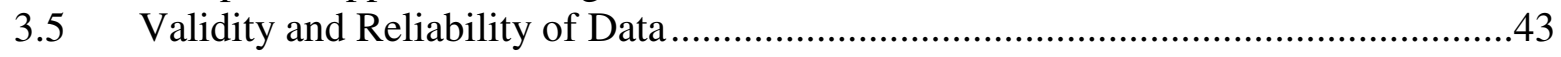

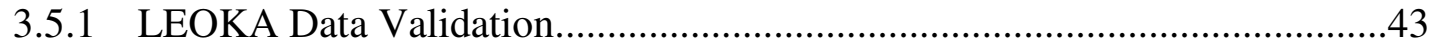

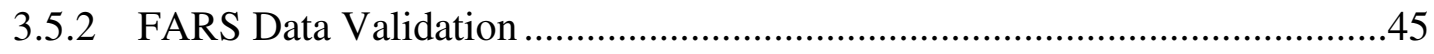

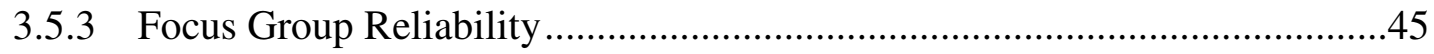

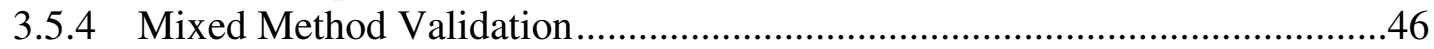

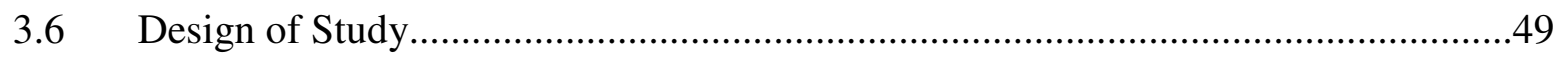

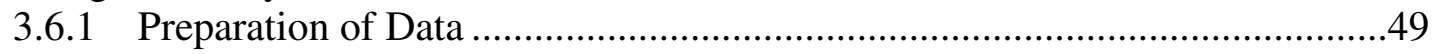

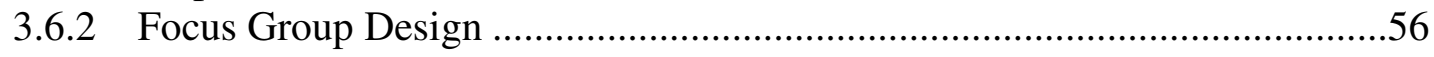

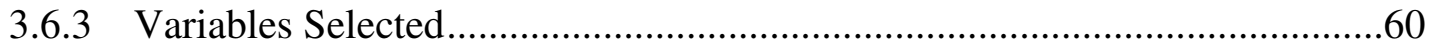


3.7 Data Analysis .61

3.8 Analysis Method Using JMP Software

CHAPTER 4 - RESULTS

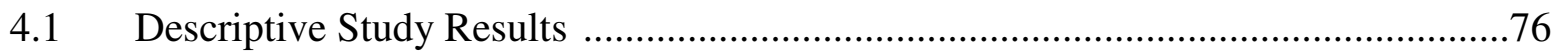

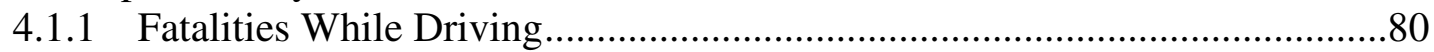

4.1.2 Fatalities While Outside the Vehicle ....................................................... 110

4.2 Focus Group Analysis Results .....................................................................138

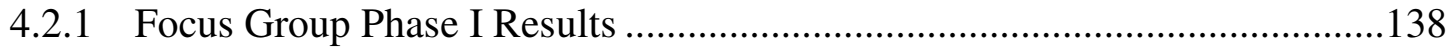

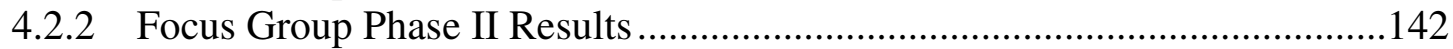

4.3 Comparison of Descriptive Study and Focus Group Results .................................146

4.4 Simple Logistic Regression Results .................................................................. 149

4.5 Multiple Logistic Regression Results ......................................................... 154

CHAPTER 5 - CONCLUSIONS AND RECOMMENDATIONS

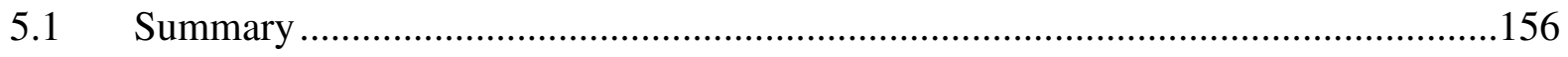

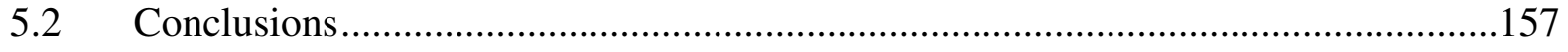

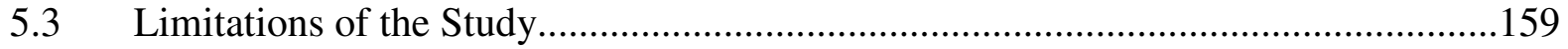

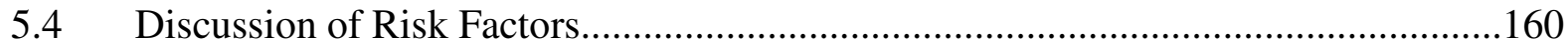

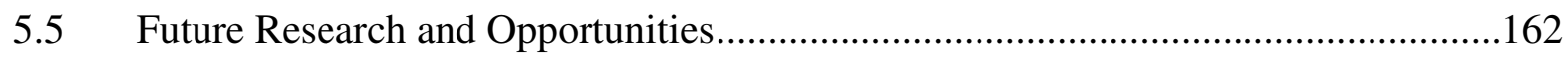

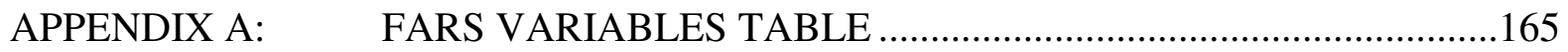

APPENDIX B: $\quad$ FOCUS GROUP RELATED MATERIALS .................................177

B:1 Letter of Recruitment to Experts in Focus Group

B:2 Instructions to Experts in Focus Group

B:3 Summary of Phase I Focus Group Responses

B:4 Agenda for Focus Group Teleconference

B:5 Focus Group Participation Check-off Sheet

B:6 Focus Group Teleconference Transcripts

APPENDIX C IRB EXEMPTION NOTIFICATION ........................................215

BIBLIOGRAPHY 


\section{List of Tables}

3.1 Identification of Missing LEOKA Cases in FARS files

3.2 Minimization of Validity Threats in Mixed Method Approach

3.3 Focus Group Risk Factors and Matching FARS Variables

3.4 Recording Criteria for Dead on Arrival

4.1 Distribution of Annual Number of Law Enforcement Highway Fatalities, 1997-2006

4.2 Distribution of Age, Law Enforcement Highway Fatalities, 1997-2006

4.3 Distribution of Fatalities while Driving, Travel Speed, Law Enforcement Highway Fatalities, 1997-2006

4.4 Summary of Risk Factor Effects on Fatalities While Driving, 1997-2006

4.5 Distribution of Fatalities While Not Driving-Outside Vehicle, Law Enforcement Highway Fatalities, 1997-2006

4.6 Summary of Risk Factor Effects on Fatalities While Not Driving-Outside Vehicle, 19972006

4.7 Focus Group Variables and Individual Rank Order

4.8 Focus Group Individual Explanations for Selection of Risk Factors

4.9 Focus Group Teleconference Responses

4.10 Number of Times Risk Factor Topics were Discussed or Mentioned

4.11 Spearman Rank Correlation Calculations for Incidents with the Officer Outside the Vehicle

4.12 Spearman Rank Correlation Calculations for Incidents While Driving the Vehicle

4.13 Summary of Odds Ratio of Driving Related Predictors of Dead on Arrival While Driving

4.14 Summary of Odds Ratio of Driving Related Predictors of Dead on Arrival While Outside the Vehicle

4.15 Multiple Logistic Regression - Odds Ratio Outcome for Fatalities While Driving

\section{List of Figures}

4.1 Number of Law Enforcement Highway Fatalities per Year, 1997-2006

4.2 Distribution of Annual Number of Law Enforcement Highway Fatalities, 1997-2006

4.3 Distribution of Age, Law Enforcement Highway Fatalities, 1997-2006

4.4 Distribution of Gender, Law Enforcement Highway Fatalities, 1997-2006

4.5 Occupational Fatalities While Driving by Day of Week, Law Enforcement Highway Fatalities, 1997-2006

4.6 Occupational Fatalities While Driving by Hour, Law Enforcement Highway Fatalities, 1997-2006

4.7 Occupational Fatalities While Driving by Time Periods, Law Enforcement Highway Fatalities, 1997-2006

4.8 Occupational Fatalities While Driving by Lighting Conditions, Law Enforcement Highway Fatalities, 1997-2006

4.9 Occupational Fatalities While Driving by Atmospheric Conditions, Law Enforcement Highway Fatalities, 1997-2006

4.10 Occupational Fatalities While Driving by Surface Condition, Law Enforcement Highway Fatalities, 1997-2006 
4.11 Occupational Fatalities While Driving by Roadway Surface Type, Law Enforcement Highway Fatalities, 1997-2006

4.12 Occupational Fatalities While Driving by Relation to Roadway, Law Enforcement Highway Fatalities, 1997-2006

4.13 Occupational Fatalities While Driving by Relation to Junction, Law Enforcement Highway Fatalities, 1997-2006

4.14 Occupational Fatalities While Driving by Roadway Alignment, Law Enforcement Highway Fatalities, 1997-2006

4.15 Occupational Fatalities While Driving by Roadway Profile, Law Enforcement Highway Fatalities, 1997-2006

4.16 Occupational Fatalities While Driving by Crash Avoidance Maneuver, Law Enforcement Highway Fatalities, 1997-2006

4.17 Occupational Fatalities While Driving by Vehicle Maneuver, Law Enforcement Highway Fatalities, 1997-2006

4.18 Occupational Fatalities While Driving by Travel Speed, Law Enforcement Highway Fatalities, 1997-2006

4.19 Occupational Fatalities While Driving by Driver Related Factors, Law Enforcement Highway Fatalities, 1997-2006

4.20 Occupational Fatalities While Driving by Vehicle Related Factors, Law Enforcement Highway Fatalities, 1997-2006

4.21 Occupational Fatalities While Driving by Crash Related Factors, Law Enforcement Highway Fatalities, 1997-2006

4.22 Occupational Fatalities While Driving by First Harmful Event, Law Enforcement Highway Fatalities, 1997-2006

4.23 Occupational Fatalities While Driving by Most Harmful Event, Law Enforcement Highway Fatalities, 1997-2006

4.24 Occupational Fatalities While Driving by Restraint System Use, Law Enforcement Highway Fatalities, 1997-2006

4.25 Occupational Fatalities While Driving by Airbag Availability/Function, Law Enforcement Highway Fatalities, 1997-2006

4.26 Occupational Fatalities While Driving by Dead on Arrival Classification, Law Enforcement Highway Fatalities, 1997-2006

4.27 Frequency Distribution of Fatalities While Driving by Circumstances, 1997-2006

4.28 Occupational Fatalities While Not Driving-Outside Vehicle by Day of Week, Law Enforcement Highway Fatalities, 1997-2006

4.29 Occupational Fatalities While Not Driving-Outside Vehicle by Hour, Law Enforcement Highway Fatalities, 1997-2006

4.30 Occupational Fatalities While Not Driving-Outside Vehicle by Time Periods, Law Enforcement Highway Fatalities, 1997-2006

4.31 Occupational Fatalities While Not Driving-Outside Vehicle by Lighting Conditions, Law Enforcement Highway Fatalities, 1997-2006

4.32 Occupational Fatalities While Not Driving-Outside Vehicle by Atmospheric Conditions, Law Enforcement Highway Fatalities, 1997-2006

4.33 Occupational Fatalities While Not Driving-Outside Vehicle by Surface Condition, Law Enforcement Highway Fatalities, 1997-2006 
4.34 Occupational Fatalities While Not Driving-Outside Vehicle by Roadway Surface Type, Law Enforcement Highway Fatalities, 1997-2006

4.35 Occupational Fatalities While Not Driving-Outside Vehicle by Relation to Roadway, Law Enforcement Highway Fatalities, 1997-2006

4.36 Occupational Fatalities While Not Driving-Outside Vehicle by Relation to Junction, Law Enforcement Highway Fatalities, 1997-2006

4.37 Occupational Fatalities While Not Driving-Outside Vehicle by Roadway Alignment, Law Enforcement Highway Fatalities, 1997-2006

4.38 Occupational Fatalities While Not Driving-Outside Vehicle by Roadway Profile, Law Enforcement Highway Fatalities, 1997-2006

4.39 Occupational Fatalities While Not Driving-Outside Vehicle by Crash Avoidance Maneuver, Law Enforcement Highway Fatalities, 1997-2006

4.40 Occupational Fatalities While Not Driving-Outside Vehicle by Vehicle Maneuver, Law Enforcement Highway Fatalities, 1997-2006

4.41 Occupational Fatalities While Not Driving-Outside Vehicle by Travel Speed, Law Enforcement Highway Fatalities, 1997-2006

4.42 Occupational Fatalities While Not Driving-Outside Vehicle by Driver Related Factors, Law Enforcement Highway Fatalities, 1997-2006

4.43 Occupational Fatalities While Not Driving-Outside Vehicle by Person Related Factors, Law Enforcement Highway Fatalities, 1997-2006

4.44 Occupational Fatalities While Not Driving-Outside Vehicle by Vehicle Related Factors, Law Enforcement Highway Fatalities, 1997-2006

4.45 Occupational Fatalities While Not Driving-Outside Vehicle by Crash Related Factors, Law Enforcement Highway Fatalities, 1997-2006

4.46 Occupational Fatalities While Not Driving-Outside Vehicle by First Harmful Event, Law Enforcement Highway Fatalities, 1997-2006

4.47 Occupational Fatalities While Not Driving-Outside Vehicle by Most Harmful Event, Law Enforcement Highway Fatalities, 1997-2006

4.48 Occupational Fatalities While Not Driving-Outside Vehicle by Dead on Arrival Classification, Law Enforcement Highway Fatalities, 1997-2006

4.49 Frequency Distribution of Fatalities Not Driving-Outside Vehicle by Circumstances While Driving, 1997-2006 


\section{Chapter 1}

\section{Introduction}

\subsection{BACKGROUND}

Occupational safety and health is not a new concept. Its existence falls long before the passage of the Occupational Safety and Health Act of 1970. Identification of employee risks has been documented back to the days of the ancient Babylonians. According to Goetsch (2005) the Code of Hammurabi, circa 2000 BC, outlined the laws of the land for the Babylonians. A component of these codes included a reference to worker injuries and monetary support for the injured. In 1567, Phillippus Aureolus wrote about the pulmonary diseases of miners. Bernardino Ramazzini wrote about the disease of workers in the eighteenth century. Today, occupational risks and hazards are identified by many entities including, but not limited to the National Institute of Occupational Safety and Health (NIOSH), National Fire Protection Association (NFPA), American National Standards Association (ANSI), Occupational Safety and Health Administration (OSHA), and the Mine Safety and Health Administration (MSHA) to name a few. More specifically, motor vehicle accidents have become a topic of interest for other entities including the Federal Highway Administration (FHWA) and National Highway Traffic Safety Administration (NHTSA). Unfortunately there is limited efforts on the focus of law enforcement highway fatalities by any of the above reference organizations.

With respect to occupational safety in the United States, the first national conference on industrial diseases was held in 1911. The following year, the Public Health Service was expanded to include a division for Occupational Health. Also in 1911, the state of New York

was the first state to pass a worker's compensation law. (Peterson, 2003) In 1913, the National 
Safety Council was founded. (2004) When the council began it was referred to as the Second Safety Congress. The following year, the Second Safety Congress was changed to National Safety Council to reflect a broader focus including traffic safety and other non-industrial safety issues. All of these pieces of work offered awareness to potential hazards, but did not offer the protection employees needed.

As the industrial revolution changed everyday life in the United States, occupational safety and health priorities began to be acknowledged. The United States government made the first regulatory effort with the passage of the 1936 Walsh-Healy Public Contracts Act. This law established standards for sanitary conditions and employee safety in which all federal contracts of $\$ 10,000$ or more were granted and retained. The act stated "No part of such contract shall be performed ....under working conditions which are hazardous, unsanitary, or dangerous to the health and safety of employees engaged in said contract." (Peterson, 2003) These elements were then enforced by the Department of Labor. In 1952, the Department of Labor published a set of safety and health standards known as the "Green Book". These sets of standards were designed to be a minimum level of safety for the employees and used by Walsh Healey inspectors. However, the enforcement of these standards was left to the individual states. (Bokat and Thompson, 1996)

According to Peterson (2003), the National Safety Council (NSC) reported that all industry accident frequency rates showed an upward trend during the period of 1961-1969 in the United States. These trends ultimately led to the passage of various congressional Acts which encouraged the emphasis of occupational safety. Such Acts included the 1969 Federal Coal 
Mine Safety and Health Act, which was passed after the events that transpired on November 20, 1968 at the Consol Mine No. 9 in Farmington, West Virginia. That mine explosion left 78 miners dead. (Bokat, 1996) The other major regulatory act to pass was the Occupational Safety and Health (OSH) Act of 1970 (Public Law 91-596). The OSH Act established a federal mandate that all employers shall

"furnish to each of his employees employment and a place of employment which are free from recognized hazards that are causing or likely to cause death or serious physical harm to his employees.” (§5 (a) (1))

This regulatory action offered protection to employees in private industry. However, government-operated entities were exempt from compliance with the same authority, including federal, state and local government employees.

In addition to mandating safety and health in the workplace, the OSH Act created two essential agencies for functionality of the intent of the law. These entities included the Occupational Safety and Health Administration (OSHA) and the National Institute for Occupational Safety and Health (NIOSH). OSHA, which is housed under the Department of Labor, serves as the enforcement arm of the safety and health movement. The Department of Health and Human Services oversees the efforts by NIOSH. NIOSH serves as the research entity for OSHA and offers recommendations for occupational safety and health standards. Another formalization resulting from the act included the injury illness data collection mandate extended to the Bureau of Labor Statistics (BLS). The BLS, also housed under the Department of Labor, collects and maintains statistical data on occupational injury and illnesses. 
After the passage of the OSH Act and the establishment of the supporting agencies, the National Safety Council (NSC) showed a steady decline in unintentional death rates until 1992. After 1992, the unintentional death rates began to rise once again. It is important to note that all unintentional deaths as referenced by the NSC were not limited to occupational fatalities only. It also included personal injury accident fatalities. The NSC has offered a graphical analysis demonstrating that motor vehicle accidents are by far the leading cause of unintentional deaths. Between the years of 1969 and 2004, the number of deaths per year related to motor vehicle accidents has declined from approximately 55,000 to 45,000, as the population has increased in that time frame. The second leading cause of unintentional deaths per year during that same time period was falls. Falls accounted for less than 20,000 per year. (NSC, 2007)

It is apparent that the United States government has made enormous legislative and regulatory efforts in it attempt to reduce the number of unintentional fatalities for occupational incidents related to highway activities. However, all populations have not been offered the same level of protection. One population identified to be at risk based on their occupation is the law enforcement professionals. According to Clark and Zak (1999), law enforcement officers have a three times greater risk of suffering a fatal incident than all other workers. This data does not reflect the variation in law enforcement officer exposure to such conditions in comparison to other occupational environments. Although law enforcement professionals' routine practices are generally guided by the US Department of Justice (DOJ) standards and protocols, the DOJ does not offer standards of practice for protection from highway fatalities. The National Institute of Justice serves as the research, development and evaluation agency for the Department of Justice. The foremost effort of the agency is to establish standards of practice for dealing with criminals, 
evidence, and information gathering practices. Limited research efforts are directed towards the safety of the law enforcement professional.

Despite significant legislative and regulatory attention paid to occupational safety in industrial settings, there has been little government focus on sources of occupational injuries and fatalities of police officers. There has also been limited policy and intervention to address the injuries and fatalities until recently. The National Law Enforcement Officers Memorial Fund (NLEOMF) (2007) reported that during a ten year period, 1997-2006, there were 582 fatalities attributable to gunshot wounds and 707 fatalities were due to automobile incidents. NLEOMF reported in their 2006 Year End Report, that there is an increase in officer fatalities due to auto accidents. The report states that in both " 2005 and 2006, the number of traffic-related deaths was greater than the number of deaths by gunshot. In fact, in the last three decades, the number of officers killed in automobile crashes has risen by 34 percent." According to the United States Department of Justice, during the time period 1996 - 2000, the population of law enforcement officers has risen by 2.1 percent per year. (BJS, 2008)

The International Association of the Chiefs of Police (IACP) is a nationally recognized organization that conducts research and offers policy guidance for the law enforcement community. The mission of the IACP is stated as:

"The IACP shall advance professional police services; promote enhanced administrative, technical, and operational police practices; foster cooperation and the exchange of information and experience among police leaders and police organizations of recognized professional and technical standing throughout the world." (2004) 
The IACP's Highway Safety Committee (HSC) continues to recognize the dilemma related to traffic safety for law enforcement professionals. In cooperation with NHTSA, IACP and other agencies have established a group referred to as the Law Enforcement Stops and Safety Subcommittee (LESSS). The goal of the LESSS is "to improve the environment in which officers operate. LESSS is attempting both to solidify past efforts, especially those significant ones of the Arizona Crown Victoria Police Interceptor (CVPI) Blue Ribbon Panel, and to explore better ways to ensure to a greater extent officer safety during traffic stops and other roadside contacts.” (IACP, 2007) The minutes of the LESSS meeting held on October 14, 2007 indicated that the committee members were interested in data analysis to form the basis for a model policy for mitigating crashes.

\subsection{STATEMENT OF THE PROBLEM}

There is a growing problem in the number of law enforcement highway fatalities. An identification of risk factors has not been conducted for federal, state, or private agencies to be used for policy development. As a result, federal and state agencies do not have useful data and information available to develop policies to prevent or reduce the number of occupational highway fatalities.

\subsection{STATEMENT OF PURPOSE}

The purpose of this study is to create the foundation for future research endeavors to test the impact of the identified risk factors and potentially offer guidance for the mitigation of law enforcement officer highway related fatalities. 


\subsection{RESEARCH OBJECTIVES}

The principal goal of this study is to identify risk factors associated with highway fatalities for law enforcement professionals. The model would be derived from looking at the frequency distributions of various circumstances, then, gathering valid and broad crash and fatality related factors through the opinions of experts via a focus group. A strength of association was measured in the form of an odds ratio outcome to assist in the identification of risk factors which may be contributing to law enforcement highway fatalities. The identification and modeling of such risk factors into useful sets shall guide administrators and future researchers in an effort to reduce the occupational fatalities of law enforcement officers occurring on highways. The identification of these predictable risk factors can be used for future research by both government and non government entities. This research shall form the basis for the identification of risk factors that may be followed for future cohort studies to determine a testable statistical model. This shall serve as a foundation for future studies to assist in the establishment of model policy for mitigating crashes and reducing law enforcement officer highway fatalities. The results of this study shall be made available for all interested entities.

Four objectives shall be met to accomplish the mission of this research. These objectives are:

1. Conducting a thorough literature review of data which identifies factors associated with risk,

2. facilitating a focus group for the arrangement and prioritization of the above objective,

3. perform statistical analysis to offer an identification of the risk factors associated with law enforcement highway fatalities, and 
4. offer general recommendations for future actions or research related to law enforcement officer fatalities.

\subsection{OVERVIEW}

This study is designed to offer government entities research results that identify the primary risk factors associated with law enforcement highway fatalities. This model will assist such agencies in determining the need for future regulatory standards or guidelines to prevent the proliferation of highway fatalities.

This study is presented in a traditional dissertation format. Chapter 1 includes; statement of the problem, objective of the study and a brief overview of the organization of this dissertation.

Chapter 2 offers a thorough review of literature for determining potential risk factors. This study also reviews the available data sets for determination of appropriate data to analyze the effectiveness of current campaign efforts to reduce law enforcement highway fatalities.

In Chapter 3 the analytical model utilized for analysis purposes is described. A description of all data set coding and analytic reference and software applications used for data analysis are also covered in this chapter.

Chapter 4 presents the results of the analysis by offering which risk factors have been identified as a cause of law enforcement highway fatalities from both the focus group and the descriptive statistical method. It also presents the results of the multivariate analysis. 
Finally, Chapter 5 includes conclusions of the research and the model developed as a result of the research, the limitations of the study, and presents potential future research opportunities. 


\section{Chapter 2}

\section{Review of Literature}

\section{$2.1 \quad$ INTRODUCTION}

The lack of occupational fatality data has long plagued the researchers in the field of occupational safety and health. Since its inception in 1970, the National Institute for Occupational Safety and Health (NIOSH) has strived to anticipate, recognize and evaluate hazardous working conditions to protect the worker. According to NIOSH, the number of cases and rates of all fatal occupational injuries during 1992-2002 have reflected a steady decline. The fatal occupational injury rate has declined from 5.3 per 100,000 workers in 1994 down to 4.0 in 2002 (2004). Although overall occupational fatalities rates have declined in recent years, occupational highway fatality have not been as progressive. Pratt (2003) states that "although other workplace fatalities have declined in recent years, the number of occupational deaths from roadway crashes has increased steadily from 1,135 in 1992 to 1,471 in 1999. In 2000, roadway crashes decreased to 1,347." In this same study, Pratt reported that work-related highway fatalities of civilian workers have averaged a rate of 1.08 per 100,000 full-time employees during the years of 1992 to 2000. After 2000, the number of highway fatalities incidents have been maintained around 1,400 per year. (USDOL BLS, 2008) Since 1992, the BLS has reported that highway incidents are the number one cause of work related fatal incidents. (USDOL BLS, 2008) This data offers a brief image of the problems related to highway fatalities.

According to data reported by the Census of Fatal Occupational Injuries (CFOI) the top four causal events for all occupational fatalities has been provided and listed from most frequent to 
least frequent: highway incidents, homicides, falls and struck-by-object incidents. (US DOL BLS, 2008) Effectively this same document holds that 40 percent of law enforcement worker fatalities during 2006 were due to highway incidents, followed by the second highest causal factor of homicides at 38 percent. (US DOL BLS, 2008)

To further evaluate a specific occupation related to highway fatalities becomes a compounding issue. According to Clark and Zak (1999), the index of relative risk of a fatal incident for law enforcement personnel and firefighters is three times greater than for all other workers." They also reported that 43 percent of fatalities incurred by law enforcement personnel during 19921997 were a result of transportation incidents.

Although an extensive literature review was conducted for this study, very few studies were found to be directly related to law enforcement fatalities. Since there was so little research related to law enforcement highway fatalities, risk factors were also reviewed for all highwayrelated fatalities and occupational highway fatalities. For purposes of this literature review, an attempt to indirectly relate law enforcement highway fatality circumstances has been segregated into three main classifications: Automobiles incidents, motorcycle incidents and struck by incidents. Each of these factors will be thoroughly discussed in the following sections of this chapter.

\subsection{AUTOMOBILE INCIDENTS}

The National Highway Transportation Safety Administration (NHTSA) is charged with the mission of saving lives, preventing injuries, and reducing vehicle related crashed. This mission 
is accomplished by offering research and guidance for the protection of motor vehicle occupants. However, NHTSA's National Center for Statistics and Analysis (NCSA) maintains data on motor vehicle accidents in general and is not specific to occupational or law enforcement related incidents.

Based on the Fatality Analysis Risk System (FARS) data presented by Pratt (2003), the same five factors are most often present for drivers of large trucks in occupational incidents and passenger vehicles. These five factors include: Driving too fast for conditions or in excess of the posted speed limit; Failure to stay in the proper lane; Running off the road; Inattention (talking, eating, etc.); Failure to yield the right of way (Pratt, 2003)

\subsubsection{Driver-Related Factors in Enforcement and Occupational Injuries}

Driver-related factors shall include elements such as driver fatigue, education, urgency or speeding, and age of driver.

Brown (1994) identifies driver fatigue as a combination of three main working arrangements.

"(a) length of continuous work spells and daily duty periods; (b) the lengths of time away from work that are available for rest and for continuous sleep; and (c) the arrangement of duty, rest, and sleep periods within the 24-h cycle of daylight and darkness, which normally entrains individuals' circadian rhythms." Based on a case control study, it was suggested that driver distraction/inattention, fatigue, and the vehicle not under proper control were factors more frequently involved in fatal commercial vehicle collision compared to nonfatal commercial vehicle collisions (Bunn, Kurpad, Struttman, 2003). 
Hamelin (1987) found that incident risk for truck drivers was dependent upon two factors; time of day and work span duration. The study reported that drivers with work shifts of less than 11 hours experienced an incident risk rate $175 \%$ higher during the hours of 8 PM to 7 AM. Interestingly he also noted that for drivers with work shifts of 11 hours or more, the accident risk rate was $76 \%$ higher from $8 \mathrm{PM}$ to $7 \mathrm{AM}$ than from $8 \mathrm{AM}$ to $7 \mathrm{PM}$. Pratt (2003) reported that FARS data from 1993-1995 indicated an excess of single vehicle occupational crashes among long-haul trucks between midnight and 6 am. In addition, the FARS data cited driver fatigue in $19 \%-21 \%$ of the crashes occurring between midnight and $6 \mathrm{am}$.

As the previous study reflects the hours that most truck driver accidents occurred, it is important to also consider the hours which law enforcement officers are accidentally killed. The FBI reported during the time period 1997-2006, the majority of officers killed in accidents (85 fatalities) occurred during the hours of 12:00 am to 2:00 am. The hours in which the least amount of accidental fatalities occurred were between 4:00 am thru 6:00 am and 6:00 am to 8:00 am (each with only 43 fatalities). In addition to the reflection of hours in which all law enforcement officers were accidentally killed, the causal factors were reviewed. During the time period of 1997 - 2006, a total of 739 law enforcement officers were unintentionally killed. Highway fatalities including motorcycle incidents, automobile incidents and struck by incidents accounted for 607 of the unintentional fatalities. (FBI, 2007)

As the data indicated that a significant portion of occupational fatalities occurred as a result of highway incidents. Consideration to the level of driver training should be taken into account. 
Individuals with occupations that involve driving receive varying levels of education. The degree of training can vary from structured commercial driving courses or defensive driving courses to the more unstructured method of on-the job training. A review of research shows that under the Motor Vehicle Safety Act of 1986 federal regulations state that an employed driver must obtain a commercial driver's license if he/she is engaged in intrastate, interstate or foreign commerce, and operate a vehicle that meets the definition of a commercial motor vehicle. This licensing process includes a review of the operator's driving record and a mandate that he/she must pass a general knowledge test and demonstrate driving skills for each vehicle classification they intend to operate.

Another driver-related factor that has been reviewed by statistics is the age of the driver. According to Pratt (2003), the age group with the highest percentage of work-related highway fatalities was between ages 35-44, accounting for 24.6\% during 1992-2000. However, when comparing the rate of crashes per 100,000 full-time employees, the age group encompassing 65 years of age and older indicated a 3.77 times greater chance of being involved in a work related highway fatality. Pratt also reported that from 1994 to 2000, fatal crashes among older workers occurred less frequently on interstate highways.

\subsubsection{Vehicle-Related Factors in Enforcement and Occupational Injuries}

As the progression of technology continues, the safety features on vehicles continue to advance as well. The evolution of safety devices has included not just simply seat belts, but also air bags, vehicle crumple zones, and anti-lock brakes, to name a few. All of these safety features have been carefully designed and installed for the protection of the occupants inside the vehicle. 
The safety of the vehicle design has been reviewed over the recent years related to specific vehicles used for law enforcement purposes. In particular, Ford Motor Company, in collaboration with the Arizona Attorney General, reviewed the safety designs of the Crown Victoria Police Interceptor (CVPI). As a result, design modifications were made to the CVPI to reduce the potential risk for fuel tank leaks resulting from CVPI vehicular accidents. This is a sign of positive efforts to protect the occupants of the vehicle. Such modifications in design have resulted in the reduction of fuel tank leaks associated with the CVPI.

Not only has technology been an ever apparent success in the design of safety related features in the automobile, but it has also offered a new line for communication and guidance. Over ten years ago, NHTSA conducted a study called "An Investigation of the Safety Implications of Wireless Communications in Vehicles". (1997) The results of this study indicated that instead of prohibiting the use of the communication, researchers needed to focus on emphasis and development of hands-free models to minimize the risk. Since this time and in comparison to the early days of the communication radio, law enforcement technology has made great strides in the progression of noninterference technologies. Now there is a range of technologies such as mobile computing technologies, wireless infrastructures, in-car cameras, computerized records management systems and much more is now available for officers. However, new technologies also bring new distractions for drivers. Law enforcement professionals are often required to use handheld communication radios as a part of their daily routine while driving. Each of the above referenced technologies requires some type of driver attention in order to activate or operate the systems. Although many entities are adopting new technologies, budgetary 
constraints prohibit the full implementation of advanced technologies in law enforcement vehicles. Many detachments or offices maintain older technologies until funding is available to invest in newer technologies.

Law enforcement personnel have begun to utilize cell phones more frequently for communication when other technologies offer a reduced clarity in communications. Although these cell phones are sometimes personal phones, officers are permitted to utilize them if the phones offer better reception and communication than company issued communication instruments. (Sergeant M. Weaver, personal communication, January 5 2008)

A new type of technology that is becoming more popular in the law enforcement vehicles is the Intelligent Transportation System (ITS). This system is a computerized system offered in the vehicles to electronically assist in various response methodologies. The ITS was initially piloted by the US Department of Transportation in 1991. Since this time, it has become adopted by various agencies across the United States. The ITS has been a powerful tool in law enforcement management. Not only does the ITS serve as a management tool, it also has the potential for greatly reducing traffic accidents and notifying drivers of crash scenes ahead. It is believed that such warning systems shall reduce the amount of rear-end collisions by 49 percent. (NHTSA \& IACP, 2004)

The conspicuity and markings of law enforcement vehicles have also been identified as a risk factor as related to rear-end collisions. Webster's dictionary defines conspicuity as the quality or state of being conspicuous. Conspicuous is defined as very readily perceived. Markings 
are defined as arrangement, pattern, or disposition of marks. Marks are defined as a conspicuous object serving as a guide for travelers. A study was conducted in 2003 by Kochhar and Tijerina of Ford Motor Company. This study was designed to evaluate the markings and conspicuity of Ford Crown Victoria police interceptors (CVPI). The study included a sample of 152 accident records involving CVPIs. The results of the study reported the following findings in reference to high speed crashes where a police vehicle was stopped on the left or right shoulder:

1. Police vehicles that are black in color appear to be over-represented in accident statistics. However, in view of the confounding effects of many other factors on vehicle color, further study of vehicle color on the likelihood of a crash is warranted.

2. Police vehicles that were stopped on the left shoulder appear to be over represented in the accident statistics.

3. Crashes during nighttime hours appear to be over represented in the accident statistics.

4. Police vehicles that did not have the emergency lights activated may be over represented in the accident statistics.

According to the results of this study, conspicuity and markings could adversely impact the potential for rear end collision of law enforcement vehicles.

\subsubsection{Environmental Conditions in Enforcement and Occupational Injuries}

One of the tasks charged to IACP's Law Enforcement Stops and Safety Subcommittee (LESSS) was to create a working group to focus on the highway environment and design. This working 
group has been charged with identifying the data elements required to determine the magnitude of the problem, for example, congestion, shoulder sufficiency, traffic, and weather; and analyze those data to ascertain appropriate engineering countermeasures. Based upon the analysis of such data, the working group shall offer recommendations to American Association of State Highway and Transportation Officials (AASHTO) and Federal Highway Administration (FHWA) appropriate countermeasures. Highway design elements include factors such as the width of travel lanes, design of highway shoulders, rumble strips, pavement markings and moveover lanes.

A review of the LESSS 2004 Staff Study Report indicated opposing opinions to the recommendation of travel lane width. Although the report referenced a guideline of a 12-foot width, it also indicated that the National Cooperative Highway Research Program recommended the reduction in travel lane width. The justification for this recommendation was for capacity increase in highly populated areas. (FHWA, 2005) However, researchers question whether the decrease in lane width increases the risk of crashes. In addition to travel lanes, shoulder width has been an issue of great consideration for the safety of law enforcement officers. A study conducted by the Highway Safety Information System (HSIS) evaluated the safety effects of using narrow lanes and shoulders to increase the capacity of urban freeways. This study suggested that there was a statistically significant increase in accident frequency when a four lane highway was converted to a five lane highway. (Bauer, 2004)

Highway shoulder design is another element that may be a contributing factor in the reduction of protection for law enforcement personnel when pulling over vehicles. If a roadway is designed 
without a shoulder, law enforcement officers must resort to walking in the lane of passing traffic. Along with the visibility of the vehicles, shoulder designs play a significant role in the reduction of struck by incidents and patrol vehicles being hit by passing traffic. Federal Highway Administration Guidelines suggest that if a vehicle must pull over on the shoulder of the roadway, the vehicle should clear the traveled lanes by at least one foot or preferably two feet. The recommended width of the shoulder is dependant upon the use of the highway. Ten feet is the recommended shoulder width for high speed roadways and 12 feet for highways carrying a large number of trucks. (NHTSA \& IACP, 2004)

As the traffic volume continues to grow in heavily populated areas, highway designers are forced to convert shoulders into travel lanes. As a result limited shoulder widths are made available to law enforcement personnel for the purpose of pulling over motor vehicles for various purposes. Therefore, the American Association of State Highway and Transportation Officials established some design guidelines in the 1997 Highway Safety Design and Operations Guide.

Other highway designs that have been implemented to prevent the occurrence of accidents on highways include rumble strips and pavement markings to offer drivers warnings. When driving over rumble strips, a loud humming sound is produced warning the driver of encroachment onto a shoulder area. These rumble strips are intended to alert the driver before an accident occurs. Several studies have reported that rumble strips have significantly reduced the off road crashes. (NHTSA \& IACP, 2004) Pavement markings are often used to direct drivers to lane changes or to help regulate traffic. These pavement markings generally include raised markings, reflective 
markings or internally illuminated markings. Research has shown mixed results on the effectiveness of the markings. (NHTSA \& LESS, 2004)

\subsection{MOTORCYCLE INCIDENTS}

Raising concerns is the steady number of motorcycle fatalities for law enforcement professionals over a ten year period. The historical data has shown any declining trends in the number of motorcycle accidents for law enforcement officers. During the years 1997-2006, motorcycle incidents were the fourth leading cause of law enforcement officer fatalities accounting for almost 5\% of the all officer fatalities. The NLEOMF reported that in 2006 motorcycle accidents accounted for $8 \%$ of law enforcement fatalities. (NLEOMF, 2007a)

Studies have shown that the greatest risk factor associated with motorcycle fatalities is the usage of helmets. Helmet usage, however, has not been referenced as a potential concern for law enforcement personnel as agencies ensure that law enforcement personnel are adequately protected by the wearing of helmets. Most agencies have internal policies that mandate law enforcement officers wear helmets when operating agency assigned motorcycles. (Sergeant M Weaver, personal communication, January 5 2008)

NHTSA's data suggest that speeding is a possible causal factor of motorcycle accident fatalities, many law enforcement officers are responsible for responding to the scene immediately for law enforcement activities. This sometimes involves high speed pursuits to enforce the laws. Historical research is not available which evaluates the involvement of motorcycle fatalities of law enforcement professionals during high speed pursuits. 
Although, blood alcohol content is not considered a potential risk factor for law enforcement officer fatalities related to motorcycle crashes. The IACP has established a model policy on standards of conduct. This policy is representative of similar polices adopted by enforcement agencies across the United States. This policy states:

a. Officers shall not consume any intoxicating beverage while on duty unless authorized by a supervisor.

b. $\quad$ No alcoholic beverage shall be served or consumed on police premises or in vehicles owned by this jurisdiction.

c. An officer shall not be under the influence of alcohol in a public place, whether on- or off-duty.

Therefore based upon the model on policy of standards of conduct by the IACP, this research shall not conduct further review of the incidents of law enforcement motorcycle fatal crashes related to driver intoxication because the author believes that driver intoxication for a law enforcement officer poses additional ethical concerns that extends well beyond the scope of this study.

\subsection{STRUCK-BY INCIDENTS RELATED TO LAW ENFORCEMENT OR OCCUPATIONAL EXPOSURE}

Minimal data has been offered for fatalities related to struck-by incidents occurring to law enforcement officers. According to the National Law Enforcement Officers Memorial Fund (NLEOMF) 151 officers were killed by struck-by incidents during the years 1998-2007. However, in-depth studies related to law enforcement struck-by incidents could not be found by 
the author after an extensive review of literature. A study performed by Pratt, Fosbroke and Marsh (2001) reported that approximately 50 percent of the occupational related struck by fatalities in work zone areas were attributable to passing traffic. The other 50 percent were attributable to incidents involving on-site construction vehicles. For construction zones, various warning methods have been employed to reduce the potential for occupational struck by incidents. These safety methods employed in construction zones are a concerted effort by the Occupational Safety and health Administration (OSHA) and the Federal Highway Administration (FHWA). Law enforcement officers are often not afforded the opportunity for safety awareness in areas in which they work or respond.

\subsection{FATALITY REDUCTION EFFORTS FOR LAW ENFORCEMENT OFFICERS}

\section{Driver Training}

Law enforcement personnel are exposed to a challenging task related to motor vehicle operations. At times they are required to quickly respond to emergency situations. This requires them to travel at a high speed in order to offer the public the greatest amount of protection. In order for them to safety accomplish this task, many officers receive emergency vehicle operations training. NHTSA has prepared traffic safety training courses to be used by the enforcement agency. However, due to the confines to budgets, additional training needs, and community needs, these training tools are not always used by the agencies. (Bolton \& Wall, 2007) 
A survey of 800 agencies conducted by Alpert for the National Institute of Justice and reported in 1997 offered a snapshot of the agency policies and training related to pursuits. Alpert (1997) reported in this study that entry-level driving training was estimated at less than 14 hours. Once the officers were in service, annual training averaged slightly more than 3 hours per year. It was also reported that the focus of the training was often on defensive driving and or pursuit driving rather than on issues that should be considered when deciding to continue or terminate pursuits.

As a response to the growing concern for law enforcement driving education, the IACP 's Highway Safety Committee's LESS released a nineteen minute video titled P.E.R.S.U.E. (Prepare, Understand, Respond, Stop, Utilize, Examine) to communicate to law enforcement personnel the decision making process that should be utilized in high speed pursuits. The release of this video occurred at the October of 2007 IACP National Conference. As agencies begin to utilize the materials made available, future studies can be conducted by researchers to test the effectiveness of the training video.

\section{NLEOMF - Drive Safely Campaign}

The National Law Enforcement Officers Memorial Fund (NLEOMF, 2007) has reported that over the past three decades, the number of officer fatalities related to automobiles has increased by forty percent. In an effort to stop this trend and reduce the number of automobile related fatalities of law enforcement officers, NLEOMF officially enacted the Drive Safely campaign on August 8,2005 . This campaign has consisted of informing the public of why so many officers have been lost to automobile accidents, the precautionary measures that can be taken by the 
public, public service announcements near highly traveled holiday seasons, offering officer testimonials and asking the public to sign a drive safely pledge.

\section{Move Over Campaign -}

On July 2, 2007 a national campaign was launched called the "Move Over America" campaign. This effort was designed to reduce the number of law enforcement fatalities related to struck by incidents. More than 150 U.S. law enforcement officers have been killed since 1997 after being struck by vehicles along America's highways, according to the National Law Enforcement Officers Memorial Fund. Initial Move Over Law efforts began as early as 2000 as such laws were implemented in the state of Kansas. However, in a concerted effort to lower that deadly toll, a new coalition of traffic safety and law enforcement groups has launched a nationwide public awareness campaign to protect emergency personnel along our nation's roadsides. A part of the public awareness effort includes a video broadcasted public service announcement and an interactive map of the United States identifying various state legislative efforts towards move over laws. Other efforts of the move-over campaign have included the passage of legislation by the states that would permit law enforcement officers to fine individuals for not complying with the move over laws. States have also installed signs on the roadway to remind drivers of their responsibility to obey the move over laws. These signs are often placed on highways which are recognized as highly used roadways.

"Move Over, America" is a cooperative effort between the National Safety Commission, the National Sheriffs' Association, and the National Association of Police Organizations. The campaign is the first nationally coordinated endeavor to educate Americans about "Move Over" 
laws and how they help protect the law enforcement officers who risk their lives protecting the public. Currently there are only 7 states which do not have move over laws implemented. The intention of the "Move Over" law is to require motorists to "Move Over" and change lanes to offer a safe clearance for law enforcement officers along the side of the road. If drivers can not change lanes or are driving on a two-lane road, then the laws encourage the drivers to slow down to at least 20 m.p.h. under the posted speed limit. If drivers do not move over or slow down, officers can and do write citations. (Move Over America, 2007)

\section{Law Enforcement Stops and Safety Subcommittee -}

In 2003, IACP's Highway Safety Committee (HSC), joined with the NHTSA to improve working conditions for police officers along roadways. With the combined efforts, the HSC established the Law Enforcement Stops and Safety Subcommittee (LESSS) to address officer safety during traffic stops and other roadside contacts. LESSS consists of 26 members from various organizations such as IACP, NTSHA, Federal Highway Administration (FHA), Federal Bureau of Investigation (FBI), various state highway patrol agencies and state department of public safety officials. The LESSS mission charges the subcommittee with three primary tasks: "Explore and examine the causes, circumstances, commonalities, and preventability of highspeed, high energy rear-end collisions resulting in the death and injury of officers during traffic stops and other roadside contacts; Develop and recommend appropriate mitigation strategies relative to those issues studied by the three primary working groups; Create and market to law enforcement executives best practices and procedures for conducting professional and safe traffic stops and other roadside contacts" (Ashton, 2004) 
To effectively accomplish these charges, LESSS has established three working focus groups with defined missions, as described below:

\begin{abstract}
"Vehicle Working Group: Study the design, manufacture, and use of police vehicles, including fleet composition, crash data collection and evaluation, effectiveness of bladders and onboard fire suppressant systems, installation of aftermarket equipment, conspicuity (lighting and markings), and whether there is a need for federal standards relating to public safety vehicles
\end{abstract}

Policy and Procedure Working Group: Ensure the manner of conducting professional and safe traffic stops and other roadside contacts becomes a nationally recognized officer safety issue; research, develop, and evaluate technology which limits police officer exposure, as well as the time expended, on traffic stops and other roadside contacts; and identify risk management practices to evaluate or to limit that exposure

Highway Environment and Design Working Group: Identify the data elements required to determine the magnitude of such problems as congestion, shoulder sufficiency, traffic, and weather; and analyze those data to ascertain appropriate engineering countermeasures, making recommendations to American Association of State Highway and Transportation Officials and Federal Highway Administration about appropriate countermeasures." (Ashton, 2007)

A positive effort resulting from the continued commitment of LESS includes the launching of a training DVD for law enforcement professional to offer law enforcement professionals some 
guidance in pursuit decision making. The 19-minute DVD was produced by the Colorado State Patrol and uses the acronym P.U.R.S.U.E.

\section{Officer Visibility - Standards}

On April 24, 2006, the FHWA published a Notice of Proposed Rulemaking based upon recommendations by the Highway Safety Committee (HSC). As both the public and the government entities recognized police officers' and highway workers multiple and divergent duties, a standard for worker visibility on federally funded highways was promulgated. On November 22, 2006, Title 23, Code of Federal Regulations (CFR), Section 634.3, passed as stating : "All workers within the right-of-way of a Federal-aid highway who are exposed either to traffic (vehicles using the highway for purposes of travel) or to construction equipment within the work area shall wear high-visibility safety apparel." According to the promulgated standard, the definition of high visibility safety apparel also comes with several caveats. The standard references the ANSI/ISEA 107-2004 standard. Since the ANSI/ISEA 207-2006 standard was still under development when Section 634.3 was issued, it could not be included in the final rule. During the comment period, the FHWA received 175 comments on the concerns related to law enforcement personnel becoming a "better target if a gunfight develops, especially in nighttime conditions." As a part of the preamble to the passage of the final rule, the FHWA modified the definition of a worker "to limit the high visibility garment requirements for law enforcement personnel to those duties that involve directing traffic, investigating crashes and handling lane closures, obstructed roadways and disasters within the right of way of a federal aid highway." (FHWA, 2006) 


\subsection{DATA SETS AVAILABLE FOR EXTERNAL ANALYSIS}

The Centers for Disease Control and Prevention (CDC) define surveillance as "the ongoing collection, analysis and interpretation of health data in the process of describing and monitoring a health [injury] event." Although the concept of surveillance systems was intended for the protection of public health, NIOSH has stated that "for occupational safety research, this (surveillance) refers to the collection, analysis, and interpretation of data on injuries, hazards, and exposures for identifying potential risk factors for further research, and for prevention planning and intervention evaluation.” (2007)

In order to effectively evaluate the various risk factors related to law enforcement highway fatalities, several data sets have been evaluated for inclusion in this study. These data sets include the National Law Enforcement Officers Memorial Fund (NLEOMF) database of all law enforcement fatalities in the United States voluntarily reported to NLEOMF, Census of Fatal Occupational Injuries (CFOI) database of all fatal occupational injuries during 1992-2006, National Electronic Injury Surveillance System (NEISS) supported by the Consumer Product Safety Commission (CPSC), Fatality Analysis Reporting System (FARS) maintained by the National Highway Transportation Safety Administration (NHTSA), Law Enforcement Officers Killed and Assaulted (LEOKA) maintained by the Department of Justice Federal Bureau of Investigation, Officers Down Memorial Page (ODMP).

Table 2.1 offers a summary of the data sets available and the organization responsible for collecting the data. 
Table 2.1: Available Data Sets for External Analysis

\begin{tabular}{|l|l|l|l|}
\hline \multicolumn{1}{|c|}{ Name of Data Set } & $\begin{array}{c}\text { Data Set Maintained } \\
\text { By }\end{array}$ & $\begin{array}{c}\text { Years Represented } \\
\text { in Data Set }\end{array}$ & $\begin{array}{c}\text { Format of Available } \\
\text { Data }\end{array}$ \\
\hline NLEOMF Database & NLEOMF & $1792-$ Present & Microsoft Access \\
\hline CFOI & US BLS & $1992-2006$ & $\begin{array}{l}\text { Must be afforded } \\
\text { access to the data set }\end{array}$ \\
\hline NEISS & CPSC & $1978-$ Present & Various formats \\
\hline FARS & NHTSA & $1975-$ Present & SAS \\
\hline LEOKA & FBI & $1937-$ Present & $\begin{array}{l}\text { Selective criteria } \\
\text { available, not entire } \\
\text { data set }\end{array}$ \\
\hline ODMP & Private Entity & 1790 's - Present & HTML \\
\hline
\end{tabular}

To be considered as a data set eligible for use in this study, the data must meet the following criteria:

1. Be limited to law enforcement officers killed in the line of duty.

2. Be highway or vehicle, motorcycle and struck-by incident related

3. Be sufficiently detailed to extract causation

4. Exist for a period of years to offer sufficient amounts of reliable data

5. Injury only data could not be considered

6. Consist of a valid reporting mechanism to offer a valid representation of data

The National Law Enforcement Officers Memorial Fund (NLEOMF) officer fatality database is maintained directly by the "Fund". For purposes of the memorial NLEOMF defines a "law enforcement officer" as an individual involved in crime control or reduction and who is directly employed on a full-time basis by a local, county, state or federal law enforcement agency of the United States Officers or its territories, with or without compensation, who is duly sworn and has full arrest powers. Law enforcement officers are listed in the database based on applications submitted by the respective agency for inclusion on the national memorial. This application 
process includes a detailed description of the incident, demographics of the officer, selection of circumstance that best describes the death, copies of incident report, court documents, and newspaper articles related to the death. All officers killed in the line of duty are eligible for inclusion on the memorial and information regarding the fatality is maintained in the NLEOMF data set. This reporting process to the NLEOMF is not a mandated protocol for the deceased's agency, it is a service offered as a respect to the fallen law enforcement professionals. The reliability and validity of this database has not been determined, as this database has not been maintained for in-depth research purposes. Therefore, it will not be considered for use in this study.

The Census of Fatal Occupational Injuries (CFOI) database began in 1992 and is presently fully operational. All CFOI data are collected by the United States Bureau of Labor Statistics (BLS) occupational safety and health statistics program. A diverse selection of federal and state data sources are used to identify, verify and describe fatal work injuries. Data sources used in the documentation process are cross-referenced to offer the most complete and accurate set of data possible. These documents include death certificates, workers' compensation reports and claims, reports to various regulatory agencies, medical examiner reports, and police reports, as well as news and other non-governmental reports. Diverse sources are used because studies have shown that no single source captures all job-related fatalities. Source documents are matched so that each fatality is counted only once. To ensure that a fatality occurred while the decedent was at work, information is verified from two or more independent source documents or from a source document and a follow-up questionnaire. Approximately 30 data elements are collected, coded, and tabulated, including information about the worker, the fatal incident, and the machinery or 
equipment involved. CFOI is a Federal/State cooperative program in which costs are shared. States provide data to BLS for inclusion in a national database and maintain their own State databases. (BLS, 2007) CFOI uses the Occupational Injury Illness Classification System (Manual) for coding to maintain consistency between data sources. The database includes the following elements (not all inclusive): Nature of Injury or Illness, Part of Body Affected, Source of Injury or Illness, Event or Exposure, and Secondary Source of Injury or Illness. Since the data set only offers the coding of 30 data elements, it does not offer a sufficient amount of information for the purposes of this study.

The National Electronic Injury Surveillance System (NEISS) is a database that is maintained by the Consumer Product Safety Commission (CPSC). This database is derived from a sample of emergency rooms incidents. CPSC's National Electronic Injury Surveillance System (NEISS) is a national probability sample of hospitals in the U.S. and its territories. Patient information is collected from each NEISS hospital for every emergency visit involving an injury associated with consumer products. This database offers a surveillance of product incidents and does not include all emergency room visits. This data set may also be limited in the reporting of fatalities since some fatalities may never be reported to the local emergency room. The NEISS data set does not accurately represent highway fatalities of law enforcement professionals. Therefore, for purposes of this study, the NEISS data set shall not be used.

The National Highway Traffic Safety Administration (NHTSA) in cooperation with the National Center for Statistics and Analysis (NCSA) maintains a database of all fatal traffic crashes within the 50 States, the District of Columbia, and Puerto Rico. This database is referred to as the 
Fatality Analysis Reporting System (FARS). Historically the Fatality Analysis Risk System was referred to as the Fatality Accident Risk System. However, due to the negative connotations and interpretations of the term accident, the dataset was retitled Fatality Analysis Risk System. (I Rockett, personal communication, August 8 , 2008) To be included in FARS, a crash must involve a motor vehicle traveling on a trafficway customarily open to the public and result in the death of a person (occupant of a vehicle or a non-motorist) within 30 days of the crash. FARS was conceived in 1975, designed, and developed to offer statistical information for the following purposes: provide an overall measure of highway safety, to help identify traffic safety problems, to suggest solutions, and to help provide an objective basis to evaluate the effectiveness of motor vehicle safety standards and highway safety programs.

The FARS database is maintained by state agencies using standard FARS forms. The state analyst uses the state's own source documents which may include; Police Accident Reports, State Vehicle Registration Files, State Driver Licensing Files, State Highway Department Data, Vital Statistics, Death Certificates, Coroner/ Medical Examiner Reports, Hospital Medical Reports, and/ or Emergency Medical Service Reports. In addition to comparing numerous sources for validity of data, FARS has established a quality control system to identify errors in data entry. The FARS database contains descriptions, in standardized formats, of each fatal crash reported. Each crash has more than 125 different coded data elements that characterize the crash, the vehicles, and the people involved. The specific data elements may be modified slightly each year to conform to changing user needs, vehicle characteristics, and highway safety emphasis areas. The FARS system requires the completion of four forms including: the accident form, the vehicle form, the driver form and the person form. Supplemental data has also been 
reported since 1987. The supplemental data has been adapted from the Multiple Cause of Death file maintained by the National Center for Health Statistics. This data includes (for fatally injured persons with a matching death certificate): specific cause of death, specific injuries, race, Hispanic origin, usual occupation, and education level. (NHTSA NCSA, 2007) The FARS data set offers an adequate amount of data elements meeting the data set eligibility criteria established for this study. Additional sources may be used in conjunction with the FARS data to ensure that all law enforcement officer fatalities are correctly identified.

The Law Enforcement Officers Killed and Assaulted (LEOKA) database is maintained the Federal Bureau of Investigation (FBI). It is mandated by Congress that the FBI's Uniform Crime Reporting Program collect and publish crime statistics. "In June 1971, the law enforcement conference, 'Prevention of Police Killings,' resulted in a Presidential directive to increase the FBI's involvement in preventing and investigating officers' deaths. In response to this directive, the UCR Program expanded its collection of data to include more details about the incidents in which law enforcement officers were feloniously killed and assaulted." (US DOJ, 2007) this Presidential Directive mandates that the LEOKA program collect and publish information on line-of-duty officer deaths which is acquired through the submission of the UCR by each entity. However, submission of the statistics/data by the agencies is voluntary.

"When the FBI receives notification of a line-of-duty death, the Law Enforcement Officers Killed and Assaulted (LEOKA) staff works with FBI field divisions to contact the fallen officer's employing agency, requesting additional details about the fatal incident and supplying information about federal programs that provide benefits to survivors of law enforcement 
officers killed in the line of duty. The LEOKA staff also obtains criminal history data from the FBI Interstate Identification Index about people who are identified in connection with line-ofduty deaths." (US DOJ, 2007)

In order for families to receive benefits, they do not have to submit anything to the FBI. The benefits programs are through the Department of Justice Public Safety Officers' Benefits (PSOB) Program and the Department of Labor. These two programs are unrelated to the FBI. They have their own forms for survivors/agencies to complete in order to receive benefits; and they have different criteria than the FBI does. To ensure that LEOKA maintains an accurate data set, LEOKA is compared to the Public Safety Officer's Benefit Program and other law enforcement officer fatality reporting systems described in Chapter 3 of this study. The LEOKA data set offers the study the most reliable source of data for identifying law enforcement officer highway fatalities. Thus, LEOKA will be used in conjunction with additional data that offers applicable variables related to highway fatalities.

The Officer Down Memorial Page, Inc., (ODMP) is a non-profit organization dedicated to honoring America's fallen law enforcement heroes. This organization maintains a website which serves as a tribute to over 18,000 fallen law enforcement professionals. With the help of data collected by the National Law Enforcement Officer's Memorial Fund, a web page has been dedicated to thousands of heroes dating back to 1790. (ODMP, 2008) This web site offers the following pieces of information for each incident that meets established criteria for inclusion: Representing agency, State, Date of Incident, Date of Fatality, Age of Victim, Description of 
Incident, Years of Experience (Tour of Duty), Officer Badge Number, Cause of Death, Weapons Used, and Suspect Information.

It has been reported by LEOKA staff that the ODMP website is a common reference instrument to ensure that the LEOKA database is accurately maintained. (Kelly, 2008) Due to the limited amount of data available on the website, this will not be used for purposes of this study.

To assist researchers in data analysis efforts, NLEOMF, CFOI, NEISS and FARS data sets are all available in various software applications as described in table 2.1. Although some data sets are not readily available for public access, organizations that maintain such databases willingly provide requested data for additional analysis purposes.

\subsection{METHOD SELECTION}

Based upon the evaluation criteria set forth in the previous sections, law enforcement mortality data sets have limited utility to provide policy guidance. A mixed method approach involving the utilization of a focus group and analyzing data from federally mandated databases has been selected. The databases selected are considered to have reasonable utility for the identification of risk factors contributing to law enforcement highway fatalities. Based upon the criteria previously identified, the LEOKA and FARS databases have been selected for purposes of this study. 


\section{Chapter 3}

\section{Methodology}

\subsection{STUDY DESIGN OBJECTIVE}

The primary objective of this research is to identify specific factors which may influence the potential for the occurrence of a highway-related fatality to law enforcement professionals. The identification of such risk factors will then be used to predict law enforcement highway fatalities and offer a basis for future studies related to law enforcement highway fatalities. In order to accomplish the mission of the study, a mixed method approach involving both quantitative and qualitative methods has been selected. The mixed method approach includes a descriptive study of frequency distributions and the use of a focus group. This study will review the mortality data related to law enforcement highway fatalities and identify the risk factors most closely related to the occurrence of law enforcement highway fatalities.

\subsection{DEFINITIONS}

In order to maintain consistency within the study, three applicable terms have been selectively defined. These terms are defined below.

Law Enforcement Officer: A law enforcement officer is defined by the National Law Enforcement Officers Memorial Fund (NLEOMF) as "an individual involved in crime control or reduction and who is directly employed on a full-time basis by a local, county, state or federal law enforcement agency of the United States or its territories, with or without compensation, who is duly sworn and has arrest powers." (2003). "A law enforcement officer is any marshal, police officer, deputy sheriff, agent, or employee of any other title employed by a municipal, 
city, county, state, or federal agency and has powers of arrest. Any employee of a public authority, railroad, private institution of higher education, or otherwise holds a police commission from a state are considered law enforcement officers. Volunteer/Auxiliary officers/deputies who are granted powers of arrest while on duty are also considered law enforcement officers." (ODMP, 2008)

Highway: "Highway" was selected because that is the term used by Bureau of Labor Statistics to represent public roadways.

Highway Fatality: "Highway fatalities" for purposes of this study shall include automobile incidents and struck-by incidents. This involves three basic categories; Driving, Not DrivingInside the Vehicle, and Not-Driving-Outside the Vehicle.

\subsection{DATA SOURCES}

For the purpose of this study, the FARS and LEOKA databases have been selected because they meet or allow the fulfillment of the criteria establish in this study. To be considered as a data set eligible for use in this study, the data must meet the following criteria:

1. Be capable of being limiting to law enforcement officers killed in the line of duty;

2. Be highway vehicle or struck by incident related;

3. Be sufficiently detailed to extract causation;

4. Exist for a period of years to sufficient to be reliable data; and

5. Consist of a valid reporting mechanism to offer a valid representation of law enforcement officer data. 
The FARS database is a collaborative effort by NHTSA/NCSA and the state agencies. The FARS database contains descriptions, in standardized formats of each fatal crash reported. Each crash has more than 125 different coded data elements that characterize the crash, the vehicles, and the persons involved. The specific data elements may be modified slightly each year to conform to changing user needs, vehicle characteristics, and highway safety emphasis areas. All data elements are collected and maintained in three different files (NHTSA, 2006):

The Accident File maintains specific information such as the time and location of the crash, whether a school bus was involved, the number of vehicles and people involved, weather conditions, and so on. The Vehicle File maintains data on each crash-involved vehicle and driver. Specific data include the vehicle type, role in the crash, initial and principal impacts points, the most harmful event, the driver's record and license status. The Person File maintains data on each person involved in the crash: their age and gender, their role in the crash (driver, passenger, non-motorist, or unknown), alcohol and drug involvement, injury severity, restraint usage, and so on. (NHTSA, 2006)

In addition, supplemental data are provided from the Multiple Cause of Death file maintained by the National Center for Health Statistics. These data include (for fatally injured persons with a matching death certificate): specific cause of death, specific injuries, race, Hispanic origin, usual occupation and education level. Each state employs a FARS coding specialist responsible for the collection and coding of all data. 
Appendix A offers a list of variables within the FARS data system that were used in this research. The variables are listed in alphabetical order.

Data analyzed were limited to incidents involving law enforcement officers. All law enforcement highway fatality incidents that occurred during the year 2002 or preceeding have been identified in the FARS system as a "driver related factor" under the list of data variables. Since the identification of law enforcement officer cases prior to 2002 could not be adequately completed, additional methods for case file selection were established.

The LEOKA database provides a comprehensive list of all law enforcement officer fatalities. This data set follows the same UCR system parameters as the data sets used by the Department of Labor's Bureau of Labor Statistics. Although the complete data set was not made available for this research endeavor, specific case file parameters were provided by LEOKA personnel for further comparison to the FARS data set. These parameters included: year, situation, agency state, incident date, incident time range, victim's age.

\subsubsection{Limitations on Data Sets}

Based on coding parameters it was understood that all cases involving a law enforcement officer fatality were coded 16 under "driver related factors" in the vehicle file. However, during initial case file selection it was discovered that cases with the coding of 16 under the "driver related factors" included all crash victims which were involved in the law enforcement incident. Thus, an alternative case file selection approach was developed. The relevant case files had to be 
selected individually by matching parameters from cases identified by LEOKA, a data set maintained by the Federal Bureau of Investigation (FBI, 2008).

\section{FARS Limitations}

The following table reflects the number of cases reported by LEOKA and the number of matching case files in FARS. It is important to note that each database has specific reporting criteria which are not exactly the same. Therefore, although a case may be listed as a fatality incident due to an automobile accident, it may not meet the standards set to be included in the FARS database. For example LEOKA may include incidents in the data set in which a fatality results from the injuries incurred during a highway incident from previous years. However, FARS only reports fatalities that occur within 30 days of the incident. This reporting criteria limitation only affected 48 out of 607 LEOKA cases or $8.1 \%$ of the cases, as listed in table 3.1 . 
Table 3.1: Identification of Missing LEOKA Cases in FARS Files

\begin{tabular}{cccc}
\hline Year & $\begin{array}{c}\text { Number of } \\
\text { LEOKA Cases }\end{array}$ & $\begin{array}{c}\text { Number of } \\
\text { Matching FARS } \\
\text { Files }\end{array}$ & $\begin{array}{c}\text { Number of } \\
\text { LEOKA Cases Not } \\
\text { Represented in this } \\
\text { Study }\end{array}$ \\
\hline 1997 & 52 & 45 & 7 \\
1998 & 65 & 58 & 7 \\
1999 & 56 & 50 & 6 \\
2000 & 62 & 60 & 2 \\
2001 & 62 & 57 & 5 \\
2002 & 59 & 55 & 4 \\
2003 & 70 & 64 & 6 \\
2004 & 68 & 63 & 5 \\
2005 & 54 & 52 & 2 \\
2006 & 59 & 53 & 6 \\
\hline Total & $\mathbf{6 0 7}$ & $\mathbf{5 5 7}$ & $\mathbf{4 8}$ \\
\# Motorcycle Accidents Removed from & $\mathbf{5 7}$ & --- \\
\hline \multicolumn{2}{c}{ the Dataset } & $\mathbf{5 0 0}$ & \\
\hline
\end{tabular}

Data from Puerto Rico are not included in the FARS database. The ODMP and LEOKA have maintained and included incidents occurring in Puerto Rico in their database.

For struck-by incidents, only the moving vehicle case was selected from the vehicle files. The case file representing the "striking" vehicle was selected when both vehicles were moving. This was coded as "initial impact" with the value equal to 12 (front end of vehicle) in the vehicle file of the FARS database.

After a test run of the descriptive study was performed, the researcher believed that the risk factors associated with motorcycle incidents may not be the same for both motorcycle and automobile incidents. Original data included 557 cases, 57 of which were motorcycle accidents, or $10 \%$ of the case files. To ensure that these 57 case files did not become a bias of the study, all 
case files representing motorcycle incidents were removed from the data set. These cases were selected by the coding Body Type $=80-89$ and Person Type $=1,2$ or 9 . As a result, only 500 cases were used for the purposes of this study.

\section{LEOKA Limitations}

LEOKA maintains a confirmation process in which a comparison of fatality listings (feloniously killed victims and accidental death victims) is performed. LEOKA fatalities are compared to lists supplied by the Concerns Of Police Survivors (COPS) organization, the National Law Enforcement Officers Memorial Fund (NLEOMF), and the Officers Down Memorial Page (ODMP). (Kelly, 2008)

\section{Missing Data Limitations:}

The current UCR reporting process and FARS database did not provide data on the years of work experience in position at time of fatality nor did the database include the amount and type of training received by the fatal victim. Also, the FARS database did not begin collecting vehicle file data for vehicles not in transport until 2005. (T Lindsey, personal communication, July 21, 2008) Therefore, the data files are limited for the category Not Driving - Inside the Vehicle.

\subsection{COMPUTER APPLICATION PROGRAM}

The National Center for Statistics and Analysis (NCSA) has designed the Fatality Analysis Reporting System (FARS) using a Statistical Analysis Software (SAS) data structure. For consistency, all statistical analysis was performed using the SAS statistical software. To provide the researcher with an automated software approach, JMP software was used. 
"JMP runs under both the Windows and Macintosh operating systems. It was created by John Sall in 1989 as a tool for discovering information in data through visualization and graphics. It was designed as a point-and-click, walk-up-and-use product that enables a user to discover more, interact more and understand more. Unlike most statistical software, JMP is task oriented, not method oriented." (Develin, 2003)

\subsection{VALIDITY AND RELIABILITY OF DATA}

\subsubsection{LEOKA Data Validation}

LEOKA data are collected based upon the Uniform Crime Reporting (UCR) System. This reporting system is the current system used by the Federal Bureau of Investigation to prepare statistical reports such as "Crime in the United States". (Vito and Blankenship, 2002).

Although this is considered a valid instrument for the federal entities, researchers contend that some limitations of the UCR are still present. The one limitation which could be reflected in this study is a concern that the UCR data are affected by the reporting practices of the individual law enforcement entities. This means that crimes or incidents may be reported in a manner which places the best light on the agency and the community. There may be a reporting bias that must be considered when reviewing the collected data from the UCR.

The FBI receives notification of a line-of-duty death via the UCR. Upon notification, "the Law Enforcement Officers Killed and Assaulted (LEOKA) staff works with FBI field divisions to contact the fallen officer's employing agency, requesting additional details about the fatal incident and supplying information about federal programs that provide benefits to survivors of law enforcement officers killed in the line of duty. The LEOKA staff also obtains criminal 
history data from the FBI Interstate Identification Index about people who are identified in connection with line-of-duty deaths." (US DOJ, 2007)

As previously discussed, LEOKA maintains a confirmation process in which a comparison of fatality listings (feloniously killed victims and accidental death victims) is performed. LEOKA fatalities are compared to lists supplied by the Concerns Of Police Survivors (COPS) organization, the National Law Enforcement Officers Memorial Fund (NLEOMF), and the Officers Down Memorial Page (ODMP). It was reported that LEOKA personnel also compared the data set with lists collected by the Public Safety Officers' Benefits Program (PSOB). However, it has become a little more difficult for LEOKA personnel to communicate with PSOB in recent years due to personal conflicts. Thus, further attempts have been halted. (Kelly, 2008)

For additional validation of data, LEOKA has been informed that COPS and the NLEOMF compare their listings with PSOB prior to providing a confirmed list to LEOKA. LEOKA database specialists report that they are extremely confident in the collected fatality statistics. Even though each of the aforementioned cross-references (COPS, NLEOMF, PSOB, and ODMP) have different criteria, there is an explanation for each victim officer, counted or not counted. For instance, LEOKA does not count, as some or all of the aforementioned references do, victims of natural causes (i.e., heart attacks, strokes, etc.); military personnel (even if they are a law enforcement officer assigned to a military assignment in Iraq at the time of incident); victims who are en route to or from their work assignments (unless there is a distinct reason for that victim to be involved in a law enforcement activity while en route). (Kelly, 2008) 


\subsubsection{FARS Data Validation}

FARS data undergo extensive coding and validation methods prior to offering the data sets available for public access and use. The data used for purposes of this research adhered to all validation methods employed by the 2006 FARS Coding and Validation Manual published by the US Department of Transportation. (Hall, 2008)

\subsubsection{Focus Group Reliability}

Various efforts were taken to ensure that valid data are accurately collected via the instruments and communications recorded from the focus group. Initial recruitment letters were submitted to various individuals that would serve the focus group with in-depth knowledge and experience. A copy of this letter is provided as Appendix B:1. Prior to Phase I of the focus group efforts, a letter of instruction was provided to all participants. A copy of this letter is provided as Appendix B:2. Initial results of the descriptive study were not provided to the focus group volunteers to ensure that the group participants were not biased by initial results.

A detailed agenda was prepared (Appendix B:3) and followed during the moderation of the focus group to ensure that the group stayed on task. In addition, a check-off sheet (Appendix B:5) was maintained by the researcher/moderator during the focus group discussion to ensure equal participation by all members. This check-off sheet was used to monitor and maintain a count of the number of responses by each participant for each question. This effort was performed to document that one focus group member did not monopolize the discussions and become an overly persuasive participant. If one participant appeared to offer an unequal balance 
in the discussions, other group participants were called upon for participation. This method of equal participation reduced the potential for bias of opinion created by one group member.

A full transcript of the teleconference discussion by the five volunteers of the focus group was generated from the meeting. These transcripts are provided as Appendix B:4. After the full focus group discussion had been transcribed, a numerical count of themes was performed on the transcripts by the researcher. The following criteria were established to make the data available for further analysis:

a. Each time a theme or risk factor was mentioned in the discussion, it was only counted if the researcher believed the risk factor was considered to be "directly contributing to highway fatalities" (more than one member mentioned it).

b. A risk factor was not counted more than once if the concept was mentioned more than once by an individual group member in one statement.

c. A data set was created for the amount of times each group member mentioned a specific theme or risk factor.

d. If the group collectively agreed upon a list of risk factors without the biased opinion of the moderator or any single group member, this collective prioritized list shall take precedence to the data count methodology proposed above. This shall eliminate the threat to validity of any conflicting data collected.

\subsubsection{Mixed Method Validation}

According to Creswell and Clark (2007), validity is defined as "the ability of the researcher to draw meaningful and accurate conclusions from all of the data in the study" (146-147). This is 
often referred to as inference quality in mixed-method approaches. The "Triangulation design method" was employed for this study. (Creswell and Clark, 2007) This design was selected because it allows the researcher to competently compare qualitative and quantitative methods within a study. "An overarching validity follows if the researcher draws evidence from different data sets that provide better results than either data set alone." (Creswell and Clark, 2007) The validity of such methodology is sometimes referred to triangulation validity or inference quality. The evidence drawn from both the data set and focus group efforts offers better results than one data collection method alone.

Potential threats to the validity of the triangulation design in this mixed method research are described in the table below. Minimization to such threats is discussed in table 3.2. 
Table 3.2: Minimization of Validity Threats in Mixed Method Approach

\begin{tabular}{|c|c|}
\hline $\begin{array}{l}\text { Potential Threats to Validity } \\
\text { (Creswell \& Clark, 2007) }\end{array}$ & Minimization Methods of Potential Threats \\
\hline \multicolumn{2}{|l|}{ Data Collection Issues: } \\
\hline $\begin{array}{l}\text { Selection of different sets of } \\
\text { data for both the qualitative and } \\
\text { quantitative data collection }\end{array}$ & $\begin{array}{l}\text { A list of potential risk factors provided to the focus group was } \\
\text { selected from the available FARS variables so that data } \\
\text { compared would be similar in representation. }\end{array}$ \\
\hline $\begin{array}{l}\text { Contradictory results are not } \\
\text { further pursued for evaluation }\end{array}$ & $\begin{array}{l}\text { Any conflicts of topics discussed in the focus group were } \\
\text { clarified and settled before convening the group discussion. }\end{array}$ \\
\hline $\begin{array}{l}\text { Bias introduced during data } \\
\text { collection }\end{array}$ & $\begin{array}{l}\text { There is not a bias in the collection of FARS data because all } \\
\text { FARS data are coded by a State Analyst specially trained in } \\
\text { FARS coding methodology. Although there may be variation } \\
\text { between the state analysts, all analysts undergo the same } \\
\text { training and instruction. The focus group was not offered any } \\
\text { precursor research data to foster a biased opinion from the } \\
\text { researcher. The researcher served only as a moderator during } \\
\text { discussion and did not interject comments during the } \\
\text { discussion other than to moderate the discussion. All } \\
\text { documentation of focus group communications are offered in } \\
\text { appendix B of this study. }\end{array}$ \\
\hline $\begin{array}{l}\text { Inadequate data transformation } \\
\text { approaches have been used }\end{array}$ & $\begin{array}{l}\text { Data transformation from qualitative data to quantitative data } \\
\text { has been performed in a straightforward manner. Based upon } \\
\text { the list of risk factors offered to the focus group, these } \\
\text { "topics" shall be counted throughout the focus group } \\
\text { discussion to determine the amount of times each risk factors } \\
\text { arises in discuss as a "contributing" factor. Criteria have been } \\
\text { established to determine when topics are "counted". }\end{array}$ \\
\hline $\begin{array}{l}\text { Data validation issues are not } \\
\text { addressed in the study }\end{array}$ & $\begin{array}{l}\text { Data validation is thoroughly discussed in this section of the } \\
\text { study. Data validity is prime consideration and carefully } \\
\text { addressed. }\end{array}$ \\
\hline $\begin{array}{l}\text { When comparing different types } \\
\text { of data, sometimes these data } \\
\text { sets do not answer the same } \\
\text { question }\end{array}$ & $\begin{array}{l}\text { Variables from the FARS database were selected and } \\
\text { provided to the focus group. The intent of selecting variables } \\
\text { was to offer the focus group a representative list of factors } \\
\text { that may contribute to law enforcement fatalities. Therefore, } \\
\text { both the focus group and the FARS variables selected were } \\
\text { chosen for the same purpose. }\end{array}$ \\
\hline
\end{tabular}




\subsection{DESIGN OF THE STUDY}

This analysis design consists of a mixed method approach. The study involves both quantitative and qualitative analytic approaches. The quantitative approach begins with a descriptive study of variable frequency distributions relative to the fatality incidents and related factors. The qualitative approach will employ the efforts of a focus group. The two approaches will then be consolidated in the conclusions offered in Chapter 5 .

\subsubsection{Preparation of Data}

Since the selected FARS database includes data on all highway fatalities, a subset of the database was created to include only law enforcement highway fatalities. These subsets have been created using the following protocol:

\section{Data for years 1997 - 2006}

\section{Selection of Data:}

A complete listing of all cases in which law enforcement officers were accidentally killed in the line of duty in vehicle related accidents was provided for the years 1997-2006 by LEOKA staff in response to a specific request by the author for the variables listed below. The following variables were offered for each case listing: year of incident, situation (automobile accident, motorcycle accident, struck by accidents), agency state, incident date, incident time range (offered in 2 hour increments), and victim age.

Based on the LEOKA list of cases, the following parameters were used to select the related FARS file for each case. 
1. Using the FARS person files, the cases were filtered to include only fatality cases (INJURY SEVERITY $=4)$ and cases of victims age 20 years old and over. The cases were then sorted based on state, month, day, hour, minute and age of victim. Using these variables, most LEOKA cases could be readily identified and labeled for further analysis. If the cases could not be selected based upon the parameters described above, additional criteria were used:

A. ODMP case description details - LEOKA routinely uses the ODMP as a reference to ensure the accuracy of their data (Kelly, 2008)

B. Gender based on ODMP listing (SEX)

C. Work related fatalities category in the FARS files

D. Struck by incidents could be identified by the coding VEHICLE \# = " 0 ".

E. Date of Death as reported by the ODMP

Note: All cases involving victims under the age of 20 were not included in the data set available for selection because, according to the Bureau of Labor Statistics, law enforcement officers must generally be at least 20 years of age in order to perform law enforcement duties.

2. Once the applicable person files were selected, a subset of labeled person files was created to use for merging with the matching FARS vehicle and accident related files.

A. Before merging files, the related vehicle file had to be identified for struck by cases. Therefore, another column was created so that all cases coded VEHICLE \# $=0$ would not be deleted from the merged data sets. The created column was titled VEHICLE \# (Related). In most cases only one vehicle form was submitted, 
therefore the related vehicle number was coded as " 1 ". If more than one vehicle was included in the incident, the ODMP case description was referenced for determination of appropriate related vehicle file number. For Struck-by incidents, only the moving vehicle case was selected from the vehicle files. The case file representing the "striking" vehicle was selected when both vehicles were moving. This was coded as "initial impact" with the value equal to 12 (front end of vehicle) in the vehicle file of the FARS database.

B. All Related Factors columns were relabeled (after each joining of data sets) in the files according to the Related Factor Clarifications listed at the end of the Data Selection Procedure. Data sets were then joined by a method of matching.

C. When joining data files, all cases were matched using matching state case numbers (ST_CASE). In addition the VEHICLE \# (Related) column created in the Person file was matched with the VEHICLE \# in the vehicle file. To eliminate duplication of data, "Merge Same Name Columns" option was selected when merging files. This is performed to ensure the data from the Vehicle file replaces the data of the same name columns in the person file. This is of particular importance in struck by incident when the data were previously missing. This will ensure that all appropriate vehicle variables are properly coded and used.

D. These merged files become titled "Person Vehicle case files of LEOKA cases". 


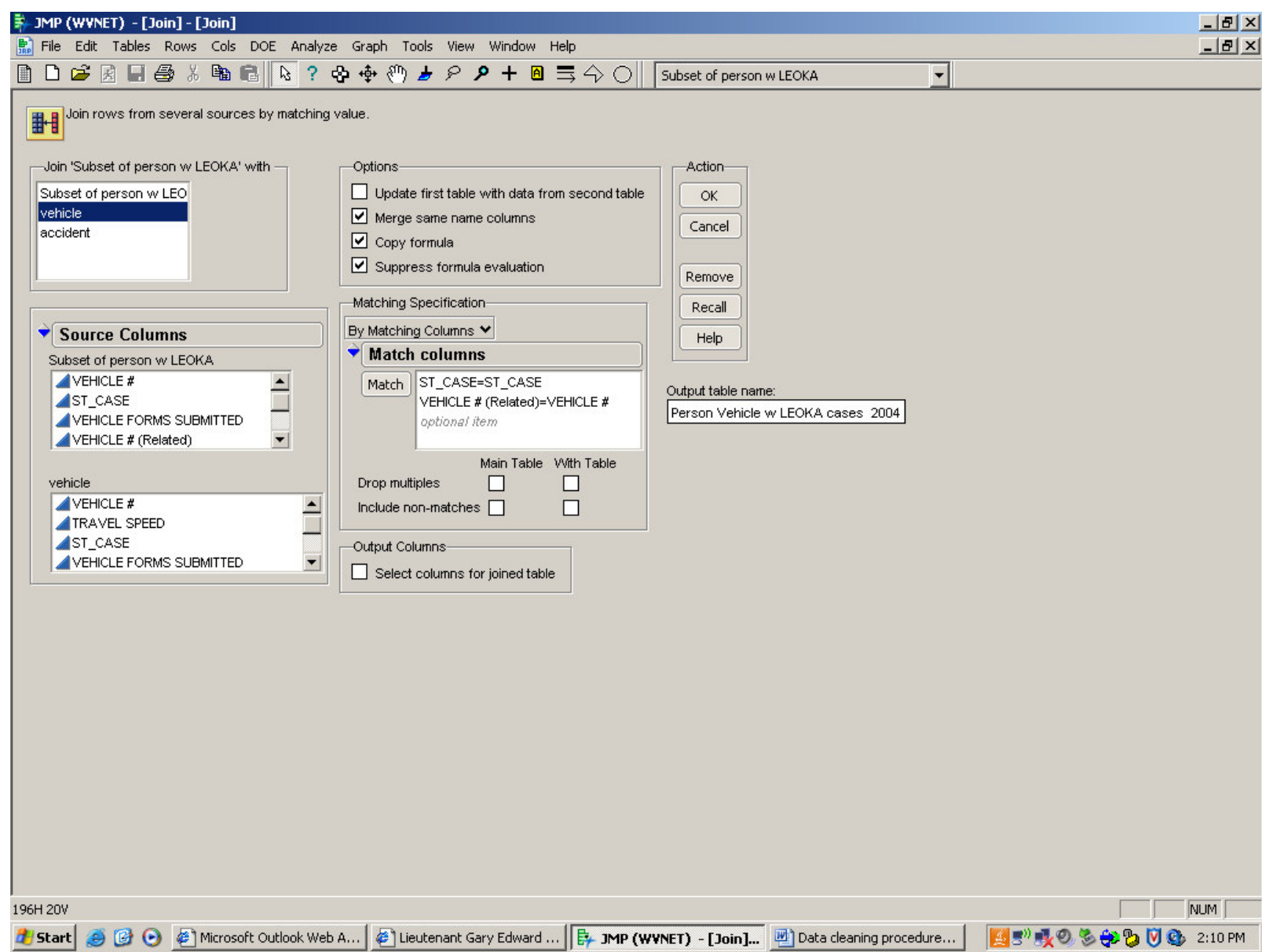

3. Merge "Person Vehicle" Files with Accident files by joining data sets with matched state case numbers (ST_CASE). Since only one accident file is created per incident, it is not necessary to delete duplicate files when joining data sets.

A. Some variables are in both the person vehicle files and the accident file. Thus, is it necessary to delete all duplicate columns and rename to the original column name. This is performed because sometimes as files are joined, matching columns are titled with a file extension name. (i.e. STATE variable column becomes STATE of person vehicle file and State of accident file). Delete all 
duplicated columns (variables) Note - verification that all related factors coded on deleted files (duplicates) are transposed onto the saved file was performed.

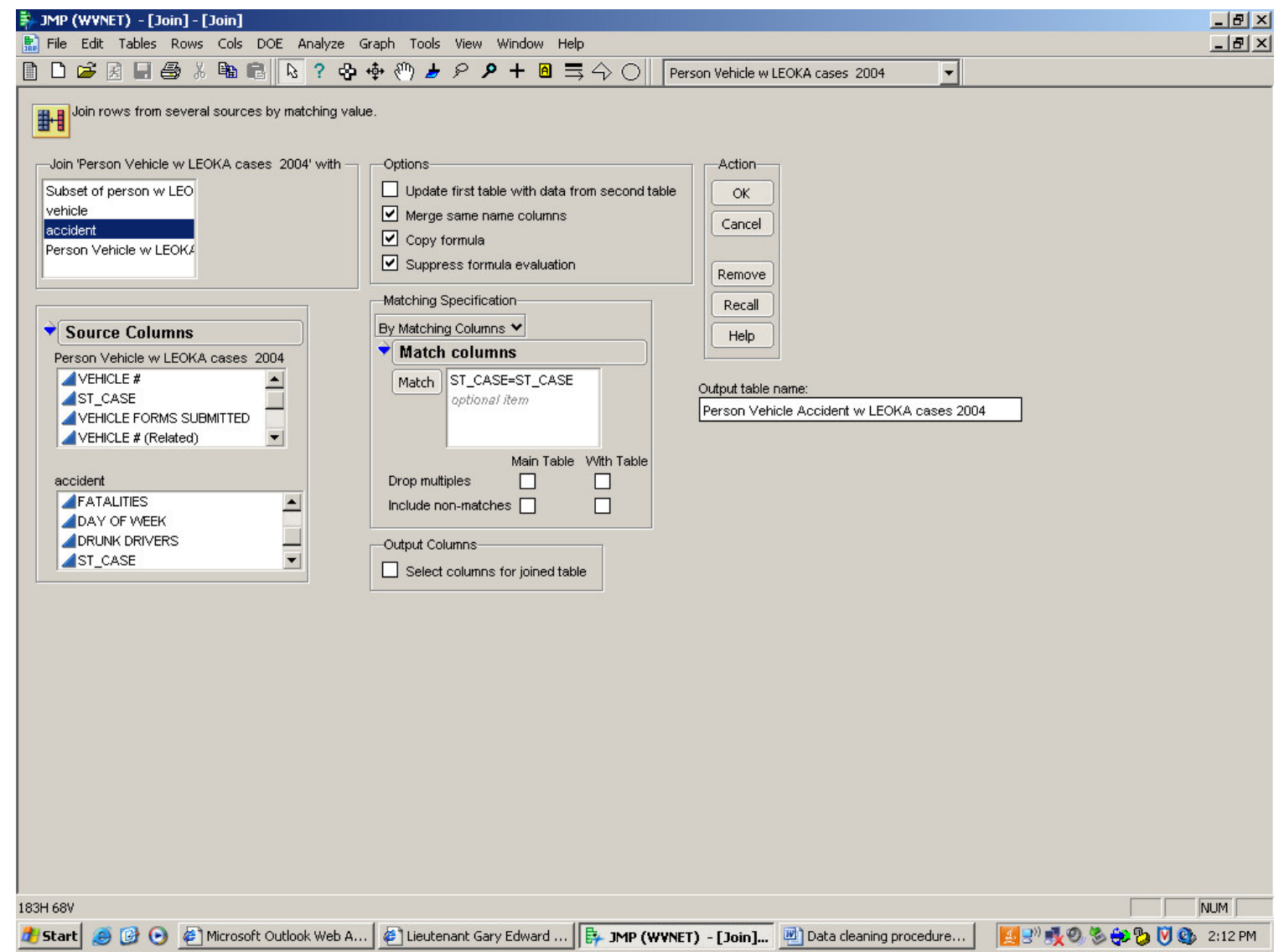

Once the data were cleaned and the person, vehicle and accident files were properly merged, all annual data subsets were joined by method of concatenation. This offered the researcher a complete collection of all data related to law enforcement highway fatalities for the period of 1997-2006. 


\section{Related Factor Clarifications:}

Driver Related Factors = Vehicle File, DR_CF1, DR_CF2, DR_CF3, DR_CF4

JMP Column Label of Joined Data:

= Related Factor 12 of vehicle, Related Factor 22 of vehicle,

Related Factor 3 of vehicle, Related Factor 4 of vehicle

Vehicle Related Factors = Vehicle File, VEH_CF1, VEH_CF2

JMP Column Label of Joined Data:

$=$ Related Factor 1 and Related Factor 2

Person Related Factors $\quad=$ Person File, P_CF1, P_CF2, P_CF3

JMP Column Label of Joined Data:

= Related Factor 1 of person, Related Factor 2 of person, Related Factor 3 of person

Crash Related Factors $=$ Accident File, CF1, CF2, CF3

JMP Column Label of Joined Data:

$=$ Crash Related Factor 1, Crash Related Factor 2, Crash

Related Factor 3 
4. All incidents involving motorcycles were identified for initial descriptive study purposes. After a sample run on the descriptive study, it was determined that all 57 motorcycle incidents should be removed from the data set to eliminate any biases that may be created between motorcycle and motor vehicle incidents. These motorcycle case files were selected based upon the following coding criteria:

Person File: $\quad$ Body Type $=80-89$ (Motorcycle)

$$
\text { Person Type }=1,2 \text {, or } 9 \text { (Occupant) }
$$

5. After a full data set was selected for the study, the data were divided into three categories. These categories were; Driving, Not Driving - Inside the Vehicle, Not Driving-Outside the Vehicle. Each of the following categories was selected based upon the criteria listed below:

A. Driving - A subset of the initial data was created for this category by selecting all case files coded with Person Type $=1,2,4$. This resulted in a total of 369 case files for this category.

B. Not Driving - Inside Vehicle: A subset of the initial data was created for this category by selecting all case files coded with Person Type $=3$. This resulted in a total of 13 case files for this category. Due to the limited number of cases, this category will not be used in the descriptive study or odds ratio portion of the analysis.

C. Not-Driving - Outside Vehicle: A subset of the initial data was created for this category by selecting all case files coded with the Person Type $=5-8$ in the Person 
File. These codes represent pedestrians and cyclists. This resulted in a total of 118 case files for this category.

\subsubsection{Focus Group Design}

The qualitative analysis method involves the application of a focus group. A nominal group technique was selected for the purpose of this study. A nominal group technique does not require a physical meeting between group members; however a collective discussion was facilitated by the researcher. This method was selected because of the influential benefits. The nominal focus group is sometimes used in research to "avoid the influence of the opinions of one or more very dominant group members on the responses of the individuals." (Stewart, Shamdasani and Rook, 2007) Another reason for selection of the nominal group method is due to the time limitations of the study.

A focus group was selectively recruited for participants that offer expertise in the field of law enforcement fatalities and accident reconstruction. Prior to acceptance for participation, potential focus group members were offered a letter identifying the objective of the study and the expectations of the participant. A copy of this letter is offered in Appendix B as B:1.

The focus group consisted of a 5 panel membership including the following members: WV State Police Sergeant, Accident Reconstructionist and Special Operations Interstate Patrol; Indiana Law Enforcement Academy, Director of Emergency Vehicle Operations; NHTSA Law Enforcement Safety Training Expert; First Responder Representative; IACP Representative. 
The focus group members were selected for participation representing a broad range of experience with an average of 25.6 years of professional experience. The participants represented a range of responsibilities including; local first responder activities, LESSS representation, IACP representation, production of pursuit training videos, routine interstate/highway patrol, accident reconstruction, NHTSA representation, development of law enforcement driver training guide for NHTSA, Pursuit management instructor, pursuit policy workshop development, assisting with preparations of the National Training Reference Guide for Emergency Vehicle Operations.

Focus group participants were not selected based upon gender or university affiliations. All participants were volunteers and did not receive any compensation for their participation.

The focus group participation involved two phases. First, all members were offered a list of variables which may be attributable to law enforcement highway fatalities. The focus group was provided a letter with explicit instructions on the task which they had been charged. A copy of this letter and instructions has been provided in Appendix B as B:2. In summary, the focus group was asked to identify and rank order what they believed to be the top five risk factors associated with law enforcement highway fatalities. Focus group members were also asked to offer an explanation for each ranked variable.

Once the group members individually identified the top five variables and submitted their opinions, the responses were evaluated by the researcher to determine if there was a collective agreement on the top risk factors. Methods to identify these collective agreements include 
identifying matched pairs, commonalities among the group and consideration of group member prioritization. After all Phase I data were collected and analyzed for collective agreements, a summary of the responses were submitted to the focus group members for further review. This summary was submitted in conjunction with additional guidance for the second phase of the focus group. These documents included the analysis of the group's results and explanations. A copy of these documents are provided in Appendix B as B:3. A summary and analysis of all focus group responses is offered in the analysis chapter of this study.

The second phase of the focus group's efforts was to participate in a group discussion via telecommunication conferencing methods and collectively rank order the top five variables from most important to least important. A strict agenda was prepared to ensure that the focus group stayed on task and accomplished the mission of the group. A copy of the focus group agenda is available in Appendix B as B:4. A transcript of all communications during the collaborative discussions of the group have been documented and offered in appendix B as B:6. A discussion of the content analysis results are covered in Chapter 4: Analysis of this study. 
The questions prepared for the moderation of the focus group discussion are listed below:

1. What does highway fatality mean to you? For example, what all does this include in this category?

2. In your professional opinion, how many law enforcement fatalities occurring nationally on an annual basis are classified as:
A.
Automobile
B. Motorcycle
C. Struck-By Incidents

Review Contributing Factors list with participants. Identify that the group has chosen 6 factors at least 2 times. Identify the top 3 risk factors.

3. Do any members have an opinion or concern with the identified top three elements, or believe that another element should be included in the list of top three?

Explain to participants why Driver training data are not available. FARS does not collect the data. LEOKA does not collect this data (the reporting system is believed to updated in the near future).

4. Do you feel that training is an important element, if so, what type of training would you believe to be appropriate to reduce the potential for law enforcement highway fatalities? (Moderator needs to monitor for key terms or concepts discussed)

5. Some group members indicated that they believe that some of the identified contributing factors may interrelate. Could you please identify which risk factors you believe interrelate and how if any?

6. Based on the above information, what do you believe is the biggest interrelation between risk factors?

7. Based upon the summary of Phase I, three risk factors appear to have been selected by more than $50 \%$ of the group participants as a contributing risk factor. These three factors are:
a. Environmental Conditions
b. Traveling speed
c. Driving maneuver

Does the group agree that these three factors are worthy of being the top three?

What does the group believe is the number one risk factor and why? 
8. As a group can you collectively decide the other two main risk factors? Do not become concerned if the group cannot develop a consensus decision, quantitative analysis will allow the researcher to identify the risk factors.

\subsubsection{Variables Selected}

Relative variables were selected by the researcher based upon information gathered through an extensive literature review, conversations with NHTSA, DOJ, and IACP and a review of frequency distributions for variables related to the incidents. The variables selected for use by the focus group are provided in table 3.3.

Table 3.3: Focus Group Risk Factors and Matching FARS Variable

\begin{tabular}{|c|c|c|c|c|}
\hline $\begin{array}{l}\text { Contributing Factors } \\
\text { (Circumstances) }\end{array}$ & $\begin{array}{l}\text { FARS } \\
\text { Variable }\end{array}$ & $\begin{array}{l}\text { Variable } \\
\text { File }\end{array}$ & $\begin{array}{l}\text { Code and } \\
(\mathrm{pg} \#)^{1}\end{array}$ & FARS Label \\
\hline 1. Police pursuits & $\begin{array}{l}\text { CF1 } \\
\text { CF2 } \\
\text { CF3 }\end{array}$ & ACCIDENT & $\begin{array}{l}20 \\
(\mathrm{~A}-47)\end{array}$ & $\begin{array}{l}\text { Crash Related } \\
\text { Factors 1-3 }\end{array}$ \\
\hline $\begin{array}{l}\text { 2. Environmental Conditions - } \\
\text { weather }\end{array}$ & WEATHER & ACCIDENT & $\begin{array}{l}1-9 \\
(\mathrm{~A}-1)\end{array}$ & $\begin{array}{l}\text { Atmospheric } \\
\text { Conditions }\end{array}$ \\
\hline 3. Lighting Conditions & LGT_COND & ACCIDENT & $\begin{array}{l}1-9 \\
(\mathrm{~A}-34)\end{array}$ & Lighting Condition \\
\hline $\begin{array}{l}\text { 4. Restraint System Use (Seat } \\
\text { Belts) }\end{array}$ & REST_USE & PERSON & $\begin{array}{l}00-08,13,15, \\
99 \\
(\mathrm{P}-72)\end{array}$ & Restraint \\
\hline 5. Air Bags & AIR_BAG & PERSON & $\begin{array}{l}01,02,07,08 \\
09,20,28,29 \\
30-32,99(\mathrm{P}- \\
73)\end{array}$ & $\begin{array}{l}\text { Restraint (Air Bag } \\
\text { Availability and } \\
\text { Deployment) }\end{array}$ \\
\hline 6. Roadway Type & PAVE_TYP & ACCIDENT & $01-09,(\mathrm{~A}-67)$ & $\begin{array}{l}\text { Roadway Surface } \\
\text { Type }\end{array}$ \\
\hline 7. Driver Training & Not Available & & & \\
\hline 8. Vision Obscured & $\begin{array}{l}\text { DR_CF1 } \\
\text { DR_CF2 } \\
\text { DR_CF3 } \\
\text { DR_CF4 }\end{array}$ & $\begin{array}{l}\text { VEHICLE } \\
\text { PERSON }\end{array}$ & $\begin{array}{l}61-72 \\
(V-76, P-67)\end{array}$ & $\begin{array}{l}\text { Driver Related } \\
\text { Factors 1-4 }\end{array}$ \\
\hline $\begin{array}{l}\text { 9. Interference Devices inside } \\
\text { vehicle (two-way radio, cell } \\
\text { phone, etc) \& Driver interference }\end{array}$ & $\begin{array}{l}\text { DR_CF1 } \\
\text { DR_CF2 } \\
\text { DR_CF3 } \\
\text { DR_CF4 }\end{array}$ & VEHICLE & $\begin{array}{l}05,93-98 \\
(\mathrm{~V}-77)\end{array}$ & $\begin{array}{l}\text { Driver Related } \\
\text { Factors } 1-4\end{array}$ \\
\hline $\begin{array}{l}\text { 10. Relation to Roadway (i.e } \\
\text { shoulder, median, off road, } \\
\text { junctions, etc) }\end{array}$ & REL_ROAD & ACCIDENT & $\begin{array}{l}01-11 \\
(\mathrm{~A}-52)\end{array}$ & Relation to Roadway \\
\hline
\end{tabular}


Table 3.3: Focus Group Risk Factors and Matching FARS Variable (Cont.)

\begin{tabular}{|c|c|c|c|c|}
\hline $\begin{array}{l}\text { Contributing Factors } \\
\text { (Circumstances) }\end{array}$ & $\begin{array}{l}\text { FARS } \\
\text { Variable }\end{array}$ & $\begin{array}{l}\text { Variable } \\
\text { File }\end{array}$ & $\begin{array}{l}\text { Code and } \\
(\text { pg\# })^{1}\end{array}$ & FARS Label \\
\hline 11. Time of Day & $\begin{array}{l}\text { HOUR } \\
\text { (or } \\
\text { NOT_HOUR, } \\
\text { NOT_MIN) }\end{array}$ & $\begin{array}{l}\text { ACCIDENT } \\
\text { PERSON }\end{array}$ & $\begin{array}{l}0-24,99 \\
(\mathrm{~A}-75, \mathrm{P}-89)\end{array}$ & $\begin{array}{l}\text { Time of Crash - } \\
\text { Hour (Military Time) }\end{array}$ \\
\hline $\begin{array}{l}\text { 12. Traveling Speed at time of } \\
\text { Crash - estimated }\end{array}$ & TRAV_SP & VEHICLE & $\begin{array}{l}00-99 \\
(V-90)\end{array}$ & Travel Speed \\
\hline $\begin{array}{l}\text { 13. Driving Maneuver at time of } \\
\text { Crash }\end{array}$ & VEH_MAN & VEHICLE & $\begin{array}{l}01-17,98,99 \\
(\mathrm{~V}-108)\end{array}$ & Vehicle Maneuver \\
\hline $\begin{array}{l}\text { 14. Manner of Collision (Rear- } \\
\text { end, head-on, sideswipe, etc) }\end{array}$ & MAN_COLL & $\begin{array}{l}\text { ACCIDENT } \\
\text { PERSONAL } \\
\text { VEHICLE }\end{array}$ & $\begin{array}{l}01-11,99 \\
(A-36, P-50 \\
\text { V-60) }\end{array}$ & Manner of Collision \\
\hline
\end{tabular}

(1) - Coding is referenced in NHTSAs FARS Analytic Reference Guide 1975 - 2006. (Tessmer, 2007)

All coding validation was performed by FARS Analysts based upon the parameters established in the FARS Coding and Validation Manual, 2006. All validation checks were performed prior to making the data set available for public research. (Hall, 2008)

To ensure that all cases during years 1997-2006 are included in the research, the data were selected using LEOKA data set provided to the author upon request. The full process for data selection/preparation is described in section 3.6 .1 of this chapter.

\subsection{DATA ANALYSIS}

Initially a descriptive study of the FARS data was conducted to identify some recognized risk factors. Once risk factors were identified by using FARS and LEOKA data sets, a comprehensive list of risk factors was distributed to the focus group members. The focus group members were asked to identify what they believed to be the top risk factors and rank order the risk factors from most important to least important related to law enforcement highway fatalities. 
After the group submitted their responses, a summary of information was created and redistributed to the focus group for review. It should be noted that group members were also offered a provision for them to add factors not originally provided for them.

Second, a teleconference with all group members was moderated to collectively identify the top risk factors. All discussions of the focus group were transcribed for data transformation. The qualitative data collected from the teleconference was transformed by counting the number of occurrences of codes or themes (risk factors) throughout the group discussions. Based upon the number of occurrences and the consensus of the group, a rank order list of risk factors from most important to least important related to law enforcement highway fatalities was prepared.

The qualitative data were transformed to a rank order list for comparison with the descriptive study results. Comparisons between data collected during descriptive study for each category and the focus group were compared by calculating a correlation coefficient. The Spearman RankOrder Correlation Coefficient was used to determine correlations between ranked data. This statistical method is used to determine the degree of association between two sets of rankings, including the focus group rankings and the descriptive study rankings. "A significant positive correlation signifies that both judges were in agreement with the rankings." (Janicak, 2007)

The following formula was used to calculate the Spearman rank-order correlation coefficient:

$$
r_{s}=1-\frac{6\left(\sum d^{2}\right)}{n\left(n^{2}-1\right)}
$$


Where:

$\mathrm{d}=$ the difference between the rankings of the two lists

$\mathrm{n}=$ Number of samples or items ranked

Upon completion of the calculation of the correlation coefficient, a determination was made if the rank ordered variables identified by the focus group and the descriptive study correlate. The results of this correlation analysis were used to assist in the identification of the appropriate variables. If the data did not preclude a high correlation, the top two or three factors identified by the focus group and the descriptive study were used in the final model in conjunction with data results from a logistic regression analysis with odds ratio as the outcome measure.

Lastly an simple logistic regression with and odds ratio outcome was performed on the various risk factor circumstances to determine if the top risk factors are associated with law enforcement highway fatalities. Resulting odds ratios were also used to determine if data collected are useful for the identification of the risk factors. If not, recommendations for data collection improvement shall be offered.

The odds ratio is a way of comparing whether the probability that a victim is pronounced dead on arrival is the same when a selected variable is or not present. An odds ratio of 1 implies that the event is equally likely in both groups of variables. The odds ratio was calculated using a typical 2 by 2 contingency table and using logistic regression when more than outcome variables were present. An overview of the contingency table layout and calculations have been provided below. 


\section{Odds Ratio: 2 x 2 Contingency Table Layout}

\# of Cases Reported as \# of Cases Reported as

Not Dead on Arrival Dead on Arrival

Reference Outcome

Variable

$a$

$b$

Undesirable

Outcome Variable

$c$

$d$

$\mathrm{a}=$ \# of fatalities that were not classified as dead on arrival and adverse conditions were not present.

$\mathrm{b}=\quad$ \# of fatalities that were classified as dead on arrival and adverse conditions were not present.

$\mathrm{c}=\quad$ \# of fatalities that were not classified as dead on arrival and adverse conditions were present.

$\mathrm{d}=\quad$ \# of fatalities that were classified as dead on arrival and adverse conditions were not present.

The odds ratio is then calculated for a $2 \times 2$ contingency table layout using the following formula:

$$
O R=\frac{a d}{b c}
$$

When the outcome variables contained greater than 2 options, a multiple logistic regression analysis was performed. The logistic regression analysis calculated the parameter estimate $(\beta)$ for each outcome variable. The odds ratio was then calculated as follows:

$$
O R=\exp \beta=e^{\beta}
$$

When calculating the odds ratio, an upper and lower confidence limit of $95 \%$ was used to allow data instability. These confidence intervals were selected based upon standard research practice for publication purposes. (I Rockett, personal communication, August 8, 2008) In addition, the JMP software used for analysis purposes maintains a default $\alpha=0.05$ or $95 \%$ limits. When 
calculating the odds ratio, when variables presented data with $\mathrm{n} \leq 3$, the results were voided and not reported.

A multiple logistic regression was performed on the risk factors identified by the focus group. The multiple logistic regression was chosen to represent the strength of association between Dead on Arrival and focus groups dichotomous predictors. This method was used to estimate the odds ratio and $95 \%$ confidence intervals for the association between the independent and dependent variables. The predictors or independent variables used in the analysis included:

1. Speed (greater than $60 \mathrm{mph}$, versus less than $60 \mathrm{mph})=\left(\mathrm{X}_{1}\right)$

2. Driving maneuver at the time of crash (crash avoidance maneuver versus no crash avoidance maneuver $)=\left(\mathrm{X}_{2}\right)$

3. Environmental Conditions (adverse weather conditions versus normal atmospheric conditions $)=\left(\mathrm{X}_{3}\right)$

4. Interference devices used at time of crash (non use of devices versus use of interference devices $)=\left(\mathrm{X}_{4}\right)$

5. Relation to Roadway (on roadway versus off roadway conditions) $=\left(\mathrm{X}_{5}\right)$

The confidence intervals for each odds ratio was calculated using the following procedure:

1. A selected confidence interval was selected of $95 \%$.

2. $95 \%$ was converted to a probability $(0.95)$ and subtracted from one. $(1-.95=0.05)$

3. The value 0.05 along with 1 degree of freedom was selected from the T-table resulting a $t$ value of 6.314 . 
4. The value of $t=6.314$ is multiplied times the standard error of $b$. The resulting value is added and subtracted from the odds ratio to find the $95 \% \mathrm{CI}$ for the odds ratios. If the CI contains the number one, then there is no association between the independent and dependent variables.

Since all cases represented in the study resulted in a fatality, it was necessary to select a dependent variable that would offer the best identification of risk factors for the study. Therefore the dependent variable chosen for the analysis was Dead on Arrival. This variable was chosen because it offers the study some suggestion on the severity of the incident. Although all victims ultimately expired as a result the incident or injuries from the incident, Dead on Arrival was selected as the response variable on the following basis:

1. It is assumed that if the victim had received alternative medical attention at the hospital, the victim may have possibly survived the incident. Unfortunately, data are not available in the LEOKA or FARS database for all law enforcement officer incidents in which the officer survived after receiving immediate medical attention.

2. It is understood that as long as there is life, there is still hope for survival. The dead on arrival patients were not afforded the opportunity for any medical attention or hope for survival.

3. Data involving law enforcement officers involved in highway accidents that did not result in a fatality have not been maintained or collected. Therefore, analysis regarding fatals versus non-fatals for law enforcement officers involved in highway incidents cannot be performed. 
The variable Dead on Arrival (DOA) required some recoding prior to analysis. During the periods of 1996-2000 the DOA indication was coded under the variable Taken to Hospital instead of DOA. Therefore the author created an additional column in the data set labeled Dead on Arrival 2. This column was coded using the following recoding rules:

1. The data for Years $2001-2006$ were copied from the Dead On Arrival column and pasted into the Dead On Arrival 2 column.

2. Data for years 1997-2000 were recoded as follows in table 3.4:

Table 3.4: Recoding criteria for Dead on Arrival

\begin{tabular}{ccc}
$\begin{array}{c}\text { Column Name: } \\
\text { Taken to Hospital }\end{array}$ & Recoded to $\Rightarrow$ & $\begin{array}{c}\text { Column Name: } \\
\text { Dead On Arrival 2 }\end{array}$ \\
\hline 1 (Yes) & $=$ & 0 (Not DOA) \\
0 (No) & $=$ & 7 (Died at Scene) \\
7 (Died at the Scene) & $=$ & 7 (Died at Scene) \\
8 (Died En Route) & & $\begin{array}{c}7 \text { (Died En Route) }- \\
\text { because the victim did not } \\
\text { receive hospital treatment }\end{array}$ \\
9 (Unknown) & $=$ & Left Blank
\end{tabular}

A logistic regression analysis was performed on the risk factors identified by the descriptive study and the focus group to determine the best identification of risk factors contributing to law enforcement highway fatalities. In order to successfully complete an odds ratio analysis, the variables listed below had to be recoded based on the listed criteria for each variable. 
1. Lighting Conditions - Recoding for Adverse v. Not Adverse

\begin{tabular}{|c|c|c|}
\hline $\begin{array}{c}\text { Column Name: } \\
\text { Light Condition }\end{array}$ & Recoded to $\Rightarrow$ & $\begin{array}{c}\text { Column Name: } \\
\text { Lighting Conditions 2 }\end{array}$ \\
\hline 1 (Day light) & $=$ & 1 (Normal Conditions) \\
\hline 2 (Dark) & $=$ & 2 (Other than Daylight) \\
\hline 3 (Dark but lighted) & $=$ & 2 (Other than Daylight) \\
\hline 4 (Dawn) & $=$ & 2 (Other than Daylight) \\
\hline 5 (Dusk) & $=$ & Left Blank \\
\hline 9 (Unknown) & &
\end{tabular}

2. Crash Avoidance Maneuver - Recoding for Adverse v. Not Adverse

\begin{tabular}{|c|c|c|}
\hline $\begin{array}{l}\text { Column Name: } \\
\text { Crash Avoidance } \\
\text { Maneuver } \\
\end{array}$ & $\underset{\Rightarrow}{\text { Recoded to }}$ & $\begin{array}{c}\text { Column Name: } \\
\text { Crash Avoidance Maneuver } \\
2\end{array}$ \\
\hline $\begin{array}{c}0 \text { (No Avoidance Maneuver } \\
\text { Reported) }\end{array}$ & $=$ & $\begin{array}{c}0 \text { (No Avoidance Maneuver } \\
\text { Reported) }\end{array}$ \\
\hline $\begin{array}{l}1 \text { (Braking, skid marks } \\
\text { evident) }\end{array}$ & $=$ & $\begin{array}{l}1 \text { (Avoidance Maneuver } \\
\text { Reported) }\end{array}$ \\
\hline 2 (Braking, no skid marks) & $=$ & $\begin{array}{c}1 \text { (Avoidance Maneuver } \\
\text { Reported) }\end{array}$ \\
\hline 3 (Braking, other evidence) & $=$ & $\begin{array}{c}1 \text { (Avoidance Maneuver } \\
\text { Reported) }\end{array}$ \\
\hline 4 (Steering) & $=$ & $\begin{array}{l}1 \text { (Avoidance Maneuver } \\
\text { Reported) }\end{array}$ \\
\hline 5 (Steering and Braking) & $=$ & $\begin{array}{l}1 \text { (Avoidance Maneuver } \\
\text { Reported) }\end{array}$ \\
\hline $\begin{array}{c}6 \text { (Other Avoidance } \\
\text { Maneuver) }\end{array}$ & $=$ & $\begin{array}{l}1 \text { (Avoidance Maneuver } \\
\text { Reported) }\end{array}$ \\
\hline 8 (Not Reported) & $=$ & Left Blank \\
\hline
\end{tabular}


3. Police Pursuits

\begin{tabular}{|c|c|c|}
\hline $\begin{array}{c}\text { Column Name: } \\
\text { Related Factors - Crash } \\
\text { Related }\end{array}$ & $\begin{array}{c}\text { Column Name: } \\
\text { Recoded to } \\
\text { Police Pursuits }\end{array}$ & \begin{tabular}{c} 
(No Pursuit Reported) \\
\hline $\begin{array}{c}\text { All elements except listed } \\
\text { below }\end{array}$
\end{tabular} \\
\hline 20 (Police Pursuit Involved) & $=$ & 1 (Involved in Police Pursuit ) \\
\hline 00(None), 99 (Unknown) & $=$ & Left Blank \\
\hline
\end{tabular}

4. Atmospheric Conditions

\begin{tabular}{|c|c|c|}
\hline $\begin{array}{c}\text { Column Name: } \\
\text { Weather }\end{array}$ & $\begin{array}{c}\text { Recoded to } \\
\Rightarrow\end{array}$ & $\begin{array}{c}\text { Column Name: } \\
\text { Weather } 2\end{array}$ \\
\hline $\begin{array}{c}1 \text { (No adverse atmospheric } \\
\text { conditions) }\end{array}$ & $=$ & $\begin{array}{c}1 \text { (No Adverse Atmospheric } \\
\text { Conditions) }\end{array}$ \\
\hline $\begin{array}{c}\text { 2-8 (Various Atmospheric } \\
\text { Conditions listed) }\end{array}$ & $=$ & $\begin{array}{l}2 \text { (All other atmospheric } \\
\text { conditions ) }\end{array}$ \\
\hline 9 (Unknown) & $=$ & Left Blank \\
\hline
\end{tabular}

5. Restraint System Use

\begin{tabular}{|c|c|c|}
\hline $\begin{array}{c}\text { Column Name: } \\
\text { Restraint System Use }\end{array}$ & $\begin{array}{c}\text { Recoded to } \\
\Rightarrow\end{array}$ & $\begin{array}{c}\text { Column Name: } \\
\text { Restraint System Use 2 }\end{array}$ \\
\hline $\begin{array}{c}\text { All other elements except } \\
\text { listed in this table }\end{array}$ & $=$ & 1 (All restraint systems ) \\
\hline $\begin{array}{c}\text { 00 (None used ), 13, } 14 \\
\text { (Used Improperly) }\end{array}$ & $=$ & $\begin{array}{c}\text { 0 (No Restraint System Used } \\
\text { or System Used Improperly) }\end{array}$ \\
\hline $\begin{array}{c}99 \text { (Unknown), } \\
\text { (Motorcycle Helmet) }\end{array}$ & $=$ & Left Blank \\
\hline
\end{tabular}


6. Air Bags

\begin{tabular}{|c|c|c|}
\hline $\begin{array}{c}\text { Column Name: } \\
\text { Air Bags }\end{array}$ & $\underset{\Rightarrow}{\text { Recoded to }}$ & $\begin{array}{l}\text { Column Name: } \\
\text { Air Bags } 2\end{array}$ \\
\hline $\begin{array}{c}\text { 01-09 (Various Air Bag } \\
\text { Deployment Conditions } \\
\text { listed) }\end{array}$ & $=$ & 1 (Airbags Deployed ) \\
\hline $\begin{array}{c}\text { 20, 28-32 (Not Deployed or } \\
\text { Not Available) }\end{array}$ & $=$ & $\begin{array}{c}2 \text { (Air Bag Not Deployed or } \\
\text { Not Available) }\end{array}$ \\
\hline 9 (Unknown) & $=$ & Left Blank \\
\hline $\begin{array}{c}00 \text { (Nonmotorist, not a motor } \\
\text { vehicle occupant) }\end{array}$ & $=$ & Left Blank \\
\hline
\end{tabular}

7. Vision Obscured

\begin{tabular}{|c|c|c|}
\hline $\begin{array}{c}\text { Column Name: } \\
\text { Related Factor - Driver }\end{array}$ & $\begin{array}{c}\text { Recoded to } \\
\Rightarrow\end{array}$ & $\begin{array}{c}\text { Column Name: } \\
\text { Vision Obscured }\end{array}$ \\
\hline $\begin{array}{c}\text { All other elements except } \\
\text { listed in the table }\end{array}$ & $=$ & 1 (Vision Not Obscured $)$ \\
\hline $61-72$ (Vision Obscured $)$ & $=$ & 2 (Vision Obscured) \\
\hline 99 (Unknown) & $=$ & Left Blank \\
\hline
\end{tabular}

8. Interference Devices

\begin{tabular}{|c|c|c|}
\hline $\begin{array}{c}\text { Column Name: } \\
\text { Related Factor - Driver }\end{array}$ & $\begin{array}{c}\text { Recoded to } \\
\Rightarrow\end{array}$ & $\begin{array}{c}\text { Column Name: } \\
\text { Vision Obscured }\end{array}$ \\
\hline $\begin{array}{c}\text { All other elements except } \\
\text { listed in the table }\end{array}$ & $=$ & $\begin{array}{c}\text { (Interference devices not in } \\
\text { use at time of accident) }\end{array}$ \\
\hline $\begin{array}{c}\text { 05, 93-98 (Interference } \\
\text { Devices ) }\end{array}$ & $=$ & $\begin{array}{c}2 \text { (Interference Devices used at } \\
\text { time of incident) }\end{array}$ \\
\hline 99 (Unknown) & $=$ & Left Blank \\
\hline
\end{tabular}


9. Relation to Roadway

\begin{tabular}{|c|c|c|}
\hline $\begin{array}{c}\text { Column Name: } \\
\text { Relation to Roadway }\end{array}$ & $\begin{array}{c}\text { Recoded to } \\
\Rightarrow\end{array}$ & $\begin{array}{c}\text { Column Name: } \\
\text { Relation to Roadway 2 }\end{array}$ \\
\hline 01 (On Roadway) & $=$ & 1 (On Roadway Conditions) \\
\hline $\begin{array}{c}02-11 \text { (Other than On } \\
\text { Roadway }\end{array}$ & $=$ & 2 (Other than On Roadway) \\
\hline 99 (Unknown) & $=$ & Left Blank \\
\hline
\end{tabular}

10. Time of Day

\begin{tabular}{|c|c|c|}
\hline $\begin{array}{c}\text { Column Name: } \\
\text { Hour }\end{array}$ & $\begin{array}{c}\text { Recoded to } \\
\Rightarrow\end{array}$ & $\begin{array}{c}\text { Column Name: } \\
\text { Time of Day }\end{array}$ \\
\hline $08-19$ (Daytime) & $=$ & 1 (Daytime) \\
\hline $0-7,20-24$ (Nighttime) & $=$ & 2 (Nighttime) \\
\hline
\end{tabular}

Dummy Variable Coding Criteria for Time of Day:

Dummy variable codes were created for each of the following categories:

$0-5$

6-11

12-17 - Reference Category for Odds Ratios - Coded as 0 $18-24$

11. Traveling Speed

\begin{tabular}{|c|c|c|}
\hline $\begin{array}{c}\text { Column Name: } \\
\text { Traveling Speed }\end{array}$ & $\begin{array}{c}\text { Recoded to } \\
\Rightarrow\end{array}$ & $\begin{array}{c}\text { Column Name: } \\
\text { Traveling Speed 2 }\end{array}$ \\
\hline $0-59$ & $=$ & 1 (Normal Traveling Speeds) \\
\hline $60-97$ & $=$ & 2 (Traveling at High Speeds) \\
\hline 98 (Not Reported) & $=$ & Left Blank \\
\hline 99 (Unknown) & $=$ & Left Blank \\
\hline
\end{tabular}


Dummy Variable Coding Criteria for Traveling Speed:

Dummy variable codes were created for each of the following categories:

0-25 mph - Reference Category for Odds Ratios - Coded as 0

25-50 mph

$51-75 \mathrm{mph}$

$75+\mathrm{mph}$

12. Roadway Surface Type

Dummy Variable Coding Criteria for Traveling Speed:

Dummy variable codes were created for each of the following categories:

Concrete

Blacktop- Reference Category for Odds Ratios - Coded as 0

Slag, Gravel or Stone

Dirt

Other

Unknown

Note: For all $2 \times 2$ categorical analyses, the reference variables were set under the Column properties - List check. The non-adverse condition was listed as the first category on the list so that the JMP software would recognize the non adverse condition as the reference category.

\subsection{ANALYSIS METHOD USING JMP SOFTWARE}

As previously discussed the JMP software was used for analysis. In order to perform an logistic regression analysis two methods were employed. A sample of each method is offered below:

\section{Adverse v. Non-Adverse Conditions or Comparison in a 2 x 2 model}

1. Under the Analyze menu, select Fit Y by X. Select "Dead on Arrival" as the Response variable. Select the risk factor column coded by adverse versus non adverse conditions as the (Crash Avoidance Maneuver 2, in the example below) X factor. Select OK to run the model. 
2. Once the model has been displayed, the report output options (odds ratio and confidence intervals) must be selected.

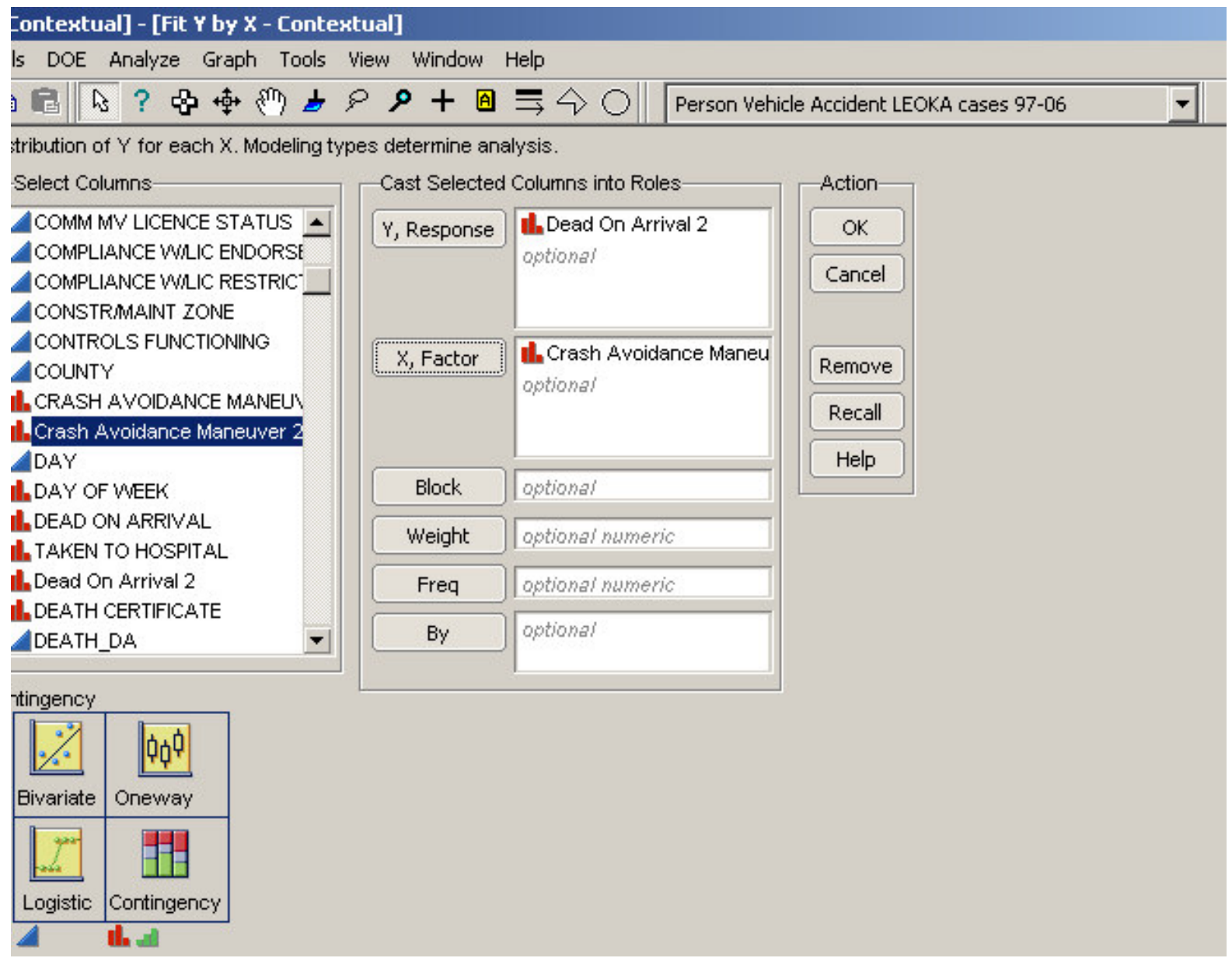

\section{Odds Ratio for Variables with Greater than One Category}

1. Dummy variable columns were created for each category. The reference variables were coded as a "0" while each category was coded as a " 1 " in separate columns. All columns containing dummy variables were continuous variables.

2. After the coding of each set of data was performed, the odds ratio was identified for each condition. Under the Analyze menu, Fit Model was selected. Dead on Arrival 2 was selected as the "Y" variable. The categorical dummy variable columns created for each condition were selected and added to the Construct Model Effects. All 
categorical dummy variable columns were selected except for the reference category because the reference category would be zeroed out in the final output of data. Select Run model for complete output. It is important to note that this was a simple regression analysis performed for each condition individually, all other conditions were excluded from the analysis. Following image offers a sample of how each analysis was performed.

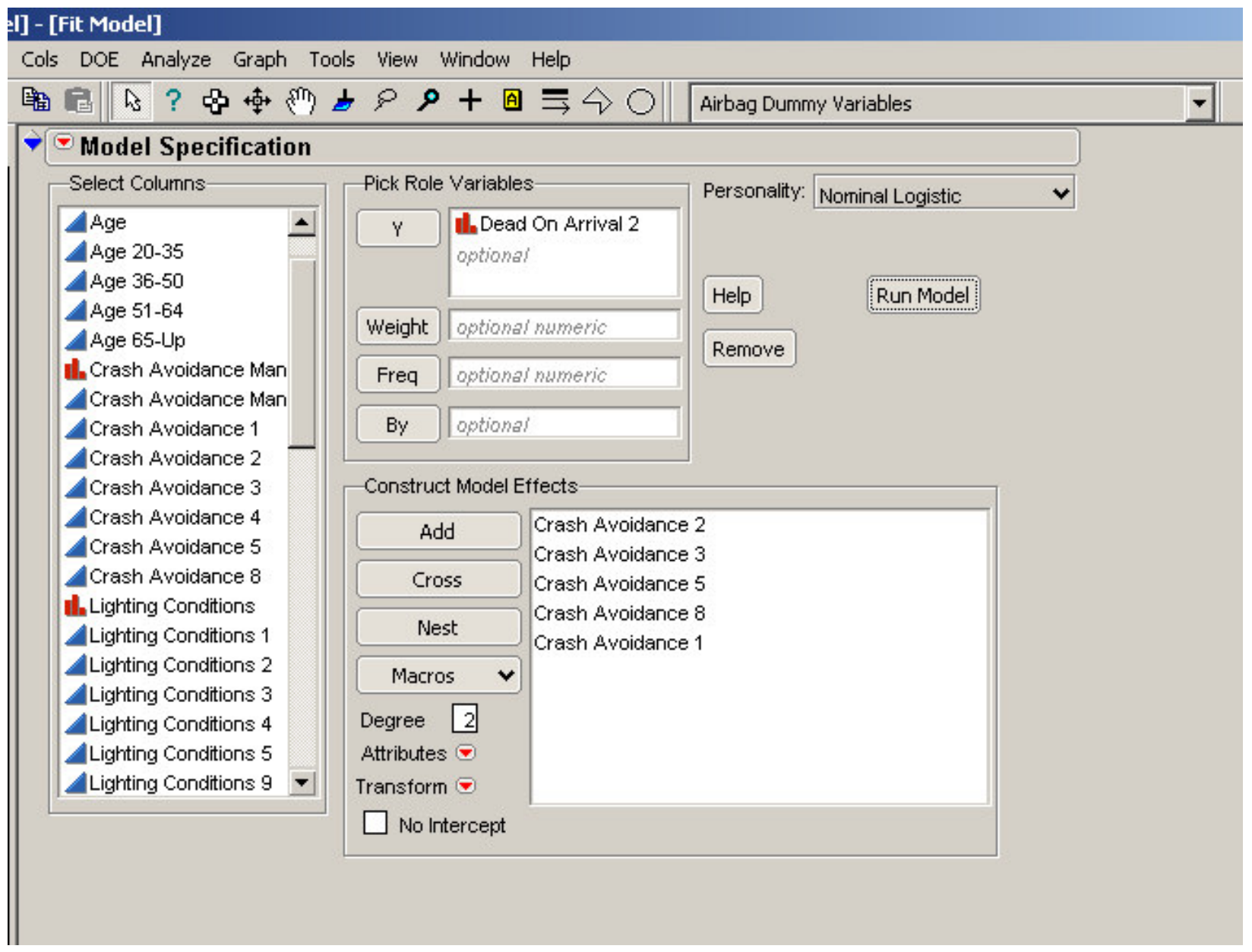

A multiple logistic regression was performed on the contributing factors identified by the focus group. 
After the performance of all analysis methods described above, a thorough review of the results is offered in the Chapter 4 of this study. Conclusions derived from these results are offered in Chapter 5. 


\section{Chapter 4}

\section{Results}

\subsection{DESCRIPTIVE STUDY RESULTS}

A descriptive study of the FARS data variables is summarized with the information and the tables provided in this section of the study. The identification of law enforcement fatalities in the FARS database was conducted by using the identified highway fatality LEOKA cases as a reference. Originally 557 cases were selected for inclusion in this study. However, since motorcycle incidents may have a different set of risk factors, all 57 motorcycle incidents were removed from the data set for further analysis. The remaining 500 cases were divided into three basic categories for an extensive review. The categories included: Driving $(n=369)$, Not Driving-Inside the Vehicle ( $n=13)$, and Not Driving - Outside the vehicle $(n=118)$. Since the Not-Driving - Inside the vehicle category contained a small sample size $(n=13)$, descriptive analysis was not performed on that data set.

This descriptive study has been performed to identify potential circumstances which may be related to law enforcement highway fatalities. The descriptive study involves the review of frequency distributions of the incidents based on various circumstances. This process is modeled after the common research practices in the field of occupational safety and health and often used by the National Institute of Occupational Safety and Health. Incident rate data would be desired, but law enforcement officer exposure to various circumstances is unavailable. The review of frequency distributions serves as a limitation of the study. However, the use of such frequency distributions in addition to the information collected from the expert volunteers of the focus group shall offer researchers a foundation for future studies. 
An overall review of all 500 case files which excludes all motorcycle incidents has been offered to identify the annual concern for law enforcement highway fatalities. The following table reports the number of highway law enforcement fatalities that occurred during the years 1997 2006. According to the data used in this study, there has been a fluctuating occurrence of incidents since the year 1997. The median number of fatalities per year is 50 fatal law enforcement highway incidents. The upper 95 percentile of the age category is calculated to be 58.0 incidents and the lower 5 percentile of the age category is calculated to be 46.4 incidents per year. Based upon this information the following years; 1997 and 1999, fall outside the 5-95 percentile range.

Figures 4.1 and 4.2 and Table 4.1 offer a graphical display of this data.

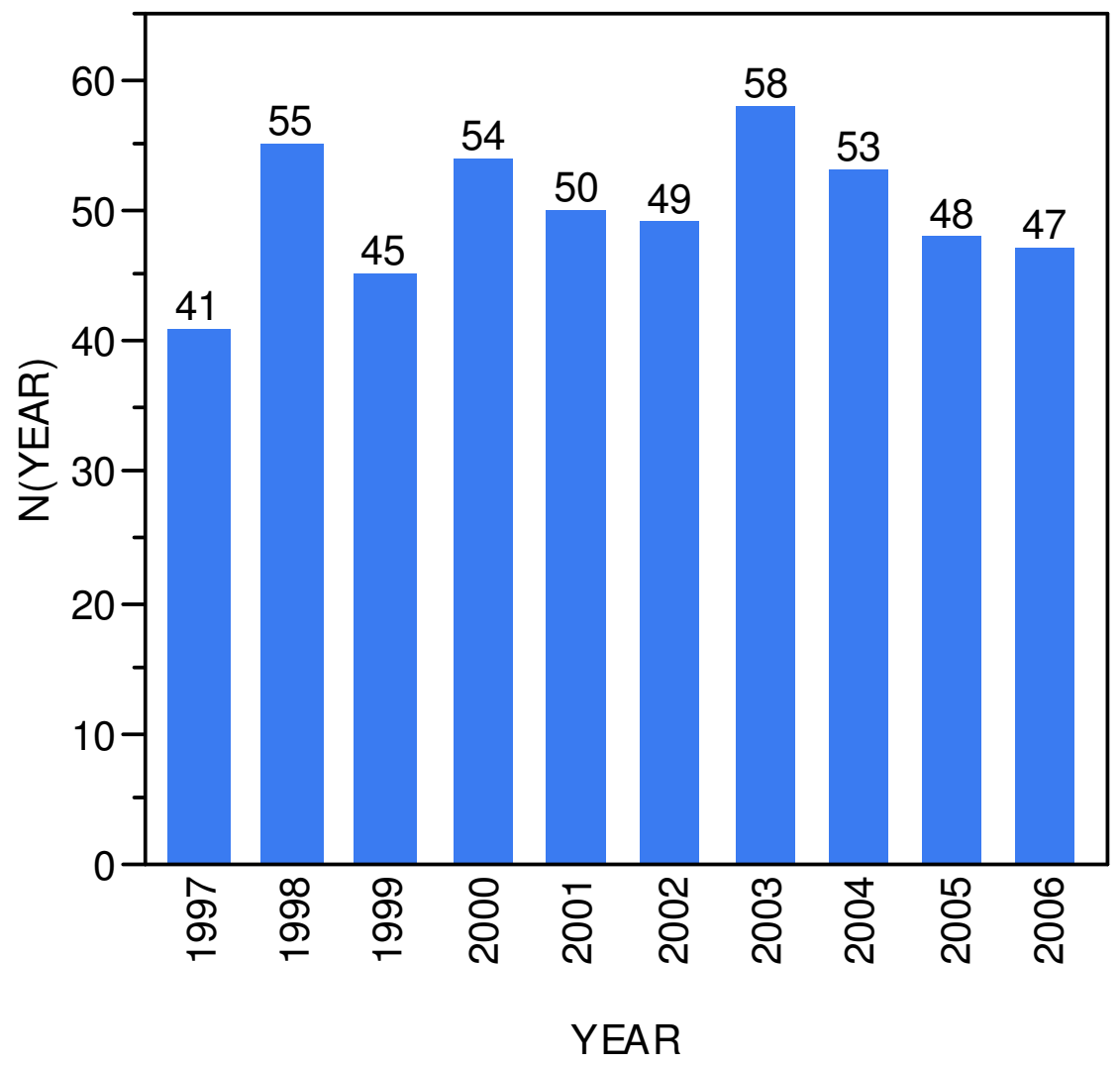

Figure 4.1

Number of Law Enforcement Highway Fatalities per year, 1997-2006 
Figure 4.2

Distribution of Annual Number of Law

Enforcement Highway Fatalities, 1997-

2006

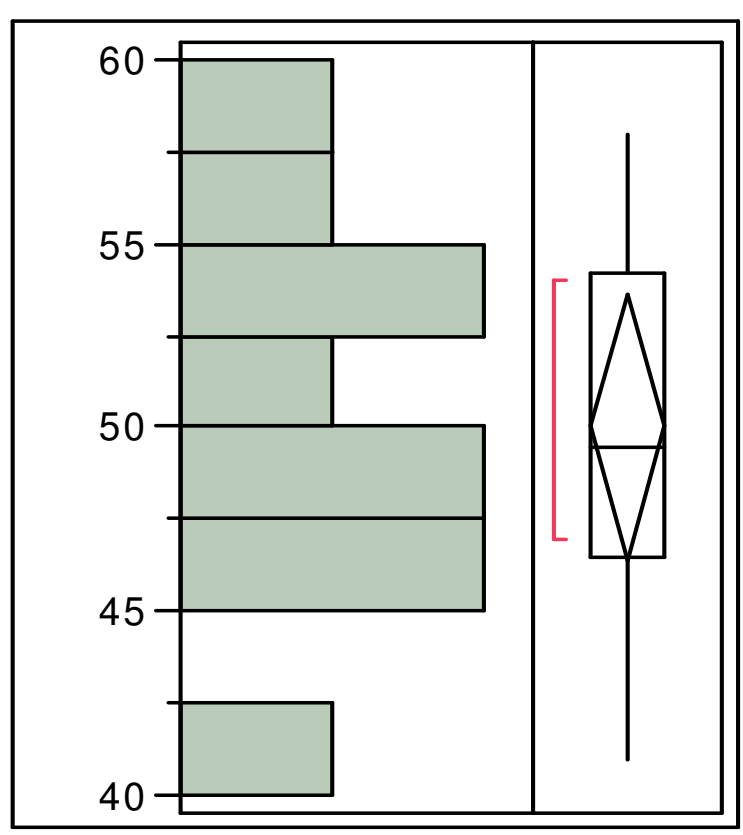

Table 4.1

Distribution of Annual Number of Law

Enforcement Highway Fatalities, 1997-2006

$\begin{array}{llr}100.0 \% & \text { maximum } & 58.000 \\ 99.5 \% & & 58.000 \\ 97.5 \% & & 58.000 \\ 90.0 \% & & 57.700 \\ 75.0 \% & \text { quartile } & 54.250 \\ 50.0 \% & \text { median } & 49.500 \\ 25.0 \% & \text { quartile } & 46.500 \\ 10.0 \% & & 41.400 \\ 2.5 \% & 41.000 \\ 0.5 \% & & 41.000 \\ 0.0 \% & \text { minimum } & \\ & & 51.000 \\ \text { Mean } & & 50 \\ \text { Std Dev } & & 1.6124515 \\ \text { Std Err Mean } & 53.647619 \\ \text { upper } 95 \% \text { Mean } & 46.352381 \\ \text { lower 95\% Mean } & 10 \\ \text { N } & \end{array}$

In order to offer some demographic information regarding the victims of the highway fatalities,

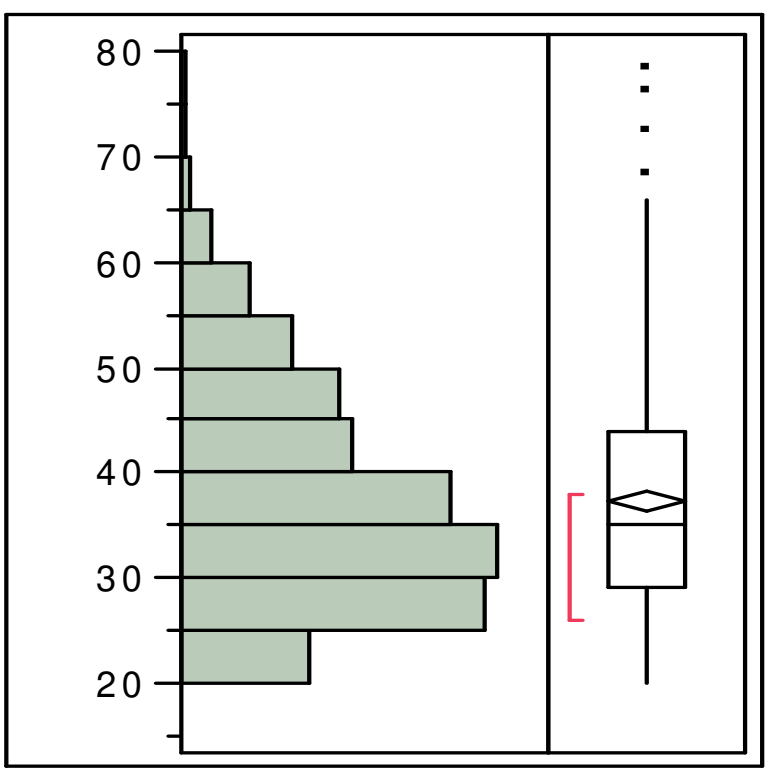

Figure 4.3

Distribution of Age, Law Enforcement

Highway Fatalities, 1997-2006 the average age of highway fatality victims is

37.2 years of age with a standard deviation of

10.7 years. The oldest victim was reported as 78

years old and the youngest fallen officer was 20

years old. This correlates with the overall

officer fatality age average of 37 years (Kouri,

2008) Figure 4.3 and Table 4.2 offer the

analysis of data regarding the age of the fallen

officers associated with highway fatalities. 
Gender was also considered in the

demographic review of the data. In a set

Table 4.2

of 500 victims, only 35 fallen officers

were female. Therefore the female

population only represents 7 percent of the

Distribution of Age, Law Enforcement Highway

Fatalities, 1997-2006

victims included in the study. Therefore

the male population of victims included in

the study accounts for 465 officers or 93

percent of the cases. The Current

$\begin{array}{llr}100.0 \% & \text { maximum } & 78.000 \\ 99.5 \% & & 73.980 \\ 97.5 \% & & 60.475 \\ 90.0 \% & & 52.000 \\ 75.0 \% & \text { quartile } & 44.000 \\ 50.0 \% & \text { median } & 35.000 \\ 25.0 \% & \text { quartile } & 29.000 \\ 10.0 \% & & 25.000 \\ 2.5 \% & & 22.000 \\ 0.5 \% & & 20.000 \\ 0.0 \% & 20.000 \\ \text { Mean } & & 37.208 \\ \text { Std Dev } & & 10.660019 \\ \text { Std Err Mean } & 0.4767305 \\ \text { upper 95\% Mean } & 38.144647 \\ \text { lower 95\% Mean } & 36.271353 \\ \text { N } & 500\end{array}$

Population Survey for 2006 conducted by the Department of Labor, US Bureau of Labor

Statistics reported that only 15.5 percent of First-line Supervisors or Managers of Police and detective are females. In addition only 12.8 percent of all police and sheriff patrol officers are females. Figures 4.4 offers a graphical display of the data.

Figure 4.4

Distribution of Gender (Sex), Law Enforcement Highway Fatalities, 1997-2006

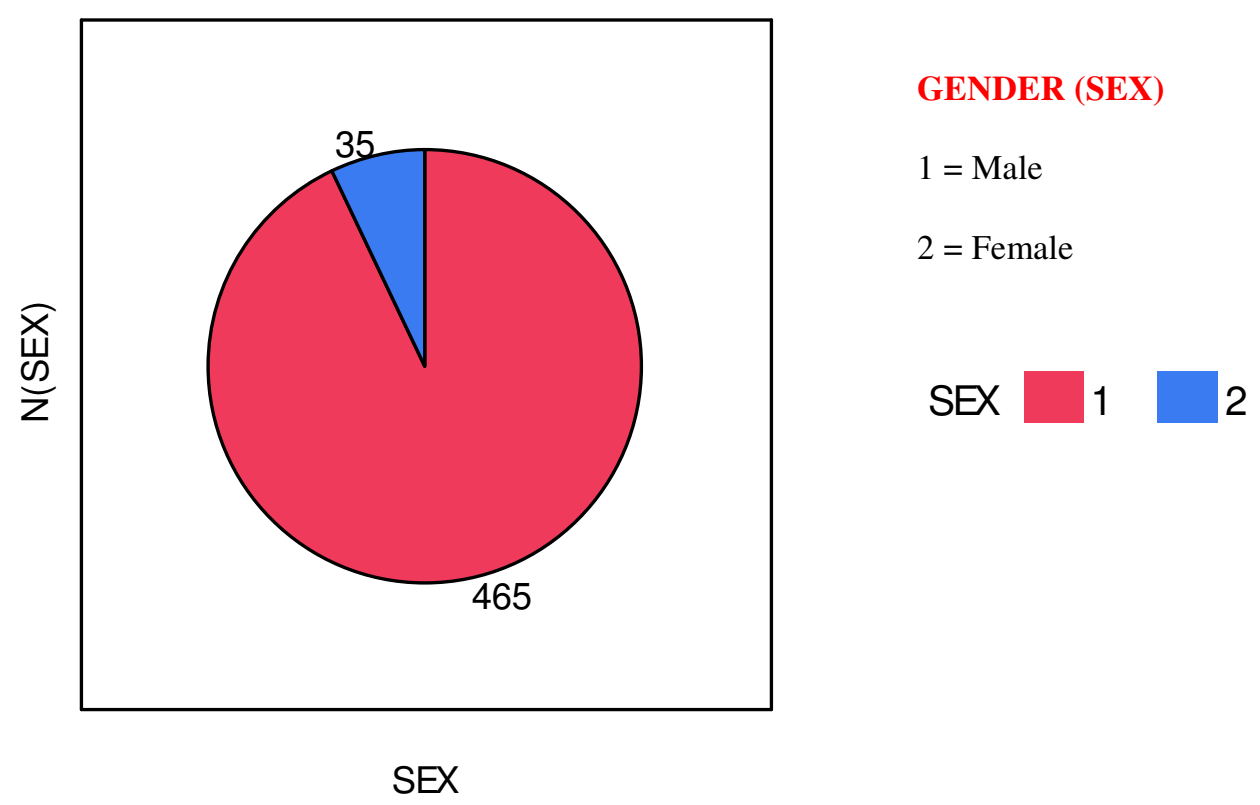


The following portions of the descriptive study will be discussed: fatalities occurring while driving (driving) and fatalities occurring while not driving and outside the vehicle (not drivingoutside vehicle). As previously noted cases that involved fatalities while not driving, but the officer remained in the vehicle were limited in number $(n=13)$ and not further reviewed in the descriptive study.

\subsubsection{Fatalities While Driving}

A common variable that is often reviewed when looking at the occurrence of fatalities is the day of the week in which the fatalities commonly occur. It is based on popular belief that there is more law enforcement activity during the weekends as compared to during the weekdays. Therefore, one may also interpret that by consensus there are more emergency response calls during the weekends. Based upon these common beliefs, the author decided to look at the occurrence of law enforcement highway fatalities during the weekend.

For purposes of this study the weekend category includes Friday, Saturday and Sunday. Out of a total 369 law enforcement officer highway fatalities occurring while the officer was driving, only 44.1 percent or 163 fatalities occurred during the weekend. A higher percentage of incidents occurred during the weekdays of Tuesday, Wednesday and Thursday. These days accounted for a total of 170 fatalities or 46.1 percent of the total fatalities. Wednesdays and Thursdays reported to be the most common day for the occurrence of law enforcement officer fatalities each with a total of 59 and 56 fatalities respectively for each day of the week over a ten year period. The day of the week in which the least amount of law enforcement officer fatalities occurred was 
on Mondays with a reported 36 fatalities or 9.8 percent. Figure 4.5 below offers a graphical distribution of the number of incidents based upon day of the week.

Figure 4.5

Occurrence of Fatalities While Driving by Day of the Week, Law Enforcement Highway Fatalities, 1997-2006

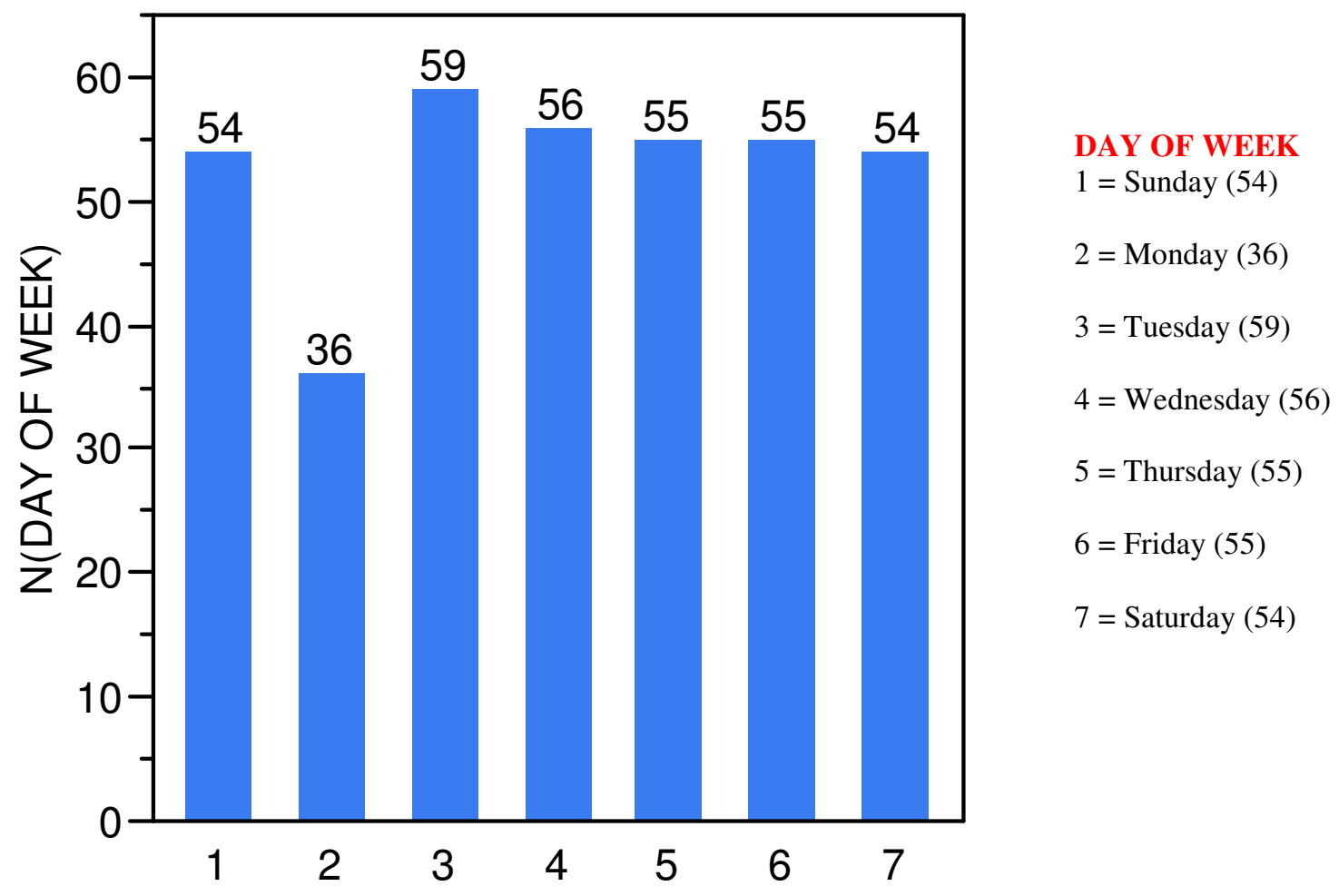

DAY OF WEEK

Another important element that is often used to describe the parameters of highway fatalities is the hour of occurrence. Although many officers work on an array of work schedules, the data was reviewed both on an hourly time frame and combined into three work periods for discussion purposes. The hours which had the reported highest number of occurrences over a ten year time frame were between the hours of 10:00 pm to 5:00 am (not inclusive). During these hours a reported 165 fatal highway incidents occurred. This accounts for 45 percent of all incidents occurring during the ten year period. The data was also combined to be representative of three 
common work schedules in the law enforcement industry, these time periods include; $4 \mathrm{pm}$ midnight (not inclusive), midnight -8 am (not inclusive) and $8 \mathrm{am}-4 \mathrm{pm}$ (not inclusive). When the data are divided based upon the three time periods referenced above, 40 percent of all incidents occurred during the midnight- 8 am time frame. Figures 4.6 and 4.7 offer a graphical display of the information.

Figure 4.6

Occurrence of Fatalities While Driving by Hour, Law Enforcement Highway Fatalities, 1997-2006

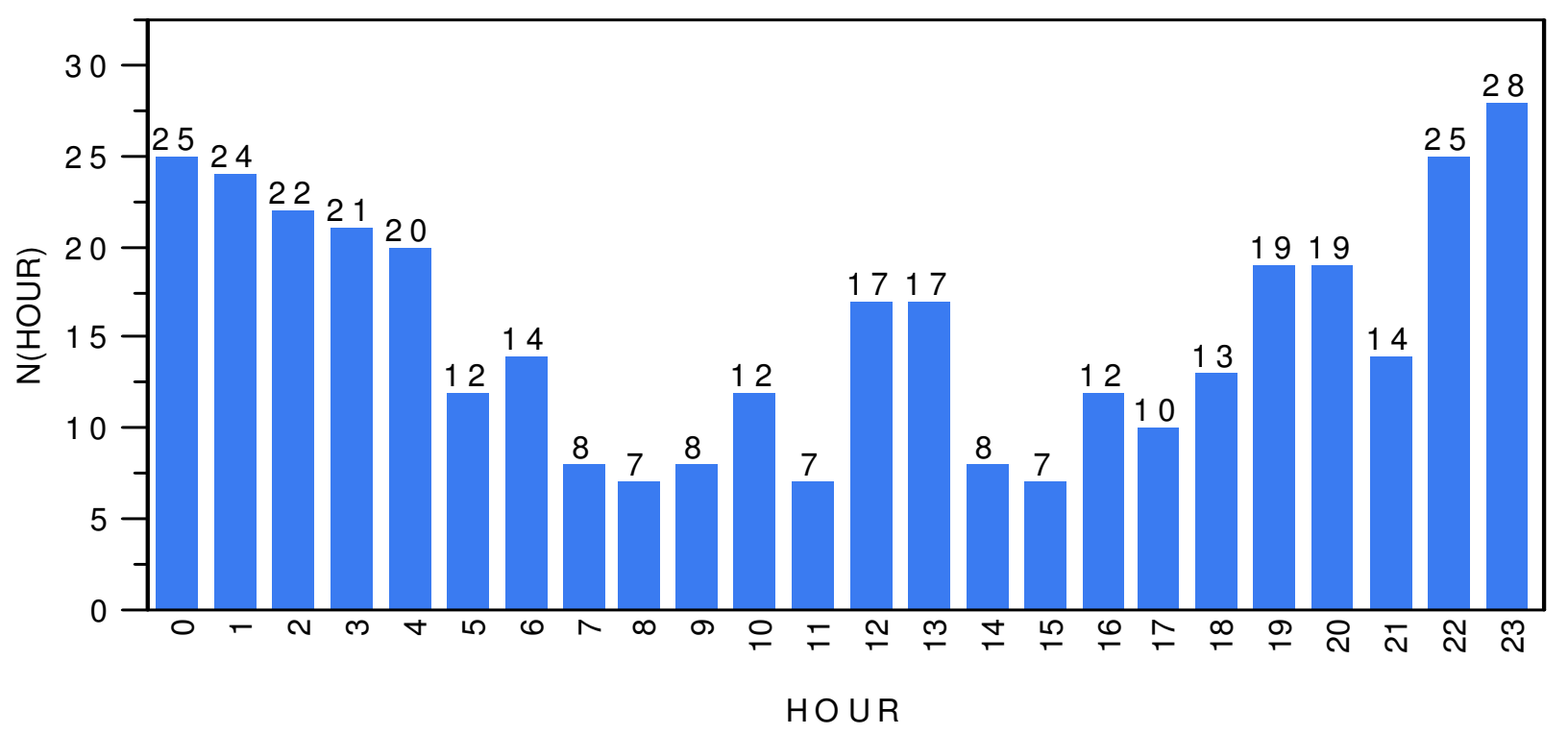

Figure 4.7

Occurrence of Fatalities While Driving by Periods, Law Enforcement Highway Fatalities, 19972006

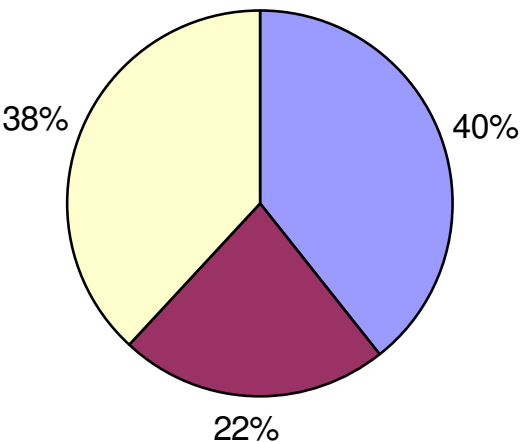


Since the time of day is also correlated with the lighting conditions, a review of reported lighting conditions was also performed to evaluate the association between the conditions and number of reported incidents. According to the FARS data, 134 incidents or 36 percent of the incidents with known lighting conditions occurred during the daylight. Daylight hours for purposes of FARS coding included the hours of 6:00 am - 6:00 pm when the daylight conditions were not reported on incident records. However, in an effort to transform the reported data to relevant percentages, the results indicate that 64 percent of the fatal incidents with known lighting conditions did not occur during daylight conditions. Daylight conditions exclude the following elements: Dark, Dark but lighted, Dawn and Dusk. Generally these elements are reported on the incident reporting forms and are coded accordingly. One incident was reported as unknown lighting conditions and not calculated into these percentages. Figure 4.8 demonstrates the division of occurrence among various lighting conditions.

\section{Figure 4.8}

Occurrence of Fatalities While Driving by Lighting Conditions, Law Enforcement Highway Fatalities, 1997-2006

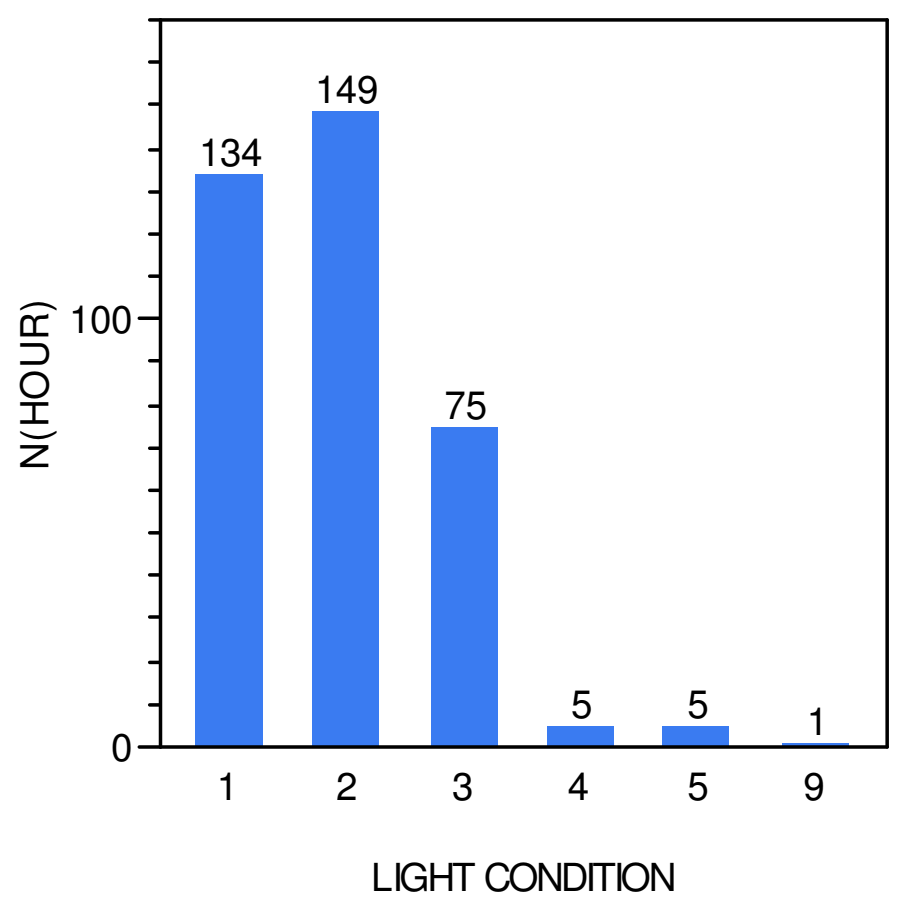

$$
\begin{aligned}
& \text { LIGHTING CONDITIONS } \\
& 1 \text { = Daylight }(134) \\
& 2 \text { = Dark (149) } \\
& 3 \text { = Dark but lighted (75) } \\
& 4 \text { = Dawn (5) } \\
& 5 \text { = Dusk (5) } \\
& 9=\text { Unknown (1) }
\end{aligned}
$$


Environmental conditions are sometimes considered to be a relevant issue related to highway incidents. Therefore, data were reviewed regarding the amount of law enforcement fatalities that occurred in the presence of adverse weather conditions. Adverse weather conditions were present for 16 percent $(n=59)$ of the incidents selected for the study. Non-adverse weather conditions were associated with 84 percent of the fatalities $(n=307)$. The most frequently occurring weather condition was reported to be rain conditions which were present in 40 of the cases or 11 percent of the cases representing fatalities while driving. The distribution of cases based on weather conditions is displayed in Figure 4.9: Occurrence of Fatalities While Driving by Atmospheric Conditions, Law Enforcement Highway Fatalities, 1997-2006.

Figure 4.9

Occurrence of Fatalities While Driving by Atmospheric Conditions, Law Enforcement Highway Fatalities, 1997-2006

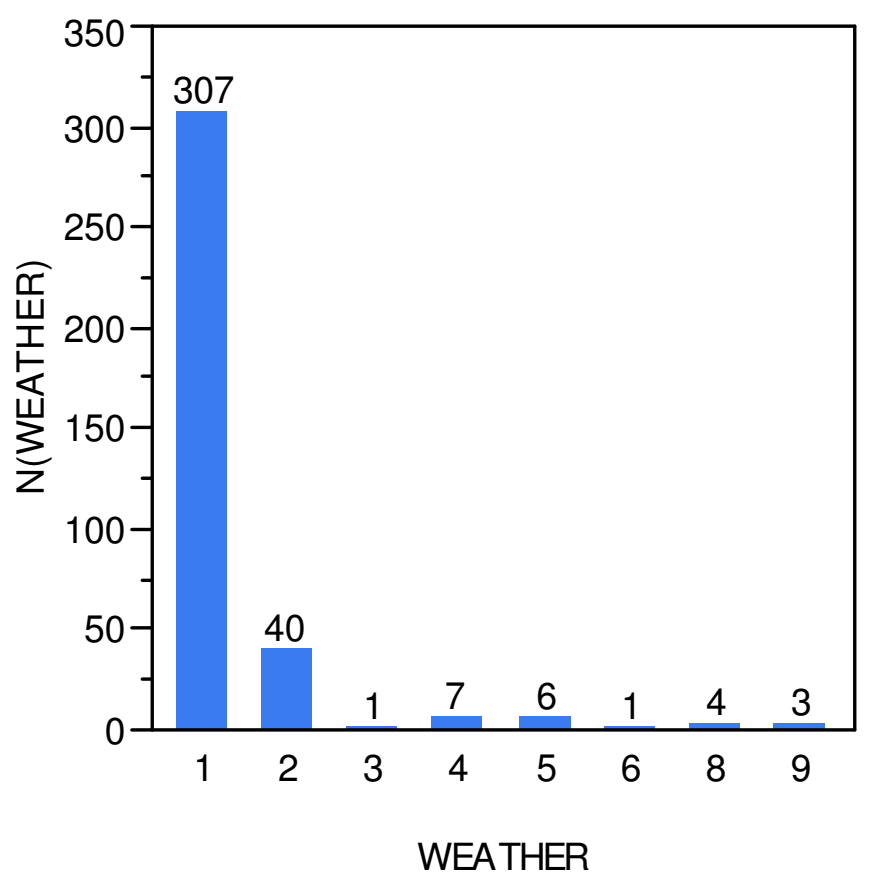

$\quad \begin{array}{r}\text { ATMOSPHERIC CONDITIONS } \\ (\text { WEATHER) }\end{array}$
$\begin{aligned} & 1 \\ & 2=\text { No adverse atmospheric conditions (307) }\end{aligned}$
$3=$ Sleet (Hail) (1)
$4=$ Snow (7)
$5=$ Fog (6)
$6=$ Rain and Fog (1)
$8=$ Other, smog, smoke, blowing sand or dust (4)
$9=$ Unknown (3)


Surface conditions may also be indirectly related to the atmospheric conditions. Thus a review of such conditions was performed to see if there was a relationship to previous weather conditions before the occurrence of the event. According to the data, dry surface conditions were present in 285 of the fatalities included in the study. This accounted for 78 percent of the incidents in which the surface conditions were known. It should be noted that the surface conditions were unknown for three cases in this portion of the study. Therefore, 22 percent of the cases reported surface conditions other than dry conditions. This included the following conditions: Wet, Snow or Slush, Ice, or Sand, Dirt or Oil. A graphical display of the data are provided in Figure 4.10: Occurrence of Fatalities While Driving by Surface Condition.

Figure 4.10

Occurrence of Fatalities While Driving by Surface Conditions, Law Enforcement Highway Fatalities, 1997-2006

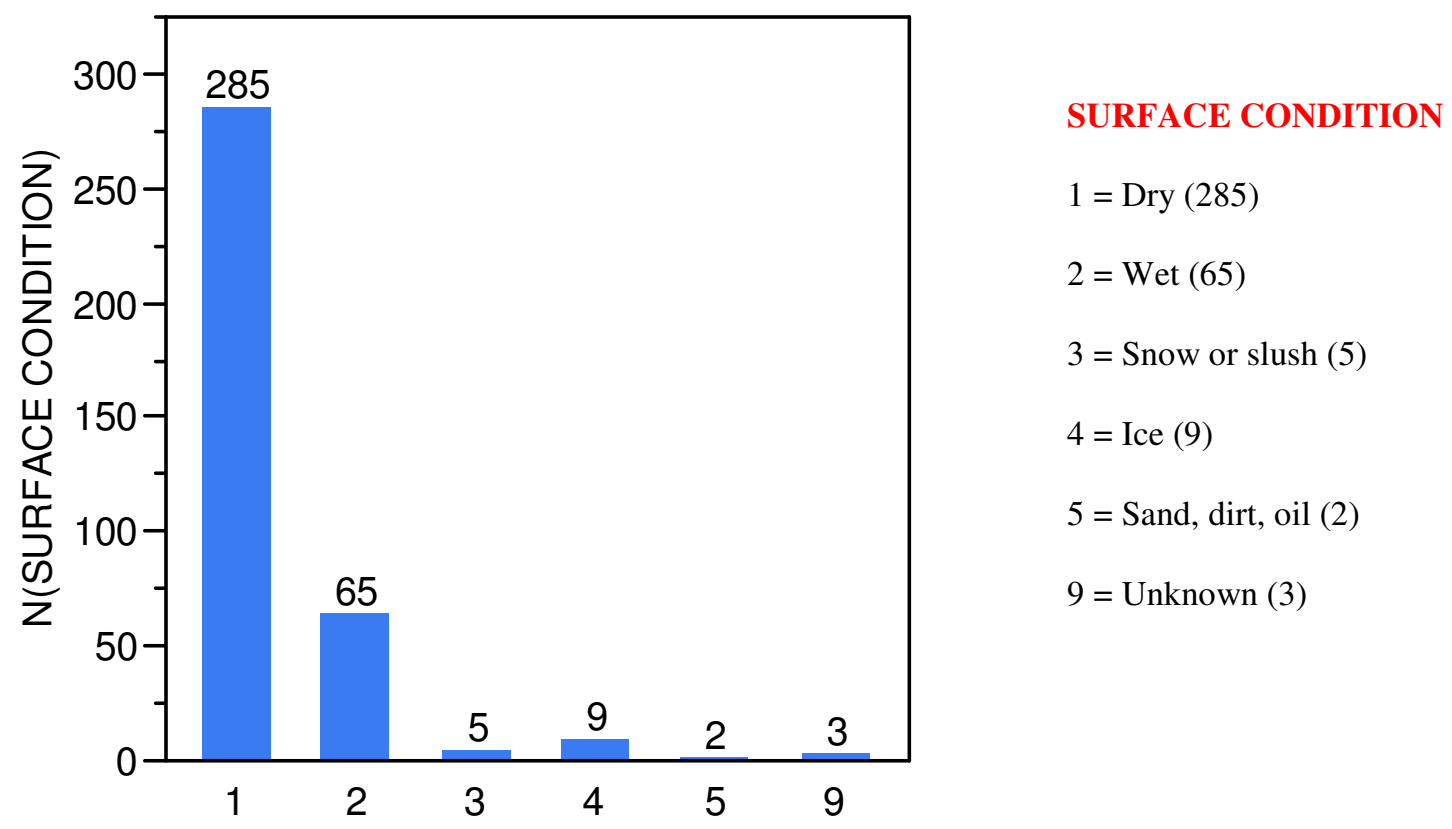

SURFACE CONDITION 
Another variable that may be related to the roadway surface is the type of surface. The FARS database offers coding for the following surface types: dirt, slag, gravel or stone, brick or block, blacktop or concrete. Based upon the data selected to represent fatalities occurring while driving, 352 case files reported a known surface type. The data indicated that 311 of the 352 case files with known surface type were blacktop. Thus, blacktop represents the roadway surface type for 88 percent of the known conditions. An additional 32 files or 9 percent of the case files indicated a roadway surface type coded as a concrete surface. As a result, 343 cases or 97 percent of known surface types are blacktop or concrete. Figure 4.11 offers a graphical display of the number of cases related to roadway surface type.

\section{Figure 4.11}

Occurrence of Fatalities While Driving by Roadway Surface Type, Law Enforcement Highway Fatalities, 1997-2006

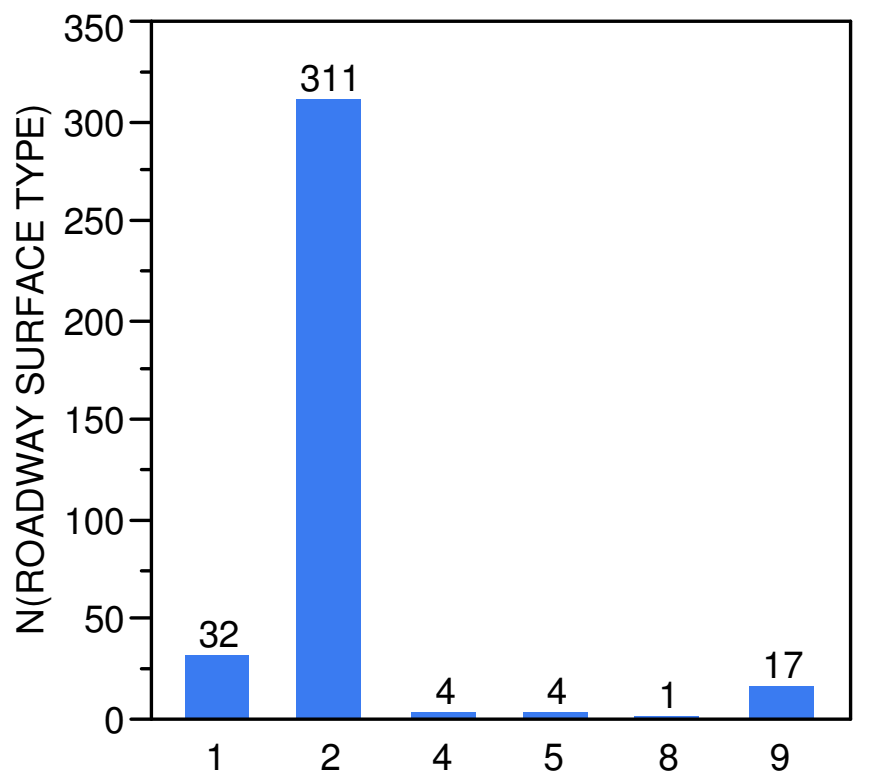

$$
\begin{aligned}
& \text { ROADWAY SURFACE TYPE } \\
& 1 \text { = Concrete (32) } \\
& 2 \text { = Blacktop (311) } \\
& 4 \text { = Slag, Gravel or Stone (4) } \\
& 5 \text { = Dirt (4) } \\
& 8 \text { = Other (10 } \\
& 9 \text { = Unknown (17) }
\end{aligned}
$$


As the review of roadways was performed this author also considered where the occurrence of the fatality resulted in relationship to the roadway. The FARS database offered coding variables for the following relations to the roadway: on roadway, shoulder, median, roadside, outside, right of way, off roadway, in parking lane, gore, separator, or two-way continuous left-turn lane. The data selected to represent fatalities that occurred while driving indicated that 53 percent of known relation to roadway or 194 fatalities occurred on the roadway. The FARS analytic reference guide defines a roadway as "that part of a trafficway designed, improved and ordinarily used for motor vehicle travel or, where various classes of motor vehicles are segregated, that part of a trafficway used by a particular class. Separate roadways may be provided for traffic going in opposite directions, for example northbound and southbound traffic or for trucks and automobiles. The roadway and any shoulder alongside the roadway together make up the roads."

According to the data set, 86 fatalities or 23 percent of the fatalities occurred on the roadside. According to FARS, roadside refers to a location off the roadway, but inside the right of way. It is the outermost part of the trafficway which lay between the outer property line or other barrier and the edge of the first road encountered in the traffic way. The roadside should not be confused with the shoulder. FARS defines the shoulder as that part of a trafficway contiguous with the roadway for emergency use, for accommodation of stopped vehicles and for lateral support of the roadway structure. A shoulder is a design feature of a road and may or may not be paved. Of the fatalities that occurred while driving, 21 fatalities or 6 percent of known relation to roadway were reported to have occurred on the shoulder of the roadway. When combining the fatalities that occurred on the shoulder and the roadside, 107 total fatalities occurred relative to these locations. Roadside and shoulder locations accounted for a combined 29 percent of the 
fatalities. Figure 4.12 provides a detailed extraction of the data based on the relation to the roadway.

Figure 4.12

Occurrence of Fatalities While Driving by Relation to Roadway, Law Enforcement Highway Fatalities, 1997-2006

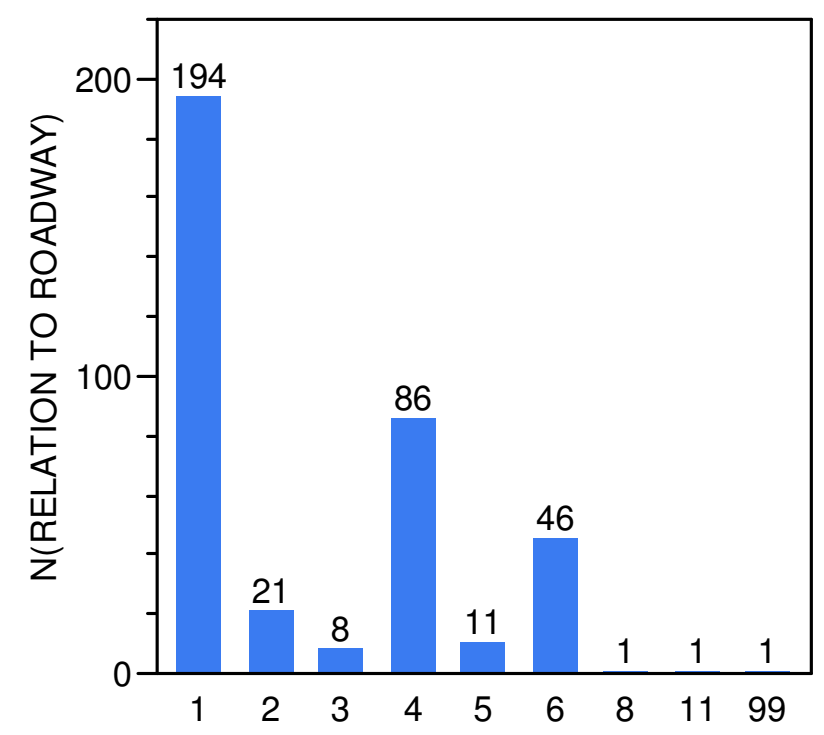

\author{
RELATION TO ROADWAY \\ $1=$ On Roadway (194) \\ $2=$ Shoulder (part of a traffic way for \\ emergency use) (21) \\ $3=$ Median (3) \\ 4 = Roadside (off of roadway, but inside \\ right of way) (86) \\ $5=$ Outside of Traffic way or Right of way \\ (11) \\ $6=$ Off roadway, relationship to right of \\ way is unknown (46)
}

\title{
RELATION TO ROADWAY
}

Some of the literature reviewed for the study suggested that highway incident occurrences may also be a result of roadway junction or disregardance to such junctions. The FARS data offered coding variables for the following elements in relationship to roadway junctions: NonInterchange Areas included: non-junction, intersection, intersection-related, driveway, alley access, entrance/exit ramp-related, rail grade crossing, in crossover, driveway-access-related, unknown non-interchange. Interchange Areas included: intersection, intersection - related, driveway access, entrance/exit ramp - related, in crossover, other location in interchange, unknown - interchange area. 
Of the 369 case files selected to represent fatalities that occurred while driving, 270 incidents or 73 percent of incidents occurred in a non-interchange, non-junction area. As a counter to that data, 99 incidents occurred in areas that where classified as other than a non-junction area as listed above. Thus, 26 percent of the incidents occurred in these junction related areas. The most common occurrence of incidents that were junction related occurred at intersections of noninterchange areas. This accounted for 70 incidents or 19 percent of the relation to junction cases. Figure 4.13 offers a summary of the number of cases based on the relation to junction.

\section{Figure 4.13}

Occurrence of Fatalities While Driving by Relation to Junction, Law Enforcement Highway Fatalities, 1997-2006

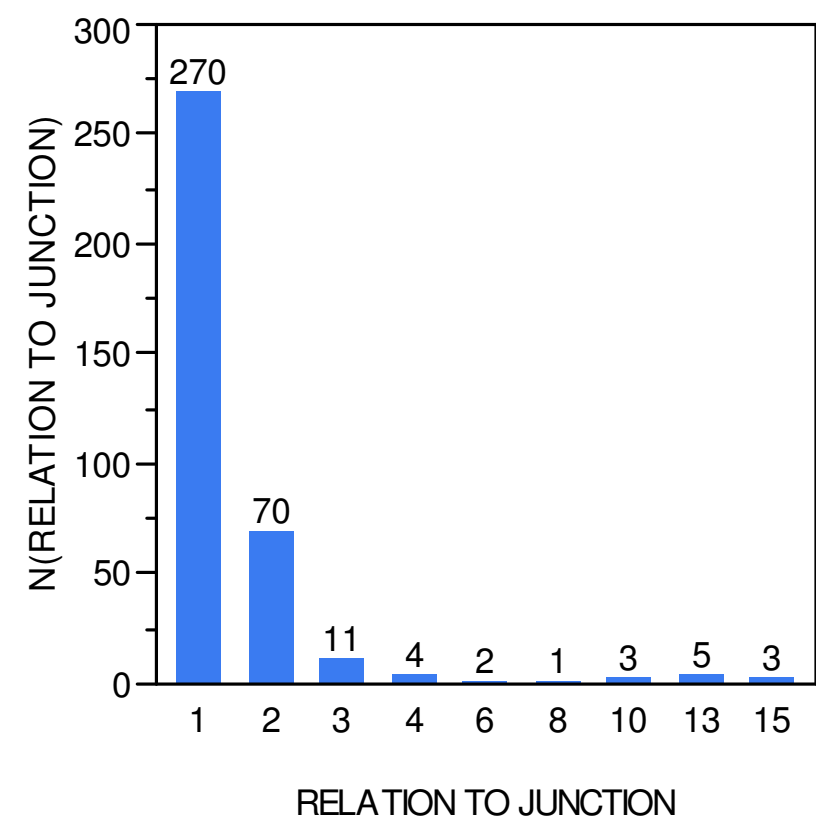

\section{RELATION TO JUNCTION}

Non-Interchange Areas:

$1=$ Non-Junction (270)

$2=$ Intersection $(70)$

$3=$ Intersection Related (11)

Interchange Areas: (Roadways of different $\underline{\text { levels) }}$

$13=$ Entrance/Exit Ramp - Related (5)

Roadway alignment has been identified as a contributing factor to many highway incidents.

However, roadway alignment has a direct relationship to the topography of the region. Out of the 365 incidents identified with a known roadway alignment, 250 of the law enforcement fatalities or 69 percent occurred on straight roadways. Therefore, 32 percent of the fatal 
incidents with a known roadway alignment occurred on curved roadways. Although this percentage may not appear to be very significant, regional topography may also be related. For example, drivers that operate in areas with primarily straight roads may not be able to compensate for the curves as well as a driver that routinely operates in an area with more curves. Figure 4.14 shows a pie chart that displays the number of fatalities based upon roadway alignment.

Figure 4.14

Occurrence of Fatalities While Driving by Roadway Alignment, Law Enforcement Highway Fatalities, 1997-2006

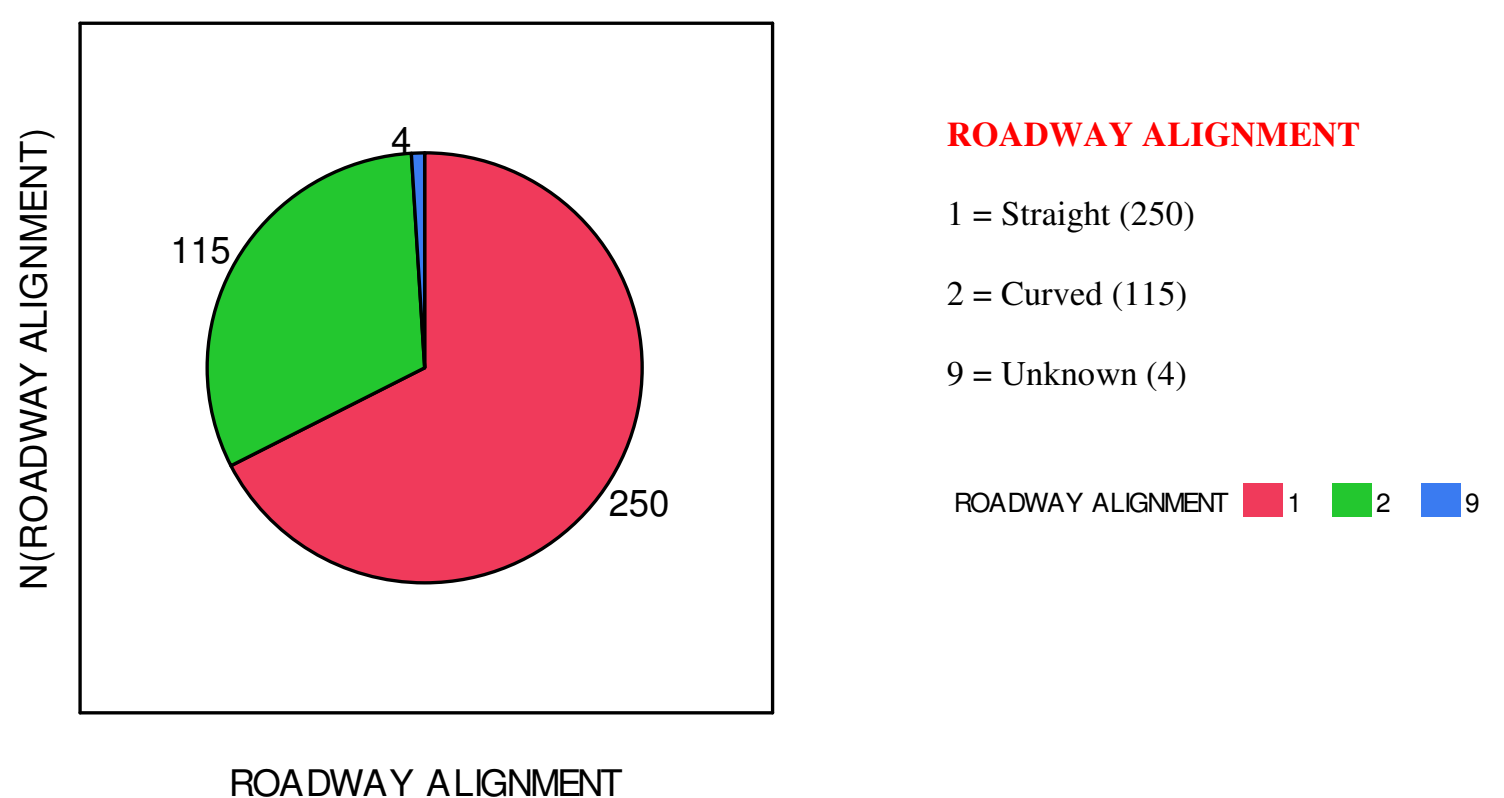

When discussing the effects of the roadway, the profile of the roadway was reviewed to determine if the descriptive parameters indicated a possible relative factor for law enforcement highway fatalities. Roadway profiles were defined to include the following categories: Level, grade, hill crest or unknown. Of the 369 case files selected to represent fatalities while driving, 360 cases were coded to have a known roadway profile. Out of the 360 cases, 245 fatalities or 
68 percent occurred on level roadway surfaces. An additional 115 fatalities or 22 percent occurred on a grade surface or a hill crest. The number of fatalities that were reported to be on grade level was 105 officers. This represents 26 percent of all fatalities with a known roadway profile. Figure 4.15 displays the number of fatalities that occurred relative to the roadway profile.

\section{Figure 4.15}

Occurrence of Fatalities While Driving by Roadway Profile, Law Enforcement Highway Fatalities, 1997-2006
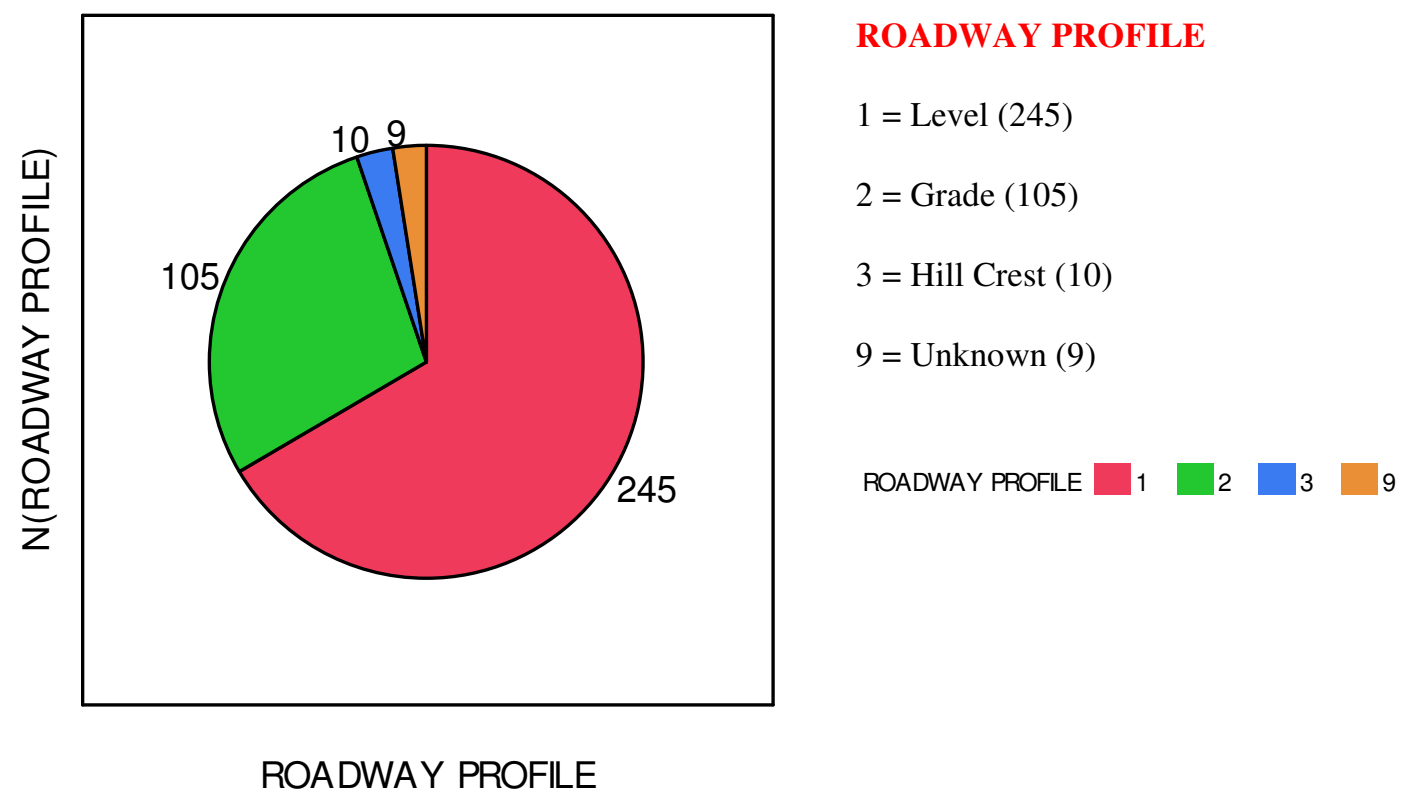

After reviewing the numerous variables related to roadway surfaces, conditions, junctions, profiles, alignment, etc., other factors shall be considered. One element that has been reflected in the literature was the maneuver performed by the law enforcement officer in an effort to avoid the crash. The FARS Analytic Reference Manual defined the Crash Avoidance Maneuver as the maneuver that the driver executed to attempt to avoid the crash. According to the data, the records offered to the FARS coding specialists did not routinely provide the information necessary to accurately identify such maneuvers. Of the 369 case files selected to represent fatalities that occurred while driving, 132 of the cases did not report the type of crash avoidance 
maneuver or were considered to be unknown. This non-reporting shall be clarified and not interpreted as "No avoidance maneuver reported". The "No avoidance maneuver reported" category reflects incidents in which it was reported that the driver did perform any maneuvers in an effort to avoid the crash. Thus, only 237 cases could correctly identify the maneuvers. This result creates a limitation of the data in relationship to the impact of crash avoidance maneuvers. "No maneuver performed" accounted for 147 of the fatalities or 62 percent of the incidents. The most frequently contributing crash avoidance maneuver involved steering. According to the data, 72 incidents or 30 percent of known maneuvers involved a "steering" or "steering and braking" action to avoid the crash. Figure 4.16 offers the number of incidents related to various crash avoidance maneuvers.

Figure 4.16

Occurrence of Fatalities While Driving by Crash Avoidance Maneuver, Law Enforcement Highway Fatalities, 1997-2006
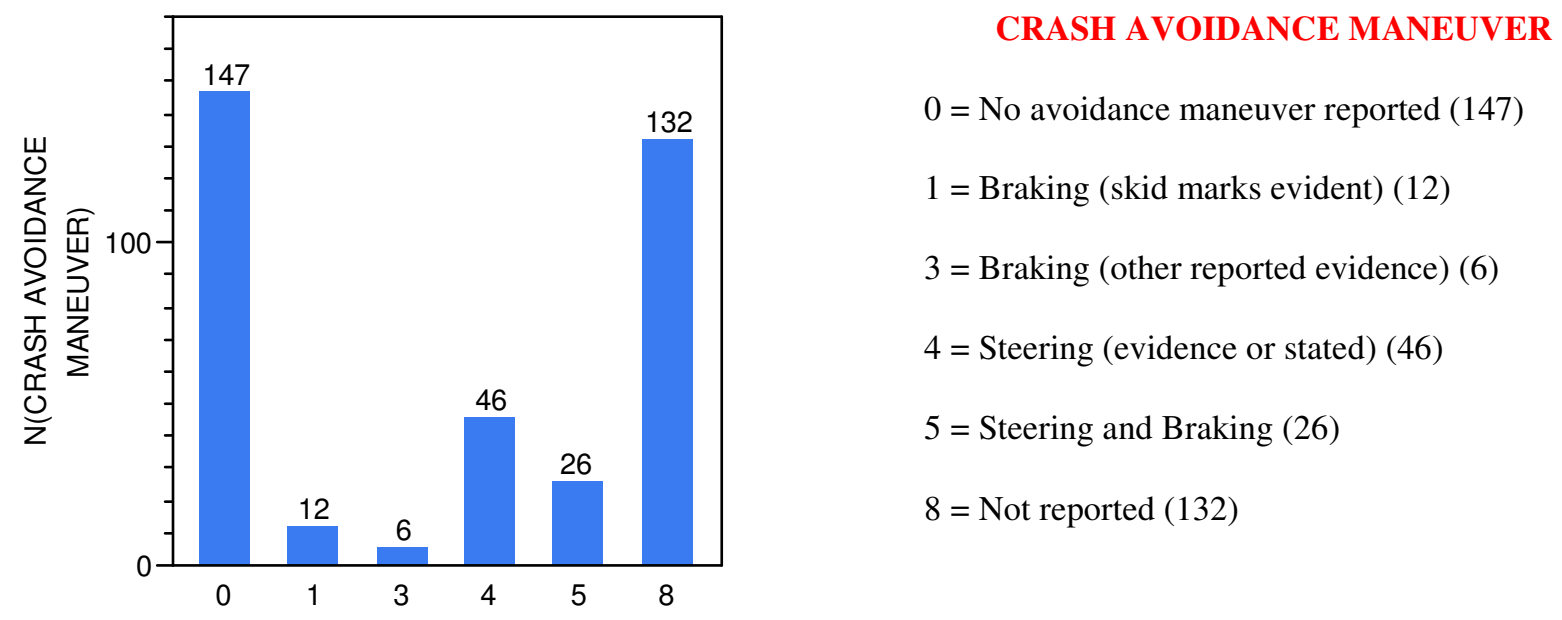

CRASH AVOIDANCE MANEUVER 
The coding criteria for the data regarding Manner of collision changed during the period selected for the study. Therefore, this data could not be used for further analysis.

"Crash avoidance maneuver" should not be confused with "vehicle maneuver". The FARS analytic reference guide defines the vehicle maneuver as the maneuver that the driver was executing just prior to entering a crash situation. The FARS coding system allowed for the differentiation of 19 different maneuvers. The most frequently occurring maneuvers included the following elements: going straight, stopped in traffic lane, passing or overtaking another vehicle, maneuvering to avoid, making a U-turn, changing lanes or merging, negotiating a curve, and unknown.

According to the data there were 366 cases of fatalities occurring while driving with a reportedly known vehicle maneuver. In the majority of the incidents the driver was going straight. This maneuver accounted for 211 fatalities or 58 percent of the fatalities with a known maneuver. Negotiating a curve accounted for 78 fatalities or 21 percent of the fatalities with a known maneuver. Figure 4.17 on the next page offers a full graphical analysis of the reported vehicle maneuvers and the number of incidents occurring while performing such maneuvers. 
Figure 4.17

Occurrence of Fatalities While Driving by Vehicle Maneuver, Law Enforcement Highway Fatalities, 1997-2006

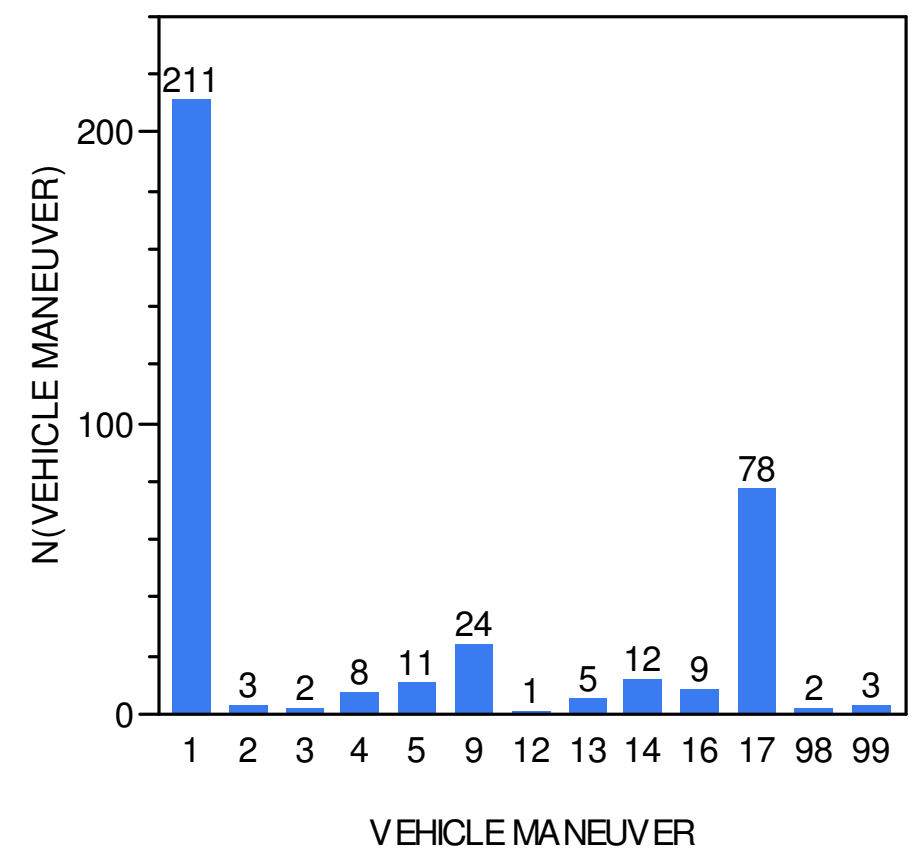

\author{
VEHICLE MANEUVER PRIOR \\ TO CRASH \\ 1 = Going Straight (211) \\ $4=$ Stopped in Traffic Lane (8) \\ $5=$ Passing or overtaking another \\ vehicle (5) \\ $9=$ Maneuvering to avoid (24) \\ 14 = Making a U-Turn (12) \\ $16=$ Changing Lanes or Merging (9) \\ $17=$ Negotiating a curve (78) \\ 99 = Unknown (3)
}

The coding element for speed was a continuous variable with a maximum reporting limit of 97 miles per hour. The coding 97 represented all speeds of 97 miles per hour or greater. Thus, the maximum reported speed was 97 miles per hour and the minimum speed was zero miles per hour or a stopped vehicle. Of the 369 cases representing fatalities that occurred while driving, only 153 cases reported a known speed at the time of the crash. According to the reported travel speed at the time of the incident, the mean travel speed was 60.3 miles per hour with a standard deviation of 27.1 miles per hour. According to a report filed to congress by NHTSA in 1998, the amount of injuries increased by $171 \%$ when the posted speed limits were raised above $60 \mathrm{mph}$ on roadways. This data shall be useful when performing further analysis in the study. Figure 4.18 
provides a graphical explanation of the distribution of travel speed at the time of the incident.

Table 4.3 offers a basic statistical outline of the distribution of travel speed.

Figure 4.18

Distribution of Fatalities While Driving by Travel Speed, Law Enforcement Highway Fatalities, 1997-2006

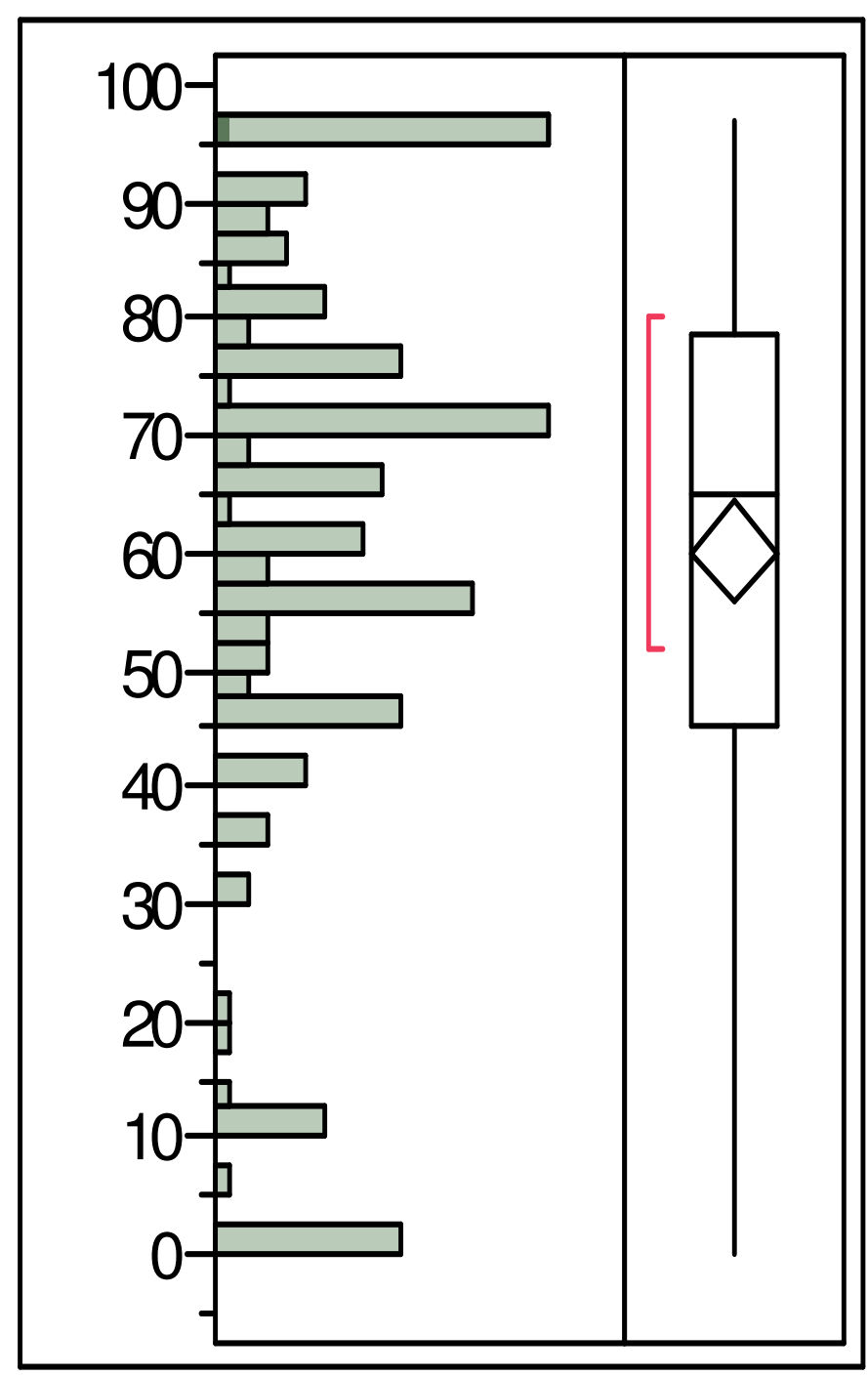

Table 4.3

Distribution of Fatalities While

Driving by Travel Speed, Law

Enforcement Highway Fatalities, 1997-2006

$\begin{array}{llr}100.0 \% & \text { maximum } & 97.000 \\ 99.5 \% & & 97.000 \\ 97.5 \% & & 97.000 \\ 90.0 \% & & 97.000 \\ 75.0 \% & \text { quartile } & 78.500 \\ 50.0 \% & \text { median } & 65.000 \\ 25.0 \% & \text { quartile } & 45.000 \\ 10.0 \% & & 10.800 \\ 2.5 \% & & 0.000 \\ 0.5 \% & & 0.000 \\ 0.0 \% & \text { minimum } & 0.000\end{array}$

\section{Moments}

$\begin{array}{lr}\text { Mean } & 60.006536 \\ \text { Std Dev } & 26.959887 \\ \text { Std Err Mean } & 2.1795776 \\ \text { upper 95\% Mean } & 64.312714 \\ \text { lower 95\% Mean } & 55.700358 \\ \text { N } & 153\end{array}$

Note: all cases labeled unknown or unreported were deleted from the data so that the mean would not be inadvertently increased when calculated. (variable speed $98=$ Not reported, $99=$ unknown) 
Related factors are divided up into four primary categories. These categories include driver related factors, person related factors, vehicle related factors and crash related factors. These categories were each assigned a variety of variables for coding purposes. The related factors were categorized based upon the type of FARS file used for reporting. As recalled from previous discussion, FARS data are recorded in three separate files; person, vehicle and accident file. Each of the related factor categories will be reviewed on the following pages.

Driver related factors are coded into a number of categories including: physical and mental condition, miscellaneous factors, vision obscured by, avoiding/ swerving or sliding, and possible distractions (inside vehicle). It is important to note that driver related factors are reflective of the driver of the vehicle involved in the crash. It does not always reflect the fallen officer because the officer may have been a passenger in the vehicle.

There are a total of 98 codes that can be utilized in the driver related factor category. The vehicle file permits the coding of up to four variables that can be recognized per case file. However, all of these variables are coded based upon the interpretation of the state FARS coding specialists from the records reviewed for inclusion in the database. If the records reviewed do not specify specific conditions present, the coding specialist may not be able to identify all related variables. This creates a limitation that all researchers must address when utilizing data collected from various sources.

Out of a total 369 case files selected to represent fatalities while driving, the most frequently occurring driver related factors was driving too fast for conditions or in excess of posted speed 
limit. These conditions were reported to be present in 123 cases or 33 percent of the cases. The second most frequently reported related factor was failure to keep in proper lane which accounted for 90 cases or 24 percent, followed by running off the road which accounted for 41 cases or 11 percent of the incidents.

Additional driver related factors that were reported frequently include: failure to obey traffic actual signs, traffic control devices, or traffic officers, or Failure to observe safety zone traffic laws; inattentive or careless; operating the vehicle in an erratic, reckless, careless, or negligent manner or suddenly changing speeds; or high speed chase with police in pursuit. Figure 4.19 offers a summary of the driver related factors and the frequency of reporting of the factors. 
Figure 4.19

Occurrence of Fatalities While Driving by Driver Related Factor, Law Enforcement Highway Fatalities, 1997-2006

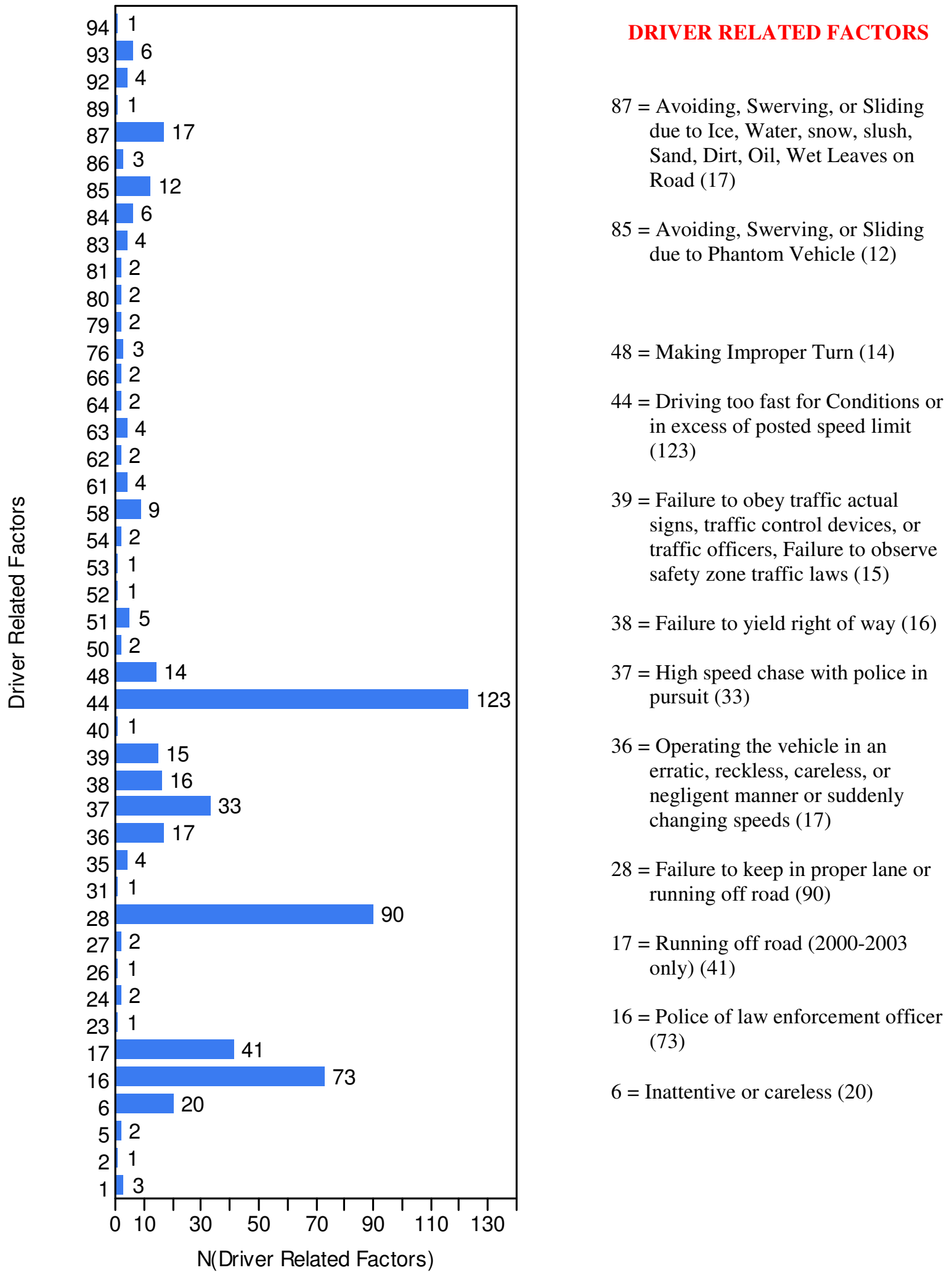


The person related factors are collected from the FARS Person file. This file represents the fatal victim involved in the incident. The FARS database allows for the coding of up to three different variables per case. The coding offers a selection of 90 different variables to choose from. The person related factors only reported four of the 369 cases as a police or law enforcement officer. This data further supports the reasoning for selecting individual case files based on LEOKA data. The strength of these related factors appears to be a weak element and is not recommended for use in the final stage of the logistic regression analysis. No other coding was reported in the data sets besides the 4 cases as police or law enforcement officers.

The vehicle related factors are collected using the FARS Vehicle files. The vehicle related factor is directly related to the physical elements of the vehicle which may have adversely affected the outcome of the event. This variable had a possible 43 different elements that may have been coded in this portion of the vehicle file. The coding specialist may select up to two elements to be identified as vehicle related factors. The most frequently reported vehicle related factor was the vehicle went airborne during crash in eight cases out of 369 representing fatalities while driving. The second highest reported factor was the condition of the tires, which only accounted for five cases. Due to the minimal vehicle related factors reported in the vehicle case files, this set of data appears to be limited in reporting and shall not be used for further analysis in this study. Figure 4.20 offers a graphic representation of the variables reported under the vehicle related factors. 
Figure 4.20

Occurrence of Fatalities While Driving by Vehicle Related Factor, Law Enforcement Highway

Fatalities, 1997-2006
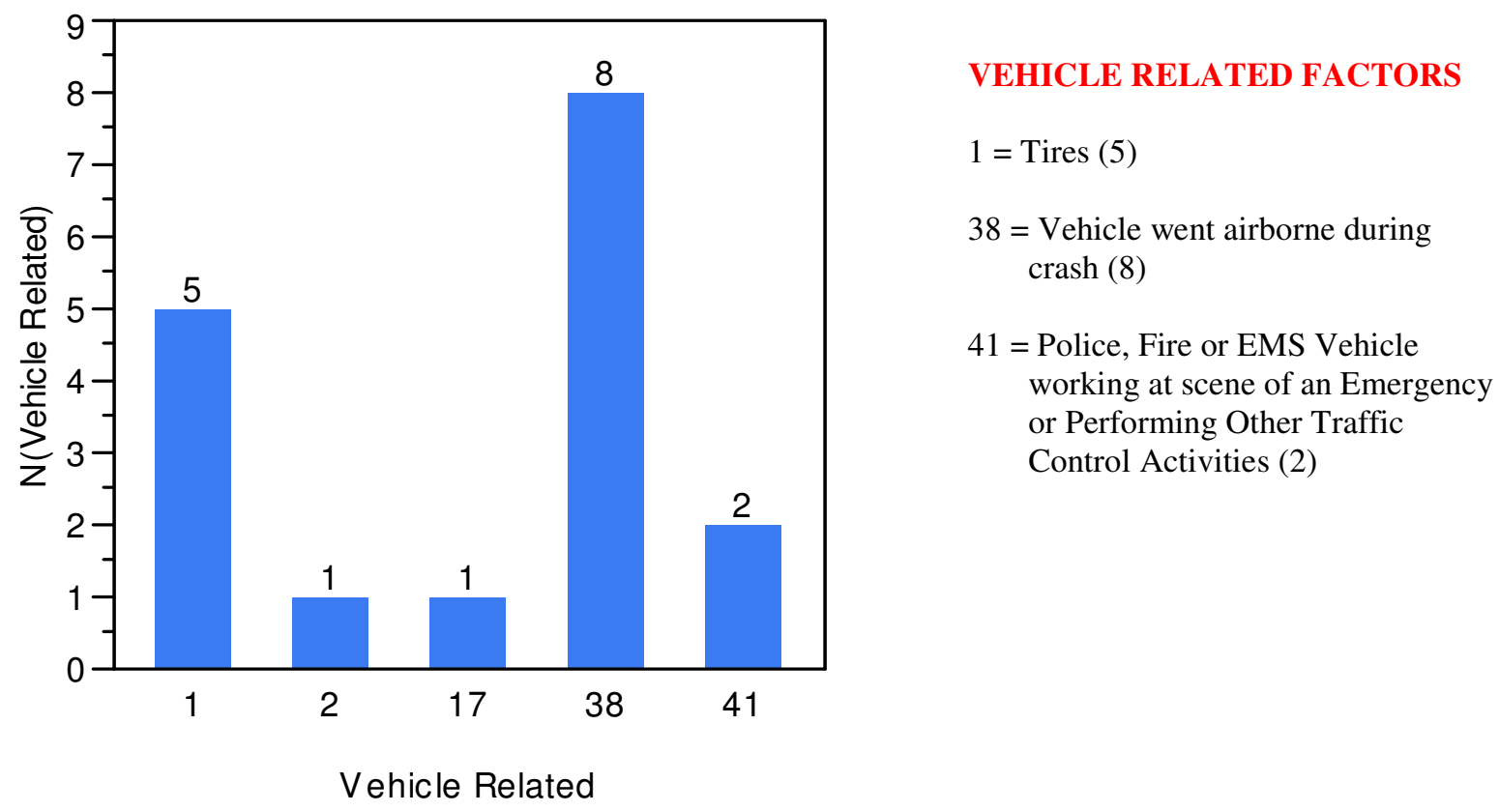

Crash related factors are collected using the FARS Accident Files. These accident files allow for the reporting of up to three variables to be coded in the case file. The coding specialist has up to 51 different variables to select from when coding the data. Some of these elements include miscellaneous factors, vision obscured factors, swerving due to factors, and roadway features. The most commonly coded element in the data set was police pursuits involved. These cases accounted for 45 cases or 12 percent of the 369 case files representing fatalities while driving. It was also reported under the crash related factors that a recent previous crash scene was nearby in five of the fatalities. This represents 1.4 percent of the incidents. Figure 4.21 displays the identified crash related factors by number of occurrences. 
Figure 4.21

Occurrence of Fatalities While Driving by Person Related Factor, Law Enforcement Highway

Fatalities, 1997-2006
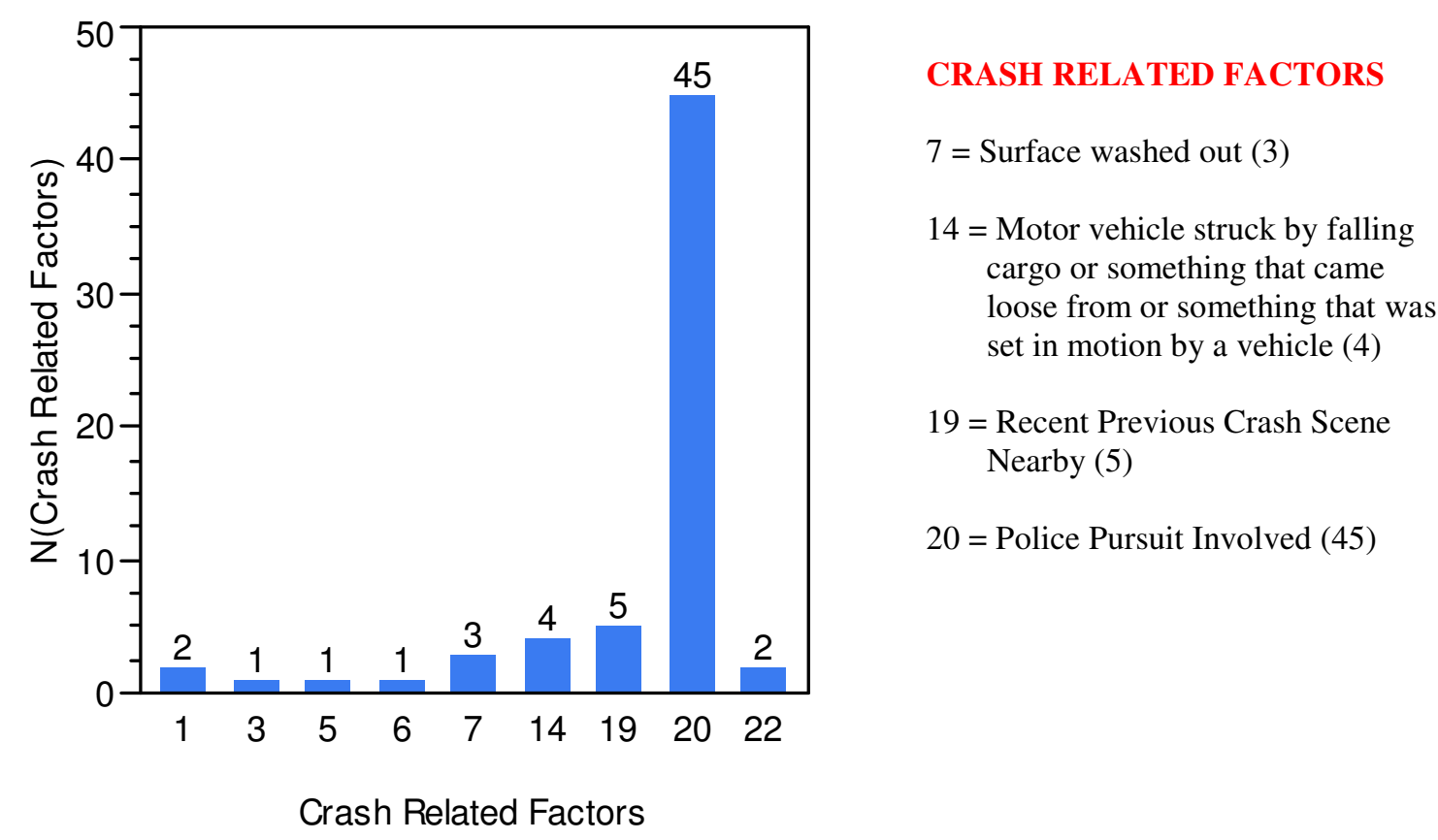

The first harmful event is reported in the FARS accident, vehicle and person files. However, the first harmful event applies to the crash. Harmful events are judgment calls of the FARS analyst based on the data within the police crash report. The first harmful event element only permits the coding of one variable from a selection of 68 different variables. Based upon the information collected from the 369 selected case files, 182 cases, or 49 percent, reported that the collision occurred with a motor vehicle on an undivided highway or the same side of a divided highway Figure 4.22 offers the graphical display of the number of fatalities associated with specific harmful events. 
Figure 4.22

Occurrence of Fatalities While Driving by First Harmful Event, Law Enforcement Highway Fatalities, 1997-2006

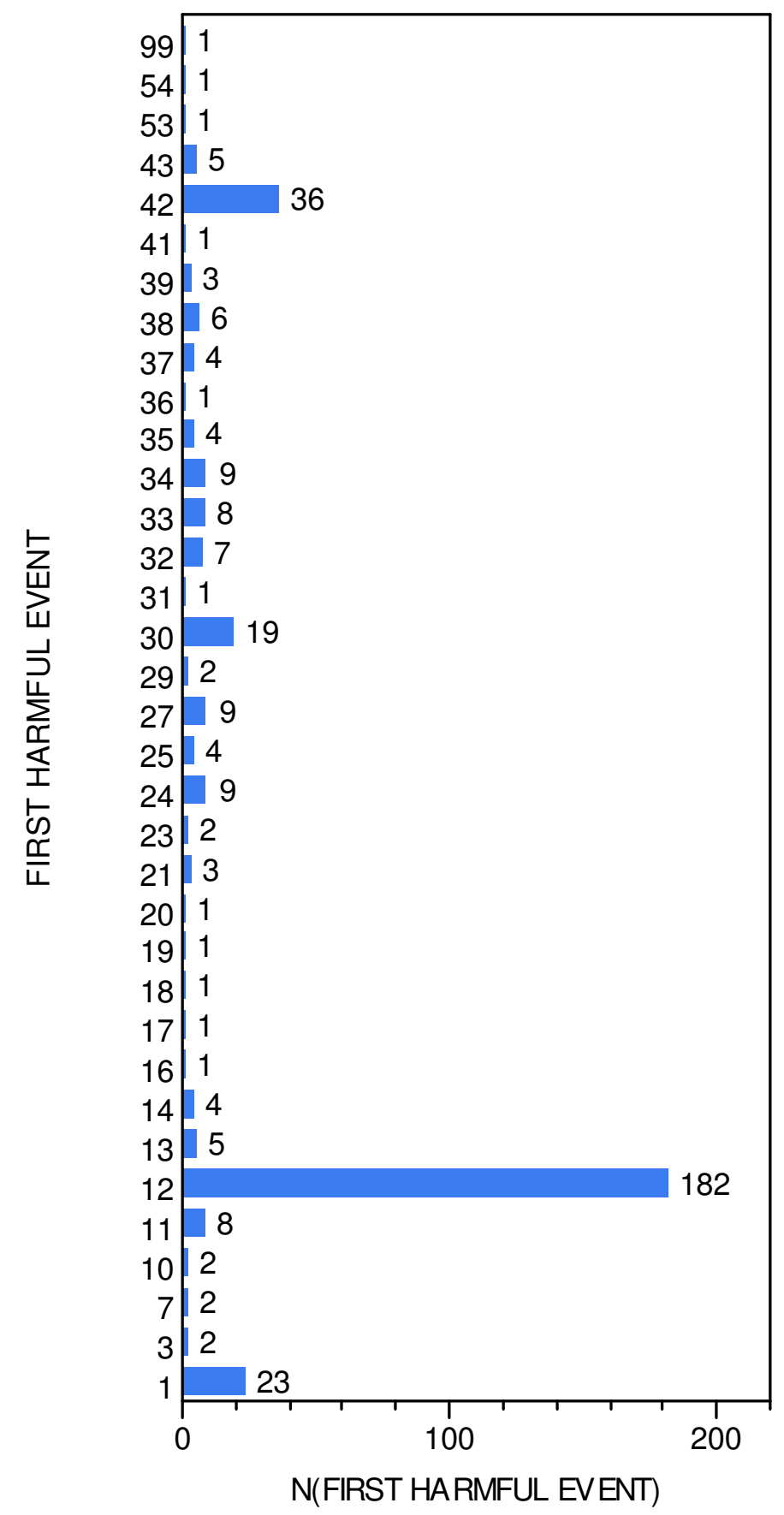

\section{FIRST HARMFUL EVENT:}

First harmful event applies to the crash. Harmful events are judgment calls of the FARS analyst based on the data within the police crash report.

$42=$ Striking a standing tree $(36)$

$30=$ Striking a utility pole (19)

$12=$ Collision with a motor vehicle on an undivided highway or the same side of divided highway (182)

$1=$ Overturn or rollover (23) 
Most harmful event applies to the vehicle. It is coded at the vehicle level versus the crash level.

It is important to note that FARS states that "one cannot assume that the most harmful event for a vehicle was the cause of any death or injury for a specific individual within the vehicle.

Therefore, the data are presented in Figure 4.23 for descriptive purposes, but will not be used in further data analysis.

Figure 4.23

Occurrence of Fatalities While Driving by Most Harmful Event, Law Enforcement Highway

Fatalities, 1997-2006

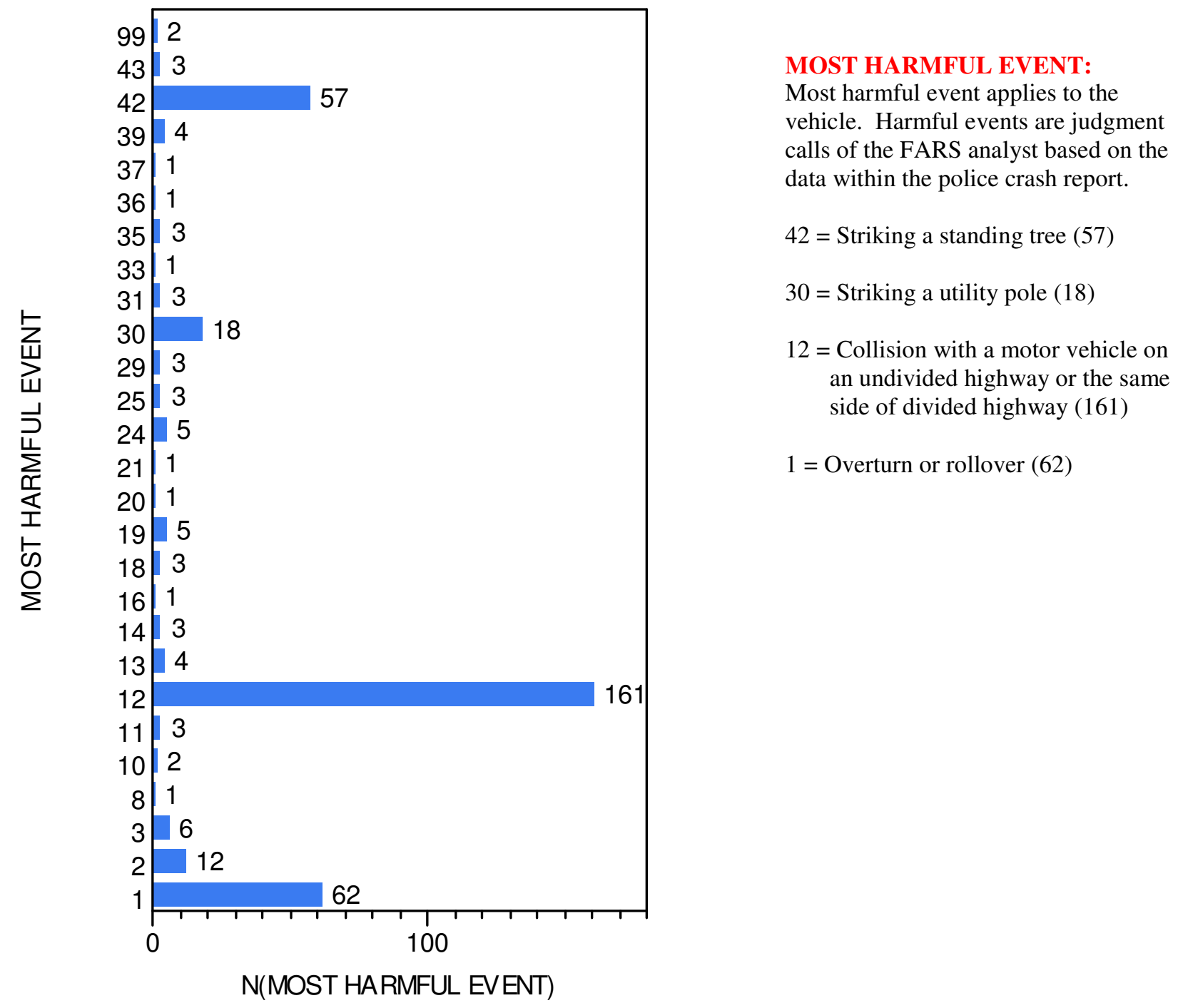


Restraint system used includes protective systems used for either motor vehicles or motorcycles. These protective systems include lap belts, lap and shoulder belts, motorcycle helmets, unknown type of restraint system used. The FARS database indicated that 336 fatalities had identified restraint system conditions at the time of the incident. 134 fatalities or 36 percent of fatalities occurred when a restraint system was reported to not be in use. 57 percent of fatalities indicated that a lap and shoulder belt were in use at the time of the incident. Figure 4.24 displays the results of analysis on the use of restraint systems.

Figure 4.24

Occurrence of Fatalities While Driving by Restraint System Use, Law Enforcement Highway Fatalities, 1997-2006

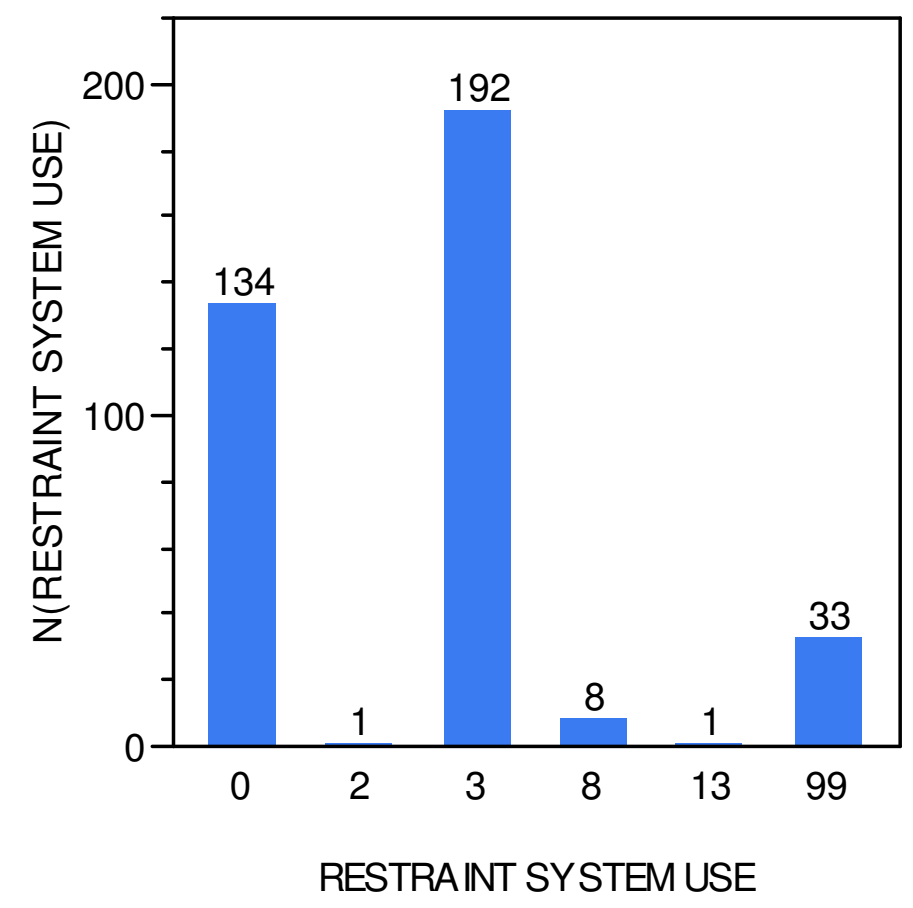

\section{RESTRAINT SYSTEM USE}

$0=$ None used (134)

$2=$ Lap belt (1)

$3=$ Lap \& shoulder belt (192)

$8=$ Restraint used, type unknown (8)

$13=$ Safety belt used improperly (1)

$99=$ Unknown (33)

Another protective system often employed in motor vehicles is air bags. The FARS data indicates several coding parameters for the availability and function of air bags related to the fatality incidents. It is important to note that the air bag availability information was collected on 
the FARS person files. Therefore, these data are specifically applicable to the fatal victims, not the vehicle involved in the accident. For example, a person file was selected for each fatality. Out of the 369 selected FARS case files, 344 fatalities reported the known circumstances of air bag availability or deployment. Out of the 344 fatalities, 174 fatalities, or 51 percent, occurred when the air bag deployed from the front direction. Only 23 fatality records reported that an air bag was not available for the seat of the victim. Figure 4.25 displays the number of fatalities related to airbag availability or function.

Figure 4.25

Occurrence of Fatalities While Driving by Airbag Availability/Function, Law Enforcement Highway Fatalities, 1997-2006

Chart

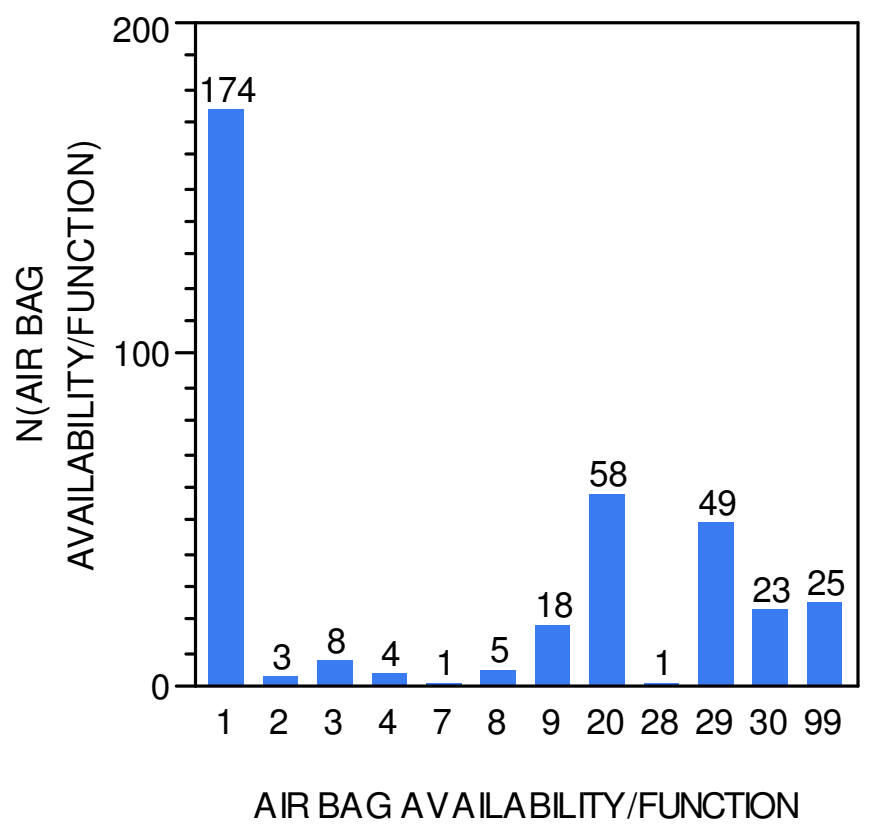

AIRBAG AVAILABILITY/ FUNCTION

$1=$ Deployed air bag from front (174)

$9=$ Deployed air bag direction unknown (18)

$20=$ Air bag available, but not deployed for this seat (58)

29 = Air bag available, deployment unknown (49)

$30=$ Air bag not available for this seat (23)

$99=$ Unknown if airbag is unavailable (25)

In order to successfully complete the odds-ratio analysis in the later stages of this study, it is important to recognize the number of fatalities that occurred on scene versus the number of fatalities that occurred during transport to the hospital or after arriving at the hospital for 
emergency care. Out of the 369 case files selected for the study, three cases could not identify where the occurrence of the fatality happened. Therefore, of the 366 fatalities of known site, 187 , or 51 percent of the fallen officers died at the scene of the incident. 179 fatalities occurred after the victim had been transported to the hospital. Figure 4.26 demonstrates the number of fatalities that occurred at scene of the incident, en route to the hospital or after transported to the hospital.

Figure 4.26

Occurrence of Fatalities While Driving by Dead on Arrival Classification, Law Enforcement Highway Fatalities, 1997-2006

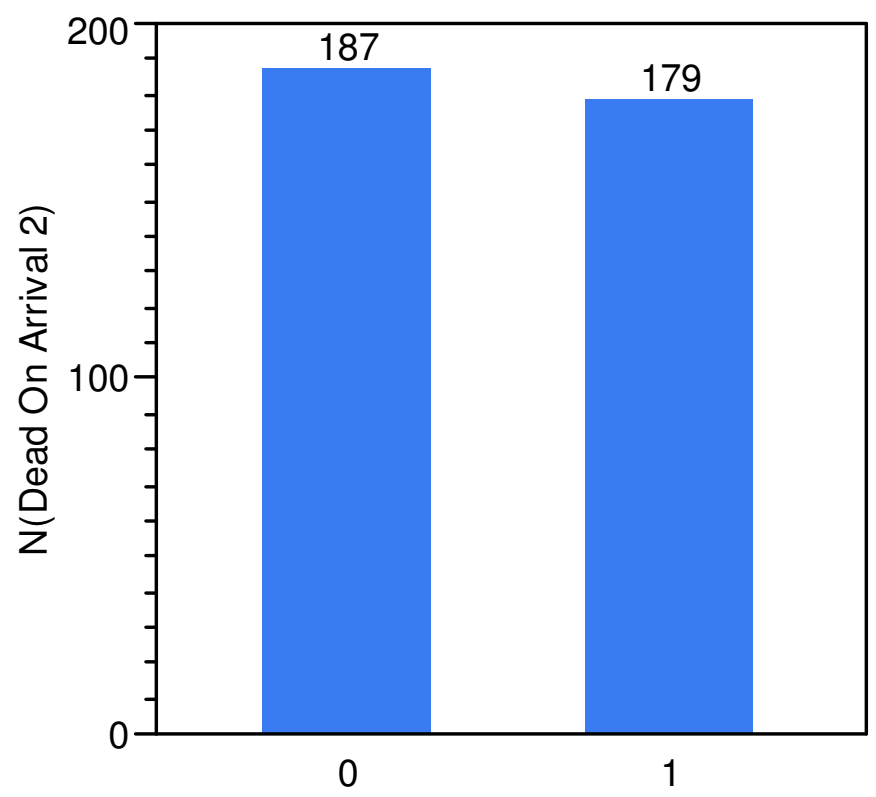

$$
\begin{aligned}
& \text { DEAD ON ARRIVAL } \\
& 0=\text { Transported to Hospital } \\
& 1=\text { Died at the Scene }
\end{aligned}
$$

Dead On Arrival 2

Figure 4.27 and Table 4.4 have been prepared to offer a complete summary of the percent of law enforcement highway fatalities related to various risk factors. These descriptive study results will be compared to the focus group findings discussed in the following section. 
Figure 4.27

Frequency Distribution of Fatalities While Driving by Circumstances, Law Enforcement Highway Fatalities, 1997-2006

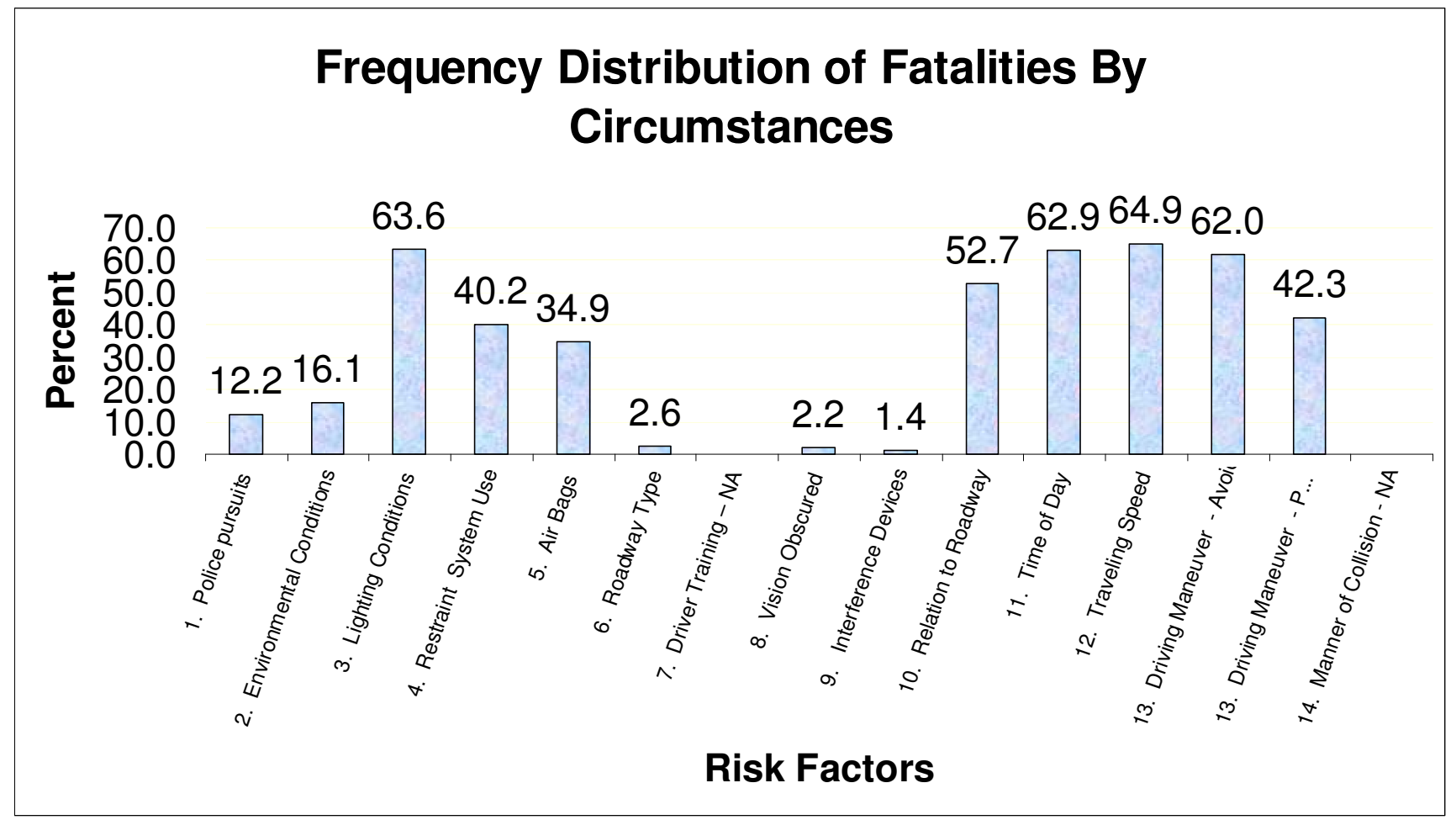

The above data table displays the percentage of fatalities reported to have adverse conditions of the risk factors present at the time of the incident.

The frequency distribution descriptive study identified the top risk factors associated with law enforcement highway fatalities while driving to be:

1. Traveling Speed at time of Crash

2. Lighting Conditions

3. Time of Day

4. Driving Maneuver (Crash Avoidance)

5. Relation to Roadway 
Table 4.4: Summary of Risk Factor Effects on Fatalities While Driving, 1997-2006

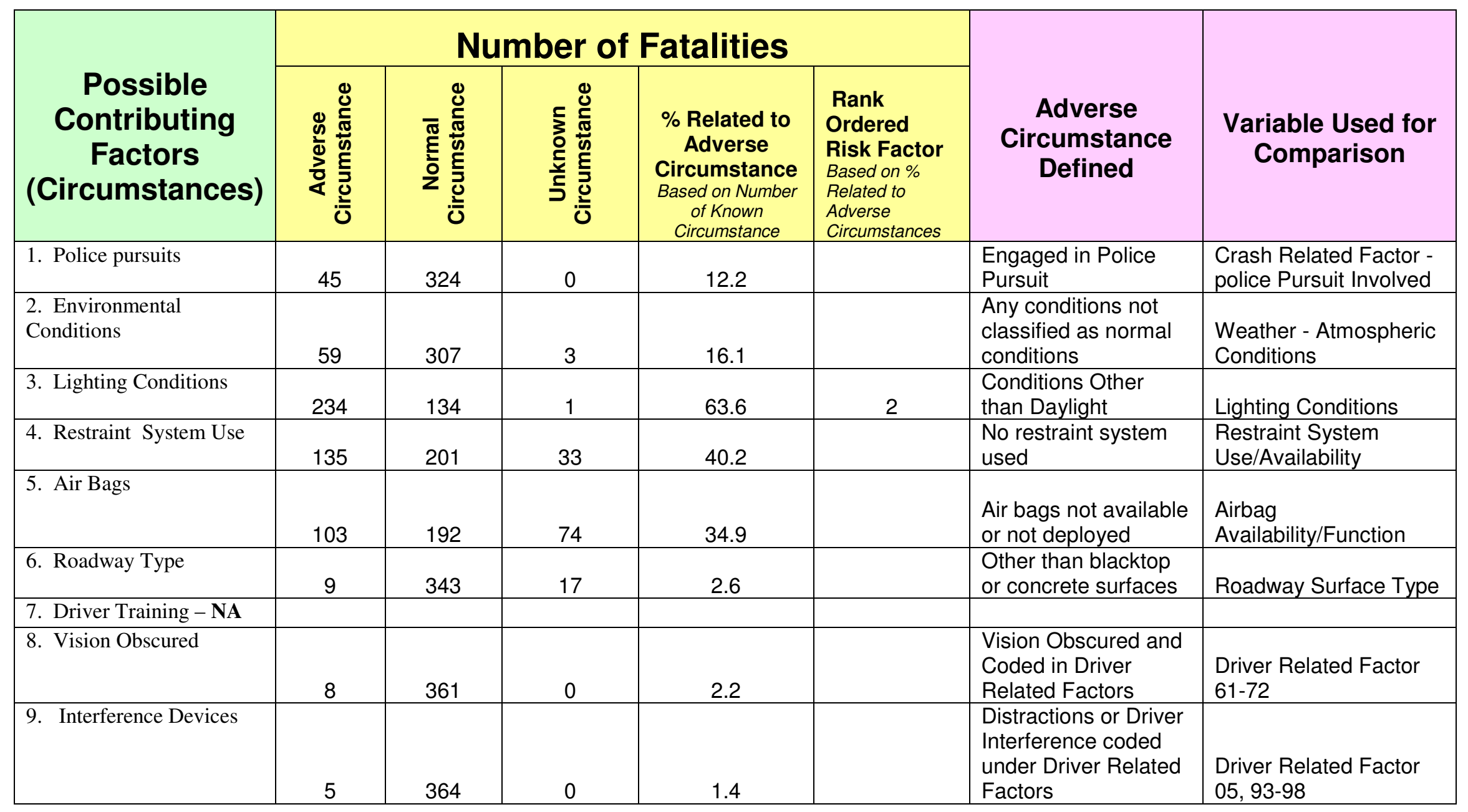


Table 4.4: Summary of Risk Factor Effects on Fatalities While Driving (Cont.)

\begin{tabular}{|c|c|c|c|c|c|c|c|}
\hline \multirow[b]{2}{*}{$\begin{array}{c}\text { Possible } \\
\text { Contributing } \\
\text { Factors } \\
\text { (Circumstance) }\end{array}$} & \multicolumn{5}{|c|}{ Number of Fatalities } & \multirow[b]{2}{*}{$\begin{array}{l}\text { Adverse } \\
\text { Circumstance } \\
\text { Defined }\end{array}$} & \multirow[b]{2}{*}{$\begin{array}{l}\text { Variable Used for } \\
\text { Comparison }\end{array}$} \\
\hline & 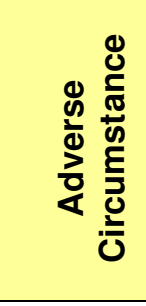 & 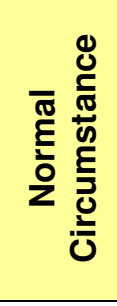 & 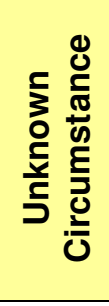 & $\begin{array}{l}\text { \% Related to } \\
\text { Adverse } \\
\text { Circumstance } \\
\text { Based on Number of } \\
\text { Known Circumstance } \\
\end{array}$ & $\begin{array}{l}\text { Prioritized } \\
\text { Risk Factor } \\
\text { Based on \% } \\
\text { Related to } \\
\text { Adverse } \\
\text { Circumstance } \\
\end{array}$ & & \\
\hline 10. Relation to Roadway & 194 & 174 & 1 & 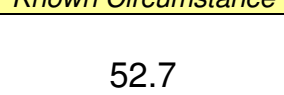 & Uivumintatuc & $\begin{array}{l}\text { Other than On-roadway } \\
\text { conditions }\end{array}$ & Relation to Roadway \\
\hline 11. Time of Day & 232 & 137 & 0 & 62.9 & 3 & 8:00 pm - 8:00 am & Time of Day \\
\hline 12. Traveling Speed & 98 & 56 & 215 & 64.9 & 1 & $\begin{array}{l}\text { Speeds greater than } 60 \\
\mathrm{mph}\end{array}$ & Travel Speed \\
\hline $\begin{array}{l}\text { 13. Driving Maneuver - } \\
\text { Avoidance }\end{array}$ & 147 & 90 & 132 & 62.0 & 4 & $\begin{array}{l}\text { No crash avoidance } \\
\text { maneuver }\end{array}$ & Avoidance Maneuver \\
\hline $\begin{array}{l}\text { 13. Driving Maneuver - } \\
\text { Prior to crash }\end{array}$ & 155 & 211 & 3 & 42.3 & $\begin{array}{l}\text { (referenced } \\
\text { above) }\end{array}$ & $\begin{array}{l}\text { All activities other than } \\
\text { driving straight }\end{array}$ & Vehicle Maneuver \\
\hline $\begin{array}{l}\text { 14. Manner of Collision } \\
\text { - NA }\end{array}$ & \multicolumn{7}{|c|}{ Data Can Not Be Used } \\
\hline
\end{tabular}




\subsubsection{Fatalities While Not Driving, Outside Vehicle}

Circumstances associated with fatalities that occurred while the fallen officer was outside the vehicle were reviewed in the descriptive study. Fatalities outside the vehicle accounted for 118 of the total 500 cases selected for this research. These various circumstances are discussed below.

The occurrence of weekend fatalities was reviewed. For purposes of this study the weekend category includes Friday, Saturday and Sunday. Out of a total 118 law enforcement officer highway fatalities occurring outside the vehicle, only 46 percent or 54 fatalities occurred during the weekend. The occurrence of fatalities ranged between 15 to 17 fatalities throughout the week except for an on Saturdays. According to the data, 23 fatalities occurred on Saturdays to officers outside their vehicles. Figure 4.28 offers a graphical distribution of the number of incidents based upon day of the week.

\section{Figure 4.28}

Occurrence of Fatalities While Not Driving - Outside vehicle, by Day of Week, Law Enforcement Highway Fatalities, 1997-2006

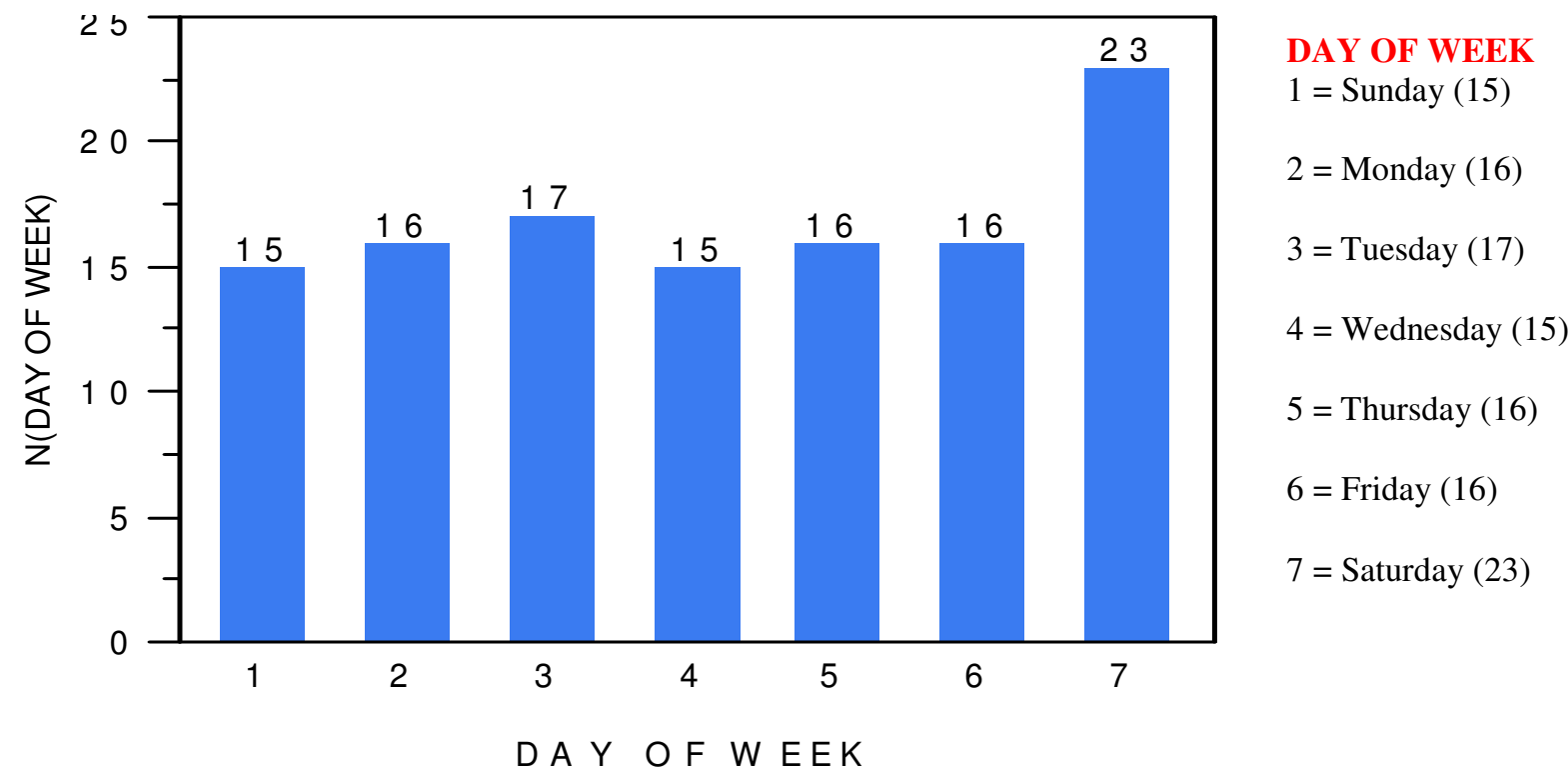


Another important element that is often used to describe the parameters of highway fatalities is the hour of occurrence. The data shows an increase at certain hours of law enforcement officer fatalities when not driving - outside the vehicle. The hours which appear to have the highest frequency for fatalities were midnight, 6:00 am and 6:00 pm. Although many officers work on an array of work schedules, the data was reviewed by on an hourly time frame and combined into three work periods for discussion purposes. The data was combined to be representative of three common work schedules in the law enforcement industry, these time periods include; $4 \mathrm{pm}$ midnight (not inclusive), midnight -8 am (not inclusive) and $8 \mathrm{am}-4 \mathrm{pm}$ (not inclusive). When the data are divided based upon the three time periods referenced above, the greatest percentage, 41 percent of all non-driving outside of vehicle incidents occurred during the $4 \mathrm{pm}-$ midnight time frame. Figures 4.29 and 4.30 offer a graphical display of the information.

Figure 4.29

Occurrence of Fatalities Not Driving - Outside Vehicle by Hour, Law Enforcement Highway Fatalities, 1997-2006

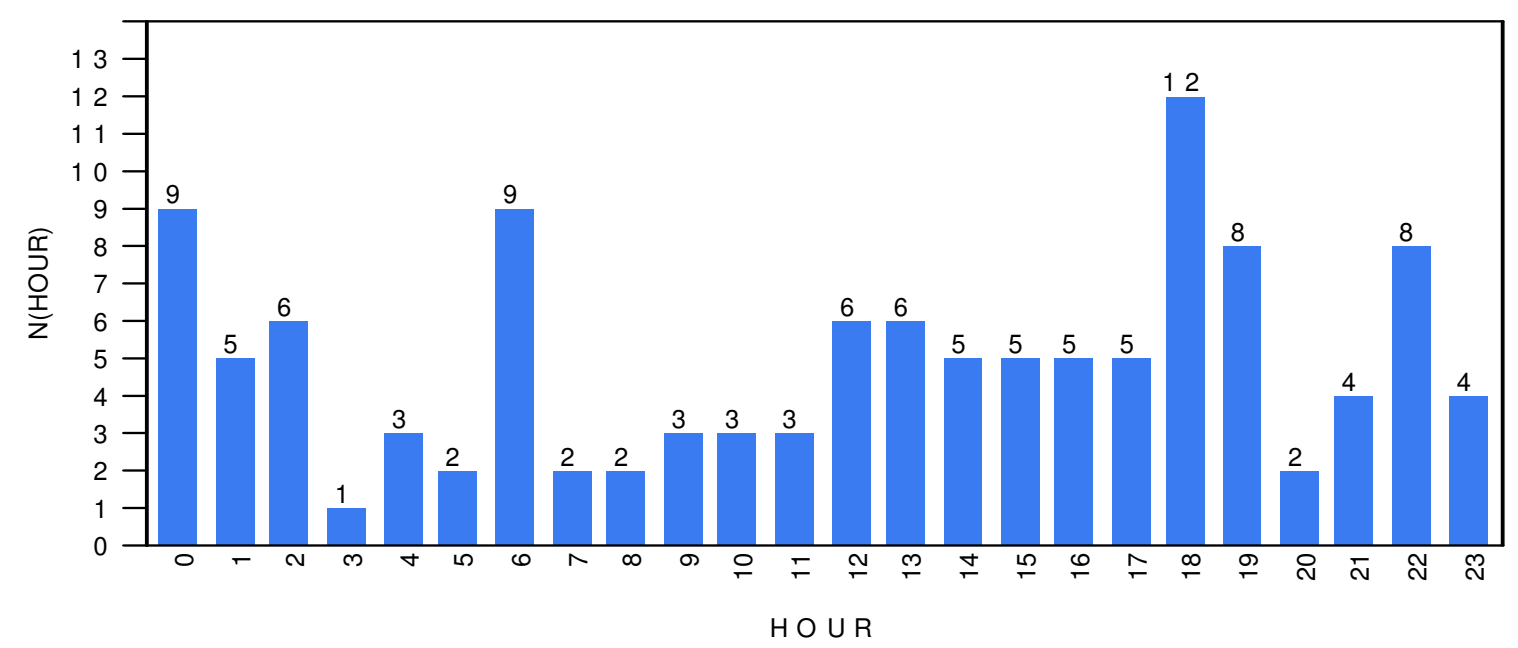


Figure 4.30

Occurrence of Fatalities Not Driving - Outside Vehicle, by Periods, Law Enforcement Highway Fatalities, 1997-2006

\section{Fatalities by Work Periods}

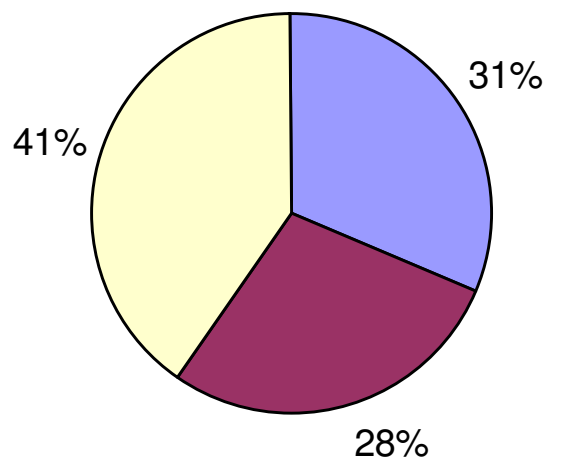

Midnight - 8am

$8 \mathrm{am}-4$ pm

$\square$ 4pm - Midnight

Since the time of day is also correlated with the lighting conditions, a review of reported lighting conditions was also performed to evaluate the association between the conditions and number of reported incidents. According to the FARS data, 49 incidents or 42 percent of the non driving outside vehicle incidents occurred during the daylight. Daylight hours for purposes of FARS coding included the hours of 6:00 am - 6:00 pm when the daylight conditions were not reported on incident records. However, in an effort to transform the reported data to relevant percentages, the results indicate that 59 percent of the fatal incidents did not occur during daylight conditions. Daylight conditions exclude the following elements: Dark, Dark but lighted, Dawn and Dusk. Generally these elements are reported on the incident reporting forms and are coded accordingly. Figure 4.31 demonstrates the division of occurrence among various lighting conditions. 
Figure 4.31

Occurrence of Fatalities Not Driving - Outside Vehicle by Lighting Conditions, Law Enforcement Highway Fatalities, 1997-2006

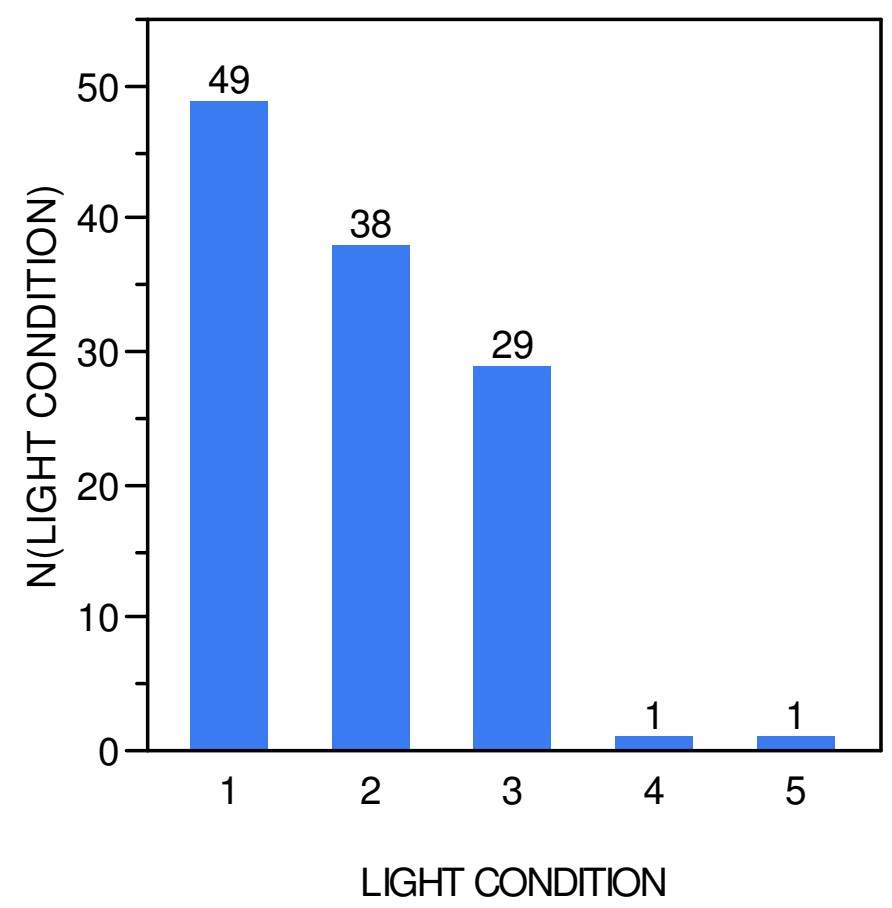

$$
\begin{aligned}
& \text { LIGHTING CONDITIONS } \\
& \text { 1 = Daylight (49) } \\
& 2 \text { = Dark (38) } \\
& 3 \text { = Dark but lighted (29) } \\
& 4 \text { = Dawn (1) } \\
& 5 \text { = Dusk (1) }
\end{aligned}
$$

Environmental conditions are sometimes considered to be a relevant issue related to highway incidents. Therefore, data was reviewed regarding the amount of law enforcement fatalities that occurred in the presence of adverse weather conditions. Adverse weather conditions were present for 15.3 percent $(n=18)$ of the incidents selected for the study. Non-adverse weather conditions were associated with 84 percent of the fatalities $(n=99)$. The most frequently occurring adverse weather condition was reported to be rain conditions which were present in 12 of the cases or 10 percent of the cases included in the study. The distribution of cases based on weather conditions is displayed in Figure 4.32: Occurrence of Fatalities by Atmospheric Conditions, Law Enforcement Highway Fatalities, 1997-2006. 
Figure 4.32

Occurrence of Fatalities Not Driving-Outside Vehicle by Atmospheric Conditions, Law Enforcement Highwav Fatalities. 1997-2006

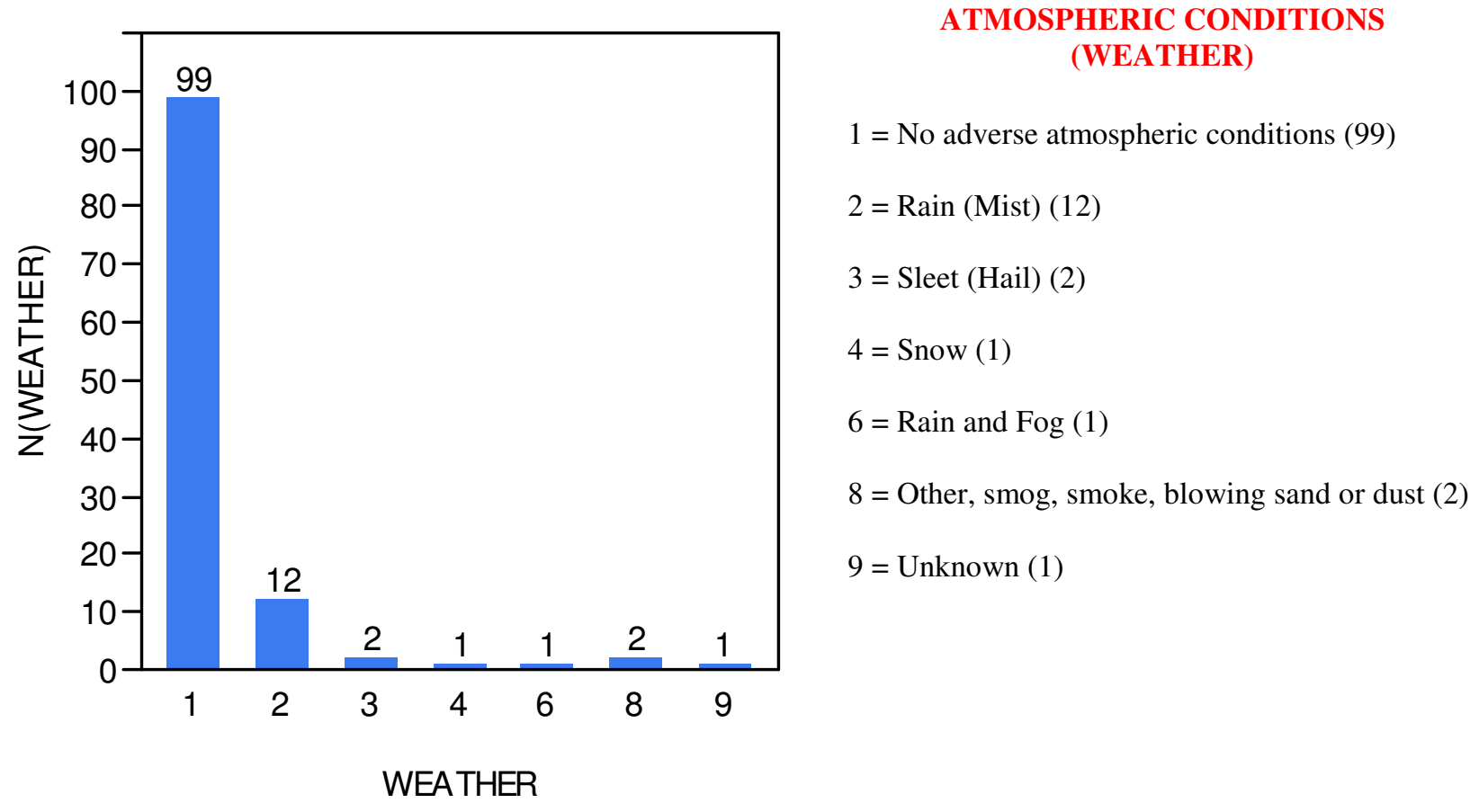

Surface conditions may also be indirectly related to the atmospheric conditions. Thus, a review of such conditions was performed to see if there was a relationship to previous weather conditions before the occurrence of the event. According to the data, dry surface conditions were present in 92 of the fatalities that occurred while not driving, outside the vehicle. This accounted for 78 percent of the incidents in which the surface conditions were known. 21 percent of the cases $(n=25)$ reported surface conditions other than dry conditions. This included the following conditions: Wet, Snow or Slush, or Ice. A graphical display of the data is provided in Figure 4.33: Occurrence of Fatalities by Surface Condition. 
Figure 4.33

Occurrence of Fatalities Not Driving-Outside Vehicle by Surface Conditions, Law Enforcement Highway Fatalities, 1997-2006

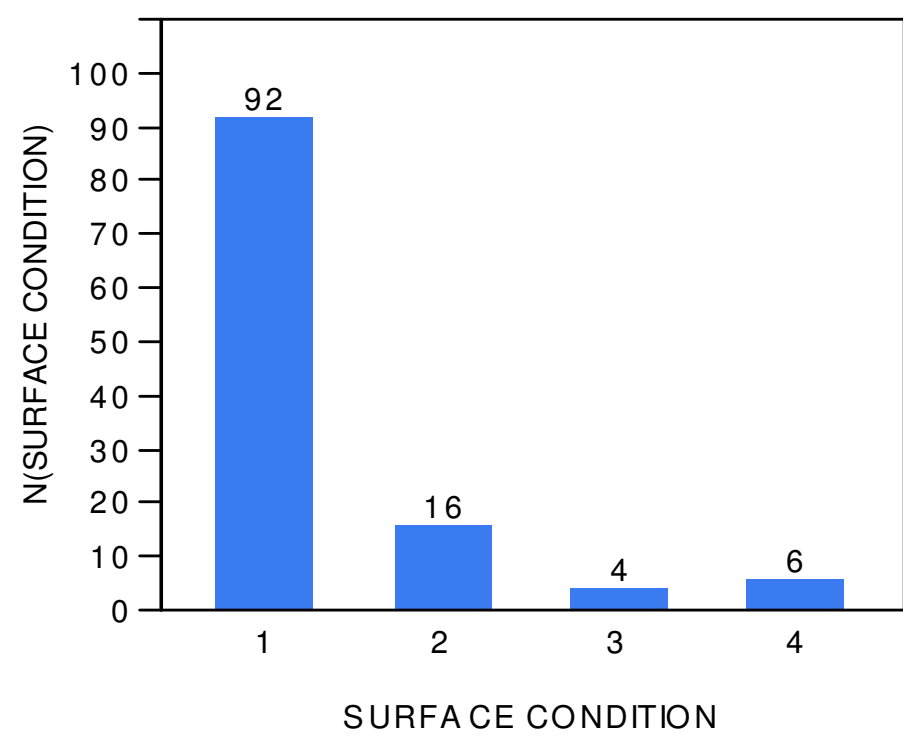

$$
\begin{aligned}
& \text { SURFACE CONDITION } \\
& 1 \text { = Dry (92) } \\
& 2=\text { Wet }(16) \\
& 3=\text { Snow or slush }(3) \\
& 4=\text { Ice }(6)
\end{aligned}
$$

Another risk factor that is related to the roadway surface is the type of surface. The FARS database offers coding for the following surface types: dirt, slag, gravel or stone, brick or block, blacktop or concrete. Based upon the data selected to represent fatalities occurring while not driving, outside the vehicle, 113 case files reported a known surface type. The data indicated that 92 of the 113 case files with known surface type were blacktop. Thus, blacktop represents the roadway surface type for 81 percent of the known conditions. An additional 21 files or 19 percent of the known surface type case files indicated a roadway surface type coded as a concrete surface. No other surface types were reported for this category of fatalities. Figure 4.34 offers a graphical display of the number of cases related to roadway surface type. 


\title{
Figure 4.34
}

Occurrence of Fatalities Not Driving-Outside Vehicle by Roadway Surface Type, Law Enforcement Highway Fatalities, 1997-2006

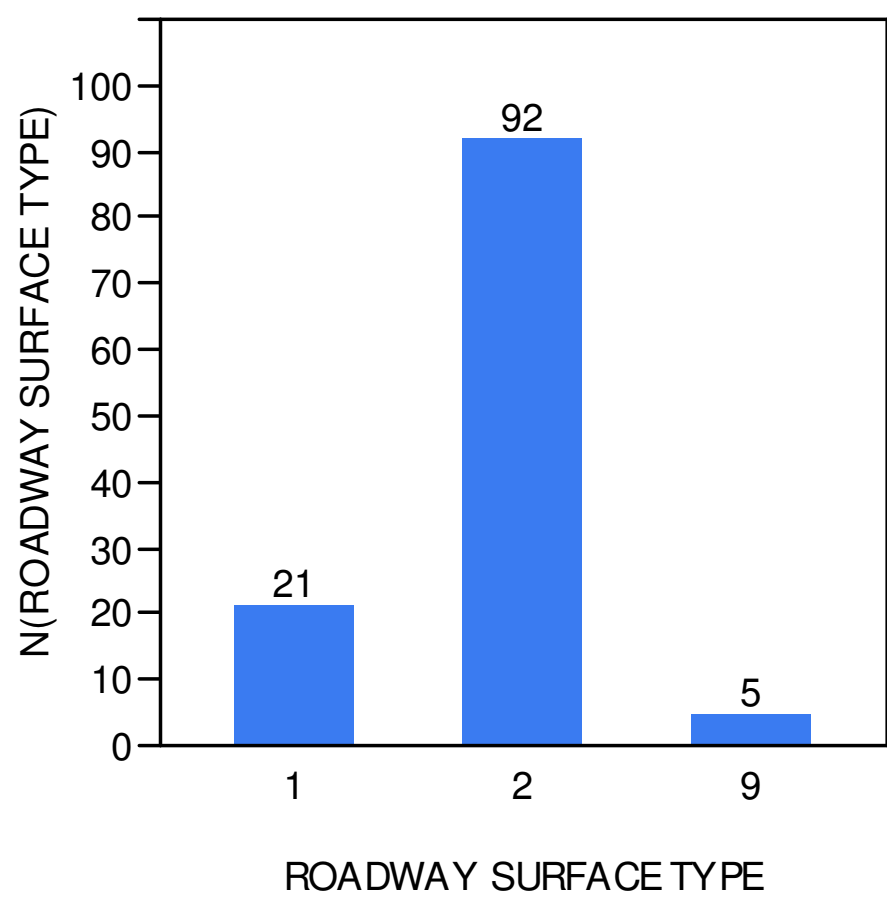

\author{
ROADWAY SURFACE TYPE \\ $1=$ Concrete $(21)$ \\ $2=$ Blacktop $(92)$ \\ $9=$ Unknown $(5)$
}

Note: No other surface types were present with this incident category.

As the review of roadways was performed, this author also considered where the occurrence of the fatality resulted in relationship to the roadway. The FARS database offered coding of variables for the following relations to the roadway: on roadway, shoulder, median, roadside, outside, right of way, off roadway, in parking lane, gore, separator, or two-way continuous leftturn lane. The data selected for fatalities outside the vehicle indicated that 54 percent or 64 fatalities occurred on the roadway. The FARS analytic reference guide defines a roadway as "that part of a trafficway designed, improved and ordinarily used for motor vehicle travel or, where various classes of motor vehicles are segregated, that part of a trafficway used by a particular class. Separate roadways may be provided for traffic going in opposite directions, for 
example northbound and southbound traffic or for trucks and automobiles. The roadway and any shoulder alongside the roadway together make up the roads."(2006)

Eight (8) fatalities or 7 percent of the fatalities occurred on the roadside. According to FARS, roadside refers to a location off the roadway, but inside the right of way. It is the outermost part of the trafficway which lay between the outer property line or other barrier and the edge of the first road encountered in the traffic way. The roadside should not be confused with the shoulder. FARS defines the shoulder as that part of a trafficway contiguous with the roadway for emergency use, for accommodation of stopped vehicles and for lateral support of the roadway structure. A shoulder is a design feature of a road and may or may not be paved. An additional 34 fatalities or 29 percent were reported to have occurred on the shoulder of the roadway. When combining the fatalities that occurred on the shoulder and the roadside, 42 total fatalities occurred relative to these locations. Roadside and shoulder incidents accounted for a combined 35.6 percent of the fatalities. Figure 4.35 on the following page provides a detailed extraction of the data based on the relation to the roadway. 
Figure 4.35

Occurrence of Fatalities Not Driving Outside Vehicle by Relation to Roadway, Law Enforcement Highway Fatalities, 1997-2006

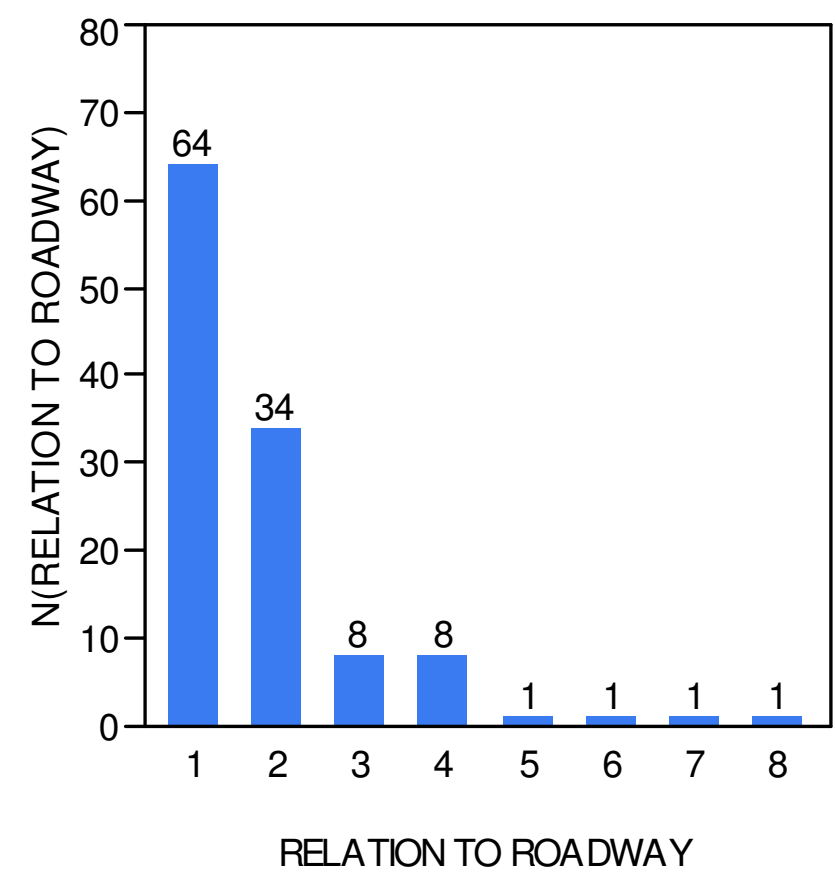

$$
\begin{aligned}
& \text { RELATION TO ROADWAY } \\
& \begin{aligned}
& 1= \text { On Roadway (64) } \\
& 2= \text { Shoulder (part of a traffic way for } \\
& \text { emergency use) (34) }
\end{aligned} \\
& 3=\text { Median (8) } \\
& \begin{aligned}
& 4= \text { Roadside (off of roadway, but inside right } \\
& \text { of way) (8) }
\end{aligned} \\
& \begin{aligned}
& 5= \text { Outside of Traffic way or Right of way (1) } \\
& 6= \text { Off roadway, relationship to right of way is } \\
& \text { unknown (1) }
\end{aligned} \\
& 7=\text { In Parking Lane (1) } \\
& 8=\text { Gore (1) }
\end{aligned}
$$

Some literature reviewed for the study suggested that highway incident occurrences may also be a result of roadway junction or disregardance to such junctions. The FARS data offered coding variables for the following elements in relationship to roadway junctions: Non-Interchange Areas including: non-junction, intersection, intersection-related, driveway, alley access, entrance/exit ramp-related, rail grade crossing, in crossover, driveway-access-related, unknown non-interchange. Interchange Areas including: intersection, intersection - related, driveway access, entrance/exit ramp - related, in crossover, other location in interchange, and unknown interchange area.

Of the 117 case files selected with a known relation to junction, 102 incidents or 86 percent of incidents occurred in a non-interchange, non-junction area. As a counter to that data, eight incidents occurred in areas that where classified as other than a non-junction area as listed above. 
Thus, 7 percent of the incidents occurred in these junction related areas. Figure 4.36 offers a summary of the number of cases based on the relation to junction.

Figure 4.36

Occurrence of Fatalities Not Driving Outside the Vehicle by Relation to Junction, Law Enforcement Highway Fatalities, 1997-2006

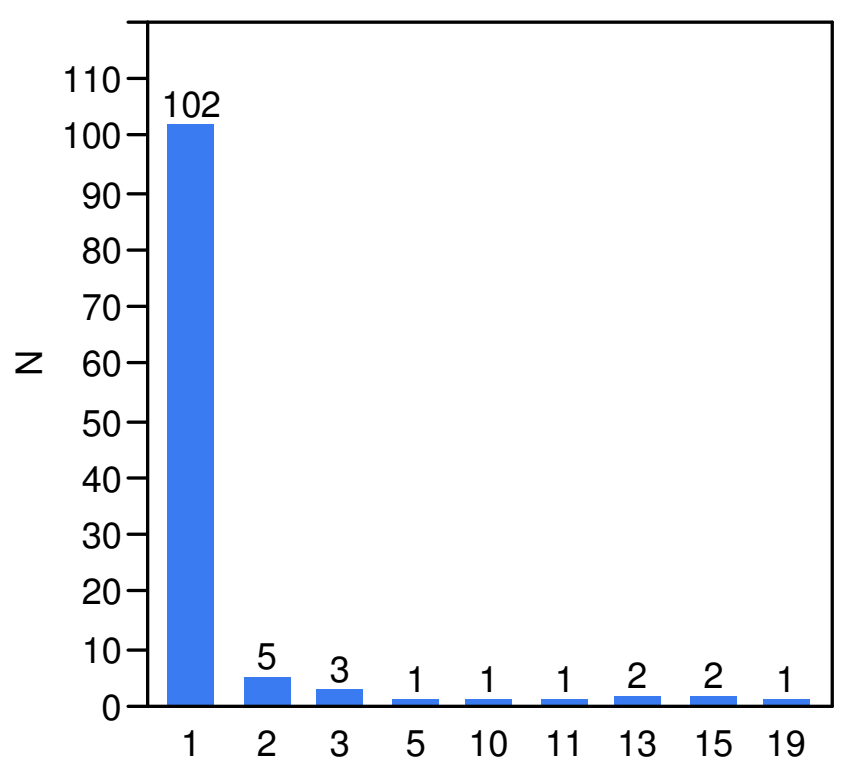

\author{
RELATION TO JUNCTION \\ Non-Interchange Areas: \\ 1 = Non-Junction (102) \\ $2=$ Intersection (5) \\ $3=$ Intersection Related (3) \\ Interchange Areas: (Roadways of different \\ $\underline{\text { levels) }}$ \\ $13=$ Entrance/Exit Ramp - Related (2) \\ $15=$ Other location in interchange (2) \\ $19=$ Unknown $(1)$
}

RELATION TO JUNCTION 
Roadway alignment has been identified as contributing factor to many highway incidents.

However, roadway alignment has a direct relationship to the topography of the region. Out of the 117 incidents identified with a known roadway alignment, 103 of the law enforcement fatalities or 88 percent occurred on straight roadways. 12 percent of the fatal incidents occurred on curved roadways. Although this percentage may not appear to be very significant, regional topography may also be related. For example, drivers that operate in areas with primarily straight roads may not be able to compensate for the curves as well as a driver that routinely operates in an area with more curves. Figure 4.37 shows a pie chart that displays the number of fatalities based upon roadway alignment.

Figure 4.37

Occurrence of Fatalities Not Driving Outside the Vehicle by Roadway Alignment, Law Enforcement Highway Fatalities, 1997-2006

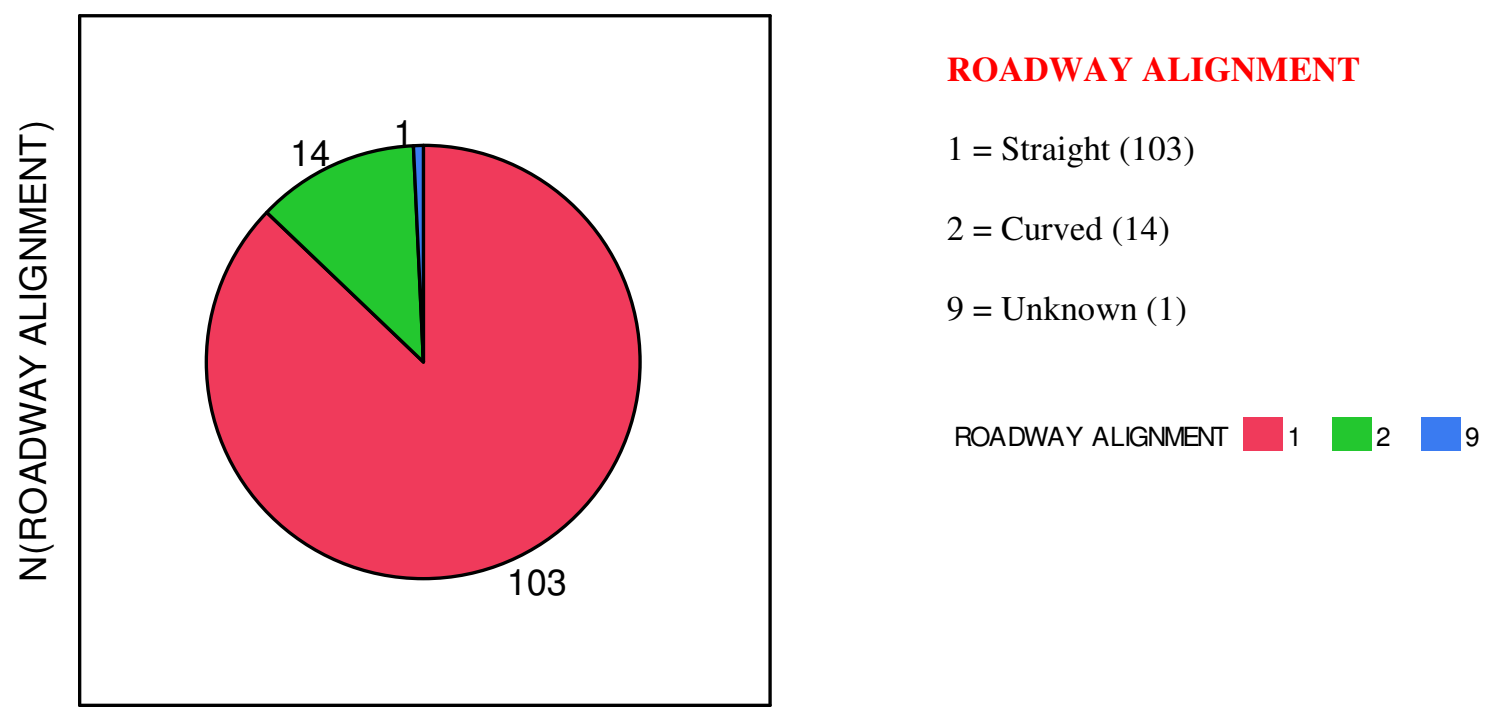

ROADWAY ALIGNMENT

When discussing the effects of the roadway, the profile of the roadway was reviewed to determine if the descriptive parameters indicated a possible relative factor for law enforcement 
highway fatalities. Roadway profiles were defined to include the following categories: Level, grade, hill crest or unknown. Of the 118 case files selected for the non driving out of vehicle category, 109 cases were coded to have a known roadway profile. Out of the 109 cases, 87 fatalities or 80 percent occurred on level roadway surfaces. An additional 26 fatalities or 24 percent occurred on a grade surface or a hill crest. The number of fatalities that were reported to be on grade level was 21 officers. This represents 20 percent of all fatalities with a known roadway profile. Figure 4.38 displays the number of fatalities that occurred relative to the roadway profile.

Figure 4.38

Occurrence of Fatalities Not Driving Outside Vehicle by Roadway Profile, Law Enforcement Highway Fatalities, 1997-2006

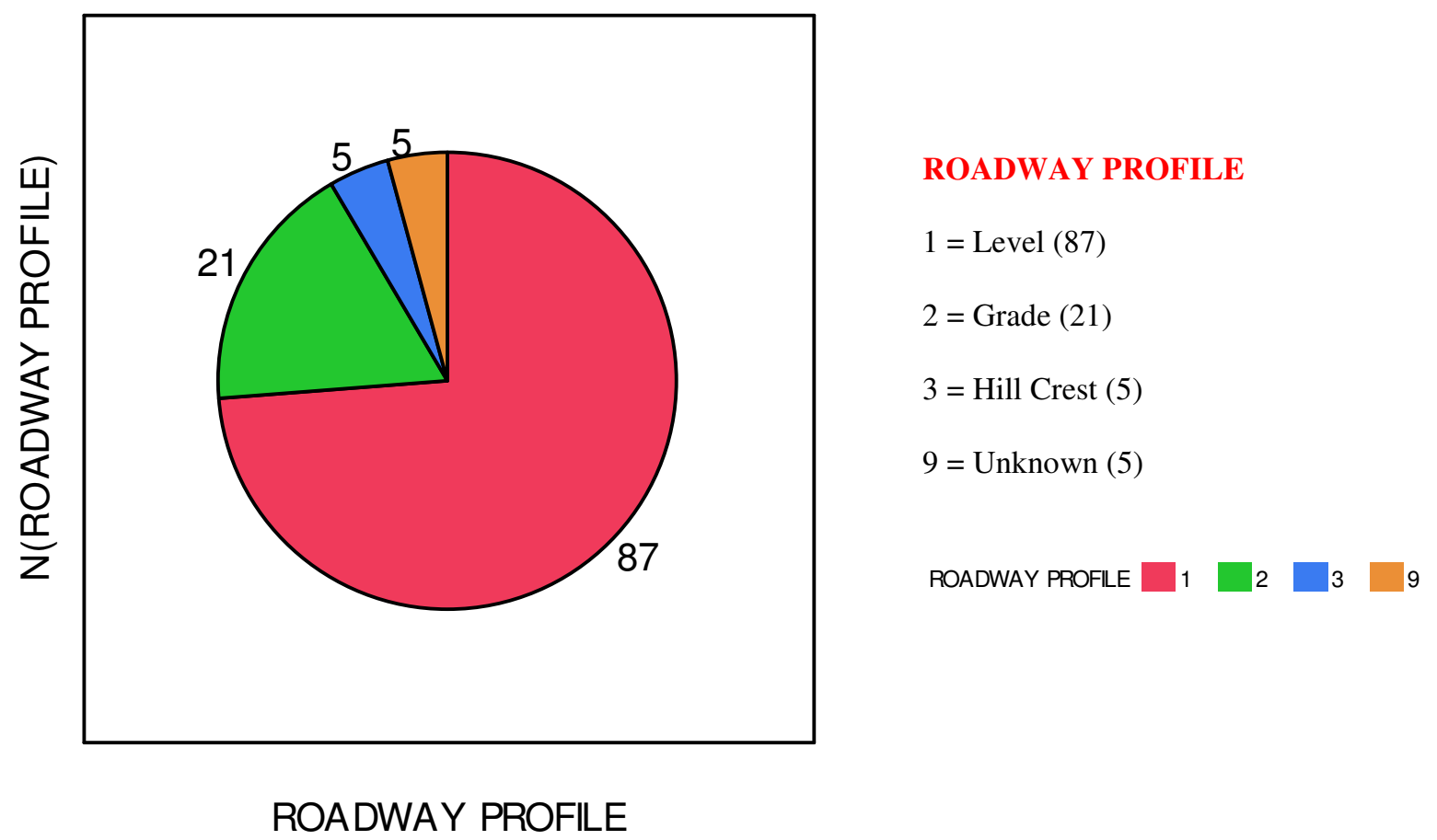

After reviewing the numerous variables related to roadway surfaces, conditions, junctions, profiles, alignment, etc., other factors shall be considered. One element that has been reflected in 
the literature was the maneuver performed by the law enforcement officer in an effort to avoid the crash. The FARS Analytic Reference Manual (2006) defined the Crash Avoidance Maneuver as the maneuver that the driver executed to attempt to avoid the crash. According to the data, the records offered to the FARS coding specialists did not routinely provide the information necessary to accurately identify such maneuvers. Of the 118 case files representing incidents with officers outside the vehicle, 44 of the cases did not report the type of crash avoidance maneuver performed by the striking vehicle or were considered to be unknown. This non-reporting shall be clarified and not interpreted as "No avoidance maneuver reported". The "No avoidance maneuver reported" category reflects incidents in which it was reported that the driver of the striking vehicle did not perform any maneuvers in an effort to avoid the crash. Thus, only 74 cases could correctly identify the maneuvers. This result creates a limitation of the data in relationship to the impact of crash avoidance maneuvers. Out of the 74 crashes with a reported avoidance maneuver, "no maneuver performed" accounted for 49 of the fatalities or 66 percent of the incidents. The most frequently contributing crash avoidance maneuver involved steering. According to data, 17 incidents or 23 percent of known maneuvers involved a "steering" or "steering and braking" action to avoid the crash. Figure 4.39 on the following page demonstrates the number of incidents related to various crash avoidance maneuvers. 
Figure 4.39

Occurrence of Fatalities Not Driving Outside Vehicle by Crash Avoidance Maneuver, Law Enforcement Highway Fatalities, 1997-2006

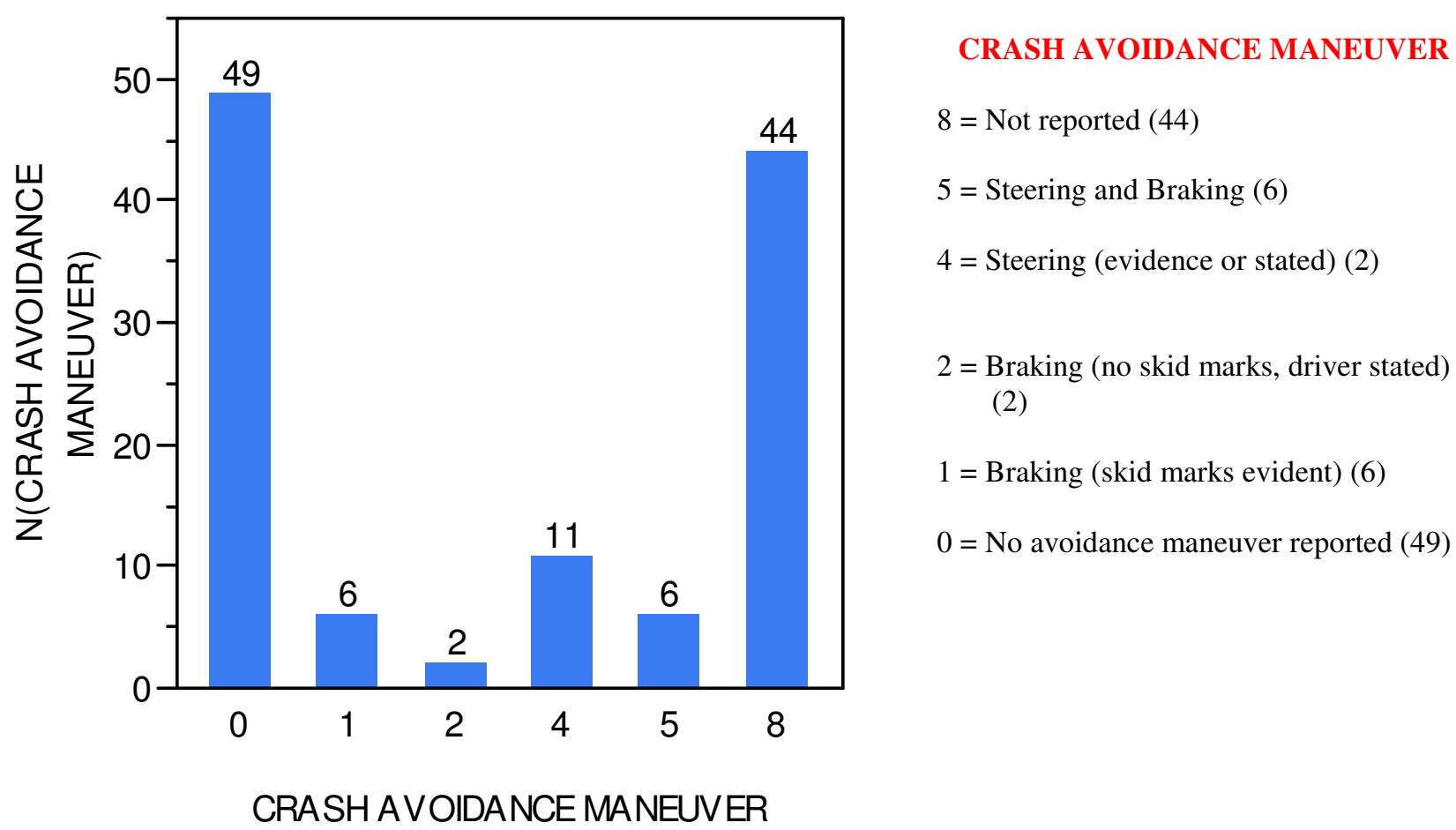

"Crash avoidance maneuver" is not synonymous with "vehicle maneuver". The FARS analytic reference guide defines the vehicle maneuver as the maneuver that the driver was executing just prior to entering a crash situation. The FARS coding system allowed for the distinction of 19 different maneuvers. The most frequently occurring maneuvers included the following elements: going straight, stopped in traffic lane, passing or overtaking another vehicle, maneuvering to avoid, making a U-turn, changing lanes or merging, negotiating a curve, or unknown.

According to the data all 118 cases representing fatalities while outside the vehicle had a known vehicle maneuver. In the majority of the incidents, the driver was going straight. This maneuver 
accounted for 93 fatalities or 79 percent of the fatalities with a known maneuver. Figure 4.40 offers a full graphical analysis of the reported vehicle maneuvers and the number of incidents occurring while performing such maneuvers.

The coding criteria for the data regarding manner of collision changed during the period in which the data represent. Therefore, this data could not be used for further analysis.

Figure 4.40

Occurrence of Fatalities Not Driving Outside Vehicle by Vehicle Maneuver, Law Enforcement Highway Fatalities, 1997-2006

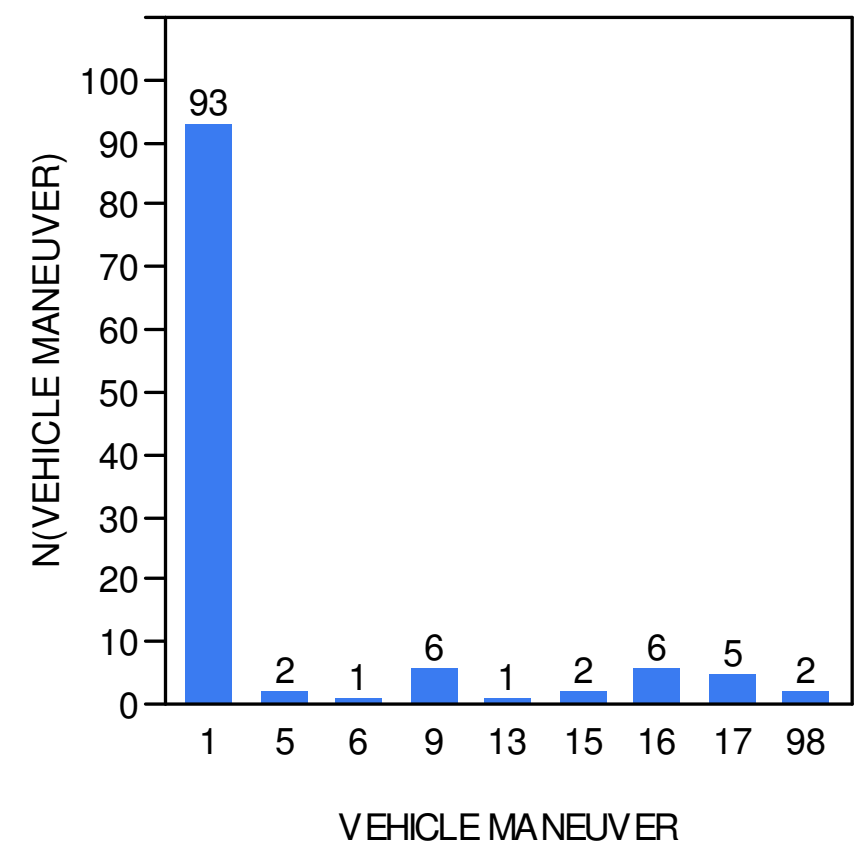

\author{
VEHICLE MANEUVER PRIOR TO \\ CRASH \\ $1=$ Going Straight (93) \\ $5=$ Passing or overtaking another vehicle (2) \\ $6=$ Leaving a parked position (1) \\ $9=$ Maneuvering to avoid (6) \\ $13=$ Turning left $(1)$ \\ 15 = Backing Up (2) \\ $16=$ Changing Lanes or Merging $(6)$ \\ 17 = Negotiating a curve (5) \\ $98=$ Other $(2)$
}

Driving speed may also be related to the crash avoidance maneuver and the vehicle maneuver. The coding element for speed was a continuous variable with a maximum reporting limit of 97 
miles per hour. The coding 97 represented all speeds of 97 miles per hour or greater. Thus, the maximum reported speed was 97 miles per hour and the minimum speed was 0 miles per hour or a stopped vehicle. Of the 118 cases selected to represent the fatalities when the officer was outside the vehicle, only 52 cases reported a known speed of the striking vehicle. According to the reported travel speed at the time of the incident, the mean travel speed was 54.75 miles per hour with a standard deviation of 17.97 miles per hour. Figure 4.41 provides a graphical explanation of the distribution of travel speed at the time of the incident. Table 4.3 offers a basic statistical outline of the distribution of travel speed.

Figure 4.41

Occurrence of Fatalities Not Driving Outside Vehicle by Travel Speed, Law Enforcement Highway Fatalities, 1997-2006

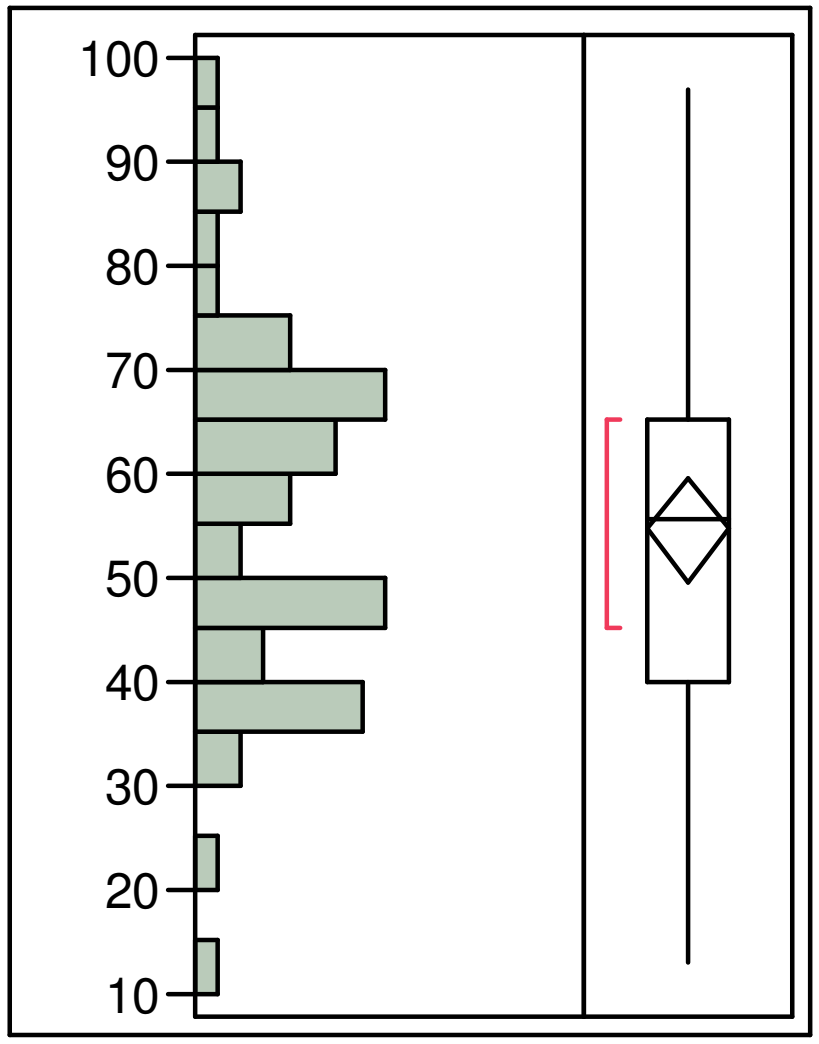

Table 4.5

Distribution of Fatalities While Not

Driving, Outside Vehicle, Travel

Speed, Law Enforcement Highway

Fatalities, 1997-2006

$\begin{array}{llr}100.0 \% & \text { maximum } & 97.000 \\ 99.5 \% & & 97.000 \\ 97.5 \% & & 94.725 \\ 90.0 \% & & 80.100 \\ 75.0 \% & \text { quartile } & 65.000 \\ 50.0 \% & \text { median } & 55.500 \\ 25.0 \% & \text { quartile } & 40.000 \\ 10.0 \% & & 35.000 \\ 2.5 \% & 15.275 \\ 0.5 \% & & 13.000 \\ 0.0 \% & 13.000 \\ & \text { minimum } & \\ \text { Mean } & & 54.75 \\ \text { Std Dev } & 17.97261 \\ \text { Std Err Mean } & 2.4923526 \\ \text { upper 95\% Mean } & 59.753607 \\ \text { lower 95\% Mean } & 49.746393 \\ \text { N } & 52\end{array}$

Note: all cases labeled unknown or unreported were deleted from the data so that the mean would not be inadvertently increased when calculated. (variable speed $98=$ Not reported, $99=$ unknown) 
Related factors are divided into four primary categories. These categories include driver related factors, person related factors, vehicle related factors and crash related factors. These categories were each assigned a variety of variables for coding purposes. The related factors were categorized based upon the type of FARS file used for reporting. As recalled from previous discussion, FARS data are recorded in three separate files; person, vehicle and accident file. Each of the related factor categories will be reviewed on the following pages.

Driver related factors are coded into a number of categories including: physical and mental condition; miscellaneous factors; vision obscured by; avoiding, swerving or sliding; possible distractions (inside vehicle).

It is important to note that driver related factors are reflective of the driver of the vehicle involved in the crash. It does not always reflect the fallen officer because the officer may have been a passenger in the vehicle or the officer may have been the victim of a struck by incident.

There are a total of 98 codes that can be utilized in the driver related factor category. The vehicle file permits the coding of up to 4 variables that can be recognized per case file. All of these variables are coded based upon the interpretation of the state FARS coding specialists from the records reviewed for inclusion in the database. If the records reviewed do not specify conditions present, the coding specialist may not be able to identify all related variables. This creates a limitation that all researchers must address when utilizing data collected from various sources. 
Out of a total 118 case files selected, the most frequently occurring driver related factor for the striking vehicle was "reported to be driving too fast for conditions or in excess of posted speed limit". These conditions reported to be present in 38 cases or 32.2 percent of the incidents involving fatalities when outside the vehicle. The second most frequently reported related factor was failure to keep in proper lane or running off the road which accounted for 36 (25 plus 11) cases or 30.5 percent of the incidents.

Additional driver related factors that were reported frequently include: inattentive or careless; operating the vehicle in an erratic, reckless, careless, or negligent manner or suddenly changing speeds, or; ice, water, snow, sand, slush, dirt, oil or wet leaves on road. Figure 4.42 on the following page offers a summary of the driver related factors and the frequency of reporting of the factors. 
Figure 4.42

Occurrence of Fatalities Not Driving Outside Vehicle by Driver Related Factor, Law Enforcement Highway Fatalities, 1997-2006

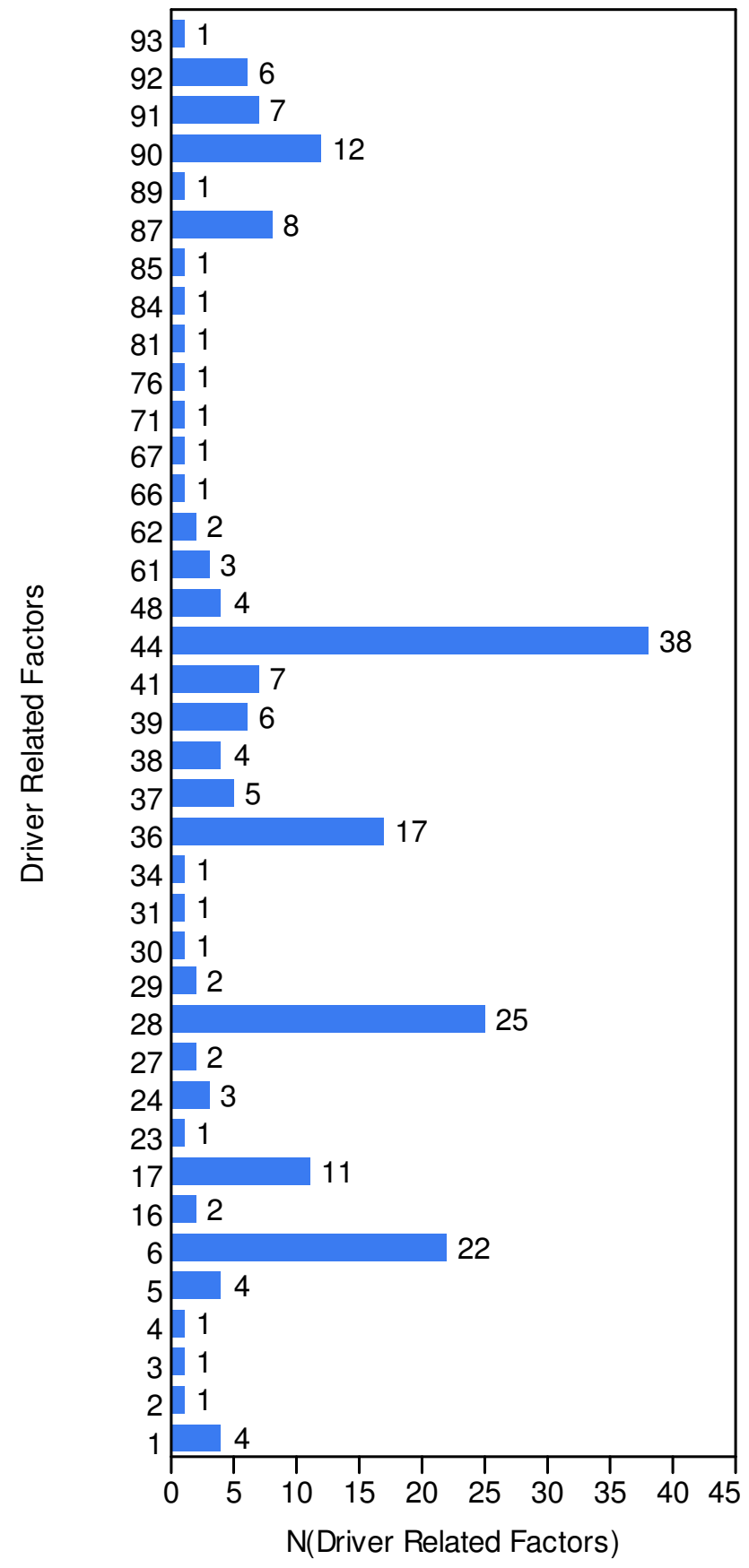

\section{DRIVER RELATED FACTORS FOR STRIKING VEHICLE}

$90=$ Hit $\&$ run vehicle driver (12)

87 = Ice, Water, snow, slush, Sand, Dirt, Oil, Wet Leaves on Road (8)

$44=$ Driving too fast for Conditions or in excess of posted speed limit (38)

$36=$ Operating the vehicle in an erratic, reckless, careless, or negligent manner or suddenly changing speeds (17)

$28=$ Failure to keep in proper lane or running off road (25)

$17=$ Running off road (2000-2003 only) (11)

$6=$ Inattentive or careless (22) 
The person related factors are collected from the FARS Person file. This file represents the fatal victim involved in the incident. The FARS database allows for the coding of up to 3 different variables per case. The coding offers a selection of 90 different variables to choose from. It is important to note that the case files selected for inclusion in this portion of the study were based upon the LEOKA database of law enforcement officers accidentally killed in struck by incidents. The person related factors only reported 29 of the 118 cases as a police or law enforcement officer. This data further support the reasoning behind selecting individual case files based on LEOKA data. The strength of these related factors appears to be a weak element and is not recommended for use in the final stage of the logistic regression analysis. Of the 118 cases representing fatalities while not driving and outside the vehicle, the other frequently reported driver related factor was "following improperly" in 26 cases or 22 percent of the cases. Figure 4.43 displays a summary of the data analyzed for identification of person related factors.

Figure 4.43

Occurrence of Fatalities Not Driving Outside the Vehicle by Person Related Factor, Law Enforcement Highway Fatalities, 1997-2006
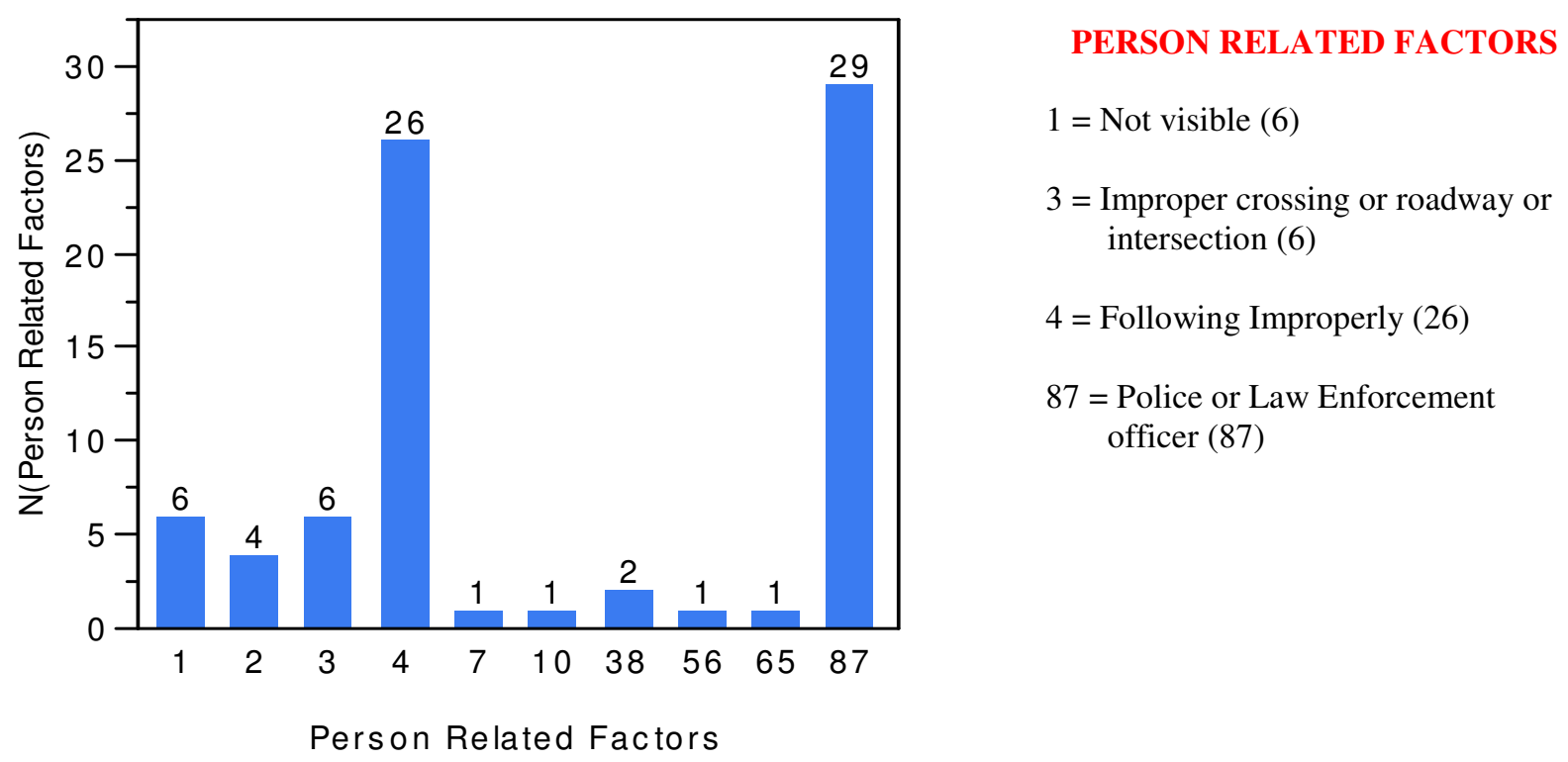
The vehicle related factors are collected using the FARS Vehicle files. The vehicle related factors are directly related to the physical elements of the vehicle which may have adversely affected the outcome of the event. This variable had a possible 43 different elements that may have been coded in this portion of the vehicle file. The coding specialist may select up to two elements to be identified as vehicle related factors. The most frequently reported vehicle related factor was "hit and run vehicles" which accounted for 13 cases or 11 percent of the variables reported. Due to the minimal number of vehicle related factors reported in the vehicle case files, this set of data appears to be limited in reporting and shall not be used for further analysis in this study. Figure 4.44 offers a graphic representation of the variables reported under the vehicle related factors.

\section{Figure 4.44}

Occurrence of Fatalities Not Driving Outside Vehicle by Vehicle Related Factor, Law Enforcement Highway Fatalities, 1997-2006

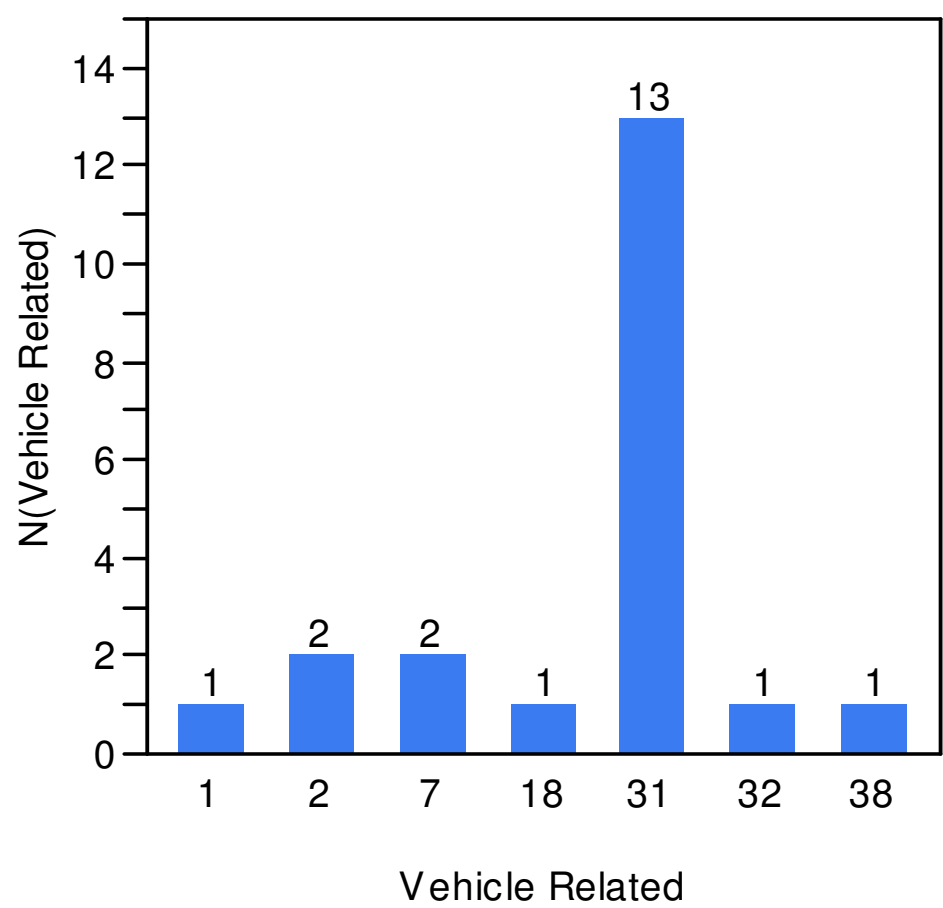

VEHICLE RELATED FACTORS OF STRIKING VEHICLE

$7=$ Headlights $(2)$

$2=$ Brake System (2)

$31=$ Hit $\&$ Run vehicle (13) 
Crash related factors are collected using the FARS Accident Files. These accident files allow for the reporting of up to three variables to be coded in the case file. The coding specialist has up to 51 different variables to select from when coding the data. Some of these elements include miscellaneous factors, vision obscured by factors, swerving due to factors, and roadway features. The most commonly coded element for the struck by incidents was the identification of a recent previous crash scene nearby. These cases accounted for 15 cases or 13 percent of the 118 case files representing fatalities while not driving - outside the vehicle. Out of the 118 selected files, eight of the cases, or 7 percent, reported a police pursuit involved. Since these crash related factors account for such a minimal number of incidents, this data will not be used in further analysis of the causal factors. Figure 4.45 displays the identified crash related factors by number of occurrences.

\section{Figure 4.45}

Occurrence of Fatalities Not Driving Outside Vehicle by Crash Related Factor, Law Enforcement Highway Fatalities, 1997-2006
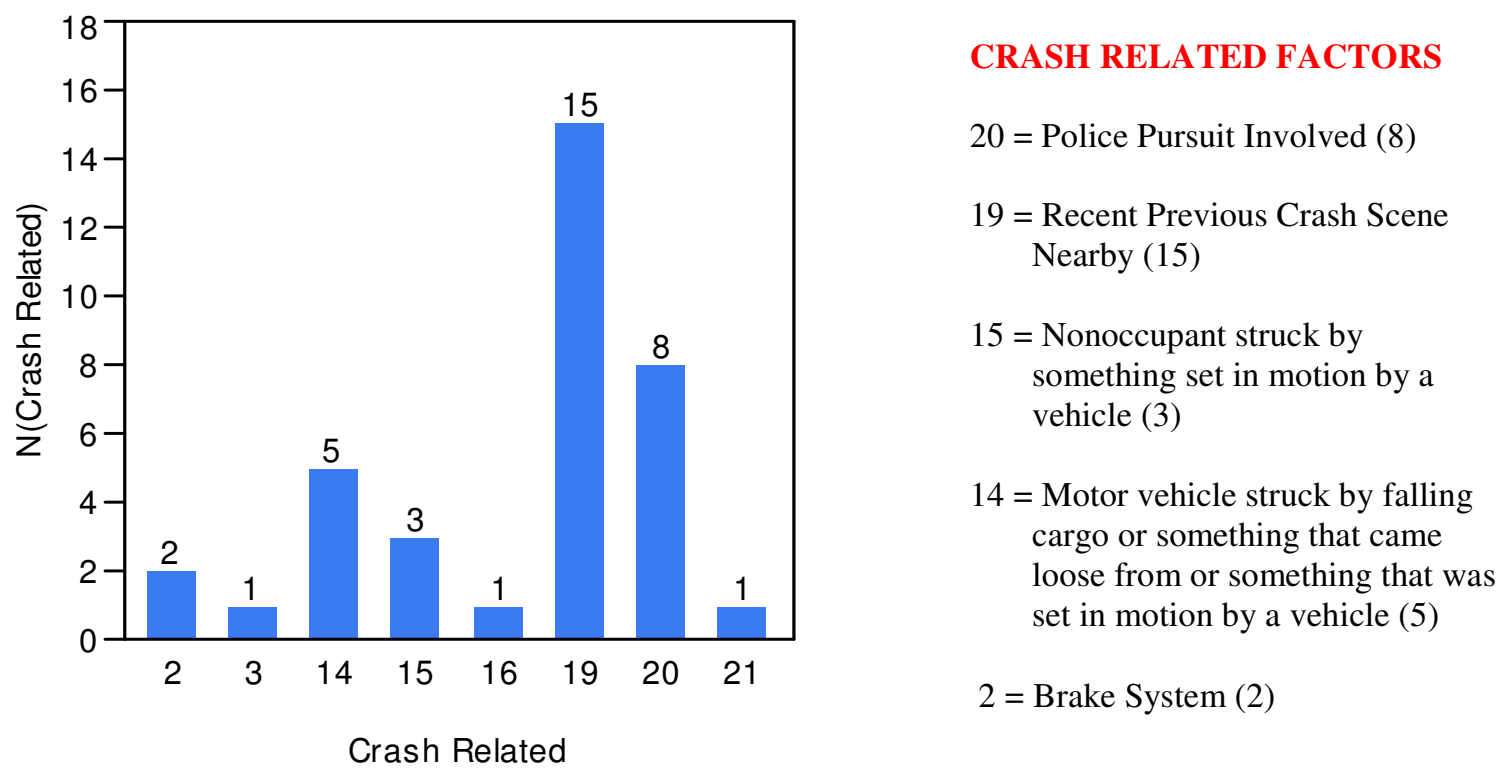
The first harmful event is reported in the FARS accident, vehicle and person files. However, the first harmful event applies to the crash. Harmful events are judgment calls of the FARS analyst based on the data within the police crash report. The first harmful event element permits only the coding of one variable from a selection of 68 different variables. Based upon the information collected from the 118 case files representing fatalities while not driving, outside the vehicle, 79 cases, or 67 percent, reported a pedestrian as the first harmful event. 23 other cases, 20 percent reported the first harmful event as "collision with a parked motor vehicle". Figure 4.46 offers the graphical display of the number of fatalities associated with specific harmful events.

\section{Figure 4.46}

Occurrence of Fatalities Not Driving Outside Vehicle by First Harmful Event, Law Enforcement Highway Fatalities, 1997-2006

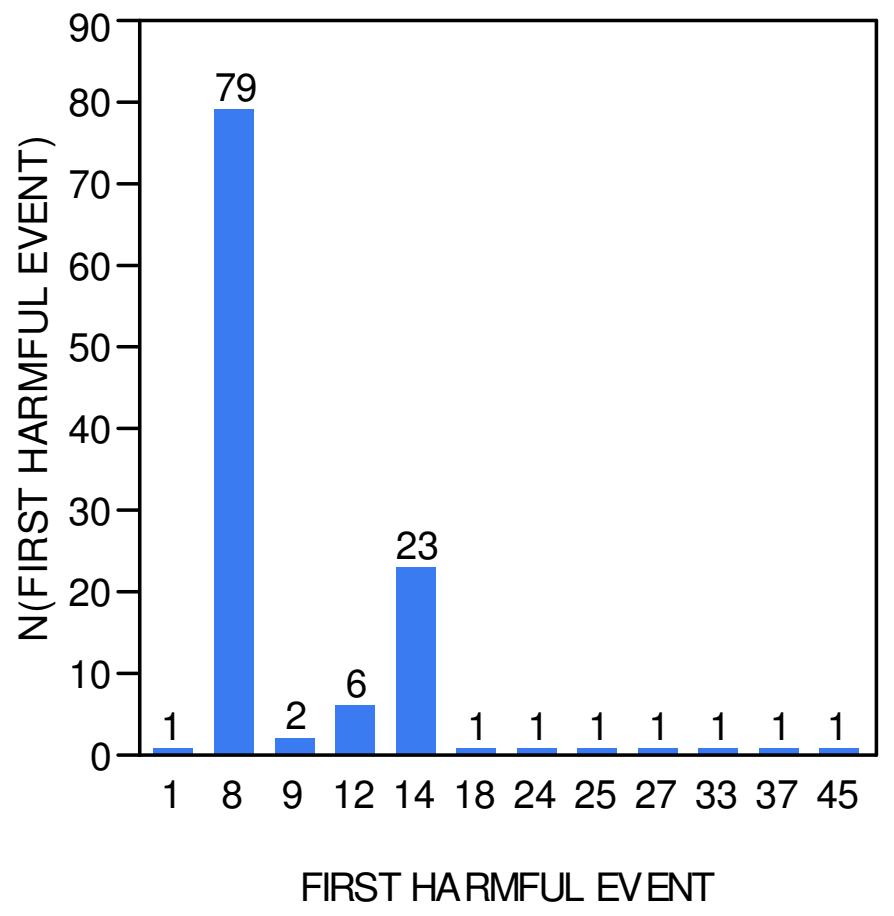

FIRST HARMFUL EVENT:

First harmful event applies to the crash. Harmful events are judgment calls of the FARS analyst based on the data within the police crash report.

$14=$ Collision with a parked motor vehicle (23)

$12=$ Collision with a motor vehicle on an undivided highway or the same side of divided highway (6)

$8=$ Pedestrian $(79)$

Note: The data using first harmful event shall not be further used. The coding variable $8=$ pedestrian. However, all incidents should be coded as 8 , because the victim was a pedestrian at the time of the incident. 
Most harmful event applies to the vehicle. It is coded at the vehicle level versus the crash level.

It is important to note that the FARS Coding manual states that "one cannot assume that the most harmful event for a vehicle was the cause of any death or injury for a specific individual within the vehicle." (2006) Therefore, the data are presented in Figure 4.47 for descriptive purposes, but will not be used in further data analysis.

Figure 4.47

Occurrence of Fatalities Not Driving Outside Vehicle by Most Harmful Event, Law Enforcement Highway Fatalities, 1997-2006

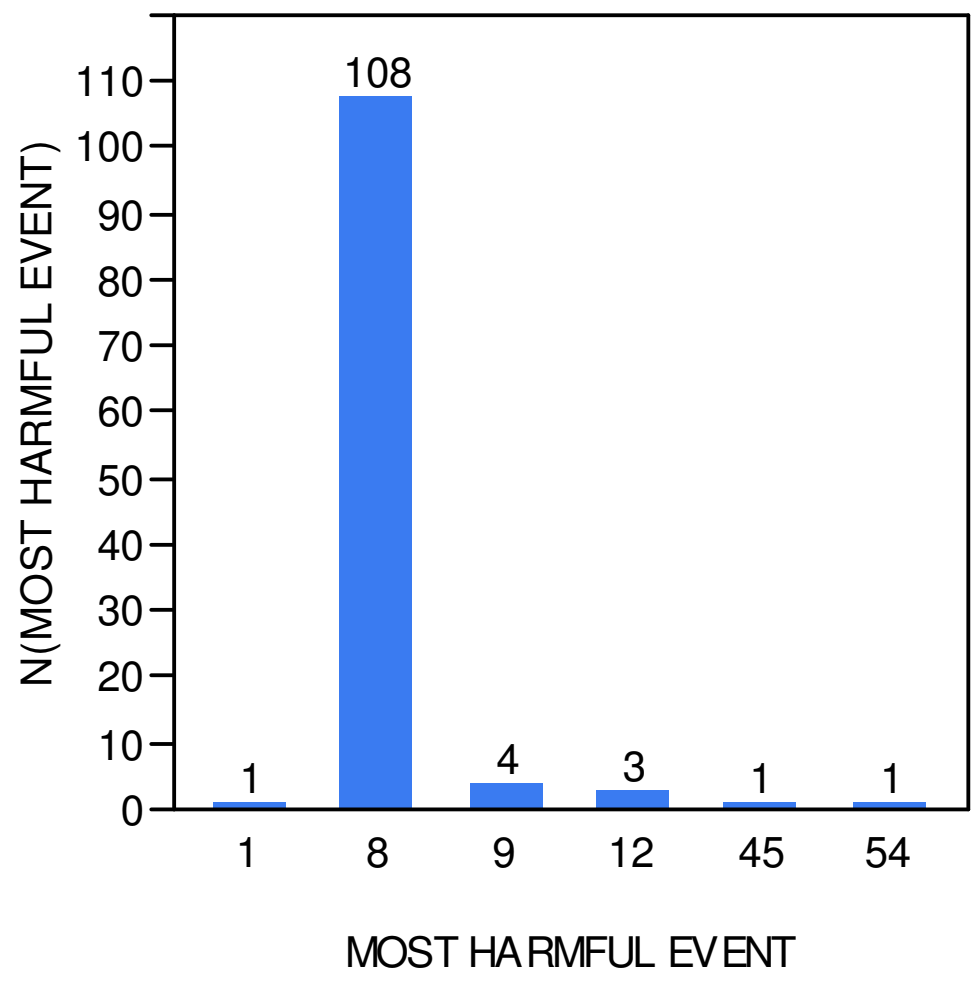

MOST HARMFUL EVENT:

Most harmful event applies to the vehicle. Harmful events are judgment calls of the FARS analyst based on the data within the police crash report.

$12=$ Collision with a motor vehicle on an undivided highway or the same side of divided highway (3)

$9=$ Pedalcycle (4)

$8=$ Pedestrian $(108)$

Note: The data using first harmful event shall not be further used. The coding variable $8=$ pedestrian. However, all incidents should be coded as 8 , because the victim was a pedestrian at the time of the incident.

In order to successfully complete the odds-ratio analysis in the later stages of this study, it is important to recognize the number of fatalities that occurred on scene versus the number of fatalities that occurred during transport to the hospital or after arriving at the hospital for emergency care. Out of the 118 case files selected to represent fatalities while not driving 
outside the vehicle, 66 cases, or 56 percent of the fallen officers died at the scene of the incident. 48 fatalities occurred after the victim had been transported to the hospital. Figure 4.48 demonstrates the number of fatalities that occurred at scene of the incident or en route/after transported to the hospital.

Figure 4.48

Occurrence of Fatalities by Dead on Arrival Classification, Law Enforcement Highway Fatalities, 1997-2006

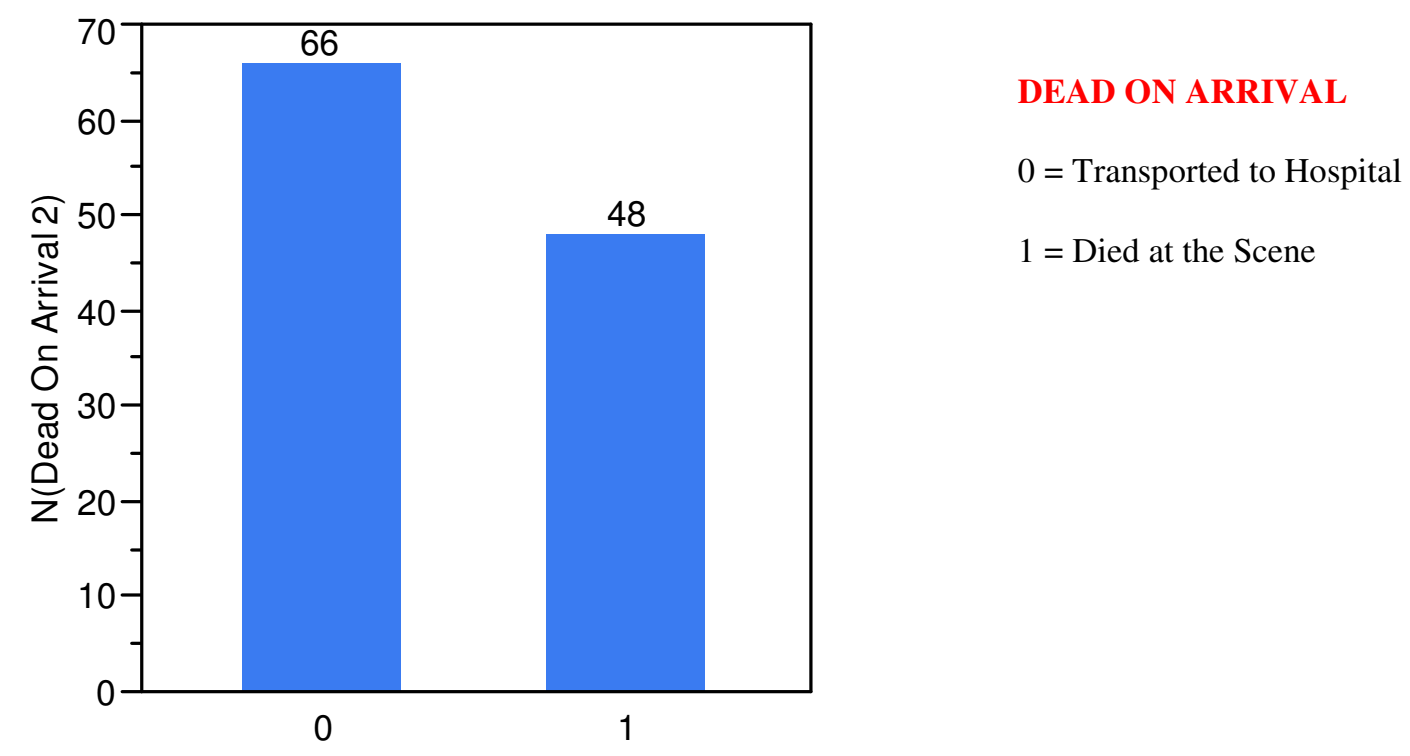

Dead On Arrival 2

Figure 4.49 and Table 4.6 have been prepared to offer a complete summary of the percent of law enforcement highway fatalities related to various risk factors. These descriptive study results will be compared to the focus group findings discussed in the following section. 
Figure 4.49

Frequency Distribution of Fatalities Not Driving Outside Vehicle by Circumstances, Law Enforcement Highway Fatalities, 1997-2006

\section{Frequency Distribution of Fatalities By Circumstances}

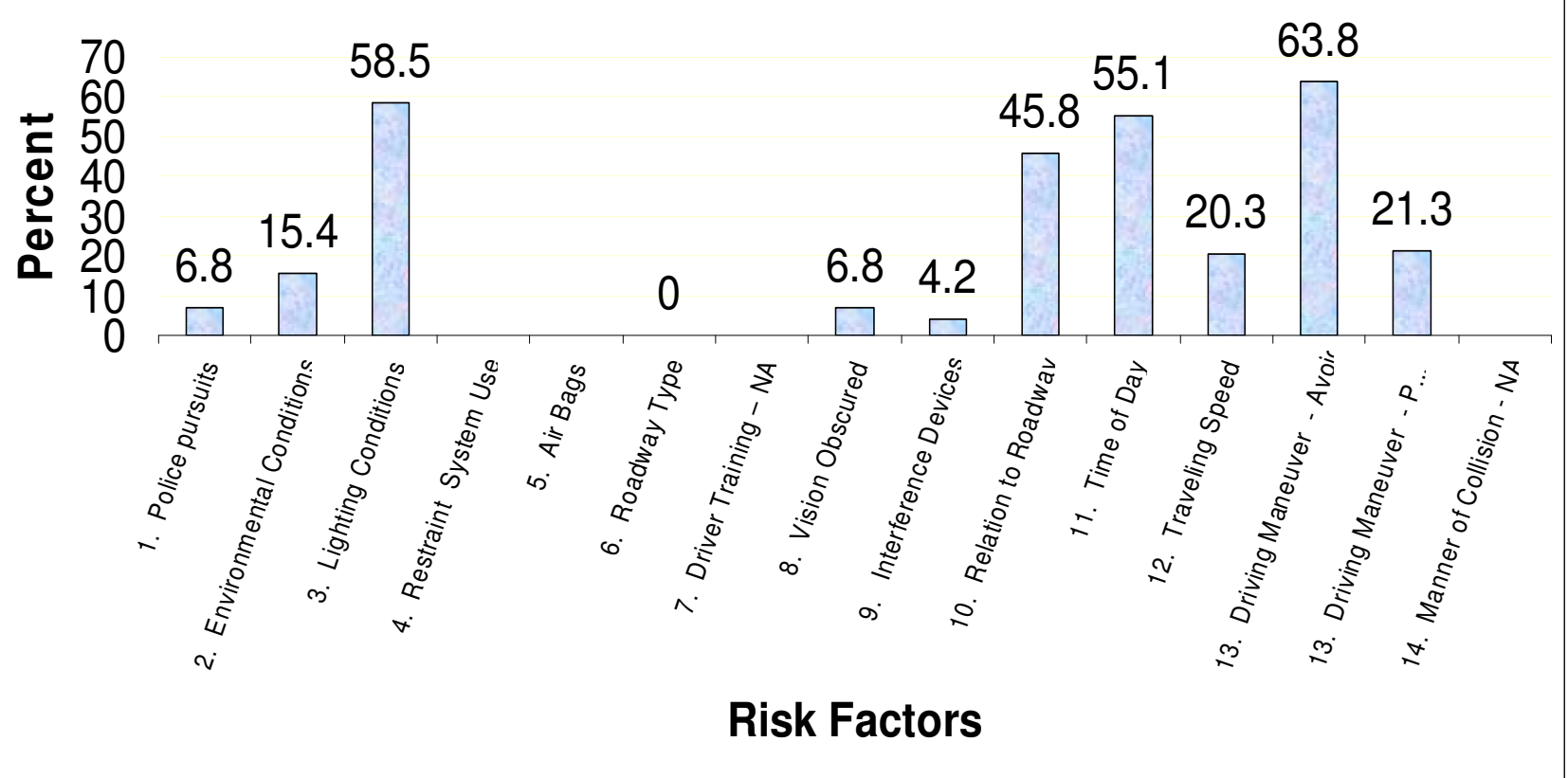

The above data table displays the percentage of fatalities reported to have adverse conditions of the risk factors present at the time of the incident.

The frequency distribution descriptive study identified the top risk factors for accidents when the officer was not driving and outside the vehicle. These are listed in rank order from most important to less importante:

1. Driving Maneuver

2. Lighting Conditions

3. Time of Day

4. Relation to Roadway

5. Traveling Speed 
Table 4.6: Summary of Risk Factor Effects on Fatalities Occurring while Not Driving, Outside the Vehicle

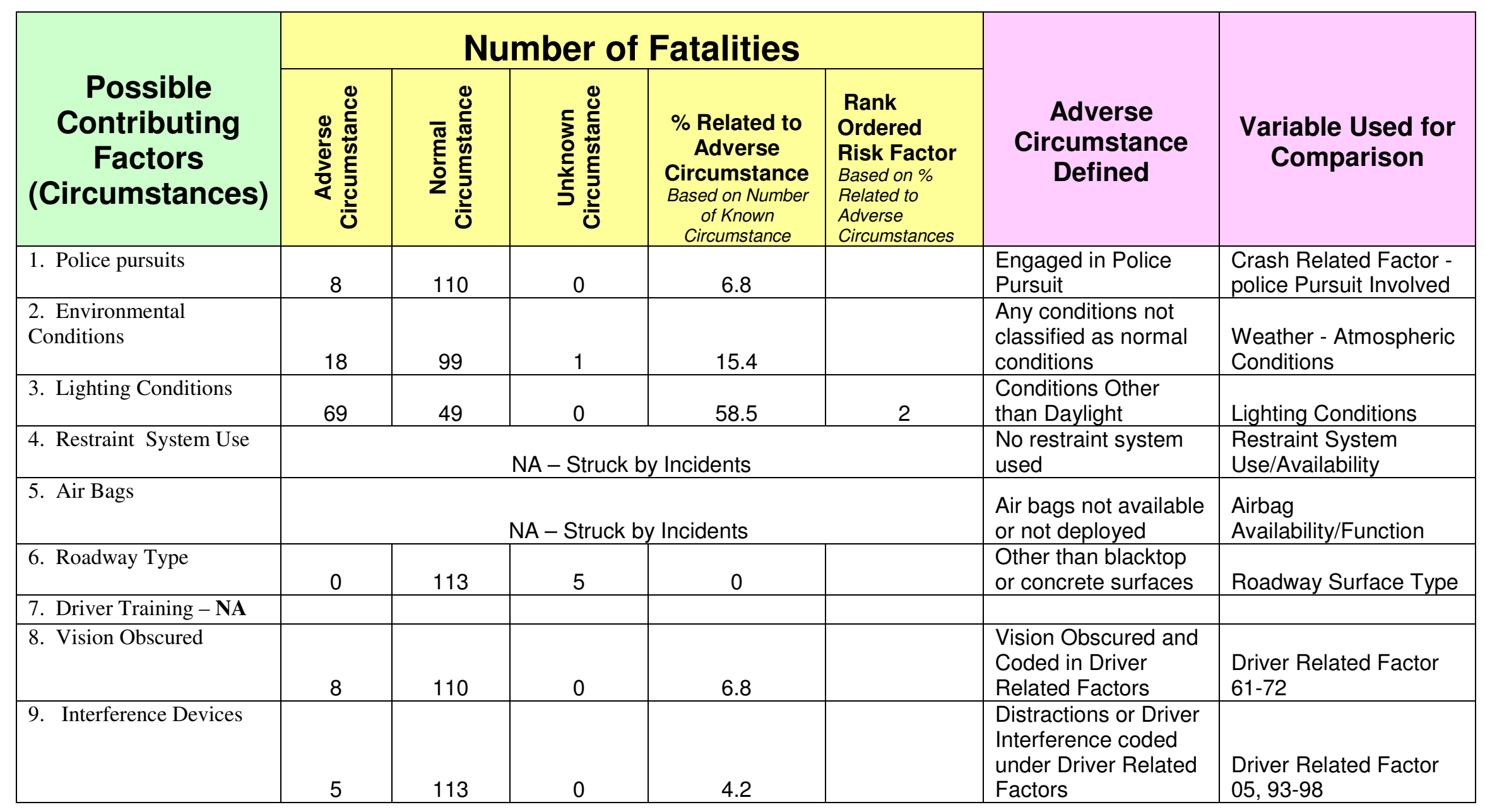


Table 4.6: Summary of Risk Factor Effects on Fatalities Occurring while Not Driving, Outside the Vehicle (Cont.)

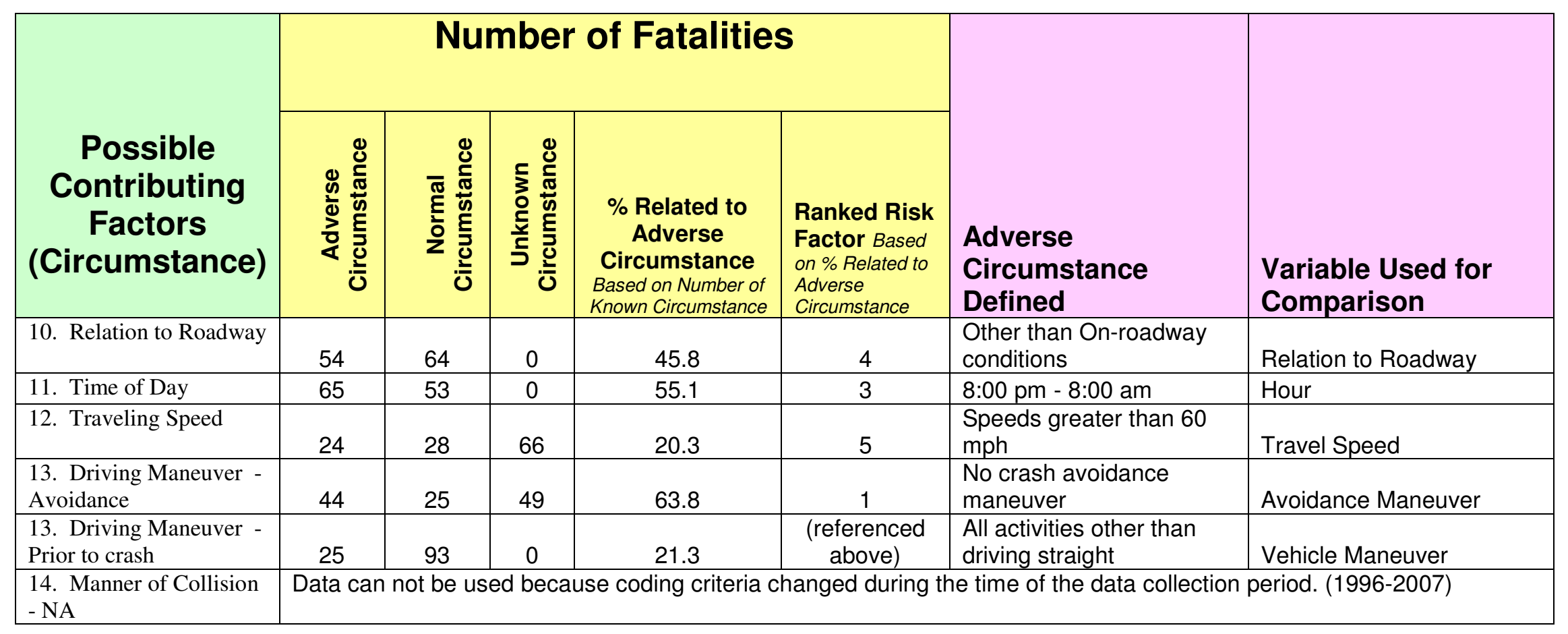




\subsection{FOCUS GROUP RESULTS}

A focus group approach was utilized to assist in the identification of predictable risk factors associated with law enforcement highway fatalities. The focus group efforts were divided into two separate phases. Phase I involved individual rank order of most important to least important and explanations based on individual experiences and expertise. Phase II of the focus group involved the moderation of a teleconference for the focus group to collectively determine what is believed to be the most important risk factors associated with law enforcement highway fatalities. The results of these efforts are thoroughly discussed below.

\subsubsection{Focus Group Phase I Results}

The results of the individual rank order from most important to least important are summarized in Table 4.7. For analysis purposes, the rankings 1-5 have been reversed to award the highest point values to the top rated risk factor. The results of the individual rank order of most important to least important indicate that the group identified traveling speed, driving maneuver at the time of crash and environmental conditions as the top three risk factors according to column totals and the criteria described in the methods portion of this study. Three other risk factors were selected by at least two group members as a top risk factor. These three included police pursuits, interference devices and relation to roadway. The top six most important factors have been highlighted purple in table 4.7 for easy reference.

The experts were also asked to offer an explanation of their selection choices. These explanations are summarized and offered in Table 4.8. 


\begin{tabular}{|c|c|c|c|c|c|c|}
\hline \multicolumn{6}{|c|}{$\begin{array}{l}\text { Ranking } \\
\text { By Group Member }\end{array}$} & \multirow{2}{*}{$\begin{array}{c}\text { Possible Contributing Factors } \\
\text { (Circumstances) }\end{array}$} \\
\hline \multirow[t]{2}{*}{$\begin{array}{l}\overrightarrow{\bar{D}} \\
\vec{E} \\
\stackrel{\overrightarrow{0}}{\Sigma}\end{array}$} & 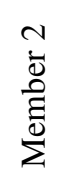 & 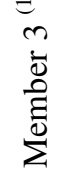 & 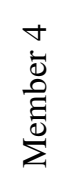 & $\begin{array}{l}n \\
\dot{\bar{D}} \\
\stackrel{0}{E} \\
\sum_{\Sigma}^{e}\end{array}$ & $\begin{array}{l}\text { Row } \\
\text { Totals }\end{array}$ & \\
\hline & 1 & & & & 4 & 1. Police pursuits \\
\hline \multirow[t]{4}{*}{1} & 2 & & 4 & 4 & 11 & 2. Environmental Conditions (weather) $\checkmark$ \\
\hline & & & 3 & & 3 & 3. Lighting Conditions \\
\hline & 3 & & & & 3 & 4. Restraint System Use (Seat Belts) \\
\hline & & & & & & 5. Air Bags \\
\hline 4 & & & & & 4 & 6. Roadway Type or Classification \\
\hline \multicolumn{6}{|c|}{$\begin{array}{l}\text { Unable to consider due to limitation } \\
\text { of data. }\end{array}$} & $\begin{array}{l}\text { 7. Driver Training - DATA ANALYSIS NOT AVAILABLE } \\
\text { BECAUSE NO COMPARISON COULD BE MADE } \\
{ }^{(\mathbf{1}}\end{array}$ \\
\hline & & & & 1 & 1 & 8. Vision Obscured \\
\hline & & 2 & & 3 & 5 & 9. Interference Devices inside vehicle (two-way radio, cell phone, etc) \\
\hline & 5 & & 2 & & 7 & 10. Relation to Roadway (i.e. shoulder, median, off road, junctions, etc) \\
\hline & & & & 2 & 2 & 11. Time of Day \\
\hline 2 & 4 & 4 & 1 & 5 & 16 & 12. Traveling Speed at time of Crash \\
\hline 5 & & 3 & 5 & & 13 & 13. Driving Maneuver at time of Crash $\checkmark$ \\
\hline & & 5 & & & 5 & 14. Manner of Collision (Rear-end, head-on, sideswipe, etc) \\
\hline
\end{tabular}

(1) Only four risk factors were identified by group member 3 during the initial phase of the focus group efforts.

\section{$\checkmark=$ Majority of group agrees it is a major factor, top rated risk factors based on row totals.}




\begin{tabular}{|c|c|}
\hline $\begin{array}{c}\text { Possible Contributing } \\
\text { Factors } \\
\text { (Circumstances) }\end{array}$ & $\begin{array}{c}\text { Focus Group Member Comments } \\
\text { Explanation for Selection }\end{array}$ \\
\hline 1. Police pursuits & $\begin{array}{l}\text { - Pursuits usually will terminate or end in another } \\
\text { enforcement jurisdiction. Officers know their own } \\
\text { jurisdiction very well but put them in another "driving } \\
\text { environment" only adds the risk of danger of the pursuit. } \\
\text { - Pursuits contribute to officer-deaths, but they are not a main } \\
\text { cause. }\end{array}$ \\
\hline 2. Environmental Conditions (weather) & $\begin{array}{l}\text { - No matter what the weather is outside, especially in areas } \\
\text { where weather is severe, officers must drive to the } \\
\text { conditions. If officers "push" themselves past their } \\
\text { limitations or their vehicles limitations, the outcome will } \\
\text { usually not be good. } \\
\text { - Officers attempt to get to calls for service as quickly as } \\
\text { possible and don't always arrive. It's related to (weather } \\
\text { and) speed. } \\
\text { - Restrict or limit a vehicle's ability to respond to driver input. } \\
\text { Again, input attempted is the outcome of a decision. } \\
\text { - Weather directly affects visibility and control of a vehicle. } \\
\text { Therefore, adverse weather conditions would adversely } \\
\text { and proportionately affect an operator's ability to control } \\
\text { a vehicle }\end{array}$ \\
\hline 3. Lighting Conditions & $\begin{array}{l}\text { - A reduction in lighting conditions can restrict or limit a } \\
\text { driver's ability to collect data upon which a decision will } \\
\text { be based, and a maneuver attempted. }\end{array}$ \\
\hline 4. Restraint System Use (Seat Belts) & $\begin{array}{l}\text { - Many officers do not to wear seat belts for a variety of } \\
\text { reasons. This is also related to speed. }\end{array}$ \\
\hline 5. Air Bags & \\
\hline 6. Roadway Type or Classification & $\begin{array}{l}\text { - The driving environment has potentially dangerous risks at } \\
\text { all times. The officers must have their eyes up looking for } \\
\text { hazardous situations. If the officer is not "scanning down } \\
\text { the roadway" they will not recognize deadly situations in } \\
\text { time to perform a safe driving maneuver to avoid the } \\
\text { situation at hand. }\end{array}$ \\
\hline $\begin{array}{l}\text { 7. Driver Training - DATA ANALYSIS } \\
\text { NOT AVAILABLE }^{(\mathbf{1})}\end{array}$ & DATA ANALYSIS NOT AVAILABLE $^{(1)}$ \\
\hline 8. Vision Obscured & $\begin{array}{l}\text { - All of the aforementioned factors relate to controlling a } \\
\text { vehicle. Nothing affects control more than the visibility } \\
\text { of the unit by others and the ability of the operator to see } \\
\text { potential hazards. }\end{array}$ \\
\hline $\begin{array}{l}\text { 9. Interference Devices inside vehicle } \\
\text { (two-way radio, cell phone, etc) }\end{array}$ & $\begin{array}{l}\text { - I believe that communication devices play more of a role in } \\
\text { police crashes than has actually been reported, } \\
\text { particularly when an officer is killed in the crash. } \\
\text { - Emergency conditions precipitate communications among } \\
\text { other response agencies and interdepartmental } \\
\text { responders. All of which contribute to distractions and } \\
\text { proportionately affect attentiveness and awareness }\end{array}$ \\
\hline
\end{tabular}


Table 4.8: Focus group individual explanations for selection of risk factors. (Cont.)

\begin{tabular}{|c|c|}
\hline $\begin{array}{c}\text { Possible Contributing } \\
\text { Factors } \\
\text { (Circumstances) }\end{array}$ & $\begin{array}{c}\text { Focus Group Member Comments } \\
\text { Explanation for Selection }\end{array}$ \\
\hline $\begin{array}{l}\text { 10. Relation to Roadway (i.e. shoulder, } \\
\text { median, off road, junctions, etc) }\end{array}$ & $\begin{array}{l}\text { - On average, one officer has been struck and killed each } \\
\text { month for more than a decade. } \\
\text { - May restrict the driver's ability to either collect data upon } \\
\text { which to make a decision or the space needed to complete } \\
\text { any attempted maneuver. }\end{array}$ \\
\hline 11. Time of Day & $\begin{array}{l}\text { - The time of day is extremely important with regard to a } \\
\text { potential for a fatality since the time of day will } \\
\text { determine traffic patterns, traffic volumes, and visibility } \\
\text { issues. }\end{array}$ \\
\hline $\begin{array}{l}\text { 12. Traveling Speed at time of Crash - } \\
\text { estimated }\end{array}$ & $\begin{array}{l}\text { - Increased speed decreases the vehicles ability to maneuver, } \\
\text { and increases the energy involved in the crash. The more } \\
\text { energy, the more injury. } \\
\text { - No matter what type of call, an officer must understand that } \\
\text { he/she can't drive } 100 \% \text {. At the Indiana Law } \\
\text { Enforcement Academy, law enforcement officers are } \\
\text { trained to utilize } 85 \% \text { of the driving ability during } \\
\text { emergency and pursuit situations. They have received } \\
\text { specialized training to handle their vehicle under the } \\
\text { worst conditions. However, during a pursuit, without } \\
\text { being trained in pursuit intervention techniques, the } \\
\text { violator is dictating how fast the pursuit is going and } \\
\text { where the pursuit is going. With better training and the } \\
\text { implementation of pursuit intervention techniques, the } \\
\text { termination point is now at the decision of the law } \\
\text { enforcement officers. } \\
\text { - Officers attempt to get to calls for service as quickly as } \\
\text { possible and don't always arrive. It's closely related to } \\
\text { environmental conditions. } \\
\text { - Speed kills! Police routinely exceed posted speed limits } \\
\text { whether responding to emergency or non-emergency } \\
\text { calls, or on routine patrol. } \\
\text { - Since force is a function of mass X velocity, and since } \\
\text { emergency responses are performed in a heavy vehicle } \\
\text { traveling at higher rates of speed, this is my highest risk } \\
\text { factor for vehicular fatalities }\end{array}$ \\
\hline 13. Driving Maneuver at time of Crash & $\begin{array}{l}\text { - I believe the number one risk factor that officers are } \\
\text { confronted with is failing to recognize the proper } \\
\text { alternatives available to them during emergency runs and } \\
\text { pursuits. The officers that are involved in accidents are } \\
\text { not utilizing proven law enforcement driving techniques } \\
\text { succumbing to the fact that "it will not happen to me." } \\
\text { - Officers routinely "overdrive" or "out drive" their patrol cars } \\
\text { and lose control, probably due to the stress of the nature } \\
\text { of the call. } \\
\text { - The maneuver attempted results from a decision based on } \\
\text { the driver's perception of the environment. Most crashes } \\
\text { result from an incorrect decision on what maneuver to } \\
\text { attempt. }\end{array}$ \\
\hline $\begin{array}{l}\text { 14. Manner of Collision (Rear-end, head- } \\
\text { on, sideswipe, etc) }\end{array}$ & $\begin{array}{l}\text { - Head-on, rear-end, and lateral impacts are all potentially } \\
\text { fatal crashes }\end{array}$ \\
\hline
\end{tabular}




\subsubsection{Focus Group Phase II Results}

After the initial data collected from the focus group was reviewed and summarized, all results were offered to the focus group for review and preparation of the moderated teleconference. The teleconference lasted approximately one hour and involved the facilitation of 8 questions to the focus group for further discussion. The results of the question are offered in table 4.9. Upon completion of the focus group teleconference, the transcript was analyzed for count and identification of listed risk factors. The results of the count and identification process are offered in table 4.10.

Table 4.9: Focus Group Teleconference Responses

\begin{tabular}{|c|c|}
\hline $\begin{array}{c}\text { Questions Presented to Focus } \\
\text { Group }\end{array}$ & Focus Group Responses \\
\hline $\begin{array}{l}\text { 1. What does highway fatality mean to } \\
\text { you? For example, what all does this } \\
\text { include in this category? }\end{array}$ & $\begin{array}{l}\text { - } \text { Pursuits and stopping angles along side of road } \\
\text { - When an individual is killed and involves a vehicle } \\
\text { - Include pedestrians, and bicycles along with motor vehicles } \\
\text { - Fatalities occurring as the impacted element, ie. Car hits house } \\
\text { and I'm in house and die } \\
\text { - Fatalities as a result of traffic accidents and law enforcement } \\
\text { officers being victims of struck by incidents }\end{array}$ \\
\hline $\begin{array}{l}\text { In your professional opinion, how many } \\
\text { law enforcement fatalities occurring } \\
\text { nationally on an annual basis are classified } \\
\text { as } \\
\text { - Automobile } \\
\text { - Motorcycle } \\
\text { - Struck By Incidents }\end{array}$ & $\begin{array}{ll}\text { - } & \text { Automobile fatalities }=130 \text { total fatalities per year } \\
\text { - } & \text { Motorcycle fatalities }=10-15 \text { per year } \\
\text { - } & \text { Struck By fatalities = Approximately } 12 \text { per year }\end{array}$ \\
\hline
\end{tabular}


Table 4.9: Focus Group Teleconference Responses (Cont.)

\begin{tabular}{|c|c|}
\hline $\begin{array}{c}\text { Questions Presented to Focus } \\
\text { Group }\end{array}$ & Focus Group Responses \\
\hline $\begin{array}{l}3 \text { Do any members have an opinion or } \\
\text { concern with the identified top three } \\
\text { elements, or believe that another element } \\
\text { should be included in the list of top three? }\end{array}$ & $\begin{array}{l}\text { - Lack of Driver training is a big factor and in-service training } \\
\text { should be implemented } \\
\text { - } \\
\text { Agree on Speed, driving maneuver and environmental factors as } \\
\text { the top } 3 \\
\text { - } \text { May want to add relationship to roadway for struck by incidents } \\
\text { - Time of day is also important because of traffic patterns and } \\
\text { condition of other drivers }\end{array}$ \\
\hline $\begin{array}{l}4 \text { Do you feel that training is an important } \\
\text { element, if so, what type of training would } \\
\text { you believe to be appropriate to reduce the } \\
\text { potential for law enforcement highway } \\
\text { fatalities? }\end{array}$ & $\begin{array}{l}\text { - Many officers do not receive training after their initial courses at } \\
\text { the training academy. } \\
\text { - Annual or Biennial in-service driver training should be required } \\
\text { for all officers } \\
\text { - Different states have different hours of minimum initial driver } \\
\text { training, NC mandates } 90 \text { hours, other states mandate } 8 \text { hours } \\
\text { - Training should include maneuvering and the operation of } \\
\text { specific vehicles, safety systems of the vehicle, on Legal } \\
\text { authority and "exemptions" they have, pursuit training, } \\
\text { emergency response training, transition training } \\
\text { Driver Simulators would be helpful in training }\end{array}$ \\
\hline $\begin{array}{l}5 \text { Some group members indicated that they } \\
\text { believe that some of the identified } \\
\text { contributing factors may interrelated. } \\
\text { Could you please identify which risk } \\
\text { factors you believe interrelate and how? }\end{array}$ & $\begin{array}{l}\text { - Environmental Conditions - Relation to roadway could be part } \\
\text { of the physical environmental conditions } \\
\text { - Roadway type and relation to roadway could be relative to one } \\
\text { another } \\
\text { - Speed and seat belts/air bags interrelate with the occurrence of } \\
\text { fatalities }\end{array}$ \\
\hline $\begin{array}{l}6 \text { Based on the above information, what } \\
\text { do you believe is the most predictive } \\
\text { interrelation between risk factors? }\end{array}$ & $\begin{array}{l}\text { (Moderator prompt) - Travel Speed and pursuits? } \\
\text { - } \quad \text { Distractions inside the car are increasing the amount of accidents } \\
\text { - } \quad \text { Normal day activities such as backing up because of } \\
\text { inattentiveness } \\
\text { - Speed is a major risk factor }\end{array}$ \\
\hline
\end{tabular}


Table 4.9: Focus Group Teleconference Responses (Cont.)

\begin{tabular}{|c|c|}
\hline $\begin{array}{c}\text { Questions Presented to Focus } \\
\text { Group }\end{array}$ & Focus Group Responses \\
\hline $\begin{array}{l}7 \text { Based upon the summary of Phase I, } \\
\text { three risk factors appear to have been } \\
\text { selected by more than } 50 \% \text { of the group } \\
\text { participants as a contributing risk factor. } \\
\text { These three factors are: } \\
\text { - Environmental Conditions } \\
\text { - Traveling speed } \\
\text { Does the group agree that these three } \\
\text { factors are worthy of being the top three } \\
\text { risk factors? What does the group believe } \\
\text { is the most important risk factor and why? }\end{array}$ & $\begin{array}{l}\text { - } \\
\text { - } \\
\text { - Tll agree these are essential elements } \\
\text { - } \\
\text { - Triving maneed is the number is the number two factor } \\
\text { Ther third would be environmental conditions }\end{array}$ \\
\hline $\begin{array}{l}8 \text { As a group can you collectively decide } \\
\text { the other two main risk factors? Do not } \\
\text { become concerned if the group cannot } \\
\text { develop a consensus decision, quantitative } \\
\text { analysis will allow the researcher to } \\
\text { identify the risk factors. }\end{array}$ & 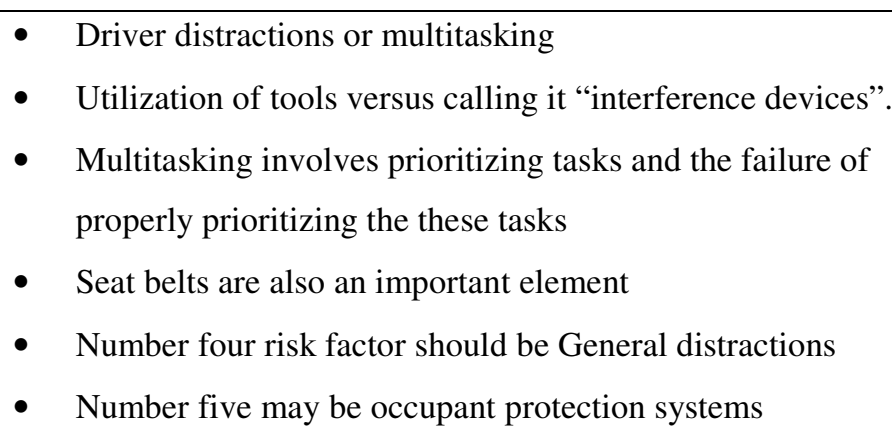 \\
\hline
\end{tabular}

Table 4.10: Number of times Risk Factor topics were discussed or mentioned during the teleconference.

\section{Possible Contributing Factors (Circumstances)}

\section{Frequency of Times Mentioned in Group Discussion ${ }^{(1)}$}

\begin{tabular}{|l|c|}
\hline 1. Police pursuits & 12 \\
\hline 2. Environmental Conditions (weather) & 3 \\
\hline 3. Lighting Conditions & 1 \\
\hline 4. Restraint System Use (Seat Belts) & 4- Mainly by one participant \\
\hline 5. Air Bags & 2 \\
\hline 6. Roadway Type & Analysis Not Available \\
\hline 7. Driver Training - DATA ANALYSIS NOT AVAILABLE ${ }^{(1)}$ & 0 \\
\hline 8. Vision Obscured & 5 \\
\hline 9. Interference Devices inside vehicle (two-way radio, cell phone, etc) & 6 \\
\hline 10. Relation to Roadway (i.e. shoulder, median, off road, junctions, etc) & 5 - Mainly by one participant \\
\hline 11. Time of Day & 18 \\
\hline 12. Traveling Speed at time of Crash - estimated & 4 \\
\hline 13. Driving Maneuver at time of Crash & 0 \\
\hline 14. Manner of Collision (Rear-end, head-on, sideswipe, etc) & \\
\hline
\end{tabular}

(1) Frequency of times included in discussion by participants excluding the moderator comments. 
The collective agreement of the focus group identified the top risk factors in the following order:

1. Speed (includes emergency response and police pursuits)

2. Driving maneuver at the time of crash

3. Environmental conditions

4. Interference Devices (tools, multitasking)

5. Relation to Roadway

These risk factors will be compared to the data gathered during the descriptive study process using a correlation coefficient.

In addition to the identification of top risk factors, the focus group emphasized emphatically that driver training for law enforcement professionals has become or continues to be lacking on a national scale. It was explained to the volunteer group members that data analysis was unavailable for operator training because such data has not historically been collected. As reported by the focus group, few law enforcement agencies offer or require refresher training for law enforcement driving operations. The focus group thoroughly discussed their concerns regarding the current limitation of officer training elements such as: training topics including multitasking or task prioritization; hours of driver training initially and annually; operator training for new vehicles; and use or implementation of driver simulators. All of these issues identified by the group are further discussed in the conclusions of this research. 


\subsection{COMPARISON OF DESCRIPTIVE STUDY AND FOCUS GROUP RESULTS}

Tables 4.11 and 4.12 summarize the rankings of the risk factors for both the Focus Group and the Descriptive Study. A Spearman Rank-Order Correlation Coefficient analysis was performed to determine if there was a correlation between the ranked data offered through the FARS database and the opinions of experts in the law enforcement/emergency response fields. Although a correlation between data would strongly support the variables selected for the model, it does not serve as the only basis for determination of risk factors. A Spearman rank order correlation coefficient has been calculated for both categories of data sets including; Officers Inside Vehicles and Officers Outside Vehicles. Comparison for the third category, Fatalities while not driving inside the vehicle, could not be performed due to the lack of available case files ( $n=13$ ).

Table 4.11: Spearman Rank Correlation Calculations for Incidents with the Officer Outside the vehicle.

\begin{tabular}{|c|c|c|c|c|}
\hline \multirow{2}{*}{$\begin{array}{c}\text { Possible Contributing } \\
\text { Factors } \\
\text { (Circumstances) }\end{array}$} & \multicolumn{2}{|c|}{ Rankings } & \multicolumn{2}{|c|}{ Computations } \\
\hline & $\begin{array}{l}\text { Focus } \\
\text { Group }\end{array}$ & $\begin{array}{l}\text { Descriptive } \\
\text { Study - }\end{array}$ & $\begin{array}{l}\text { Difference between } \\
\text { Rankings }\end{array}$ & $\begin{array}{l}\text { Difference } \\
\text { Squared }\left(d^{2}\right)\end{array}$ \\
\hline \multicolumn{5}{|l|}{ 1. Police pursuits } \\
\hline 2. Environmental Conditions & 3.0 & 6.0 & 3 & 9 \\
\hline 3. Lighting Conditions & 6.0 & 2.0 & 4 & 16 \\
\hline \multicolumn{5}{|l|}{ 4. Restraint System Use } \\
\hline \multicolumn{5}{|l|}{ 5. Air Bags } \\
\hline \multicolumn{5}{|l|}{ 6. Roadway Type } \\
\hline \multicolumn{5}{|l|}{ 7. Driver Training - NA } \\
\hline \multicolumn{5}{|l|}{ 8. Vision Obscured } \\
\hline 9. Interference Devices & 4.0 & 7.0 & 3 & 9 \\
\hline 10. Relation to Roadway & 5.0 & 4.0 & 1 & 1 \\
\hline 11. Time of Day & 7.0 & 3.0 & 4 & 16 \\
\hline 12. Traveling Speed & 1.0 & 5.0 & 4 & 16 \\
\hline 13. Driving Maneuver - Avoidance & 2.0 & 1.0 & 1 & 1 \\
\hline \multicolumn{5}{|l|}{ 14. Manner of Collision - NA } \\
\hline & & & Sum $\left(D^{2}\right)$ & 68 \\
\hline
\end{tabular}


The calculations below were performed on the data.

Where:

$\mathbf{r}_{\mathrm{S}}=$ Correlation Coefficient

$\Sigma d^{2}=$ The difference between the rankings squared $=68$

$\mathrm{n}=\quad$ Number of factors (cells) $=7$

$$
r_{s}=\frac{1-6(68)}{7\left(7^{2}-1\right)}=-0.214
$$

The analysis results indicate that there is a slight negative correlation $(r=-0.21)$ between the ranked data sets. This means that the rankings of the focus group and descriptive study do not positively relate to one another.

Table 4.12: Spearman Rank Correlation Calculations for Incidents with While Driving the Vehicle.

\begin{tabular}{|c|c|c|c|c|}
\hline \multirow{2}{*}{$\begin{array}{c}\text { Possible Contributing } \\
\text { Factors } \\
\text { (Circumstances) }\end{array}$} & \multicolumn{2}{|c|}{ Rankings } & \multicolumn{2}{|c|}{ Computations } \\
\hline & $\begin{array}{l}\text { Focus } \\
\text { Group }\end{array}$ & $\begin{array}{l}\text { Descriptive } \\
\text { Study - }\end{array}$ & $\begin{array}{l}\text { Difference between } \\
\text { Rankings }\end{array}$ & $\begin{array}{l}\text { Difference } \\
\text { Squared }\left(d^{2}\right)\end{array}$ \\
\hline \multicolumn{5}{|l|}{ 1. Police pursuits } \\
\hline 2. Environmental Conditions & 3.0 & 6.0 & 3 & 9 \\
\hline 3. Lighting Conditions & 6.0 & 2.0 & 4 & 16 \\
\hline \multicolumn{5}{|l|}{ 4. Restraint System Use } \\
\hline \multicolumn{5}{|l|}{ 5. Air Bags } \\
\hline \multicolumn{5}{|l|}{ 6. Roadway Type } \\
\hline \multicolumn{5}{|l|}{ 7. Driver Training - NA } \\
\hline \multicolumn{5}{|l|}{ 8. Vision Obscured } \\
\hline 9. Interference Devices & 4.0 & 7.0 & 3 & 9 \\
\hline 10. Relation to Roadway & 5.0 & 5.0 & 0 & 0 \\
\hline 11. Time of Day & 7.0 & 3.0 & 4 & 16 \\
\hline 12. Traveling Speed & 1.0 & 1.0 & 0 & 0 \\
\hline 13. Driving Maneuver - Avoidance & 2.0 & 4.0 & 2 & 4 \\
\hline \multicolumn{5}{|l|}{ 14. Manner of Collision - NA } \\
\hline & & & Sum $\left(D^{2}\right)$ & 54 \\
\hline
\end{tabular}


The calculations below were performed on the data.

Where:

$\mathbf{r}_{\mathrm{S}}=$ Correlation Coefficient

$\Sigma d^{2}=$ The difference between the rankings squared $=54$

$\mathrm{n}=\quad$ Number of factors (cells) $=7$

$$
r_{s}=\frac{1-6(54)}{7\left(7^{2}-1\right)}=0.036
$$

The analysis results indicate that there is a no correlation $(r=0.036)$ between the ranked data sets. This means that the two ranked lists do not relate to one another.

Both calculated correlation coefficients do not immediately reflect a desired response with the data, it offers the author useful information that is further discussed in the conclusions portion of this study. It is important to note that the focus group was asked to rank order the risk factors based upon all types of highway fatalities including both motor vehicle and struck by incidents.

Although the correlation coefficient was used to compare the focus group data and the descriptive study results, greater emphasis was placed on the opinions of the experts in the focus group. Since the database offers sterile data and the experts are considered to be live and seasoned, the focus group results shall carry greater strength when offering conclusions and recommendations for this study. 


\subsection{SIMPLE LOGISTIC REGRESSION RESULTS}

A multiple regression analysis was performed on the risk factors identified by the descriptive study and the focus group to assist in determining the best identification of the risk factors contributing to law enforcement highway fatalities. The odds ratio output was generated on the two categories previously discussed in the descriptive study. These categories include; Officer fatalities while driving the vehicle and Officer fatalities while outside the vehicle. In addition to this analysis, odds ratios were calculated for age and gender effects on the response variable. The response variable selected for analysis was Dead on Arrival. Table 4.13 offers a summary of the logistic regression analysis of the risk factors for fatalities of officers while driving. Table 4.14 offers a summary of the logistic regression analysis results for risk factors of officers while outside the vehicle. All recoding criteria and calculation methods were defined in the methodology chapter of this study. It is important to note that odds ratios were calculated using only the conditions referenced in the table. All other conditions, where $n<3$, were excluded from the fit model script when performing the analysis. 
Table 4.13 Summary of Odds Ratio of Driving Related Predictors of Dead on Arrival While Driving

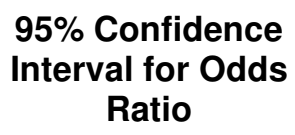

\begin{tabular}{|c|c|c|c|c|c|}
\hline Variable & $\begin{array}{c}\text { Reference } \\
\text { Variable } \\
\text { (Normal } \\
\text { Conditions }\end{array}$ & $\begin{array}{l}\text { Odds } \\
\text { Ratio }\end{array}$ & $\begin{array}{l}\text { Lower } \\
\text { Limit }\end{array}$ & $\begin{array}{l}\text { Upper } \\
\text { Limit }\end{array}$ & $\begin{array}{l}\text { Association } \\
\text { of Findings }\end{array}$ \\
\hline \multirow{2}{*}{$\begin{array}{l}\text { 1. Police pursuits v. Non } \\
\text { Pursuits }\end{array}$} & Pursuits & 1.0 & & & \multirow[b]{2}{*}{$\begin{array}{l}\text { Not enough evidence } \\
\text { to suggest Association }\end{array}$} \\
\hline & Non Pursuits & 0.7695 & 0.407677 & 1.452449 & \\
\hline \multirow{3}{*}{$\begin{array}{l}\text { 2. Environmental } \\
\text { Conditions (weather) } \\
\text { v. Normal Conditions }\end{array}$} & Normal Atmospheric & & & & \multirow[b]{3}{*}{$\begin{array}{l}\text { Not enough evidence } \\
\text { to suggest Association }\end{array}$} \\
\hline & Conditions & 1.0 & & & \\
\hline & $\begin{array}{l}\text { Adverse Atmospheric } \\
\text { Conditions }\end{array}$ & 1.182459 & 0.676572 & 2.066608 & \\
\hline \multirow{2}{*}{$\begin{array}{l}\text { 3. Lighting Conditions } \\
\text { (adverse lighting v. } \\
\text { daylight) }\end{array}$} & Daylight & 1.0 & & & \multirow[b]{2}{*}{$\begin{array}{l}\text { Not enough evidence } \\
\text { to suggest Association }\end{array}$} \\
\hline & Other than Daylight & 0.882677 & 0.575779 & 1.353155 & \\
\hline \multirow{4}{*}{$\begin{array}{l}\text { 3. Lighting Conditions } \\
\text { by Category }\end{array}$} & Daylight & 1.0 & & & \multirow{4}{*}{$\begin{array}{l}\text { Not enough evidence } \\
\text { to suggest Association } \\
\text { Association } \\
\text { Not enough evidence } \\
\text { to suggest Association }\end{array}$} \\
\hline & Dark & 0.685812 & 0.426564 & 1.09914 & \\
\hline & Dark But Lighted & 3.507692 & 1.881218 & 6.797733 & \\
\hline & Dawn & 0.261538 & 0.013185 & 1.826825 & \\
\hline \multirow{2}{*}{ 4. Restraint System Use } & No Use & 1.0 & & & \multirow[b]{2}{*}{$\begin{array}{l}\text { Not enough evidence } \\
\text { to suggest Association }\end{array}$} \\
\hline & Normal Use & 1.014493 & 0.65434 & 1.572875 & \\
\hline \multirow{2}{*}{ 5. Air Bags } & Air Bag Deployed & 1.0 & & & \multirow[b]{2}{*}{$\begin{array}{l}\text { Not enough evidence } \\
\text { to suggest Association }\end{array}$} \\
\hline & Air Bag Not Deployed & 1.227214 & 0.791583 & 1.902585 & \\
\hline \multirow{2}{*}{$\begin{array}{l}\text { 6. Roadway Type } \\
\text { (Alignment) }\end{array}$} & Straight Roadways & 1.0 & & & \multirow[b]{2}{*}{ Association } \\
\hline & $\begin{array}{l}\text { Roadways that are } \\
\text { other than straight }\end{array}$ & 1.75944 & 1.122847 & 2.756947 & \\
\hline \multicolumn{6}{|l|}{ 7. Driver Training - NA } \\
\hline \multirow[b]{2}{*}{ 8. Vision Obscured } & Vision Not Obscured & 1.0 & & & \multirow[b]{2}{*}{$\begin{array}{l}\text { Not enough evidence } \\
\text { to suggest Association }\end{array}$} \\
\hline & Vision Obscured & 1.045714 & 0.257532 & 4.246143 & \\
\hline \multirow[t]{2}{*}{ 9. Interference Devices } & $\begin{array}{l}\text { No Devices reportedly } \\
\text { used at time of crash }\end{array}$ & 1.0 & & & \\
\hline & $\begin{array}{l}\text { Other Devices Used at } \\
\text { time of crash }\end{array}$ & 4.251429 & 0.470598 & 38.40782 & $\begin{array}{l}\text { Not enough evidence } \\
\text { to suggest Association }\end{array}$ \\
\hline
\end{tabular}

Note: Outcome variable was dichotomized as dead on arrival versus died in hospital or after receiving medical attention. 
Table 4.13 Summary of Odds Ratio of Driving Related Predictors of Dead on Arrival While Driving (Continued)

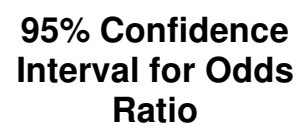

\begin{tabular}{|c|c|c|c|c|c|}
\hline Variable & $\begin{array}{c}\text { Reference } \\
\text { Variable } \\
\text { (Normal } \\
\text { Conditions }\end{array}$ & $\begin{array}{l}\text { Odds } \\
\text { Ratio }\end{array}$ & $\begin{array}{l}\text { Lower } \\
\text { Limit }\end{array}$ & $\begin{array}{l}\text { Upper } \\
\text { Limit }\end{array}$ & $\begin{array}{l}\text { Association } \\
\text { of Findings }\end{array}$ \\
\hline \multirow[b]{2}{*}{ 10. Relation to Roadway } & On Roadway & 1.0 & & & \multirow[b]{2}{*}{$\begin{array}{l}\text { Not enough evidence } \\
\text { to suggest Association }\end{array}$} \\
\hline & $\begin{array}{l}\text { Off Roadway - All } \\
\text { conditions }\end{array}$ & 0.880933 & 0.583809 & 1.329277 & \\
\hline \multirow{6}{*}{$\begin{array}{l}\text { 10. Relation to Roadway } \\
\text { (by category) }\end{array}$} & On Roadway & 1.0 & & & \multirow{6}{*}{$\begin{array}{l}\text { Not enough evidence } \\
\text { to suggest Association }\end{array}$} \\
\hline & Shoulder & 0.927835 & 0.370599 & 2.298103 & \\
\hline & Median & 3.061852 & 0.686222 & 21.21043 & \\
\hline & Roadside & 1.296461 & 0.776809 & 2.175221 & \\
\hline & $\begin{array}{l}\text { Outside Trafficway } \\
\text { /Right-of-Way }\end{array}$ & 2.721649 & 0.762174 & 12.69557 & \\
\hline & Location Unknown & 0.718213 & 0.370569 & 1.369309 & \\
\hline \multirow[b]{2}{*}{ 11. Time of Day - } & $8: 00 \mathrm{am}-8: 00 \mathrm{pm}$ & 1.0 & & & \multirow[b]{2}{*}{$\begin{array}{l}\text { Not enough evidence } \\
\text { to suggest Association }\end{array}$} \\
\hline & $8: 00 \mathrm{pm}-8: 00 \mathrm{am}$ & 0.977485 & 0.639625 & 1.493809 & \\
\hline \multirow{4}{*}{$\begin{array}{l}\text { 11. Time of Day (by } \\
\text { category) }\end{array}$} & Hour $12-17$ & 1.0 & & & \multirow{4}{*}{$\begin{array}{l}\text { Not enough evidence } \\
\text { to suggest Association }\end{array}$} \\
\hline & Hour $-0-5$ & 1.52765 & 0.849045 & 2.76769 & \\
\hline & Hour 6-11 & 0.973985 & 0.476367 & 1.98428 & \\
\hline & Hour $18-24$ & 1.519172 & 0.839066 & 2.769562 & \\
\hline \multirow[b]{2}{*}{ 12. Traveling Speed } & Travel Speed $<60 \mathrm{mph}$ & 1.0 & & & \multirow[b]{2}{*}{$\begin{array}{l}\text { Not enough evidence } \\
\text { to suggest Association }\end{array}$} \\
\hline & Travel Speed $>60 \mathrm{mph}$ & 1.576577 & 0.825615 & 3.010597 & \\
\hline \multirow{5}{*}{$\begin{array}{l}\text { 12. Traveling Speed (by } \\
\text { category) }\end{array}$} & Travel Speed $<26 \mathrm{mph}$ & 1.0 & & & \multirow{5}{*}{$\begin{array}{l}\text { Not enough evidence } \\
\text { to suggest Association }\end{array}$} \\
\hline & Travel Speed 26-50 & 1.145454 & 0.342905 & 3.836091 & \\
\hline & Travel Speed 51-75 & 0.690341 & 0.244097 & 1.91044 & \\
\hline & Travel Speed 75+ & 0.564264 & 0.193448 & 1.606154 & \\
\hline & Travel Speed Unknown & 0.950413 & 0.369135 & 2.387272 & \\
\hline 13. Driving Maneuver & $\begin{array}{l}\text { Crash Avoidance } \\
\text { Maneuver performed } \\
\text { No crash avoidance } \\
\text { maneuver performed }\end{array}$ & 1.34489 & 0.791126 & 2.28627 & $\begin{array}{l}\text { Not enough evidence } \\
\text { to suggest Association }\end{array}$ \\
\hline \multicolumn{6}{|c|}{ 14. Manner of Collision - NA } \\
\hline \multirow{4}{*}{ Age } & Age $20-35$ & 1.0 & & & \multirow{4}{*}{$\begin{array}{l}\text { Not enough evidence } \\
\text { to suggest Association }\end{array}$} \\
\hline & Age $36-50$ & 0.870793 & 0.556461 & 1.361404 & \\
\hline & Age 51-64 & 0.840385 & 0.420149 & 1.675724 & \\
\hline & Age $65+$ & 0.294872 & 0.014454 & 2.347745 & \\
\hline Gender & Male & 1.0 & & & $\begin{array}{l}\text { Not enough evidence } \\
\text { to suggest Association }\end{array}$ \\
\hline
\end{tabular}

Note: Odds ratios were not reported for all conditions which contained $n<3$ cases. 
The only contributing factors that showed an association with fatalities that occurred while driving and resulting in dead on arrival was with lighting conditions that are dark but artificially lighted and on roadways that are other than straight roadways. According to the logistic regression analysis an officer involved in an incident when lighting conditions are dark but artificially lighted is 3.5 times more likely to be announced dead on arrival than to receive medical treatment prior to their death. An officer involved in an incident when roadways are not straight is 1.75 times more likely to be announced dead on arrival than to receive medical treatment prior to death.

Table 4.14 Summary of Odds Ratio of Driving Related Predictors of Dead on Arrival While Driving

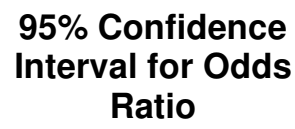

\begin{tabular}{|c|c|c|c|c|c|}
\hline Variable & $\begin{array}{c}\text { Reference } \\
\text { Variable } \\
\text { (Normal } \\
\text { Conditions }\end{array}$ & $\begin{array}{l}\text { Odds } \\
\text { Ratio }\end{array}$ & $\begin{array}{l}\text { Lower } \\
\text { Limit }\end{array}$ & $\begin{array}{l}\text { Upper } \\
\text { Limit }\end{array}$ & $\begin{array}{l}\text { Association } \\
\text { of Findings }\end{array}$ \\
\hline \multirow{2}{*}{$\begin{array}{l}\text { 1. Police pursuits v. Non } \\
\text { Pursuits }\end{array}$} & Pursuits & 1.0 & & & \multirow[b]{2}{*}{$\begin{array}{l}\text { Not enough evidence } \\
\text { to suggest Association }\end{array}$} \\
\hline & Non Pursuits & 0.179331 & 0.02131 & 1.509113 & \\
\hline \multirow{3}{*}{$\begin{array}{l}\text { 2. Environmental } \\
\text { Conditions (weather) } \\
\text { v. Normal Conditions }\end{array}$} & Normal Atmospheric & & & & \multirow[b]{3}{*}{$\begin{array}{l}\text { Not enough evidence } \\
\text { to suggest Association }\end{array}$} \\
\hline & Conditions & 1.0 & & & \\
\hline & $\begin{array}{l}\text { Adverse Atmospheric } \\
\text { Conditions }\end{array}$ & 1.717105 & 0.609046 & 4.841094 & \\
\hline \multirow{2}{*}{$\begin{array}{l}\text { 3. Lighting Conditions } \\
\text { (adverse lighting v. } \\
\text { daylight) }\end{array}$} & Daylight & 1.0 & & & \multirow[b]{2}{*}{$\begin{array}{l}\text { Not enough evidence } \\
\text { to suggest Association }\end{array}$} \\
\hline & Other than Daylight & 0.621118 & 0.291512 & 1.323403 & \\
\hline \multirow{3}{*}{$\begin{array}{l}\text { 3. Lighting Conditions } \\
\text { by Category }\end{array}$} & Daylight & 1.0 & & & \multirow{3}{*}{$\begin{array}{l}\text { Not enough evidence } \\
\text { to suggest Association }\end{array}$} \\
\hline & Dark & 1.127451 & 0.475149 & 2.689723 & \\
\hline & Dark But Lighted & 2.395833 & 0.903164 & 6.785568 & \\
\hline \multicolumn{6}{|c|}{ 4. Restraint System Use - NA } \\
\hline \multicolumn{6}{|c|}{ 5. Air Bags - NA } \\
\hline \multirow{2}{*}{$\begin{array}{l}\text { 6. Roadway Type } \\
\text { (Alignment) }\end{array}$} & Straight Roadways & 1.0 & & & \multirow[b]{2}{*}{$\begin{array}{l}\text { Not enough evidence } \\
\text { to suggest Association }\end{array}$} \\
\hline & $\begin{array}{l}\text { Roadways that are } \\
\text { other than straight }\end{array}$ & 2.769231 & 0.863631 & 8.879536 & \\
\hline
\end{tabular}


Table 4.14 Summary of Odds Ratio of Driving Related Predictors of Dead on Arrival While Driving (Continued)

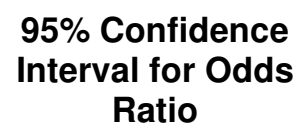

\begin{tabular}{|c|c|c|c|c|c|}
\hline Variable & $\begin{array}{c}\text { Reference } \\
\text { Variable } \\
\text { (Normal } \\
\text { Conditions }\end{array}$ & $\begin{array}{l}\text { Odds } \\
\text { Ratio }\end{array}$ & $\begin{array}{l}\text { Lower } \\
\text { Limit }\end{array}$ & $\begin{array}{l}\text { Upper } \\
\text { Limit }\end{array}$ & $\begin{array}{l}\text { Association } \\
\text { of Findings }\end{array}$ \\
\hline \multirow{2}{*}{ 8. Vision Obscured } & Vision Not Obscured & 1.0 & & & \multirow[b]{2}{*}{$\begin{array}{l}\text { Not enough evidence } \\
\text { to suggest Association }\end{array}$} \\
\hline & Vision Obscured & 0.259574 & 0.029329 & 2.29736 & \\
\hline \multirow{2}{*}{ 9. Interference Devices } & $\begin{array}{l}\text { No Devices reportedly } \\
\text { used at time of crash }\end{array}$ & 1.0 & & & \multirow[b]{2}{*}{$\begin{array}{l}\text { Not enough evidence } \\
\text { to suggest Association }\end{array}$} \\
\hline & $\begin{array}{l}\text { Other Devices Used at } \\
\text { time of crash }\end{array}$ & 0.913043 & 0.146593 & 5.686836 & \\
\hline \multirow[b]{2}{*}{ 10. Relation to Roadway } & On Roadway & 1.0 & & & \multirow[b]{2}{*}{$\begin{array}{l}\text { Not enough evidence } \\
\text { to suggest Association }\end{array}$} \\
\hline & $\begin{array}{l}\text { Off Roadway - All } \\
\text { conditions }\end{array}$ & 1.672241 & 0.788878 & 3.544766 & \\
\hline \multirow{4}{*}{$\begin{array}{l}\text { 10. Relation to Roadway } \\
\text { (by category) }\end{array}$} & On Roadway & 1.0 & & & \multirow{4}{*}{$\begin{array}{l}\text { Not enough evidence } \\
\text { to suggest Association }\end{array}$} \\
\hline & Shoulder & 0.462963 & 0.193803 & 1.083411 & \\
\hline & Median & 1.785712 & 0.377573 & 12.82406 & \\
\hline & Roadside & 0.793651 & 0.16211 & 4.300132 & \\
\hline \multirow[b]{2}{*}{ 11. Time of Day - } & 8:00 am - 8:00 pm & 1.0 & & & \multirow[b]{2}{*}{$\begin{array}{l}\text { Not enough evidence } \\
\text { to suggest Association }\end{array}$} \\
\hline & $8: 00 \mathrm{pm}-8: 00 \mathrm{am}$ & 1.046753 & 0.496593 & 2.206418 & \\
\hline \multirow{4}{*}{$\begin{array}{l}\text { 11. Time of Day (by } \\
\text { category) }\end{array}$} & Hour 12-17 & 1.0 & & & \multirow{4}{*}{$\begin{array}{l}\text { Not enough evidence } \\
\text { to suggest Association }\end{array}$} \\
\hline & Hour $-0-5$ & 0.52381 & 0.174814 & 1.523108 & \\
\hline & Hour 6-11 & 0.8 & 0.260496 & 2.449844 & \\
\hline & Hour 18-24 & 1.388889 & 0.507576 & 3.827606 & \\
\hline \multirow{5}{*}{$\begin{array}{l}\text { 12. Traveling Speed (by } \\
\text { category) }\end{array}$} & Travel Speed $<26 \mathrm{mph}$ & 1.0 & & & \multirow{5}{*}{$\begin{array}{l}\text { Not enough evidence } \\
\text { to suggest Association }\end{array}$} \\
\hline & Travel Speed 26-50 & 0.000302 & 0 & 0 & \\
\hline & Travel Speed 51-75 & 0.00011 & 0 & 0 & \\
\hline & Travel Speed 75+ & 0.000202 & 0 & 0 & \\
\hline & Travel Speed Unknown & 0.000111 & 0 & 0 & \\
\hline \multirow{2}{*}{ 13. Driving Maneuver } & $\begin{array}{l}\text { Crash Avoidance } \\
\text { Maneuver performed }\end{array}$ & 1.0 & & & \multirow{3}{*}{$\begin{array}{l}\text { Not enough evidence } \\
\text { to suggest Association }\end{array}$} \\
\hline & $\begin{array}{l}\text { No crash avoidance } \\
\text { maneuver performed }\end{array}$ & 0.82069 & 0.299375 & 2.249793 & \\
\hline 14. Manner of Collision - & & & & & \\
\hline \multirow{3}{*}{ Age } & Age $20-35$ & 1.0 & & & \multirow{3}{*}{$\begin{array}{l}\text { Not enough evidence } \\
\text { to suggest Association }\end{array}$} \\
\hline & Age $36-50$ & 1.1375 & 0.493532 & 2.645755 & \\
\hline & Age 51-64 & 0.509091 & 0.169922 & 1.469023 & \\
\hline \multirow{2}{*}{ Gender } & Male & 1.0 & & & \multirow[b]{2}{*}{$\begin{array}{l}\text { Not enough evidence } \\
\text { to suggest Association }\end{array}$} \\
\hline & Female & 0.666667 & 0.158143 & 2.810397 & \\
\hline
\end{tabular}

Note: Odds ratios were not reported for any conditions which contained $\mathrm{n}<3$ cases. 
According to the odds ratio results for fatalities occurring while outside the vehicle, no contributing circumstances were determined to be associated with the officers expiring at the scene of the incident prior to any medical intervention.

\subsection{MULTIPLE LOGISTIC REGRESSION RESULTS}

A multiple logistic regression analysis was performed on the variables identified as potential risk factors by the focus group. These variables were identified and discussed in section 4.2 and have been provided below:

1. Speed (includes emergency response and police pursuits)

2. Driving maneuver at the time of crash

3. Environmental conditions

4. Interference Devices (tools, multitasking)

5. Relation to Roadway

The multiple logistic regression analysis was performed on incidents that occurred while the officer was driving the vehicle. This was conducted to estimate the strength of association between dead on arrival and the above referenced dichotomous variables when controlling for other factors. SAS software was used to estimate the parameters $(\beta)$ for the variables. The multiple logistic regression analysis was not performed on incidents that occurred while the officer was outside of the vehicle not driving due to the limited number of cases $(n=40)$.

The multiple logistic regression analysis results have been provided in tables 4.15 and 4.16. 
Table 4.15 Multiple Regression Analysis with Odds Ratio as the measurable Outcome on Focus Group Risk Factors.

95\% Confidence
Interval for Odds
Ratio

\begin{tabular}{|c|c|c|c|c|c|c|}
\hline Variable & $\begin{array}{c}\text { Reference } \\
\text { Variable } \\
\text { (Normal } \\
\text { Conditions }\end{array}$ & $\beta$ & $\begin{array}{l}\text { Odds } \\
\text { Ratio }\end{array}$ & $\begin{array}{l}\text { Lower } \\
\text { Limit }\end{array}$ & $\begin{array}{l}\text { Upper } \\
\text { Limit }\end{array}$ & $\begin{array}{l}\text { Association } \\
\text { of Findings }\end{array}$ \\
\hline \multirow[t]{2}{*}{ 1. $\quad$ Travel Speed } & $0-59 \mathrm{mph}$ & & 1.0 & & & \\
\hline & 60 & 0.278 & 1.744 & 0.722 & 4.31 & $\begin{array}{l}\text { Not enough evidence } \\
\text { to suggest Association }\end{array}$ \\
\hline \multirow[t]{2}{*}{$\begin{array}{l}\text { 2. Crash Avoidance } \\
\text { Maneuvers }\end{array}$} & $\begin{array}{l}\text { Avoidance } \\
\text { maneuvers } \\
\text { employed }\end{array}$ & & 1.0 & & & \\
\hline & $\begin{array}{l}\text { No avoidance } \\
\text { maneuvers were } \\
\text { used }\end{array}$ & -0.072 & 0.867 & 0.386 & 1.392 & $\begin{array}{l}\text { Not enough evidence } \\
\text { to suggest Association }\end{array}$ \\
\hline \multirow[t]{2}{*}{ 3. Weather } & $\begin{array}{l}\text { No Adverse weather } \\
\text { conditions }\end{array}$ & & 1.0 & & & \\
\hline & $\begin{array}{l}\text { Adverse weather } \\
\text { conditions }\end{array}$ & 0.159 & 1.373 & 0.370 & 2.263 & $\begin{array}{l}\text { Not enough evidence } \\
\text { to suggest Association }\end{array}$ \\
\hline \multirow{2}{*}{$\begin{array}{l}\text { 4. Interference } \\
\text { Devices }\end{array}$} & $\begin{array}{l}\text { No interference } \\
\text { devices used }\end{array}$ & & 1.0 & & & \\
\hline & $\begin{array}{l}\text { Interference devices } \\
\text { used at time of crash }\end{array}$ & 0.571 & 3.132 & 0.370 & 66.15 & $\begin{array}{l}\text { Not enough evidence } \\
\text { to suggest Association }\end{array}$ \\
\hline \multirow{2}{*}{$\begin{array}{l}\text { 5. Relation to } \\
\text { Roadway }\end{array}$} & On Roadway & & 1.0 & & & \\
\hline & Off Roadway & -0.095 & 0.827 & 0.348 & 1.930 & $\begin{array}{l}\text { Not enough evidence } \\
\text { to suggest Association }\end{array}$ \\
\hline
\end{tabular}

According to the logistic analysis results none of the risk factors identified by the focus group are indicators that a law enforcement officer is more likely to be pronounced dead on arrival than receive medical attention prior to their death. 


\section{Chapter 5}

\section{Summary and Conclusions}

\subsection{SUMMARY}

The objective of this research was to identify the risk factors associated with law enforcement highway fatalities. This was performed through the utilization of a focus group, descriptive study and logistic regression analysis. From the results of the study, the identification of risk factors contributing to law enforcement fatalities shall offer guidance for future research and policy development. The results of this study shall be made available to the IACP, LEOKA, DOJ, NLEOMF, NHTSA, and other entities with a vested interest in law enforcement highway fatalities.

The findings of the research based upon the focus group efforts, the descriptive study results, and a logistic regression analysis identified risk factors for two categories. These findings included categories where law enforcement fatalities occurred while driving and while outside the vehicle. Results of the study are not representative of law enforcement fatalities that occurred while officers were not driving and inside the vehicle.

Additional elements that may be relevant to the study were identified by the focus group but could not be analyzed statistically. These elements include driver responsibility for decision making and multitasking. Both of which could be possibly controlled through better officer highway safety training. Future studies related to these elements cannot be performed without the modification to current data collection mechanisms. 


\subsection{CONCLUSIONS}

An initial investigation was performed on the current efforts to reduce law enforcement officer fatalities. However, limited evidence was available to indicate that there has been a significant reduction in law enforcement officer highway fatalities. Since minimal data was available to support the continuance of current efforts, this research shall offer additional support for future endeavors to reduce law enforcement highway fatalities.

The collective agreement of the focus group identified the top risk factors in the following order:

1. Speed (includes emergency response and police pursuits)

2. Driving maneuver at the time of crash

3. Environmental conditions

4. Interference Devices (tools, multitasking)

5. Relation to Roadway

One concern that was identified by the focus group, but could be not be analyzed using the FARS data was driver training. The focus group emphasized that annual refresher driver training is seldom offered to law enforcement officers. In addition, a standard protocol for driver training has not been mandated for the agencies. Some officers receive only 8 hours of initial training during their enrollment at the training academy. After they leave the academy they do not receive any refresher training during their professional career. They do not participate in annual training to reiterate the important elements such as multitasking, driving maneuvers, or other decision making practices often facing law enforcement officers. Based upon these findings, this author states that law enforcement officer driver training is a secondary causal factor. 
The descriptive study assisted in the identification of the most important risk factors related to law enforcement highway fatalities while driving. When looking at the percentage of driving fatalities related to the adverse conditions, the results of the descriptive study identified the top risk factors in rank order to be:

1. Traveling Speed at time of Crash

2. Lighting Conditions

3. Time of Day

4. Driving Maneuver (Crash Avoidance)

5. Relation to Roadway

A descriptive study was also performed on a set of data representative of law enforcement highway fatalities while the officer was outside the vehicle. The top risk factors for this category are listed in rank order below. These are listed in rank order from most important to less important:

1. Driving Maneuver

2. Lighting Conditions

3. Time of Day

4. Relation to Roadway

5. Traveling Speed

It is important to note that both sets of risk factors contain the same circumstances. These circumstances are just simply ranked differently due to the type of fatality based on the victims classification of driving or outside the vehicle. 
A final effort to combine the information collected by the descriptive study and focus group was performed by analyzing the data using an multiple regression analysis method. The logistic regression analysis method was used with Dead on Arrival as the response variable since all cases resulted in fatalities. Only two elements indicated a significant association with fatalities while driving resulting in dead on arrival. The odds ratio for lighting conditions dark but artificially lighted was 3.5. This can be interpreted to state that an officer involved in an incident when conditions are dark but lighted is 3.5 times more likely to be pronounced dead on arrival. Additionally, an officer involved in an incident when roadways are not straight is 1.75 times more likely to be announced dead on arrival than to receive medical treatment prior to death.

\subsection{LIMITATIONS OF THE STUDY}

This study was designed using the case files from LEOKA to identify all law enforcement fatality cases in the FARS database. However, some of the variables in the FARS database are based upon the interpretations of the FARS coding specialist. A couple of variables that are not represented in the study are driver training information and hours and years of officer experience on the job. It is recommended that such variables be collected in the future to offer additional information for future research endeavors.

This study only focused on the fatalities that occurred to law enforcement officers. It did not include information on any other victims of the incidents. All victim data were collected by FARS, but was not selected for analysis by the author. Additional cases selected would have individuals that were not law enforcement officers, thus not meeting the parameters of this study. 
Since all cases represented fatalities, the variable Dead on Arrival was selected as the dependant variable for analysis. The logistic regression analysis results of this study indicate an association between the circumstance and fatalities that occurred prior to the intervention of any medical services.

A major limitation of this study which is often a limitation in occupational safety and health research is that the descriptive study is performed only on frequency of fatalities. Since exposure data are not available for law enforcement officers under identified circumstances, frequency data are the best available method to perform initial research. This limitation shall assist in the guidance of future data collection to offer exposure information.

\subsection{DISCUSSION OF RISK FACTORS}

Based upon the findings from the descriptive study, focus group, and logistic refression analysis results the following four risk factors have been identified as important circumstances related to law enforcement highway fatalities. These risk factors are:

1. Traveling Speed

2. Driver Related Factors

3. Environmental Elements

4. $\quad$ Training

The multiple regression analysis on the data only supports the purpose behind employing various analysis methods within the research. As previously stated in the conclusions, there are limitations in the data that need to be corrected for future studies. 


\section{Traveling Speed}

The odds ratio outcome measure did not report any association between the occurrence of dead on arrival fatalities and the circumstances included in the regression analysis. However, the focus group and descriptive study both identified traveling speed as an important contributing factor. Various entities need to review their current protocol on emergency response driving to determine if such protocol address traveling speed. Future research could then be performed to evaluate the frequency and severity of incidents involving increased travel speeds. Ultimately, the IACP and DOJ could utilize such studies for the development and passage of legislation related to high speed travels.

\section{Driver Related Factors}

As previously discussed a greater emphasis was placed on the focus group results than the results from the descriptive study or logistic regression analysis. As reported by the focus group, driver related factors should include items such as multitasking, cognitive decision making such as crash avoidance maneuver and utilization of tools and instruments. It should be noted that the driver related factors are specific to fatalities that occurred while the officer was driving.

\section{Environmental Elements}

Environmental elements should extend beyond the traditional nomenclature of weather conditions. As discussed by the focus group, environmental conditions should also include relation to roadway and lighting conditions. Both of these circumstances have been identified by

the descriptive study as a priority of concern. Although some policies have been implemented in relationship to these circumstances, further actions should be taken. The IACP and DOJ should 
mandate move over laws in all states. To further protect the officers, they should be well informed of the risks associated with the environmental elements through training.

\section{Officer Training}

Although the data would not permit the analysis of officer training, the focus group strongly suggested the need for annual training by the agencies which they serve. Figure 5.1 shows how the officer training is interrelated with the other contributing factors. Currently there is a significant limitation in the amount and type of training received by the officers. Future training should include instruction on how to respond and perform in various environmental elements, instruction on multitasking and utilization of instruments inside the vehicle, and operations of the vehicle at high speeds.

\subsection{FUTURE RESEARCH AND OPPORTUNITIES}

Based upon the analysis results and the conclusions discussed in the previous sections, this author offers three sets of recommendations for the future:

1. Data quality improvements for evaluation of law enforcement professionals involved in highway incidents which include injuries and fatalities

2. Further structuring and implementation of officer training programs

3. Performance of future research to evaluate the impact of the modified training and future analysis of better data collection. This could be a collaborative effort designed to be similar to fire fighter fatalities division at NIOSH. 


\section{Data Quality Improvements}

Data quality improvements shall include the collection of additional elements including:

previous highway safety training hours, frequency, date of last training; years of work experience; maintain a database of all highway incidents involving law enforcement officer injuries and fatalities. This would have to be implemented though policy mandates by the DOJ to insure accurate data collection. Modified data collection methods shall be performed by FARS and LEOKA. However, due to the limitations on database access with the LEOKA dataset, the modification to FARS would be more advantageous from a research perspective.

\section{Restructuring of Officer Training}

The IACP needs to lobby with federal entities such as the Department of Justice to establish a mandate for annual refresher highway safety training for federal, state and local organizations. Training is routinely offered to law enforcement agencies via state officers training academy. Therefore, the training mandates can be facilitated to all levels of law enforcement officers, not limited to: State Police and municipal law enforcement officers. After the initial implementation of training, data can be collected to evaluate and modify the minimal training criteria and content.

\section{Future Research}

In order to offer effective data for future analysis, it is recommended that FARS collect additional data regarding the driver emergency response training such as hours, frequency of training, and last date trained. These elements could offer opportunities for future research to answer the following questions: What elements should be offered in driver training? How often 
should drivers receive refresher training? How much training is considered appropriate for prevention of law enforcement highway fatalities?

Other potential research questions include: Are there cognitive pressures on an officer that prohibit the officer from making rational prioritized decisions? 


\section{Appendix A}

\section{Fatality Analysis Reporting System Variables}




\begin{tabular}{|c|c|c|c|c|}
\hline $\begin{array}{c}\text { FARS } \\
\text { VARIABLES }\end{array}$ & $\begin{array}{l}\text { ACCIDENT } \\
\text { VARIABLES }\end{array}$ & $\begin{array}{c}\text { VEHICLE } \\
\text { VARIABLES }\end{array}$ & $\begin{array}{c}\text { PERSON } \\
\text { VARIABLES }\end{array}$ & $\begin{array}{c}\text { FARS } \\
\text { LABELS }\end{array}$ \\
\hline AGE & & & AGE & Age \\
\hline AIR_BAG & & & AIR_BAG & Air Bag Availability \\
\hline ALC_DET & & & ALC_DET & Method of Alcohol Determination \\
\hline ALC_RES & & & ALC_RES & Alcohol Test Results \\
\hline ALIGNMNT & ALIGNMNT & & & Roadway Alignment \\
\hline ARR_HOUR & ARR_HOUR & & & Arrival Time EMS - Hour \\
\hline ARR_MIN & ARR_MIN & & & Arrival Time EMS - Minutes \\
\hline ATST_TYP & & & ATST_TYP & Alcohol Test Type \\
\hline AUT_REST & & & AUT_REST & Automatic Restraint - Function \\
\hline AVOID & & AVOID & & Crash Avoidance Maneuver \\
\hline AXLES & & AXLES & & Number of Axles \\
\hline BODY_TYP & & BODY_TYP & BODY_TYP & Body Type \\
\hline BUS_USE & & BUS_USE & & Bus Use \\
\hline CARGO_BT & & CARGO_BT & & Cargo Body Type \\
\hline CDL_STAT & & CDL_STAT & & $\begin{array}{l}\text { Commercial Motor Driver } \\
\text { License Status }\end{array}$ \\
\hline CERT_NO & & & CERT_NO & Death Certificate \\
\hline CF1 & CF1 & & & Crash Related Factor 1 \\
\hline CF2 & CF2 & & & Crash Related Factor 2 \\
\hline CF3 & CF3 & & & Crash Related Factor 3 \\
\hline CHAS_TR & & CHAS_TR & & VIN Chassis - Truck \\
\hline
\end{tabular}




\begin{tabular}{|c|c|c|c|c|}
\hline $\begin{array}{c}\text { FARS } \\
\text { VARIABLES }\end{array}$ & $\begin{array}{l}\text { ACCIDENT } \\
\text { VARIABLES }\end{array}$ & $\begin{array}{l}\text { VEHICLE } \\
\text { VARIABLES }\end{array}$ & $\begin{array}{l}\text { PERSON } \\
\text { VARIABLES }\end{array}$ & $\begin{array}{l}\text { FARS } \\
\text { LABELS }\end{array}$ \\
\hline CITY & CITY & & & City \\
\hline CL_TWAY & CL_TWAY & & & Class Trafficway \\
\hline COUNTY & COUNTY & & COUNTY & County \\
\hline C_M_ZONE & C_M_ZONE & & & Construction/Maintenance Zone \\
\hline DAY & DAY & & DAY & Crash Date - Day \\
\hline DAY_WEEK & DAY_WEEK & & & Day of Week \\
\hline DEATHS & & DEATHS & & Fatal in Vehicle \\
\hline DEATH_DA & & & DEATH_DA & Death Date - Day \\
\hline DEATH_HR & & & DEATH_HR & Death Time - Hour \\
\hline DEATH_MN & & & DEATH_MN & Death Time - Minute \\
\hline DEATH_MO & & & DEATH_MO & Death Date - Month \\
\hline DEATH_TM & & & DEATH_TM & Death Time \\
\hline DEATH_YR & & & DEATH_YR & Death Date - Year \\
\hline DOA & & & DOA & Dead on Arrival \\
\hline DRINKING & & & DRINKING & $\begin{array}{l}\text { Police Reported Alcohol } \\
\text { Involvement }\end{array}$ \\
\hline DEFORMED & & DEFORMED & & Extent of Deformation \\
\hline DRUGRES1 & & & DRUGREST1 & Drug Test Results 1 \\
\hline DRUGRES2 & & & DRUGREST2 & Drug Test Results 2 \\
\hline DRUGRES3 & & & DRUGREST3 & Drug Test Results 3 \\
\hline DRUGS & & & DRUGS & Drug Involvement \\
\hline DRUGTEST & & & DRUGTEST & Drug Test Type \\
\hline
\end{tabular}




\begin{tabular}{|c|c|c|c|c|}
\hline $\begin{array}{c}\text { FARS } \\
\text { VARIABLES }\end{array}$ & $\begin{array}{c}\text { ACCIDENT } \\
\text { VARIABLES }\end{array}$ & $\begin{array}{c}\text { VEHICLE } \\
\text { VARIABLES }\end{array}$ & $\begin{array}{c}\text { PERSON } \\
\text { VARIABLES }\end{array}$ & $\begin{array}{c}\text { FARS } \\
\text { LABELS }\end{array}$ \\
\hline DRUGTST1 & & & DRUGTST1 & Drug Test Type 1 \\
\hline DRUGTST2 & & & DRUGTST2 & Drug Test Type 2 \\
\hline DRUGTST3 & & & DRUGTST3 & Drug Test Type 3 \\
\hline DRUG_DET & & & DRUG_DET & Drug Determination \\
\hline DRUG_RES & & & DRUG_RES & Drug Test Results \\
\hline DRUNK_DR & DRUNK_DR & & & Drinking Drivers \\
\hline DR_CF1 & & DR_CF1 & & Driver Related Factor 1 \\
\hline DR_CF2 & & DR_CF2 & & Driver Related Factor 2 \\
\hline DR_CF3 & & DR_CF3 & & Driver Related Factor 3 \\
\hline DR_CF4 & & DR_CF4 & & Driver Related Factor 4 \\
\hline DR_DRINK & & DR_DRINK & & Drunk Drivers \\
\hline DR_HGT & & DR_HGT & & Driver Height \\
\hline DR_PRES & & DR_PRES & & Driver Presence \\
\hline DR_TRAIN & & DR_TRAIN & & Driver Training \\
\hline DR_WGT & & DR_WGT & & Driver Weight \\
\hline DR_ZIP & & DR_ZIP & & Driver Zip Code \\
\hline EJECTION & & & EJECTION & Ejection \\
\hline EJ_PATH & & & EJ_PATH & Ejection Path \\
\hline EMER_USE & & EMER_USE & EMER_USE & Emergency Use \\
\hline EXTRICAT & & & EXTRICAT & Extrication \\
\hline FATALS & FATALS & & & Crash Fatalities \\
\hline FED_AID & FED_AID & & & Federal Aid System \\
\hline
\end{tabular}




\begin{tabular}{|c|c|c|c|c|}
\hline $\begin{array}{c}\text { FARS } \\
\text { VARIABLES }\end{array}$ & $\begin{array}{l}\text { ACCIDENT } \\
\text { VARIABLES }\end{array}$ & $\begin{array}{c}\text { VEHICLE } \\
\text { VARIABLES }\end{array}$ & $\begin{array}{c}\text { PERSON } \\
\text { VARIABLES }\end{array}$ & $\begin{array}{l}\text { FARS } \\
\text { LABELS }\end{array}$ \\
\hline FIRE_EXP & & FIRE_EXP & FIRE_EXP & Fire Occurrence \\
\hline FIRST_MO & & FIRST_MO & & First Crash - Month \\
\hline FIRST_YR & & FIRST_YR & & First Crash - Year \\
\hline FLDCD_TR & & FLDCD_TR & & Truck Fuel Code \\
\hline GVWR & & GVWR & & GVW Rating \\
\hline HARM_EV & HARM_EV & HARM_EV & HARM_EV & First Harmful Event \\
\hline HAZ_CARG & & HAZ_CARG & & Hazardous Cargo \\
\hline HISPANIC & & & HISPANIC & Hispanic Origin \\
\hline HIT_RUN & HIT_RUN & HIT_RUN & & Hit-and-Run \\
\hline HOSPITAL & & & HOSPITAL & Taken to Hospital \\
\hline HOSP_HR & HOSP_HR & & & EMS Time at Hospital - Hour \\
\hline HOSP_MN & HOSP_MN & & & EMS Time at Hospital - Minute \\
\hline HOUR & HOUR & & HOUR & Time of Crash - Hour \\
\hline IMPACT1 & & IMPACT1 & IMPACT1 & Impact Point - Initial \\
\hline IMPACT2 & & IMPACT2 & IMPACT2 & Impact Point - Principal \\
\hline IMPACTS & & IMPACTS & IMPACTS & Vehicle Role \\
\hline INJ_SEV & & & INJ_SEV & Injury Severity \\
\hline J_KNIFE & & J_KNIFE & & Jackknife \\
\hline LAG_HRS & & & LAG_HRS & Crash to Death - Hours \\
\hline LAG_MINS & & & LAG_MINS & Crash to Death - Minutes \\
\hline LAND_USE & LAND_USE & & & Land Use \\
\hline LAST_MO & & LAST_MO & & Last Crash, etc - Month \\
\hline
\end{tabular}




\begin{tabular}{|c|c|c|c|c|}
\hline $\begin{array}{c}\text { FARS } \\
\text { VARIABLES }\end{array}$ & $\begin{array}{l}\text { ACCIDENT } \\
\text { VARIABLES }\end{array}$ & $\begin{array}{c}\text { VEHICLE } \\
\text { VARIABLES }\end{array}$ & $\begin{array}{c}\text { PERSON } \\
\text { VARIABLES }\end{array}$ & $\begin{array}{l}\text { FARS } \\
\text { LABELS }\end{array}$ \\
\hline LAST_YR & & LAST_YR & & Last Crash, etc-Year \\
\hline LATITUDE & LATITUDE & & & Global Position - Latitude \\
\hline LGT_COND & LGT_COND & & & Light Condition \\
\hline LOCATION & & & LOCATION & Nonmotorist Location \\
\hline LONGITUD & LONGITUD & & & Global Position - Longitude \\
\hline L_CL_VEH & & L_CL_VEH & & $\begin{array}{l}\text { License/Class Vehicle } \\
\text { Compliance }\end{array}$ \\
\hline L_COMPL & & L_COMPL & & Driver License Type Compliance \\
\hline L_ENDORS & & L_ENDORS & & Compliance with License Status \\
\hline L_RESTRI & & L_RESTRI & & $\begin{array}{l}\text { Compliance with License } \\
\text { Restrictions }\end{array}$ \\
\hline L_STATE & & L_STATE & & License State \\
\hline L_STATUS & & L_STATUS & & Driver License Status/Type \\
\hline L_TYPE & & $L_{-}$TYPE & & Driver License Status/Type \\
\hline MAKE & & MAKE & MAKE & Vehicle Make \\
\hline MAK_MOD & & MAK_MOD & MAK_MOD & Vehicle Model \\
\hline MAN_COLL & MAN_COLL & MAN_COLL & MAN_COLL & Manner of Collision \\
\hline MAN_REST & & & MAN_REST & Manual Restraint-Use \\
\hline MCARR_ID & & MCARR_ID & & Motor Carrier ID \\
\hline MCYCL_DS & & MCYCL_DS & MCYCL_DS & Motorcycle CC Displacement \\
\hline MCYCL_TY & & MCYCL_TY & & VIN Type Motorcycle \\
\hline MILEPT & MILEPT & & & Milepoint \\
\hline MINUTE & MINUTE & & MINUTE & Minute \\
\hline
\end{tabular}




\begin{tabular}{|c|c|c|c|c|}
\hline $\begin{array}{c}\text { FARS } \\
\text { VARIABLES }\end{array}$ & $\begin{array}{l}\text { ACCIDENT } \\
\text { VARIABLES }\end{array}$ & $\begin{array}{l}\text { VEHICLE } \\
\text { VARIABLES }\end{array}$ & $\begin{array}{l}\text { PERSON } \\
\text { VARIABLES }\end{array}$ & $\begin{array}{l}\text { FARS } \\
\text { LABELS }\end{array}$ \\
\hline MODEL & & MODEL & & Vehicle Model Code \\
\hline MOD_YEAR & & MOD_YEAR & MOD_YEAR & Model Year \\
\hline MONTH & MONTH & MONTH & MONTH & Crash Date - Month \\
\hline M_HARM & & M_HARM & & Most Harmful Event \\
\hline NHS & NHS & & & National Highway System \\
\hline NOT_HOUR & NOT_HOUR & & & Notification Time EMS - Hour \\
\hline NOT_MIN & NOT_MIN & & & Notification Time EMS - Minute \\
\hline NO_LANES & NO_LANES & & & Number of Travel Lanes \\
\hline N_MOT_NO & & & N_MOT_NO & Striking Vehicle \\
\hline OCUPANTS & & OCUPANTS & & Number of Occupants \\
\hline OWNER & & OWNER & & Registered Vehicle Owner \\
\hline PAVE_TYP & PAVE_TYP & & & Roadway Surface Type \\
\hline PEDS & PEDS & & & $\begin{array}{l}\text { Number of Forms Submitted } \\
\text { for Persons Not in Motor } \\
\text { Vehicles }\end{array}$ \\
\hline PERSONS & PERSONS & & & Person Forms Submitted \\
\hline PER_NO & & & PER_NO & Person Number \\
\hline PER_TYP & & & PER_TYP & Person Type \\
\hline PREV_ACC & & PREV_ACC & & Previous Recorded Crashes \\
\hline PREV_DWI & & PREV_DWI & & Previous DWI Convictions \\
\hline PREV_OTH & & PREV_OTH & & $\begin{array}{l}\text { Previous Other Harmful MV } \\
\text { Convictions }\end{array}$ \\
\hline PREV_SPD & & PREV_SPD & & Previous Speeding Convictions \\
\hline
\end{tabular}




\begin{tabular}{|c|c|c|c|c|}
\hline $\begin{array}{c}\text { FARS } \\
\text { VARIABLES }\end{array}$ & $\begin{array}{c}\text { ACCIDENT } \\
\text { VARIABLES }\end{array}$ & $\begin{array}{c}\text { VEHICLE } \\
\text { VARIABLES }\end{array}$ & $\begin{array}{c}\text { PERSON } \\
\text { VARIABLES }\end{array}$ & $\begin{array}{c}\text { FARS } \\
\text { LABELS }\end{array}$ \\
\hline PREV_SUS & & PREV_SUS & & Previous Recorded Suspensions \\
\hline PROFILE & PROFILE & & & Roadway Profile \\
\hline P_CF1 & & & P_CF1 & Person Related Factor 1 \\
\hline P_CF2 & & & P_CF2 & Person Related Factor 2 \\
\hline P_CF3 & & & P_CF3 & Person Related Factor 3 \\
\hline RACE & & & RACE & Race Origin \\
\hline RAIL & RAIL & & & Rail Grade Xing ID \\
\hline REG_STAT & & REG_STAT & & Registration State \\
\hline REL_JUNC & REL_JUNC & & & Relation to Junction \\
\hline REL_ROAD & REL_ROAD & & & Relation to Roadway \\
\hline REST_USE & & & REST_USE & Restraint System Use \\
\hline ROAD_FLO & ROAD_FLO & & & Roadway Flow \\
\hline ROAD_FNC & ROAD_FNC & & ROAD_FNC & Roadway Function Class \\
\hline ROLLOVER & & ROLLOVER & ROLLOVER & Rollover \\
\hline ROUTE & ROUTE & & & Route Signing \\
\hline $\mathrm{SCH}$ BUS & SCH_BUS & & SCH_BUS & School Bus Related \\
\hline SEAT_POS & & & SEAT_POS & Seating Position \\
\hline SER_TR & & SER_TR & SER_TR & VIN Series - Truck \\
\hline SEQ1 & & SEQ1 & & Sequence of Event \\
\hline SEQ2 & & SEQ2 & & Sequence of Event \\
\hline SEQ3 & & SEQ3 & & Sequence of Event \\
\hline SEQ4 & & SEQ4 & & Sequence of Event \\
\hline
\end{tabular}




\begin{tabular}{|c|c|c|c|c|}
\hline $\begin{array}{c}\text { FARS } \\
\text { VARIABLES }\end{array}$ & $\begin{array}{l}\text { ACCIDENT } \\
\text { VARIABLES }\end{array}$ & $\begin{array}{c}\text { VEHICLE } \\
\text { VARIABLES }\end{array}$ & $\begin{array}{c}\text { PERSON } \\
\text { VARIABLES }\end{array}$ & $\begin{array}{c}\text { FARS } \\
\text { LABELS }\end{array}$ \\
\hline SEQ5 & & SEQ5 & & Sequence of Event \\
\hline SEQ6 & & SEQ6 & & Sequence of Event \\
\hline SEX & & & SEX & Sex \\
\hline SPEC_USE & & SPEC_USE & SPEC_USE & Special Use \\
\hline SP_JUR & SP_JUR & & & Special Jurisdiction \\
\hline SP_LIMIT & SP_LIMIT & & & Speed Limit \\
\hline STATE & STATE & STATE & STATE & State \\
\hline ST_CASE & ST_CASE & ST_CASE & ST_CASE & State/Case Number \\
\hline SUR_COND & SUR_COND & & & Roadway Surface Condition \\
\hline TA_1_CL & TA_1_CL & & & TA-1 Class \\
\hline TEST_RES & & & TEST_RES & Alcohol Test Results \\
\hline TOWAWAY & & TOWAWAY & & Manner of Leaving Scene \\
\hline TOW_VEH & & TOW_VEH & TOW_VEH & Towed Trailing Unit \\
\hline TOXCLGY & & & TOXCLGY & Drug Noted in Toxicology Report \\
\hline TRAF_FLO & TRAF_FLO & & & Trafficway Flow \\
\hline TRA_CONT & TRA_CONT & & & Traffic Controls \\
\hline TRAV_SP & & TRAV_SP & & Travel Speed \\
\hline TWAY_FLO & TWAY_FLO & & & Trafficway Flow \\
\hline TWAY_ID & TWAY_ID & & & Trafficway ID \\
\hline TWAY_ID2 & TWAY_ID2 & & & Trafficway ID \\
\hline T_CONT_F & T_CONT_F & & & Controls Functioning \\
\hline UNDERRIDE & & UNDERRIDE & & Underride/override \\
\hline
\end{tabular}




\begin{tabular}{|c|c|c|c|c|}
\hline $\begin{array}{c}\text { FARS } \\
\text { VARIABLES }\end{array}$ & $\begin{array}{l}\text { ACCIDENT } \\
\text { VARIABLES }\end{array}$ & $\begin{array}{l}\text { VEHICLE } \\
\text { VARIABLES }\end{array}$ & $\begin{array}{l}\text { PERSON } \\
\text { VARIABLES }\end{array}$ & $\begin{array}{l}\text { FARS } \\
\text { LABELS }\end{array}$ \\
\hline UNITTYPE & & UNITTYPE & & Unit Type \\
\hline VEHICLES & VEHICLES & & & Vehicles Involved in Crash \\
\hline VEH_CF1 & & VEH_CF1 & & Vehicle Related Factor 1 \\
\hline VEH_CF2 & & VEH_CF2 & & Vehicle Related Factor 2 \\
\hline VEH_MAN & & VEH_MAN & & Vehicle Maneuver \\
\hline VEH_NO & & VEH_NO & VEH_NO & Vehicle Number \\
\hline VE_FORMS & VE_FORMS & VE_FORMS & VE_FORMS & Vehicle Forms Submitted \\
\hline VE_TOTAL & & VE_TOTAL & & Vehicle Forms Submitted \\
\hline VIN & & VIN & & Vehicle ID Number \\
\hline VINA_MOD & & VINA_MOD & VINA_MOD & VIN Model \\
\hline VIN_1 & & VIN_1 & & \\
\hline VIN_2 & & VIN_2 & & \\
\hline VIN_3 & & VIN_3 & & \\
\hline VIN_4 & & VIN_4 & & \\
\hline VIN_5 & & VIN_5 & & \\
\hline VIN_6 & & VIN_6 & & \\
\hline VIN_7 & & VIN_7 & & \\
\hline VIN_8 & & VIN_8 & & \\
\hline VIN_9 & & VIN_9 & & \\
\hline VIN_10 & & VIN_10 & & \\
\hline VIN_11 & & VIN_11 & & \\
\hline VIN_12 & & VIN_12 & & \\
\hline VIN_BT & & VIN_BT & VIN_BT & VIN Body Type \\
\hline
\end{tabular}




\begin{tabular}{|c|c|c|c|c|}
\hline $\begin{array}{c}\text { FARS } \\
\text { VARIABLES }\end{array}$ & $\begin{array}{l}\text { ACCIDENT } \\
\text { VARIABLES }\end{array}$ & $\begin{array}{l}\text { VEHICLE } \\
\text { VARIABLES }\end{array}$ & $\begin{array}{l}\text { PERSON } \\
\text { VARIABLES }\end{array}$ & $\begin{array}{l}\text { FARS } \\
\text { LABELS }\end{array}$ \\
\hline UNITTYPE & & UNITTYPE & & Unit Type \\
\hline VEHICLES & VEHICLES & & & Vehicles Involved in Crash \\
\hline VEH_CF1 & & VEH_CF1 & & Vehicle Related Factor 1 \\
\hline VEH_CF2 & & VEH_CF2 & & Vehicle Related Factor 2 \\
\hline VEH_MAN & & VEH_MAN & & Vehicle Maneuver \\
\hline VEH_NO & & VEH_NO & VEH_NO & Vehicle Number \\
\hline VE_FORMS & VE_FORMS & VE_FORMS & VE_FORMS & Vehicle Forms Submitted \\
\hline VE_TOTAL & & VE_TOTAL & & Vehicle Forms Submitted \\
\hline VIN & & VIN & & Vehicle ID Number \\
\hline VINA_MOD & & VINA_MOD & VINA_MOD & VIN Model \\
\hline VIN_1 & & VIN_1 & & \\
\hline VIN_2 & & VIN_2 & & \\
\hline VIN_3 & & VIN_3 & & \\
\hline VIN_4 & & VIN_4 & & \\
\hline VIN_5 & & VIN_5 & & \\
\hline VIN_6 & & VIN_6 & & \\
\hline VIN_7 & & VIN_7 & & \\
\hline VIN_8 & & VIN_8 & & \\
\hline VIN_9 & & VIN_9 & & \\
\hline VIN_10 & & VIN_10 & & \\
\hline VIN_11 & & VIN_11 & & \\
\hline VIN_12 & & VIN_12 & & \\
\hline VIN_BT & & VIN_BT & VIN_BT & VIN Body Type \\
\hline
\end{tabular}




\begin{tabular}{|c|c|c|c|c|}
\hline $\begin{array}{c}\text { FARS } \\
\text { VARIABLES }\end{array}$ & $\begin{array}{l}\text { ACCIDENT } \\
\text { VARIABLES }\end{array}$ & $\begin{array}{l}\text { VEHICLE } \\
\text { VARIABLES }\end{array}$ & $\begin{array}{l}\text { PERSON } \\
\text { VARIABLES }\end{array}$ & $\begin{array}{l}\text { FARS } \\
\text { LABELS }\end{array}$ \\
\hline VIN_LNGT & & VIN_LNGT & & VIN Length \\
\hline VIN_WGT & & VIN_WGT & VIN_WGT & VIN Weight - Auto \\
\hline VIOL_CHG & & VIOL_CHG & & Violations Charged \\
\hline VIOLCHG1 & & VIOLCHG1 & & Violation Charge 1 \\
\hline VIOLCHG2 & & VIOLCHG2 & & Violation Charge 2 \\
\hline VIOLCHG3 & & VIOLCHG3 & & Violation Charge 3 \\
\hline V_CONFIG & & V_CONFIG & & Vehicle Configuration \\
\hline WEATHER & WEATHER & & & Atmospheric Condition \\
\hline WGTCD_TR & & WGTCD_TR & WGTCD_TR & Weight Code - Truck \\
\hline WHLBS_LG & & WHLBS_LG & WHLBS_LG & Wheelbase Long - Auto \\
\hline WHLBS_SH & & WHLBS_SH & WHLBS_SH & Wheelbase Short - Auto \\
\hline WORK_INJ & & & WORK_INJ & Fatal At Work \\
\hline YEAR & YEAR & & & \\
\hline
\end{tabular}




\section{Appendix B \\ Focus Group Related Materials}

B:1 Letter of Recruitment to Experts in Focus Group

B:2 Phase I Instruction

B:3 Phase I Summary

B:4 Agenda of Focus Group Teleconference

B:5 Participation Charts

B:6 Transcript of Teleconference 


\section{To Whom It May Concern:}

I would like to introduce myself to you. I am a Doctoral candidate in the field of Occupational Safety and Health at West Virginia University. My field of research for my dissertation is the development of an empirical model of the risk factors associated with law enforcement highway fatalities. Law enforcement highway fatalities have become an increasing concern over the past few years and my research efforts are to eventually reduce such incidents.

As a part of my research methods, I am facilitating a focus group of experts whom may be directly or indirectly related to the field of study. I would like to ask for your professional expertise as a member of the focus group. The responsibility of the focus group would be to prioritize identified variables which may serve as contributing elements resulting in law enforcement highway fatalities.

The focus group would be involved in two phases. Initially, all members would be asked to prioritize the top variables which the individual believes are associated with law enforcement highway fatalities. Selection choices shall be provided by the researcher and focus group members are asked to offer explanations for each variable. As the facilitator of the focus group, I would then ensure that all participant responses would be summarized and distributed to all participants. A second phase of the focus group's efforts would be to participate in a group discussion via telecommunication conferencing methods and collectively prioritize the variables.

As I understand that you have many other obligations as a part of your professional commitments, I will strive to minimize the burden on you.

Your participation in these research efforts would be greatly appreciated. If you are interested in participating in this study, please contact me as soon as possible.

Respectfully,

\section{Melissa Abbott}

Melissa W. Abbott, CSP

Fairmont State University

Assistant Professor

Occupational Safety

1201 Locust Ave.

Fairmont, WV 26554

(304) 367-4633

Mabbott2@fairmontstate.edu 
April 11, 2008

\section{Dear Focus Group Members,}

I would like to first thank you very much for offering your expertise in my research efforts to identify potential risk factors related to law enforcement officer highway fatalities. The mission of this focus group is to collectively identify the top risk factors believed to be associated with law enforcement officer highway fatalities. The efforts of the focus group will be performed in two phases.

Initially, all members are being asked to prioritize the top variables provided by myself and offer explanations for each variable. This data will then be combined and analyzed using selected statistical descriptive analysis methods. After reviewing and analyzing the initial responses, I will then offer a report summarizing the input from the focus group. This report shall be distributed to all group participants.

The second phase of the focus group's efforts will be to participate in a group discussion via telecommunication conferencing methods and collectively prioritize the variables.

Therefore, at this time, I am asking all focus group members to utilize the list of variables on the following page and select the items they believe to be the top five associated variables. Please note that although driver training is listed as a possible contributing factor data are not available for analysis on this variable. This limitation will be discussed in the summary of findings. Thus, DO NOT select 7 . Driver Training as one of your top 5 variables. You are also being asked to prioritize your list of 5 variables from most contributing to least contributing. Please offer a brief explanation as to your selection decisions for reporting purposes as I distribute the results. A report table has been created for you to submit your responses. Please utilize this report table to ensure consistency in all data collected.

I am asking that you complete this first phase of the group mission by April 18, 2008. Please submit your responses to me electronically via my e-mail address mabbott2@fairmontstate.edu.

If you have any questions regarding the instructions provided, I would be more than happy to answer them. Feel free to contact me at (304) 367-4633. 
Once again, your input and participation is much appreciated.

Respectfully,

Melissa Abbott

Melissa W. Abbott, CSP

Fairmont State University

Assistant Professor

Occupational Safety

1201 Locust Ave.

Fairmont, WV 26554

(304) 367-4633

Mabbott2@fairmontstate.edu 


\section{Focus Group Variables}

\section{Possible Contributing Factors}

\begin{tabular}{|l|}
\hline 1. Police pursuits \\
\hline 2. Environmental Conditions (weather) \\
\hline 3. Lighting Conditions \\
\hline 4. Restraint System Use (Seat Belts) \\
\hline 5. Air Bags \\
\hline 6. Roadway Type \\
\hline 7. Driver Training - DATA ANALYSIS NOT AVAILABLE ${ }^{(\mathbf{I})}$ \\
\hline 8. Vision Obscured \\
\hline 9. Interference Devices inside vehicle (two-way radio, cell phone, etc) \\
\hline 10. Relation to Roadway (i.e. shoulder, median, off road, junctions, etc) \\
\hline 11. Time of Day \\
\hline 12. Traveling Speed at time of Crash - estimated \\
\hline 13. Driving Maneuver at time of Crash \\
\hline 14. Manner of Collision (Rear-end, head-on, sideswipe, etc) \\
\hline
\end{tabular}

(1) All data analysis will be performed using data collected the by the National Traffic Highway Safety Administration. Therefore, this study will not permit analysis of Driver Training as a possible contributing factor. This limitation of the data will be discussed in the reporting of the data.

\begin{tabular}{|l|l|l|}
\multicolumn{2}{|c|}{ Prioritized List of Selected Contributing Factors } \\
\hline $\begin{array}{l}\text { Priority } \\
\text { (Most } \\
\text { contributing } \\
\text { tolest } \\
\text { contributing) }\end{array}$ & Risk Factor & Explanation \\
\hline 1. & & \\
\hline 2. & & \\
\hline 3. & & \\
\hline 4. & & \\
\hline 5. & & \\
\hline
\end{tabular}




\section{Dear Focus Group Members,}

I would like to thank you for your continued assistance in my research efforts to identify potential risk factors related to law enforcement officer highway fatalities. As previously stated, the mission of this focus group is to collectively identify the top risk factors believed to be associated with law enforcement officer highway fatalities. We are now approaching the second phase of this research endeavor.

Initially, all members are being asked to prioritize the top variables provided by myself and offer explanations for each variable. This data has been combined and analyzed using selected statistical descriptive analysis methods. This summary of responses has been prepared and is attached to this correspondence.

As we approach the second phase of the focus group's efforts. I would like to schedule a group discussion via telecommunication conferencing methods to collectively prioritize the variables. I have scheduled it for 3:00 pm (EST) on Thursday, June 26, 2008. If this time is not conducive to your schedule please let me know as soon as possible so that we can reschedule. It is important that all members participate in the discussion.

Please take some time to review the responses in order to effectively discuss the risk factors.

If you have any questions regarding the instructions provided, I would be more than happy to answer them. Feel free to contact me at (304) 367-4633 or (304) 363-6637.

Once again, your input and participation is much appreciated.

Respectfully,

\section{Melissa Abbott}

Melissa W. Abbott, CSP

Fairmont State University

Assistant Professor

Occupational Safety

1201 Locust Ave.

Fairmont, WV 26554

(304) 367-4633

Mabbott2@fairmontstate.edu 


\section{Focus Group Variables}

\section{Assigned Priority}

\section{Possible Contributing Factors}

\begin{tabular}{|c|c|c|c|c|c|}
\hline 3 & 5 & & & & 1. Police pursuits \\
\hline \multirow[t]{4}{*}{5} & 4 & & 2 & 2 & 2. Environmental Conditions (weather) \\
\hline & & & 3 & & 3. Lighting Conditions \\
\hline & 3 & & & & 4. Restraint System Use (Seat Belts) \\
\hline & & & & & 5. Air Bags \\
\hline 2 & & & & & 6. Roadway Type \\
\hline \multicolumn{5}{|c|}{$\begin{array}{l}\text { Unable to consider due to } \\
\text { limitation of data. }\end{array}$} & 7. Driver Training - DATA ANALYSIS NOT AVAILABLE ${ }^{(1)}$ \\
\hline & & & & 5 & 8. Vision Obscured \\
\hline & & 4 & & 3 & 9. Interference Devices inside vehicle (two-way radio, cell phone, etc) \\
\hline & 1 & & 4 & & $\begin{array}{l}\text { 10. Relation to Roadway (i.e. shoulder, median, off road, junctions, } \\
\text { etc) }\end{array}$ \\
\hline & & & & 4 & 11. Time of Day \\
\hline 4 & 2 & 2 & 5 & 1 & 12. Traveling Speed at time of Crash - estimated \\
\hline 1 & & 3 & 1 & & 13. Driving Maneuver at time of Crash \\
\hline & & 1 & & & 14. Manner of Collision (Rear-end, head-on, sideswipe, etc) \\
\hline
\end{tabular}

(1) All data analysis will be performed using data collected the by the National Traffic Highway Safety Administration. Therefore, all this study will not permit analysis of Driver Training as a possible contributing factor. This limitation of the data will be discussed in the reporting of the data. 


\begin{tabular}{|c|c|}
\hline 1. Police pursuits & $\begin{array}{l}\text { - Pursuits usually will terminate or end in another } \\
\text { enforcement jurisdiction. Officers know their own } \\
\text { jurisdiction very well but put them in another "driving } \\
\text { environment" only adds the risk of danger of the pursuit. } \\
\text { - Pursuits contribute to officer-deaths, but they are not a main } \\
\text { cause. }\end{array}$ \\
\hline 2. Environmental Conditions (weather) & $\begin{array}{l}\text { - No matter what the weather is outside, especially in areas } \\
\text { where weather is severe, officers must drive to the } \\
\text { conditions. If officers "push" themselves past their } \\
\text { limitations or their vehicles limitations, the outcome will } \\
\text { usually not be good. } \\
\text { - Officers attempt to get to calls for service as quickly as } \\
\text { possible and don't always arrive. It's related to (weather } \\
\text { and) speed. } \\
\text { - Restrict or limit a vehicle's ability to respond to driver input. } \\
\text { Again, input attempted is the outcome of a decision. } \\
\text { - Weather directly affects visibility and control of a vehicle. } \\
\text { Therefore, adverse weather conditions would adversely } \\
\text { and proportionately affect an operator's ability to control } \\
\text { a vehicle }\end{array}$ \\
\hline 3. Lighting Conditions & $\begin{array}{l}\text { - A reduction in lighting conditions can restrict or limit a } \\
\text { driver's ability to collect data upon which a decision will } \\
\text { be based, and a maneuver attempted. }\end{array}$ \\
\hline 4. Restraint System Use (Seat Belts) & $\begin{array}{l}\text { - Many officers do not to wear seat belts for a variety of } \\
\text { reasons. This is also related to speed. }\end{array}$ \\
\hline \multicolumn{2}{|l|}{ 5. Air Bags } \\
\hline 6. Roadway Type & $\begin{array}{l}\text { - The driving environment has potentially dangerous risks at } \\
\text { all times. The officers must have their eyes up looking for } \\
\text { hazardous situations. If the officer is not "scanning down } \\
\text { the roadway" they will not recognize deadly situations in } \\
\text { time to perform a safe driving maneuver to avoid the } \\
\text { situation at hand. }\end{array}$ \\
\hline \multicolumn{2}{|l|}{$\begin{array}{l}\text { 7. Driver Training - DATA ANALYSIS NOT } \\
\text { AVAILABLE }{ }^{(\mathbf{1})}\end{array}$} \\
\hline 8. Vision Obscured & $\begin{array}{l}\text { - All of the aforementioned factors relate to controlling a } \\
\text { vehicle. Nothing affects control more than the visibility } \\
\text { of the unit by others and the ability of the operator to see } \\
\text { potential hazards. }\end{array}$ \\
\hline $\begin{array}{l}\text { 9. Interference Devices inside vehicle (two-way } \\
\text { radio, cell phone, etc) }\end{array}$ & $\begin{array}{l}\text { - I believe that communication devices play more of a role in } \\
\text { police crashes than has actually been reported, } \\
\text { particularly when an officer is killed in the crash. } \\
\text { - Emergency conditions precipitate communications among } \\
\text { other response agencies and interdepartmental } \\
\text { responders. All of which contribute to distractions and } \\
\text { proportionately affect attentiveness and awareness }\end{array}$ \\
\hline $\begin{array}{l}\text { 10. Relation to Roadway (i.e. shoulder, median, } \\
\text { off road, junctions, etc) }\end{array}$ & $\begin{array}{l}\text { - On average, one officer has been struck and killed each } \\
\text { month for more than a decade. } \\
\text { - May restrict the driver's ability to either collect data upon } \\
\text { which to make a decision or the space needed to complete } \\
\text { any attempted maneuver. }\end{array}$ \\
\hline
\end{tabular}




\begin{tabular}{|c|c|}
\hline 11. Time of Day & $\begin{array}{l}\text { - The time of day is extremely important with regard to a } \\
\text { potential for a fatality since the time of day will } \\
\text { determine traffic patterns, traffic volumes, and visibility } \\
\text { issues. }\end{array}$ \\
\hline 12. Traveling Speed at time of Crash - estimated & $\begin{array}{l}\text { - Increased speed decreases the vehicles ability to maneuver, } \\
\text { and increases the energy involved in the crash. The more } \\
\text { energy, the more injury. } \\
\text { - No matter what type of call, an officer must understand that } \\
\text { he/she can't drive } 100 \% \text {. At the Indiana Law } \\
\text { Enforcement Academy, law enforcement officers are } \\
\text { trained to utilize } 85 \% \text { of the driving ability during } \\
\text { emergency and pursuit situations. They have received } \\
\text { specialized training to handle their vehicle under the } \\
\text { worst conditions. However, during a pursuit, without } \\
\text { being trained in pursuit intervention techniques, the } \\
\text { violator is dictating how fast the pursuit is going and } \\
\text { where the pursuit is going. With better training and the } \\
\text { implementation of pursuit intervention techniques, the } \\
\text { termination point is now at the decision of the law } \\
\text { enforcement officers. } \\
\text { - Officers attempt to get to calls for service as quickly as } \\
\text { possible and don't always arrive. It's closely related to } \\
\text { environmental conditions. } \\
\text { - Speed kills! Police routinely exceed posted speed limits } \\
\text { whether responding to emergency or non-emergency } \\
\text { calls, or on routine patrol. } \\
\text { - Since force is a function of mass X velocity, and since } \\
\text { emergency responses are performed in a heavy vehicle } \\
\text { traveling at higher rates of speed, this is my highest risk } \\
\text { factor for vehicular fatalities }\end{array}$ \\
\hline 13. Driving Maneuver at time of Crash & $\begin{array}{l}\text { - I believe the number one risk factor that officers are } \\
\text { confronted with is failing to recognize the proper } \\
\text { alternatives available to them during emergency runs and } \\
\text { pursuits. The officers that are involved in accidents are } \\
\text { not utilizing proven law enforcement driving techniques } \\
\text { succumbing to the fact that "it will not happen to me." } \\
\text { - Officers routinely "overdrive" or "out drive" their patrol cars } \\
\text { and lose control, probably due to the stress of the nature } \\
\text { of the call. } \\
\text { - The maneuver attempted results from a decision based on } \\
\text { the driver's perception of the environment. Most crashes } \\
\text { result from an incorrect decision on what maneuver to } \\
\text { attempt. }\end{array}$ \\
\hline $\begin{array}{l}\text { 14. Manner of Collision (Rear-end, head-on, } \\
\text { sideswipe, etc) }\end{array}$ & $\begin{array}{l}\text { - Head-on, rear-end, and lateral impacts are all potentially } \\
\text { fatal crashes }\end{array}$ \\
\hline
\end{tabular}




\section{Focus Group - Agenda}

Telephone Conference: June 24, 2008, 2:00 pm

Participants:

Richard Ashton -

Scott Crouch -

Earl Hardy -

Mike Reath -

David Fetty -

Shirley Haney - Transcriptionist present

202-366-4292
800-843-4227 x 276

Cell: $304-282-7150$

Home: 812-332-0978

Office: $304-284-7481$

Moderator: Melissa Abbott

\section{Agenda:}

2:00-2:05 pm

Introduction and Thank Participants

Introduce Self

Ask each participant to introduce name, organization and what experience they offer to the focus group.

2:05-2:08

- Explain the purpose of the focus group is to collectively decide the top 5 risk factors associated with law enforcement fatalities.

- Explain how a focus group works

a. I will serve as the moderator and administer questions to the group to facilitate discussion. Various participants will be asked to respond and follow-up responses are encouraged.

b. Each participant is asked to state their name before speaking. The entire discussion is being recorded and will allow for easier identification of speaker when being transcribed.

c. After the discussion is transcribed, key themes will be identified in the discussion and transformed to a quantitative set of data.

d. Remind participants that they need to have an open mind to establish a collective agreement among the group. However, it is important that participants speak freely in order to obtain a valid set of data.

e. The moderator will maintain a checklist of participation throughout the discussion. If it appears that one participant is dominating the group discussion, other participants will be solicited for responses.

2:08 - 2: 48 Each Question shall be administered and allow 5 mins. For discussion.

1. What does highway fatality mean to you? For example, what all does this include in this category? 
(This research entails automobile, motorcycle and struck by incidents)

2. In your professional opinion, how many fatalities do you believe are classified as

B. Automobile (ODMP, Avg = 40/year)

C. Motorcycle (ODMP, Avg = 7/year)

D. Struck By Incidents (ODMP, Avg = 12-15/year)

3. Review Contributing Factors list with participants. Identify that the group has chosen 6 factors at least 2 times.

Focus Group Variables

\section{Assigned Priority \\ Possible Contributing Factors}

\begin{tabular}{|l|l|l|l|l|l|}
\hline 3 & 5 & & & & 1. Police pursuits \\
\hline 5 & 4 & & 2 & 2 & 2. Environmental Conditions (weather)
\end{tabular}

$\checkmark=$ Majority of group agrees it's a major factor 
4. Explain to participants why Driver training data are not available. FARS does not collect the data. LEOKA does not collect this data (the reporting system is believed to updated in the near future). ODMP provides the years of duty, but not training information.

5. What is your belief on the driver's training effects? And what kind of training should the officers have versus what kind they currently receive? (Moderator needs to monitor for key terms or concepts discussed)

6. Some group members indicated that they believe that some of the identified contributing factors may interrelate. Could you please identify which risk factors you believe interrelate and how?

7. Based on the above information, what do you believe is the biggest interrelation between risk factors? 
8. Based upon the summary of Phase I, three risk factors appear to have been selected by more than $50 \%$ of the group participants as a contributing risk factor. These three factors are:
a. Environmental Conditions
b. Traveling speed
c. Driving maneuver

Does the group agree that these three factors are worthy of being the top three?

What does the group believe is the number one risk factor and why?

As a group can you collectively decide the other two main risk factors? Do not become concerned if the group cannot develop a consensus decision, quantitative analysis will allow the researcher to identify the risk factors.

Thank the participants and inform them that they will receive notification of the research results. 
B:5

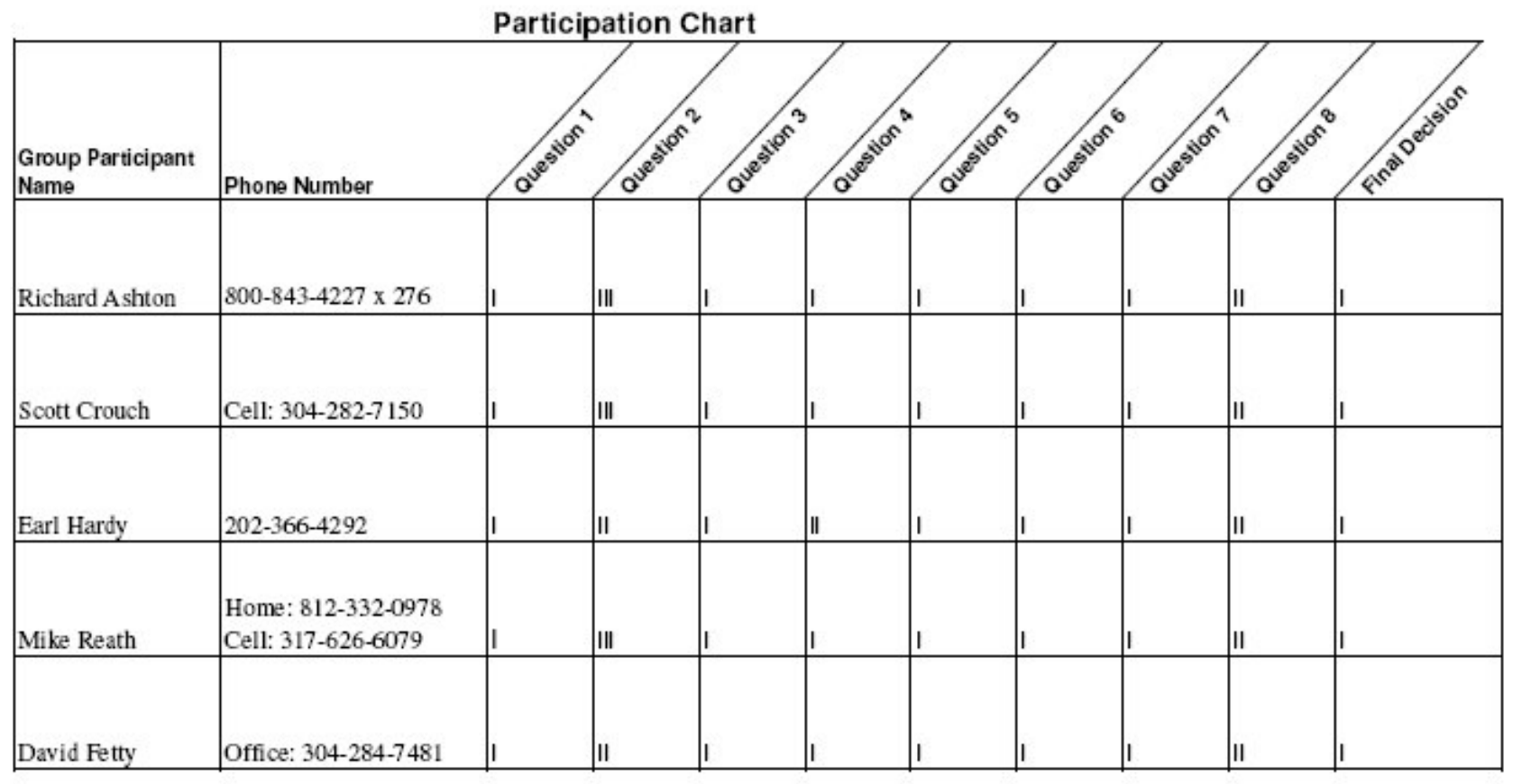

\begin{tabular}{|l|l|}
\hline Question 8: \#1 Risk Factor: & Speed \\
\hline
\end{tabular}

Final Collective Decision:

$\begin{array}{lll} & 1 & \text { Speed } \\ \text { Risk Factors: } & 2 & \text { Driving maneuver } \\ & 3 & \text { Ervironmental Conditions } \\ & 4 & \text { Multi-Tasking (Interference devices, inattentiveness, etc) } \\ & 5 & \text { Seat Belts }\end{array}$


Transcript of Focus Group Conference

June 24, 2008

2:00 PM

Fairmont State University

Moderator: Melissa Abbott

Participants:

Richard Ashton - International Association of Chiefs of Police

Scott Crouch - West Virginia State Police

Earl Hardy - National Highway Traffic Administration

Mike Reath - Director, Emergency Law Enforcement Academy

David Fetty - Professional Fire Department, Emergency Response

Abbott - Ok, gentlemen what I am going to do is I want to get started. I want to lay out, just kinda explain to you a little bit of the purpose of this focus group as a group and then I have just a couple of things I need to go through with you as a moderator, just so we can kind of stay on task for this discussion and so we can do this in a timely fashion. Again, I think I have introduced myself to you before, Mit Abbott. I am currently working on my dissertation at WVU and I am a faculty member at Fairmont State University. What I would like to do... First I want to say thank you all for taking time out of your busy schedule to meet with me and to meet with each other to discuss this and I hope that we can come to sometime kind of a collective agreement. I would like for each of you to just briefly introduce yourself and tell the other focus group members how you can offer a little bit of contribution to this meeting and hopefully we all can have a little bit more of an understanding where everybody is coming from when ever they approach an issue or a concern or anything like that. So I would like to start with Dick Ashton.

Dick Ashton - Ok 
Abbott - Do you want to go ahead and introduce yourself tell them what organization you represent and what experience you offer the group?

Ashton - I am Dick Ashton and I am currently with the International Association of Chiefs of Police and I do highway safety projects. I have been here for six years and one of the projects I worked on is law enforcement stops and safety summit committee and we have done a number of low call videos. Most recently is Pursue, which is a decision making during pursuits and we came out with that last year and we distributed it nationwide. Prior to being with the IACP I have 32 years in city law enforcement in Maryland and I guess that is what I have to offer.

Abbott - OK, great, thank you. Sgt Crouch

Sgt. Scott Crouch - Yes.

Abbott - Would you like to introduce yourself?

Crouch - I am an 18 year veteran of West Virginia State Police. I have been an accident reconstructionalist for ten years and currently assigned out of the Fairmont Detachment for the interstate patrol, so all I do is traffic. I stop cars and am responsible for the accident reconstruction from the first and second districts of our troop.

Abbott - Thanks you. Earl

Earl Hardy - I am Earl Hardy with National Highway Traffic Administration and The Enforcement Justice Services Division. Part of my responsibility here is the law enforcement driving training reference guide of which we derived a couple of training programs. One being the Pursuit Management Instructors Training Program and more recently the Pursuit Policy Workshop, which will be coming out soon. Prior to my life, in federal government I was with the North Carolina Department of Justice, where I was 
responsible for training the law enforcement driving training instructors and managing the driver training program there.

Abbott - OK, wonderful, thank you. Mike.

Mike Reath - Yes, Lt. Mike Reath. Twenty-three years of law enforcement. I have been the Director of Emergency Operations at the Indiana Law Enforcement Academy for, I am in my sixteenth year there. I have been the director there for 14 years for training all city, county, and state officers in driving under emergency response. Worked hand in hand last year with Earl as far as the Pursuit Policy Workshop as well as assisting in redeveloping, and rewording, or rewriting the National Training Reference Guide for Emergency Vehicle Operations.

Abbott - Wonderful, thank you. David, Chief Fetty

Chief David Fetty - I am probably the least prepared of anybody on here. What I bring to the table is that I have been on the paid professional fire department for the last 31 years and chief in that department for ten years and I have either wrecked enough fire trucks to give me in some cases credibility here and I have done some accident reconstruction and making excuses for other firemen who have done the same. But with that being said, probably a different perspective, emergency response, different forum than the police but I have been in it a long time and hopefully I can contribute something.

Abbott - And I also think, Chief Fetty, one of the other things I had approached you with is also the first responders perspective. One of the things that my dissertation committee had emphasized was someone with a little bit of EMT or First Responders perspective just to look at it from that angle. So they had suggested that. 
Fetty - I have been an EMT twice, and we provide First Response emergency medical first response in our department as well.

Abbott - OK, wonderful guys, thank you very much. Ok what I would like to do is, I am going to let you honestly, I am going let you guys guide the discussion a little bit. I have certain questions I am planning to ask, and for each question I have about five minutes that I will allow for discussion. I basically am just serving as the moderator, although my research has given me a good inclination as to what is going on out there in the field. I am not going to be a participant in this discussion because I don. $t$ want to bias any decisions or information. I really ask that, you guys, when I do ask a question that you guys will respond to these. I have in front of me I have a participation chart and as we go through I am going to try to keep track and make sure that everybody feels that they are being able to give ample opportunity to speak so that if I feel that maybe somebody has not been able to speak up, then I may just pick them out directly and say, : Hey, Chief, what do you think about this? Don. $t$ feel bad if I pick on you, I just want to give you an opportunity as well. One thing that I will tell you is that this entire conversation is going to be transcribed, so we are recording you. I have with me Shirley Haney, she is the transcriptionist for this and if at any point we may ask you to repeat something so we can clarify it. If there is something that you didn. $t$ quite understand we will ask them to explain that again. The other thing is that when you guys are speaking some your voices sound very similar, so if you guys would just please, state your name or your last name before you speak so that when we are transcribing this we remember who was referencing certain related risk factors or anything like that. So we can kinda keep track who is saying what. What I will do at the end of this once this is all transcribed, I will be going back through and look at the transcript and actually look for certain things themes or concepts that routinely come up within the discussion and I will use that to come up with our analysis methodology for this. Guys, I want to remind you all to have an open mind but be honest about your opinions. This is what a focus group is intended to do. I really have looked forward to this and I want to thank you so much for taking the time out of your busy schedules. 
I am going to get started with question \#1 and I am going to pick on Sgt. Scott Crouch to get us started with this. The question is. What does highway fatality mean to you? For example, what all does this include in this category? If you were to define something as a highway fatality, what all would you categorize in that? How do you define that?

Crouch - You are talking to specifically to law enforcement officers?

Abbott - Yes, please, yes, thank you.

Crouch - Oh my gosh, highway fatalities that law enforcement officers covers, usually you think of the pursuit, the high speed pursuit, and the angle that I have been trying to enforce on interstate highway is getting hit by other motorists. I really don. $t$ know what more to say about that but.

Abbott - That is good. That helps. I will tell you what. Earl,

Hardy - Yes.

Abbott - Do you want to give us your thoughts on that?

Hardy - Fatality to me is any individual that is killed that involves a vehicle, being a motor vehicle through definition or a vehicle. That would include on the roadway or off the roadway. We would consider a fatality a fatality if it incurred on private property but it involved a vehicle.

Abbott - OK, OK. Thank you. Mike.

Reath - I think that Earl. s and Sgt. both combined is excellent. I think you have to through in also pedestrians, such as hitchhikers, along the roadway. Anyone involved in any type of an accident, has to be considered I think, into the highway fatality. There 
are transients that get struck by vehicles. We lost two officers on our Indiana Cops bicycle ride a couple years ago that were in a caravan of bike riders who travel around the state. They were hit by a semi and the semi ran into a box truck that was behind them as a safety vehicle and then they were run over, so, I think anyone involved, bicyclists, pedestrians, motor vehicles, anything should be considered and probably a part of highway fatalities.

\section{Abbott - OK, Chief Fetty}

Fetty - The only thing that I can possibly add is that I think that any fatality caused directly or indirectly by a motor vehicle. The example that comes to mind is this. If I am in my house, and a vehicle runs into my house and causes me or a family member to die, then I would say the cause is a motor vehicle accident, which is somewhat indirect but the root cause is still a vehicle.

Abbott - Ok and Dick, how about you?

Ashton - I guess I probably have two perspectives. When you think of traffic fatalities you think of the 40 plus thousand people killed every year on the highway and the lack of attention that is given to the problem. The fact that a person is killed every twelve minutes. Yet my second perspective will be law enforcement. The first thing that comes to mind are the officers that are struck along the highway and over the past decade we. ve averaged one officer being struck and killed every month for ten years.

Abbott - Wow, OK, great guys. What I can tell you is that my research has actually addressed and focused the automobile accidents, the motorcycle accidents, and most definitely, those struck by accidents, and thats what I wanted to hear from you guys is that you all collectively believe that those struck by accidents are just as important as the other one. That kinda helps me a little bit. Question \#2, in your professional opinion, how many fatalities do you believe are classified as automobile accidents, 
motorcycle, struck by, if you were to give me a rough estimate as to how many you think died per year as a result of an automobile accident, how many would you guys tell me?

Fetty - This is Fetty, what is your defining area, nationally?

Abbott - Yes, national.

Hardy - Are you defining law enforcement officers?

Abbott - I am sorry, yes this should be law enforcement officers.

Hardy - I would say, what 130.

Ashton - Yea, I would agree to that.

Abbott - Who said 130?

Hardy - Earl.

Abbott - Then Dick you agreed with him.

Ashton - Yes

Reath - And Mike.

Abbott - And Mike agrees with him. Scott, are you there?

Crouch - This is Scott, that sounds about right. I don. t remember any law enforcement officers getting killed in West Virginia. In the years I have been in, we have had a courtesy patrol driver struck and killed by the Department of Highways workers, not as far as law enforcement officers, we have had them struck but not killed. 
Abbott - OK, OK, Well, collectively what we are looking at on an average basis,.. Let me ask you this guys how about motorcycle accidents? Does anyone have a rough estimate what they believe are an average number of law enforcement highway motorcycle accident fatalities?

Hardy - 15

Abbott - Is that Earl?

Hardy - This is Earl.

Abbott - OK 15 for Earl.

Reath - Mike, I would say less than, I. II say 10.

Abbott - Less than 10.

Ashton - Dick, I would agree, I think it is relatively small number.

Abbott - OK, you other guys, do you have any opinions?

Fetty - This is Fetty, I could not venture to guess, but I would have to, I would go with these guys, I am sure they are more knowledgeable than me, so I would agree probably 10.

Abbott - OK, what do you think, Scott?

Crouch - Yea, I would agree in that range. Of course, the state police doesn . t have any motorcycle patrols. I would not have any comment about that. 
Abbott - OK, Then the last one, is I wanted do know if you guys could give me a rough estimate of what you believe the struck by incidents would be? On a national average, law enforcement, struck by incidents. Law enforcement fatalities as a result of struck by incidents.

Ashton - Along the side of the road?

Abbott - Yes.

Ashton - This is Dick, the average is one a month, and it has been that, and so would be twelve for the year an it has been that way for the last ten years.

Abbott - So I think, Dick, has pretty much got the statistics on that one, so does anyone want to contribute to any of that, any ideas or any thoughts.

Crouch - This is Scott, I know that Pennsylvania is talking about increasing their penalties for not merging left. Away from stopped emergency vehicles. I think the trend is increasing.

Abbott - OK. Great.

Crouch - I probably am more scared of getting hit than I am of getting shot.

Abbott - Yep

Reath - This is Mike, I completely agree to that, same thing here in Indiana with the move over law. Again, just like the previous gentleman said, our penalties are starting to get stiffer and stiffer. So, yes. 
Abbott - OK, great guys. All right, the next thing I would like to do, I would like to move on to question \# 3. I want to go over this quick list that I had originally submitted to you guys and based on that list, I am not sure if you guys all got a chance to take a look at the summary of the results or the information. What I found is, and I am sure that you guys probably noticed this, there were actually six contributing factors you guys, that was selected at least twice as atop five variable, let me say. Those top six were police pursuit, environmental conditions or weather conditions, interference devices inside the vehicle, the relation to the roadway, traveling speed at the time of the crash, and the driving maneuver at the time of the crash. What I wanted to do is I wanted to ask you guys if you have any collective agreement out of those six, there were actually there were three of them that were recognized more frequently than just twice. That was the traveling speed at the time of the crash, the driving maneuver at the time of the crash, and the weather conditions. I wanted to ask you guys if any of you have any opinion on that or any concerns with those three being the top or do you feel something else should be one of the top three?

Ashton - Mit, could you give us the top three again?

Abbott - The top three would be environmental conditions, traveling speed at the time of the crash and driving maneuver at the time of the crash.

Ashton - OK, thank you.

Abbott - Your welcome. So does anyone want to throw something out there as to whether they think maybe there is something else that maybe as a group it wasn $\mathrm{t}$ recognized or maybe there is a different interpretation that they feel something else should be a little more important.

Reath - This is Mike. Being a driving instructor for almost twenty years and at the academy as director of driving, those are three things that I have been reinforcing or 
have been reinforced to me since I became a police officer. I really don . $t$ think much has changed as far as the top three that we have as far as contributing factors. Speed is always an issue. It always has been, always will be. It is the first thing determined in an accident crash site. The driving maneuver at the time, even though with what you sent us, it could not be determined really, the lack of driving training, I believe it was, I cannot really remember the words you used, that is you know, so many departments, we finally got passed this year in Indiana which starts in 2009 that in our continuing education emergency vehicle operation have to be a part of the 24 hours of inservice that every law enforcement officer has to have. Now it is not much. It is two hours but at least its something. I have been trying to push for this for a number of years and we finally got it into our inservice training. Environmental conditions always play apart, So I really think from the group, I think the three things that have been mentioned by everyone, I strongly agree with those are probably the three that have in time, in past and in present have contributed to law enforcement accidents.

Abbott - Great, thanks. Dick, have you any thought on this?

Ashton - Yea, I would go along with those three. I think probably the most important one would be traveling speed at the time of the crash. Once, in all the years I have been in law enforcement know that once the guys put their sirens on and they got an emergency call they kinda have - they loose track what is around them and a lot times their hearts are in the right place and they want to get there, but they do not get there so I think speed is definitely one. I think the only one I would consider or suggest that you might add would be the relationship to the roadway. We do loose a lot of officers that are struck directing traffic or making traffic stops and I think that is also serious issue.

Abbott - Great, thank you. Earl.

Hardy - Yes 
Abbott - Do you have any thoughts on this?

Hardy - Pretty much I concur with what has been said. It is going vary, I think you are going to see some variants depending on what area of the country you are in. A more urban area those issues are going to differ and probably be more focused on objects that you would strike or an object striking you various a rural area which would be more inclined to lean toward the speed issue. I think it is going to vary.

Abbott - Thank you, very good point. Sgt. Crouch

Crouch - Yes, I concur with Mike and Earl and everyone about the factor. The two examples I can think of, we lost a trooper last year, Brian Lead over in Charles Town, who was responding to assist another trooper. Over 100 miles an hour on a two lane road in the left lane passing, and when he topped the hill, when he approached the hill crest he lost control and the car hit a telephone pole and was killed. The other example I can think of is the Illinois trooper that was responding to a routine traffic pass on I64 I believe that lost control, crossed the median and hit two teenage girls head on and killed them. So yea, the speed and the evasive maneuvers, not just pursuit driving, but just the emergency vehicle driving. I love Mike. s idea of having a minimum number of hours in inservice every year. I think that will keep it on the front burner and keep it fresh in the guys mind, especially these young troopers, these young police officers who are out there wanting to do the right thing but over drive their vehicle.

Abbott - Very good. Chief Fetty.

Fetty - I concur with everything that has been said here. The one factor that I might have put a little more emphasis on that I do not necessarily think that it would be in the top three, it is a close fourth though, would be the time of day. The reason I say that is the time of day is contingent on the traffic patterns, the traffic congestion, and the condition of the people driving. Most of the, if you are responding in a vehicle and late 
at night, police officers know way better than I know, a lot of times if it is after midnight nothing good happens after midnight and a lot of people are under the influence of something and contribute to vehicle incidents. That is the only thing I have to say about the time. Sometimes the time of day is a big factor.

Abbott - Your spoken like true father, my mother always said nothing good goes on after midnight. Ok gentlemen, let me move on. I think you have all touched on the next point which is great. This is really kind of directing the conversation a little bit. The reason we were not able to analysis the driver training data is because in the FARS data base there was not a coding factor available: (1. To identify the training, and (2.) for the coding analyst, one of the problems becomes what did we consider training and not training and how long, and how can we define, like are we saying once a month, or are we saying three hours. So there was too many variables associated with that, so that is not in the FARS data base. But what I would like to do is I wanted to ask your opinion on that as if maybe as a part of my research I may be able to put a disclaimer in there and I am going to identify this as a limitations of study, that I do not have the data on driving training, but if you feel. Do you feel, I guess, that training is a very important element? I think that Scott you emphasized that, you supported my belief in some of that about the training concept and I wanted you guys to give me some suggestions as to what you think would be considered appropriate training.

Crouch - This is Scott. We, I do not remember having formalized driving training since the academy. I think that the refresher classes for inservice.

Reath - Right, and this is Mike. And that is, we approach, we are in a unique situation because we are, the State of Indiana is guided by the Law Enforcement Training Board, so we got only one entity that oversees all the training for the State of Indiana. It does not matter if you are from the northern part of the state or the southern part, what the Law Enforcement Training Board dictates is what going to be done. I was, have been pushing for that for years, because just like you said, so many officers, Our dedicated 
driving facility is outside Indianapolis, at the driving academy and that is the only one we have, and departments come and utilize it but if you are two and a half hours away and some of the other officer once they graduate from the academy never receive any driver training and that is something that 90 to 95 percent of the time the officers are doing every day. They are driving. No matter what type of circumstances and conditions, they have got to be able to handle that car and bad habits always develop and having that annual refresher or annual training once or twice a year for inservice officers is immeasurable, I believe, in how important it is.

Hardy - This is Earl, if I could wade in, and I do not want to be speaking from the federal perspective on hours because clearly, that is a state issue. But for example, state officers in North Carolina would receive a minimum of 90 hours of vehicle operation training while the other academies were offering eight. If you look at the task we ask officers we ask officers to perform on the street, probably more time is spent operating a patrol vehicle than any other task we ask them to perform so the training has got to match up with the task or the needs assessment. The other thing is that not only training in the academy, but once they go out, while inservice training is valuable and there should be annual or periodic inservice training to insure that those skills are kept sharp. There needs to be transition training also, when they change from one vehicle to another, on what those vehicle capabilities are and what those vehicle limitations are. Often you will take an officer from a sedan and put him in an SUV with no transition training and we realize that they encounter some problems up front. Those of us who have been in it for a while, like some of us, remember the old ABS issue when we put officers in vehicles with ABS and we did not train them, and we were having officers getting killed because they were pumping the brakes trying to get that ABS system pumped up.

***** That is like when going from the rear wheel drive to the front wheel drive. 
Hardy - Exactly, exactly. I think transition training is an issue that needs to be addressed throughout the industry.

Abbott - Thank you guys, may I pause you for just a minute while we switch tapes.

Abbott - Let me ask you this question, what kind of training, and I think you mentioned this a little bit, Earl, like transition training, what if you are saying that maybe they need certain hours of training or whatever, what do they need to be trained on?

Hardy - I do not think I have enough time because I have a 3:00 meeting. I think there are a couple of issues that can be resolved.

Abbott - Earl, that is you talking?

Hardy - This is Earl. First they need to know what authority they have to operate a vehicle. They need to know the legal authority they are given to operate the vehicle and what exemptions to the rules of the roads are. They understand some of the civil liabilities to attach when they get in that patrol vehicle. They need to understand the basic skills on issues like parking, turning radius of the vehicle, tire tracking, some of those. Then, the two big areas. One is emergency response which is driving from point $A$ to point $B$, utilizing the equipment to maximize or minimize that driving time, and maximize the vehicle efficiency. And the other is pursuit driving which is driving from point $A$ to point unknown, where, there again, driving the vehicle in a manner that you have got to maximize that vehicles capabilities.

Abbott - OK, Dick, do you have any thoughts on this.

Ashton - Yea, I go along with what everybody else said. I think its important, I think most agency probably hit it to one degree or another. But there is a problem with them getting it initially, and even more a problem with them getting it inservice. And that is 
one of the issues the IHB Highway Safety meeting is looking at, in terms of their see authorization a safety lieu, we are looking at possibly recommending that driver simulators be funded so that officers can have some training, either initially, or probably more importantly, inservice. I mean things change and techniques change and officers have some review to be made aware of them.

Abbott - Great, thank you. You know that five minutes for that question is up so I am going to move on to the next one. The next question is a that some group members indicated that they believe that some of these identified contributing factors in that list that I originally offered you, may interrelate. If you guys believe that some of these variables interrelate, could you explain, or identify which ones that you believe interrelate and kinda tell me how you think that? Dave Fetty, we will start with you.

Fetty - The one was environmental factors and I forget what, did that include weather? I can not remember.

Abbott - Yes, an example of the environmental conditions was referenced as weather conditions. Yes.

Fetty - OK,

Abbott - If someone wants to help you out, they are allowed to. You can tag team.

Fetty - Someone else jump in there and give me a second here. Here it was, relation to roadway, shoulder, would that, that could be the same as, or could be incorporated in environmental conditions. Because that is an environment condition, not only the weather. Probably combine those two .

Abbott - OK . I see what you mean like a physical environment in addition to just atmospheric conditions. 
Fetty - Yes

Abbott - OK

Fetty - That is my contribution.

Abbott - OK. Thank you.

Fetty - You are welcome.

Abbott - OK, Scott, what do you think? Were there any of them that you felt were kinda interrelated?

Crouch - No, no I did not comment on those.

Abbott - OK, I am trying to remember who may have. Mike, did you?

Reath - I do not believe so because I thought they were all pretty well distinct.

Abbott - OK

Reath - The only one that I may have, would be the ... Let s see I am trying to think, would be the roadway type or classification. Now, with me I think that could be possibly related to relation of roadway. But still, could you have an example there of shoulder, medium, off road junction, you know roadway type or classification, those two possibly could be interrelated or used interchangeably but I think that is probably about the only one.

Abbott - OK, Earl, did you have any thoughts on that or any confusion with any of that? 
Hardy - No confusion and I have nothing I could add of value to that.

Abbott - Ok, and not a problem, and we can move on forward to the next one.

Ashton - Before we move on can I comment.

Abbott - Absolutely

Ashton - I agree that the speed is a problem but, I think interrelated with that is the use of seat belts. I mean, officers do not use seat belts like they should and I think it is more important now a days than it ever has been to use seat belts because the cars are engineered from a safety stand point to assuming that the seat belt is worn. So I would think the speed and the seat belts and air bags would be related to each other.

Abbott - OK great, thank you guys. Alright, on question number seven, well, this kinda eliminates question number, I guess from my stand point, one of the things that I was going to ask you guys then if there were some interrelations or some variables that were very relative to one another, if you could as a group say, you know, what do you believe has the biggest relationship. And I don. $t$ know and we have heard just a couple of relationships here, maybe the relation to roadway, and the, what do we say, the, hang on I am losing my thought now guys, and the environment, we had that relationship there and we also had, I think someone said the roadway type is also related to relation of roadway as well and then we had the seat belts and the speed. Is there, one of the things I think I saw in some of my literature and maybe I am creating a bias in this group some, is traveling speed and police pursuit was also very interrelated with one another. What I wanted to ask you guys is that do you feel that any of these elements would appear to be of biggest concern? What would be the greatest concern, I guess? 
Crouch - This is Scott. I think my focus on, a trend that I am, maybe I am just feeling this, just from experience, but the distractions inside the police car are becoming more and more conducive to traffic wrecks for law enforcement officers.

Abbott - OK,

Ashton - I don . t mean, pursuits obviously involve speed, but I do not think pursuits are a main cause of officers deaths. I guess my experiences most of collisions officers are involved in is when they doing normal things like other people and in the department where I have been chief one of big ones is backing and a lot of the backing ones is in the police parking lot.

Abbott - OK, I will tell you what guys, we are going to move to the next question because I think that one is pretty open there. Of the top three risk factors we mentioned, environmental conditions, traveling speed and driving maneuver, which one would you guys, or can you collectively agree as to what you believe would be the number one risk factor.

Fetty - Mit, I can jump in there, this is Fetty, and I have one observation is that when you are talking about fatality, fatalities are generally equal to force. The force causes the fatality. Since the primary law of physics is that force is a product of mass vs. velocity that you have to factor in speed as number one. When you have this mass, a given mass of a vehicle then the other half of that force factor is the speed of which it is traveling and that is what is causing the death.

Crouch - This is Scott, I agree because in that formula, the velocity squared in that formula, the old adage that speed kills is still true and will always be true because of the kinetic energy.

Abbott - OK, any other opinions on that or does everybody agree that speed is the ? 
Ashton - Yea, I would agree that speed is the main one.

Abbott - Ok, OK thanks Dick. Earl, what do you think?

Hardy - I will go along with the group on that. If you look a specifically fatalities and I will go with speed.

Abbott - Mike, what do you think?

Reath - Yea, I agree I mean that its followed very closely by the drivers inability to maneuver that vehicle safely at the speed that he was trying or he was traveling, but, yea, I think, yea, I think speed is definitely the number one.

Abbott - OK, so how would everybody feel, who is on board, or agrees with Mike as far as the maneuver being the second most contributing factor?

Hardy - I feel the same.

Abbott - Who was that? Earl was that you.

Hardy - Earl ,yes.

Abbott - Anybody else have any thoughts on that?

Ashton - I would go along with that, Mit.

Abbott - Thanks, Dick. Scott, what do you think?

Crouch - Yes, I agree, it is a secondary factor after the speed. 
Abbott - OK, OK. Dave

Fetty - Yes

Abbott - Ok, then here is my next question. We obviously, you guys have all agreed that, you know that environmental conditions, traveling speed, and driving maneuver are probably your top three most contributing factors, the next concern becomes, what about these bottom two. If I need to pick five, does anybody have any thoughts as too, or you guys want to have any discussion on what you can say you believe would be the other two most important pieces to this puzzle.

Fetty - This is Fetty. Like I said before I think the time of day is, in my estimation would be fourth because of the reasons given previously.

Abbott - OK, anybody else want to throw something else out there or want to agree or disagree?

Could I ask you to just list those again, please?

Abbott - Sure, do you want the top six that you guys chose or do you want the 14 that are available?

The top six.

Abbott - OK, in the top six you have police pursuit, and then we have already said environmental conditions, interference devices, relation to roadway, are probably the next three that you guys have identified. And then , of course Chief Fetty is saying that he has a concern about the time of the day, and somebody else actually put in a concern about lighting conditions as well. So I do not know if you guys want to say those two interrelate in some manner. What I am looking for is, I am trying to pull 
another two. I think we have collectively agreed about the top three, and I need to pull five and I am trying to get, just pick your brains a little bit if you guys can not collectively agree, that is fine. I am just trying to facilitate some discussion and like I said I can go back through the transcript and do a little bit of an analysis based on what comes up in the conversation.

Crouch - This is Scott, I still want to throw out there driver distractions inside a patrol car whether you are in a pursuit or just emergency driving. Those factors with lighting and distractions all pertain to perception and reaction time differences. And when you are talking about 100 mile an hour plus, I think that all that contributes to the crashes.

Abbott - Great, thank you, Scott.

Ashton - I will agree with the interference devices if it could be possibly reworded as somehow with the inability as well inside the car as outside the car. Officers have a hard time multitasking. So not only interference inside the car, officers also fail to multitask outside the vehicle. Not recognizing, recognizing one threat and then not recognizing another one, so I think the interference devices could be if they could maybe include inside and out or somehow involving multitasking, I would agree strongly that that would be another one in the top five.

Hardy - I kinda agree with Mike. It is

Abbott - Earl is that you.

Hardy - Yes, this is Earl. I do not know if using the term interference devices because these devices are not really interference devices. They are tools most likely inside the vehicle. I think the issue is one, multitasking, and two priority of task. If you are operating a vehicle in a pursuit situation, and we used to in training, call their cell phone and they would grab their cell phone and answer. So I think sometimes that is officers fail to prioritize the tasks they are being asked to perform at any given moment and then 
the ability to multitask if necessary. But interference device, I mean we talking about patrol radios, and things that are in the vehicle that are not necessarily inter, they are just tools.

Abbott - That is a good point. Dick, you were going to say something a moment ago.

Ashton - Yes, I was just going to reiterate that I think that seat belts is an important issue. I agree a lot of officers do not wear them and they, they got the speed and are ejected and that is how some of them die. But, I think this is a serious problem that I think should go along with rest of the things.

Hardy - And I would like to go along with Dick on that which whole heartedly concur with is the whole occupant protection system which is afforded officers includes their vest.

Abbott - Now wait, Earl you were saying their vest is a protective system?

Hardy - It is part of their occupant protective system for law enforcement.

Abbott - OK, OK. Well guys, what I am looking at here is I think that you guys think that you guys have collectively agreed that there are some major contributing factors and as a group I think that we can maybe say that do feel a concern for those top three. Does anybody strongly feel that those additional three that I mentioned is a definite four or five in there. They were police pursuit, again interference devices, and the relation to roadway. I think that from talking, maybe several of you guys are saying these interference devices or let us refer to them as tools might be a number four. Is that what I am hearing.

Crouch - This is Mike again. I would think it would be number four if it would possibly be reworded. Like Earl said, they are tools that are there for the officer to utilize but I am thinking more outside the vehicle as well as inside, somehow, stating some type of 
multitasking or lack of recognizing threats, or lack of multitasking. So I would agree that interference devices if it was reworded would be number four and then like I said, the restraint systems. But I am, that is just what I was throwing out there.

I did not like the way the interference devices was worded. I want to say it would be more toward multitasking.

Abbott - OK

Ashton - General distractions.

Exactly, general distractions.

Hardy - General distractions, then I agree that the occupant protection probably needs to be. If you have got to do five it sounds like four or five.

Abbott - OK

Hardy - I hate to do this to you but I have got a three oclock and I have just been called up to my bosses office before that three oclock.

Abbott - You are fine, because I think we are pretty well closing up. I think we have finished everything up. I really appreciate your time. I will definitely follow up with all of you just to let what the consensus is. OK

Abbott - Thanks guys. 


\section{Appendix C}

\section{IRB Exemption Notification}




\title{
WWestVirginiaUniversity. \\ Office of Research Compliance
}

\section{Expedited - IRB Protocol - Exemption}

\author{
To: $\quad$ Winn, Gary \\ From: $\quad$ WVU Office of Research Compliance \\ Date: $\quad$ Thursday, August 07, 2008 \\ Subject: No action required
}

Tracking \#: $\mathrm{H}-21047$

Title: $\quad$ Developing a predictive model for risk factors associated with highway fatalities occurring to law enforcement professionals.

The above-referenced study was reviewed by the Institutional Review Board and was granted exemption on [Review Date Not Found] in accordance with 45 CFR 46.101(2).

While no action is required on your part, the IRB made the following findings:

This research study was granted an exemption in accordance withEducational tests, survey procedures, interview procedures, or observation of public behavior [45 CFR 46.101(2)].

The following documents have been approved and validated for use in this study and are available in the BRAAN system:

Thank you.

Board Designee: Ast, Lilo

Letter Sent By: Ast, Lilo, 8/7/2008 11:22 AM

Once you begin your human subject research the following regulations apply:

1. Unanticipated or serious adverse events/side effects encountered in this research study must be reported to the IRB within five (5) days.

2. Any modifications the study protocol or informed consent form must be reviewed and approved by the IRB prior to implementation.

3. You may not use a modified informed consent form until it has been approved and validated by the IRB. 


\section{Bibliography}

$\S 5$ (a) (1), 29 United States Code $\$ 654$ (a) (1) (1979).

Alpert, Geoffrey P. "Police Pursuit: Policies and Training," Research in Brief (Washington, D.C.: U.S. Department of Justice, 1997), 2.

Ashton, Richard J. (2007). Law Enforcement Stops and Safety. Retrieved November 10, 2007, from IACP - Committees, Divisions \& Sections Web site: http://www.theiacp.org/div_sec_com/committees/LESS/

Ashton, Richard J. (July 2004). Solutions for Safer Traffic Stops. Police Chief Magazine, 71(7).

Bauer, K. M., Harwood, D.W., Richard, K.R., \& Hughes, W.E. (2004). Safety effects of using narrow lanes and shoulder-use lanes to increase the capacity of urban freeways. Transportation Research Record, Journal of the Transportation Research Board, 1897.

BLS. (2007). National Census of Fatal Occupational Injuries in 2006 (USDOL 07-1202). Washington, DC: Bureau of Labor Statistics.

Bolton, Joel \& Wall, Robert T. (2007, September). IACP Law Enforcement Challenge-Part III: The Value of Training. The Police Chief, 749.

Bokat, S. A., \& Thompson, III, H. A. (1996). Occupational Safety and Health Law. Washington, DC: BNA Books.

Brown ID. (1994) Driver Fatigue. Human Factors, Vol. 36, No. 2., pp. 298-314. 
Bunn, TL, \& Kurpad A, Struttmann TW, (2003). Driver Distraction/Inattention and Driver Fatigue as Risk Factors for a Fatal Commercial Vehicle Collision in Kentucky. NOIRS 2003 ABSTRACTS (pp. 41-43). Cincinnati, OH: NIOSH.

Bureau of Justice Statistics (BJS), (2008, Sept. 17). State and Local Law Enforcement Statistics. Retrieved November 5, 2008, from US Department of Justice Web site: http://www.ojp.usdoj.gov/bjs/sandlle.htm

Checkoway, H., Pearce, N. E., and Crawford-Brown, D. J.. Research Methods in Occupational Epidemiology. New York: Oxford University Press, 1989.

Clarke, Cindy, \& Zak, Mark J. (1999). Fatalities to law enforcement officers and firefighters. Compensation and Working Conditions. Summer 1999, 3-7.

Creswell, J, \& Clark, V (2007). Designing and conducting mixed methods research.Thousand Oaks, CA: Sage.

Devlin, Thomas (2003). JMP manual for Moore and McCabe's introduction to the practice of statistics. New York: WH Freeman Co..

FARS, (2007). FARS Encyclopedia. Retrieved December 9, 2007, from Fatality Analysis Risk System Database Web site: http://www-fars.nhtsa.dot.gov/Crashes/CrashesTime.aspx.

FBI. (2007). Law Enforcement Officers Killed and Assaulted 2006 Clarksburg, WV: National Uniform Crime Reporting Program.

FHWA. (2005). Safety Effects of Using Narrow Lanes and Shoulder-Use Lanes to Increase the Capacity of Urban Freeways (FHWA-HRT-05-001, HRDS-06/05-05(2M300)E). McLean, VA: Turner-Fairbank Highway Research Center. 
FHWA. (2006). Final Rule: Worker Visibility. Department of Transportation: Federal Highway Administration. FR Vol.71, No. 226 (p. 67792-67800).

Floyd, Craig, A. (January 6, 2000). A Record of law enforcement's sacrifice during the twentieth century. National Law Enforcement Officers Memorial Fund Facts and Figures, Retrieved June 26, 2007, from http://www.nleomf.org/TheMemorial/Facts/CenturySacrifice.htm

Genarro, V, \& Blankenship, M. Statistical analysis in criminal justice and criminology: A users guide..Saddle River, NJ: Prentice Hall, NJ.

Goetsch, David L. (2005). Occupational Safety and Health: For Technologists Engineers and Managers. Upper Saddle River, NJ: Pearson Prentice Hall.

Hall, Louann. "FARS Validation Question." E-mail to author.19 Jun 2008.

Hamelin, P. Lorry (1987) Driver's Time Habits in Work and Their Involvement in Traffic Accidents. Ergonomics, Vol. 30. No. 9, pp. 1323-1333.

IACP. (2004). IACP Strategic Plan Alexandria, VA: International Association of Chiefs of Police.

IACP, (2007). Law Enforcement Stops and Safety. Retrieved November 20, 2007, from International Association of Chiefs of Police Committees, Divisions \& Sections Web site: http://www.theiacp.org/div_sec_com/committees/LESS/

IACP. (2007). IACP Highway Safety Committee: LESS Subcomittee Meeting Minutes, October 14, 2007 (LESSS Minutes 10-14-07). New Orleans, LA: IACP. 
Janicak, Christopher (2007). Applied statistics in occupational safety and health. Lanham, MD: Government Institute.

Kelly, Frankie. "Law Enforcement Officers Killed in Vehicle-Related Incidents." E-mail to author.05 May 2008.

Kochhar, D.S. \& L. Tijerina (2003). Police vehicle struck rear-end crashes: Problem description. The Ford Motor Company-State of Arizona Blue Ribbon Panel: Committee on Lighting and Conspicuity.

Kouri, Jim (2008, Oct. 18). http://mensnewsdaily.com/2008/10/18/fbi-releases-2007 statistics on law enforcement officer killed and assaulted. Retrieved Nov. 2 2008, from http://mensnewsdaily.com/2008/10/18/fbi-releases-2007-statistics-on-law-enforcementofficers-killed-and-assaulted/

Move Over America, (2007, July, 2). Move Over, America: National Campaign Launches Effort Educating Drivers to "Move Over" and Protect Officers on Roadways. Business Wire, Retrieved October 10, 2007, from http://findarticles.com/p/articles/mi_m0EIN/is_2007_July_2/ai_n19330232

NHTSA. (2001). Traffic safety facts 2000 motorcycles (DOT HS 809 326). Washington, DC: NHTSA.

NHTSA \& IACP. (2004). Law Enforcement Stops \& Safety Subcommittee Staff Study 2004 (LESSS Staff Study). Washington, DC: IACP, NHTSA.

NHTSA. (2005). Traffic Safety Facts: Crash Stats (DOT HS 809 890). Washington, DC: NHTSAs National Center for Statistics and Analysis.

NHTSA. (2006). Traffic Safety Facts: Motorcycles (DOT HS 810 620). Washington, DC: NHTSAs National Center for Statistics and Analysis. 
NHTSA. (2006a). Motorcycle Safety Program Plan (DOT HS 810 615). Washington, DC: NHTSA.

NHTSA. (2006b). 2006 FARS coding and validation manual Washington DC: US DOT.

NHTSA. (December 2006). Motor Vehicle Traffic Crash Estimates of People Injured for 2005 (DOT HS 810 639). National Highway Transportation Safety Administration.

NHTSA. (2007). Traffic Safety Facts Data 2006 (DOT HS 810 814). Washington, DC: NHTSAs National Center for Statistics and Analysis.

NHTSA. (2007a). "Click it or Ticket Campaign' Planner Fact Sheet \& Talking Points. 2007 National Click It or Ticket Mobilization Campaign Planner, Retrieved October 10, 2007, from http://www.nhtsa.gov/buckleup/ciot-planner/planner07/FactSheet.doc

NHTSA. (2007b). FARS Analytic Reference Guide 1975 to 2006 Washington, DC: US GPO.

NHTSA, NCSA. (2007). Fatality Analysis Reporting System: Fatal crash data overview (DOT HS 809 726). Washington, DC: NHTSA.

NIOSH. (2004). Worker Health Chartbook, 2004 (13,244, DHHS(NIOSH) 2004-146 ). Cincinnati, OH: National Institute for Occupational Safety and Health Publications.

NIOSH, (2007). NIOSH: Traumatic Occupational Injuries. Retrieved September 30, 2007, from NIOSH Topic: Traumatic Occupational Injuries Web site: http://www.cdc.gov/niosh/injury/\#data.

NLEOMF, (2007). Drive safely: The NLEOMF campaign to decrease law enforcement fatalities on the road. Retrieved November 17, 2007, from National Law Enforcement Officers Memorial Fund Web site: http://www.nleomf.org/TheFund/programs/DriveSafely/ 
NLEOMF (2007a). Causes of law enforcement deaths 1997-2006. Retrieved November 11, 2007, from National Law Enforcement Officers Memorial Fund: Facts and Figures Web site: http://www.nleomf.org/TheMemorial/Facts/causes.htm

National Safety Council. (2007, March 29). Report on injuries in America: All unintentional injuries, 2005. Retrieved October 26, 2007, from NSC Web site: http://www.nsc.org/library/report_table_1.htm

National Safety Council. (2004, January 2). NSC Timeline. Retrieved September 17, 2007, from NSC Web site: http://www.nsc.org/about_timeline.htm

ODMP, (2008). History of the Officer Down Memorial Page. Retrieved March 18, 2008, from Officer Down Memorial Page Web site: http://www.odmp.org/info/history.php

Peterson, Dan (2003). Techniques of safety management: A systems approach. Des Plaines, Illinois: American Society Safety Engineers.

Pratt, Stephanie G. (2003). Work related roadway crashes: Challenges and opportunities for prevention. (DHHS (NIOSH) 2003-119) Cincinnati, OH: NIOSH Publications.

Pratt, Stephanie, David Fosbroke and Suzanne Marsh. United States. NIOSH.Building Safer Highway Work Zones: Measures to Prevent Worker Injuries from Vehicles and Equipment. Cincinnati, OH: NIOSH Publications, 2001.

Stewart, D, Shamdasani, P, \& Rook, D (2007). Focus groups: theory and practice. Thousand Oaks, CA: Sage. 
US DOJ, "Law Enforcement Officers Killed and Assaulted, 2006." Uniform Crime Report. October 2007. US Department of Justice, Federal Bureau of Investigation. 13 Apr 2008 <http://www.fbi.gov/ucr/killed/2006/methodologykilled.html>.

US DOL BLS, "National Census of Fatal Occupational Injuries in 2006." News Release USDL 07-120209 Aug 200718 Jun 2008 <http://www.bls.gov/news.release/pdf/cfoi.pdf>.

US DOL BLS, "Current Population Survey." Employed persons by detailed occupation and sex, 2006 annual averages. 2007. US Department of Labor Bureau of Labor Statistics. 19 Jun $2008<$ http://www.bls.gov/cps/wlf-table11-2007.pdf>.

US DOL BLS, (2008a). Census of Fatal Occupational Injury Charts. Retrieved July 6, 2008, from Bureau of Labor Statistics Web site: http://www.bls.gov/iif/oshwc/cfoi/cfch0005.pdf

US FHWA. (1998). Report to Congress: The Effect of Increased Speed Limits in the Post-NMSL Era (NHTSA Report to Congress). Washington DC: GPO. 